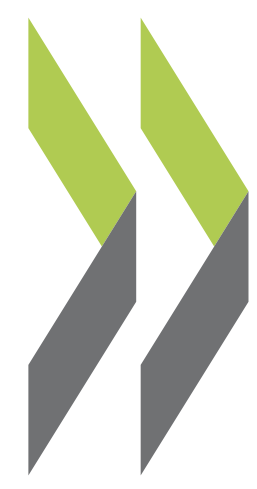

OECD Local Economic and Employment Development (LEED) Papers 2012/02

Knowledge Networks and Their Impact on New and Small Firms in Local Economies: The Case Studies of the Autonomous Province of Trento and Alessandra Proto,
Simone Tani,
Joerg Bühnemann, Magdeburg Mathias Raith 



\section{KNOWLEDGE NETWORKS AND THEIR IMPACT ON NEW AND SMALL FIRMS IN LOCAL ECONOMIES ${ }^{1}$}

The case studies of the Autonomous Province of Trento and Magdeburg an OECD LEED Study in collaboration with the University of Trento

The study is part of the research project "Innovation Policy and its Effects on Locally Embedded Global Dynamics" (OPENLOC), which is co-ordinated by the University of Trento and is financed by the Autonomous Province of Trento in Italy. 



\section{ACKNOWLEDGMENTS}

This project has been undertaken by the LEED Trento Centre for Local Development of the Organisation for Economic Co-operation and Development (OECD) in collaboration with the University of Trento. The work was coordinated by Alessandra Proto, who also edited the report, and Andrea-Rosalinde Hofer who supervised the German case study.

Dr Simone Tani, Municipality of Florence, and Alessandra Proto (OECD) in collaboration with Roberto Chizzali (OECD) prepared the case study on Trento; Joerg Bühnemann, Olaf Gaus and Professor Mathias Raith from the Interaktionszentrum Entrepreneurship at the Otto-von-GuerickeUniversität Magdeburg prepared the Magdeburg case study.

We thank contributors and reviewers of this paper for their time and critical remarks: Professor Giovanni Pegoretti, Dr Francesco Rentocchini and Dr Giuseppe Vitucci from the University of Trento, Mr Stefano Barbieri and Dr Jonathan Potter at the OECD Centre for Entrepreneurship.

Last but not least, the commitment of all interview partners has been fundamental. Essential inhouse support to manage the data collection through questionnaires and finalise the paper was

provided by Roberto Chizzali from the OECD secretariat and Lodovico Bertuzzi and Francesca Romana Lenzi who participated in the project as research interns. 


\section{TABLE OF CONTENTS}

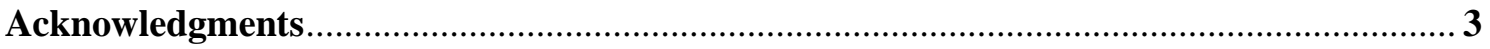

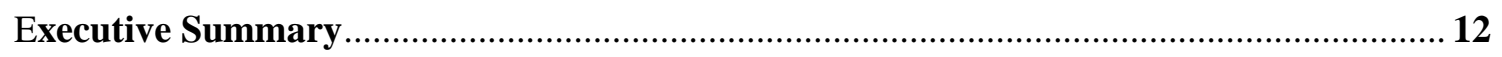

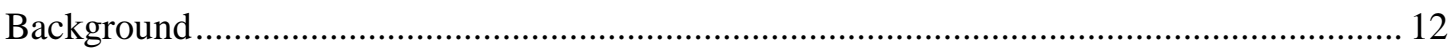

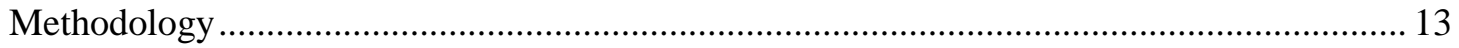

Summary of the Trentino Case study with key issues from firm evidence ……….................. 16

Summary of the Magdeburg Case study with key issues from firm evidence......................... 22

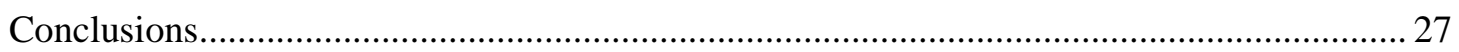

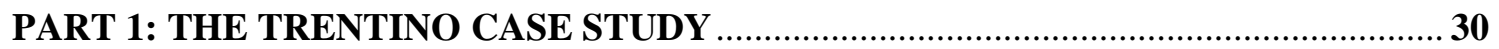

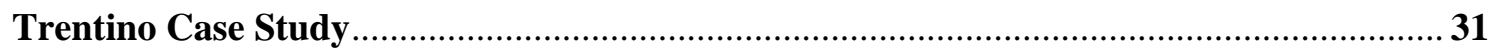

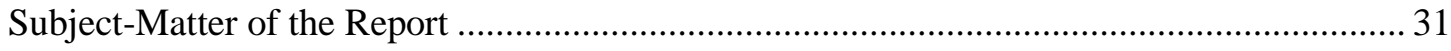

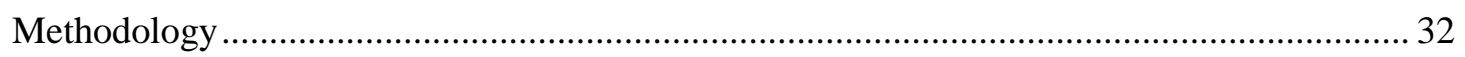

Theoretical Assumptions and an Overview of the Main Reports on the Issue ..................... 35

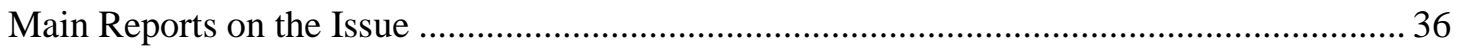

Evolution of the Province's Research and Innovation Policies ............................................ 38

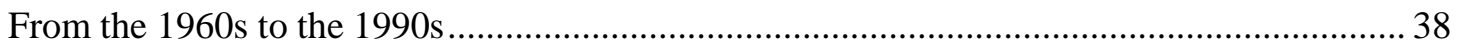

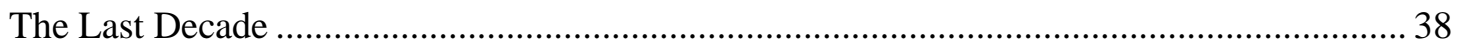

Law for the Review of the Research and Innovation System .................................................. 39

Multiannual Research Programme and Provincial Development Plan



The New Provincial Development Programme …….............................................................. 41

Trentino Knowledge Network: Social and Economic Embedding ...................................... 45

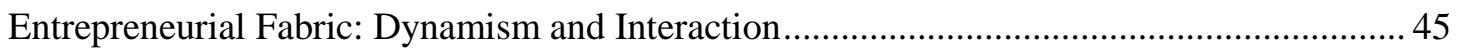








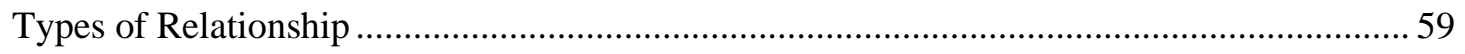

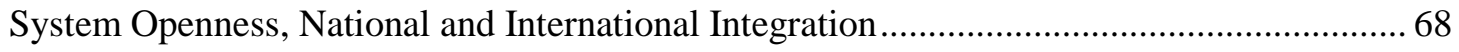

Knowledge Networks: The Trentino Business Perspective ................................................ 71

Description of the Companies Participating in the Study ..................................................... 71

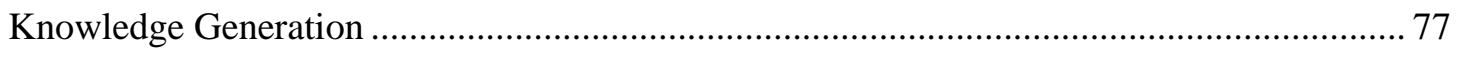

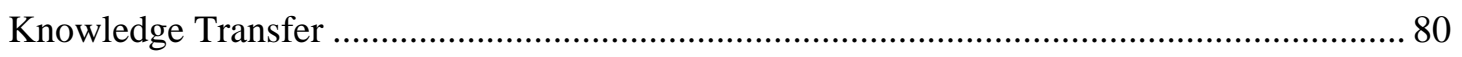

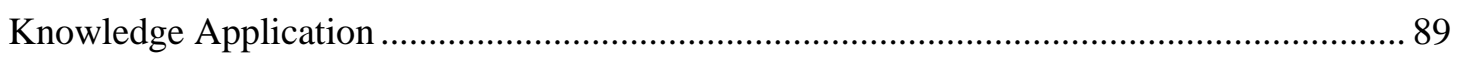

Business' Assessment of Industrial Policy and Innovation Issues .......................................... 93

Experts' Assessment of Industrial Policy and Innovation Issues .............................................. 96

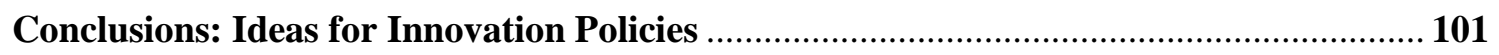

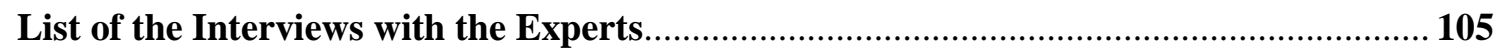

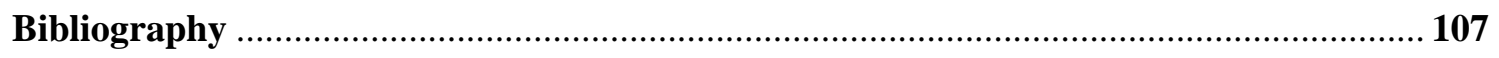

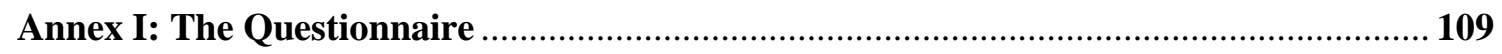





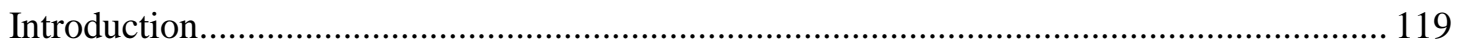

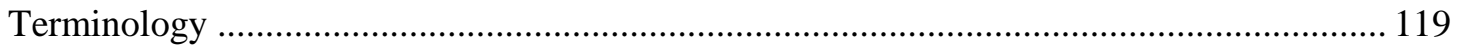

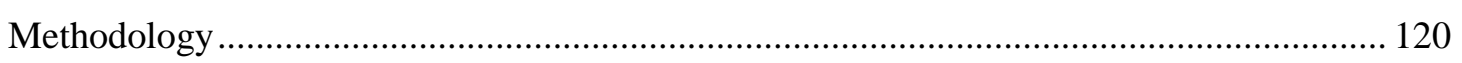

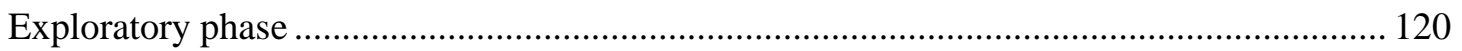

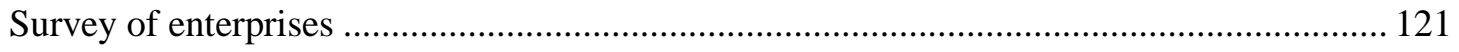

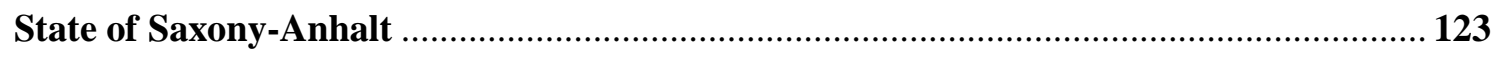

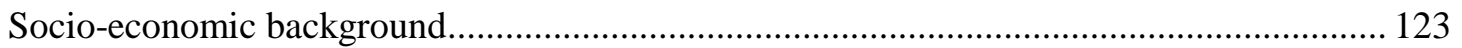

Comparison of R\&D data between East-German states ...................................................... 124

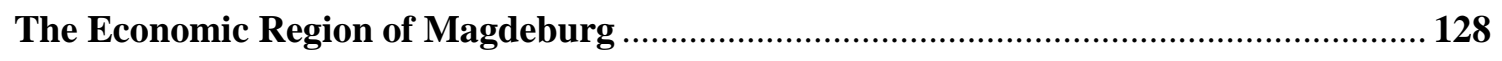

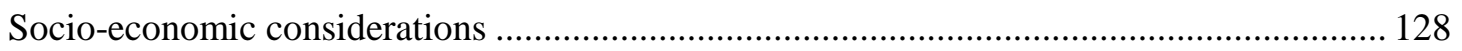

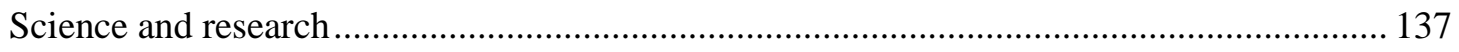

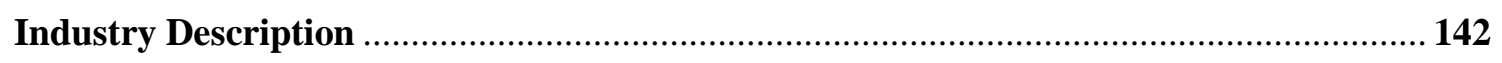

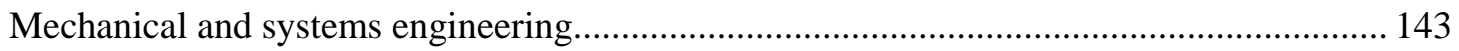

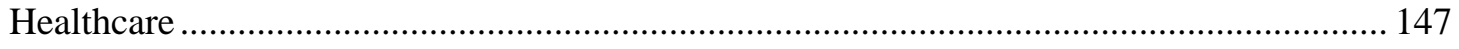

Environmental technology and recycling management .................................................... 151 
Identification of network structures and the role of knowledge exchange ............................ 156

Importance of new and small local firms within the knowledge transfer networks .............. 161



Perspectives of experts from financial institutions ............................................................... 169

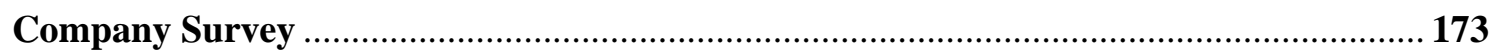

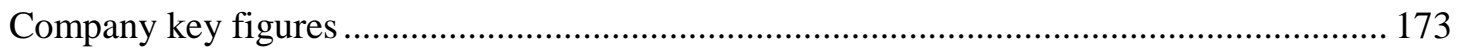





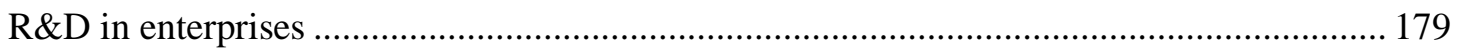

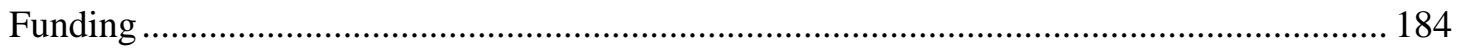

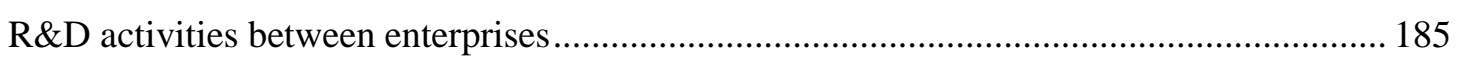



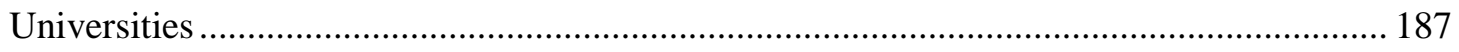

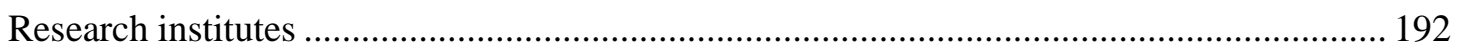



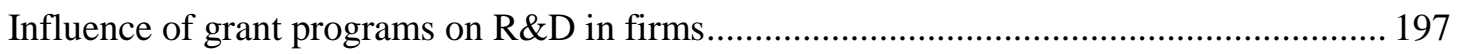

R\&D framework conditions in the economic region of Magdeburg ................................... 198





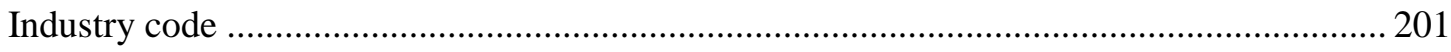

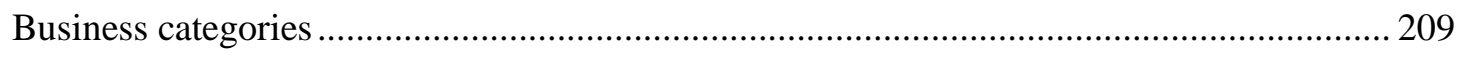



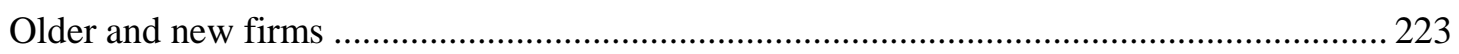

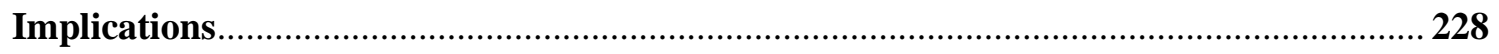

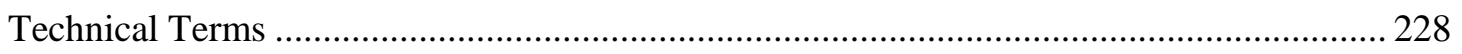

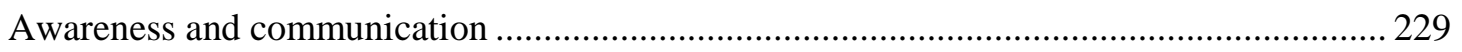

The process chain of knowledge transfer networks ............................................................. 230

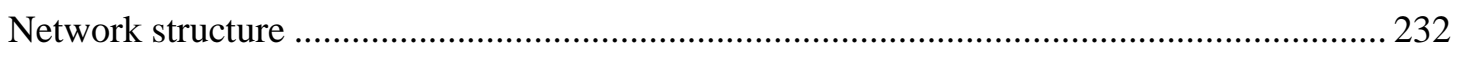

Importance of knowledge transfer networks....................................................................... 234

Importance of R\&D funding for firms and facilitation structures ........................................ 235

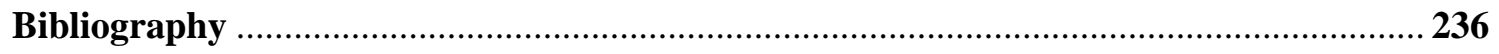




\section{Tables}

Table 1. The Trentino production system. 45

Table 2. R\&D expenditure per institutional sector

(value at current prices in thousands of Euro)

Table 3. R\&D expenditure: 2007 comparison

(value at current prices in thousands of Euro) 49

Table 4. Trentino research system: strengths and weaknesses (2006) ............................. 50

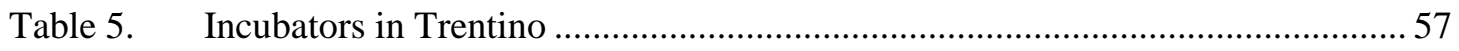



Table 7. Which of the following improved conditions would benefit your

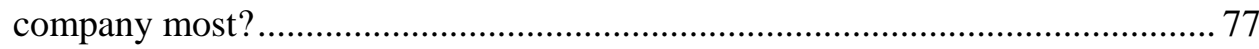

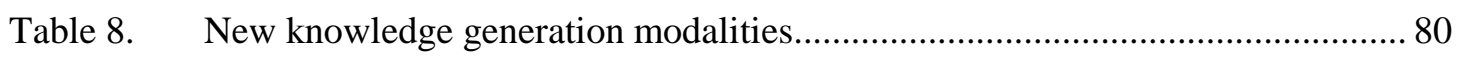



Table 10. Type of partnership between research and business....................................... 85

Table 11. Why the company is not involved in institutional collaboration

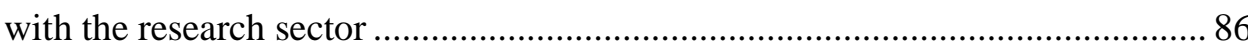

Table 12. Barriers to achieving high quality standards in the technology transfer between research and business in Trentino 87

Table 13. Weaknesses in industry-research institute relationship (\%) ................................. 88

Table 14. Strengths and weaknesses in the exploitation of technological knowledge by Trentino companies 89

Table 15. Relationship between innovation and internationalisation ................................. 92

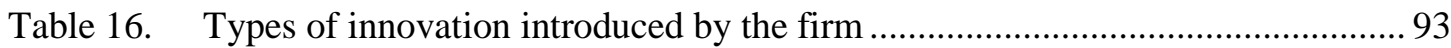

Table 17. Benefits derived or expected from participation in the …................................ 100

Table 18. SWOT analysis of Trentino innovation policies and knowledge networks: the enterprise system.

table 19. SWOT analysis of Trentino innovation policies and knowledge networks: foundation and research bodies.

Table 20. SWOT analysis of Trentino innovation policies and knowledge networks:



Table 21. Population fluctuation of Magdeburg 2004-2008 ............................................. 130

Table 22. Number of CIC enterprises in the city of Magdeburg, by industrial sectors

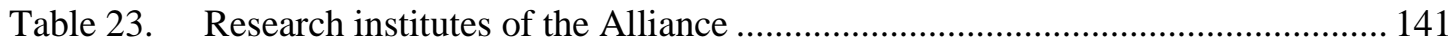

Table 24. Key figures regarding sales distribution as related to geographical markets

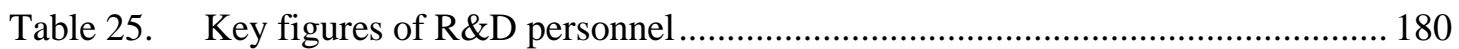

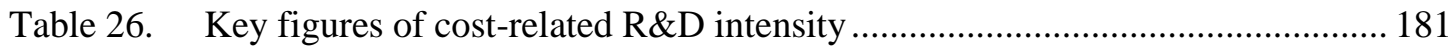


Table 27. Parameters for the different funding authorities ............................................ 184

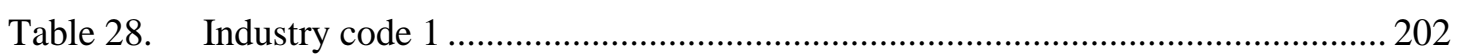

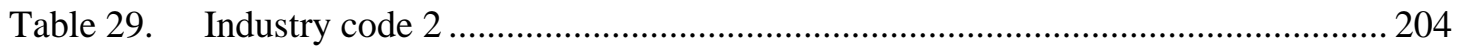

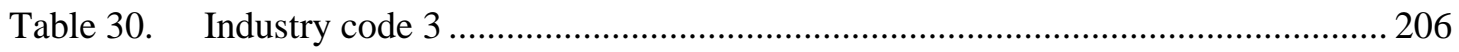

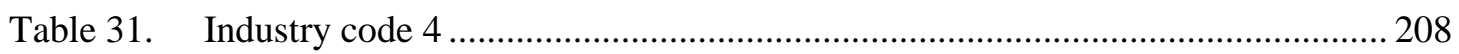

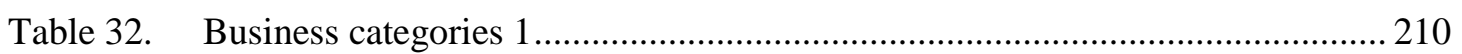

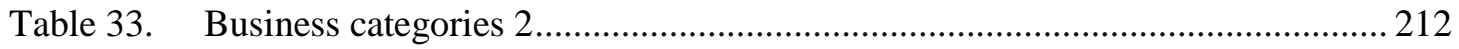

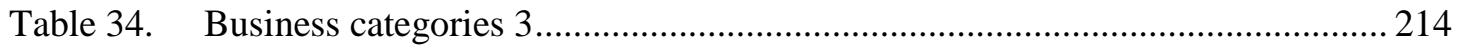

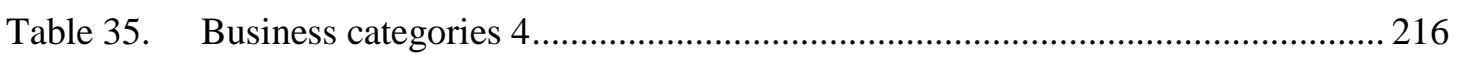

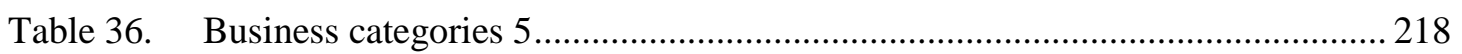



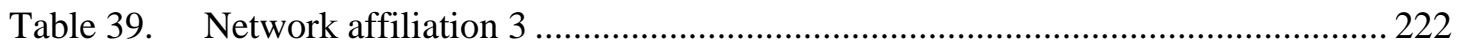

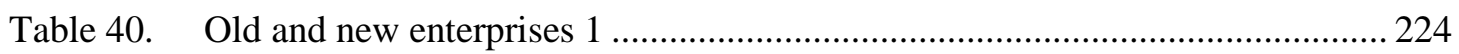

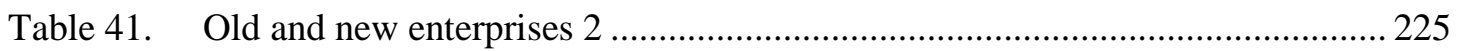

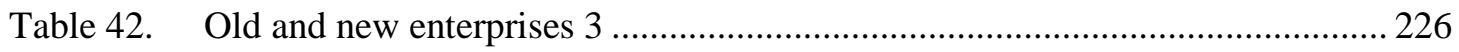

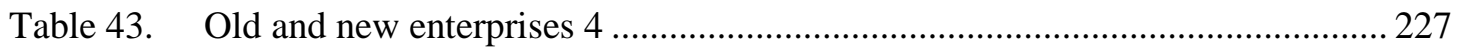

\section{Figures}

Figure 1. Number of workers employed by the interviewed companies ........................... 72

figure 2. Number of graduates hired over the last five years ............................................ 72

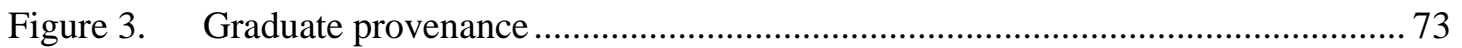

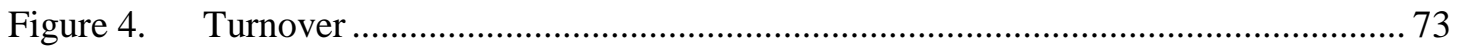

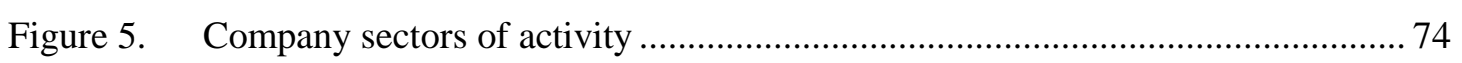

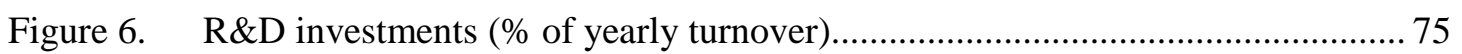

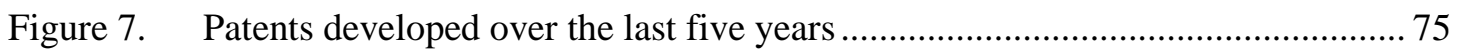

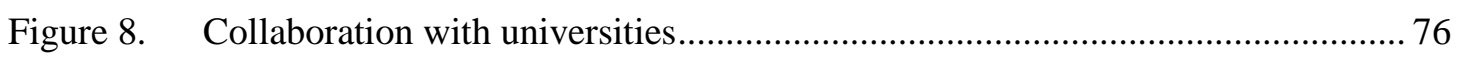

Figure 9. Firm's assessment of the PAT research and innovation activity ......................... 94

Figure 10. The state of Saxony-Anhalt with counties and county boroughs .................... 123

Figure 11. Distribution of companies continuously and temporarily involved in R\&D in the New Federal States in 2008 ................................................. 125

Figure 12. Number of $R \& D$ personnel working in companies with continuous R\&D involvement in the New Federal States in 2008

Figure 13. Sales of companies in the New Federal States with continuous R\&D in 2008

Figure 14. R\&D expenditures of companies with continuous R\&D involvement in the New Federal States in 2008

Figure 15. Magdeburg, the state capital of Saxony-Anhalt 
(subdivided into districts)

Figure 16. Overview of the various areas: itemizing actual use

Figure 17. Development of the population of Magdeburg 2004-2008

Figure 18. Number of unemployed and unemployment rate on average

2004-2008.

Figure 19. Absolute numbers of employed persons, number of salaried employees

and number of the self-employed at the location of Magdeburg (2004-2007)

Figure 20. Percentage distribution of employed persons among the industries

in Magdeburg (2007 annual average)

Figure 21. Percentage distribution of gross value added for the industry sectors of Magdeburg, (2007 annual average)

Figure 22. Percentage of enterprises by employment categories ............................... 135

Figure 23. Development of GDP in the city of Magdeburg 2004-2007 ...................... 136

Figure 24. GDP per inhabitant and per employed person

in Magdeburg 2004-2007

Figure 25. Number of students at the universities of Magdeburg

during the 2004/2005-2008/2009 winter semesters

Figure 26. Numbers of firms in mechanical and systems engineering,

the CIC main industrial sector in the economic regionof Magdeburg

Figure 27. Value-adding activities of the main industrial sector, mechanical and systems engineering.

Figure 28. Value-adding areas of healthcare industry priority sector.... 148

Figure 29. Number of enterprises in the healthcare and social service sector in Magdeburg

Figure 30. Value-adding activities in the priority sector of environmental technology and recycling management .....

Figure 31. The number of enterprises in the priority sector of environmental technology and recycling management.....

Figure 32. Number of applications in Saxony-Anhalt approved in the R\&D field ......... 166

Figure 33. Funding per grant program in Saxony-Anhalt in thousands of EUR ............. 166

Figure 34. Number of enterprises in the priority sectors .............................................. 174

Figure 35. individual and team enterprise foundation ................................................. 174

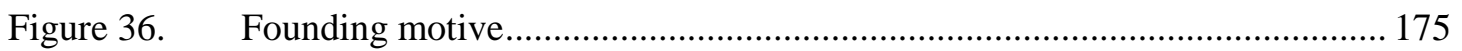





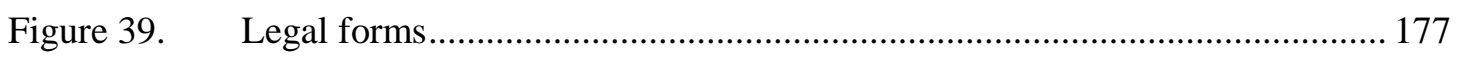

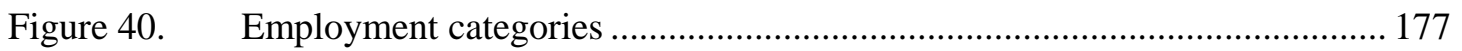

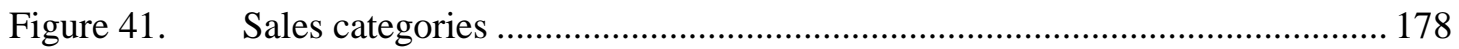


Figure 42. Sales distribution among the geographical markets ................................... 179

Figure 43. Number of full-time and part-time R\&D employees...................................... 180

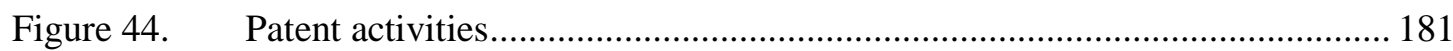

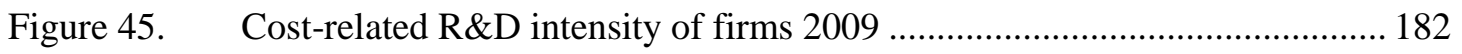

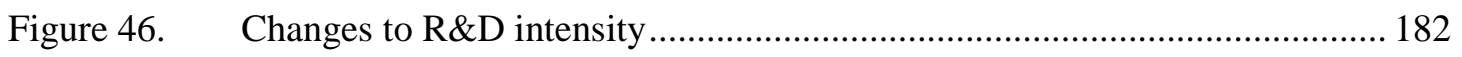

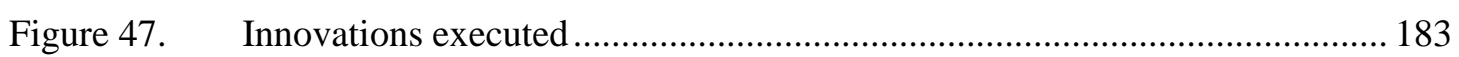



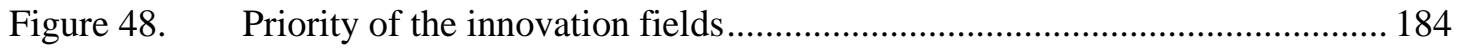

Figure 49. Number of funding programs by funding authority .................................... 185

Forms of R\&D knowledge transfer between firms .............................................................. 186

Figure 51. Reasons why firms do not cooperate with the research sector ...................... 187

Figure 52. University cooperation's ....................................................................... 188

Figure 53. Forms of knowledge transfer at Otto-von-Guericke University.................... 189

Figure 54. Forms of knowledge exchange at the HS MD-SDL .................................... 190

Figure 55. Forms of knowledge exchange with other universities in Germany .............. 191

Figure 56. Cooperation with research institutes ............................................................ 192

Figure 57. Forms of knowledge exchange at the Fraunhofer IFF.................................. 193

Figure 58. Forms of knowledge exchange with other research institutes

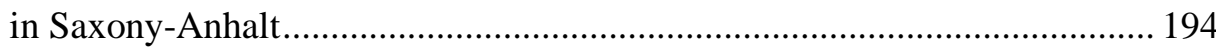

Figure 59. Difficulties in cooperation between science and industry ............................. 195

Figure 60. Additional facilities for the acquisition of R\&D knowledge .......................... 196

Figure 61. Additiona alternatives for the acquisition of R\&D knowledge ...................... 197

Figure 62. Influence of grant programs on R\&D in firms ........................................... 197

Figure 63. Framework conditions for R\&D in the region of Magdeburg ....................... 198

Figure 64. Integration in network structures .............................................................. 199

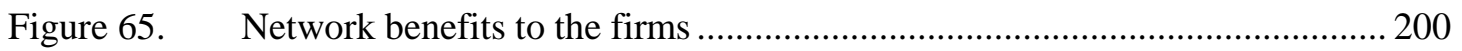

Figure 66. Optimization possibilities of networks ......................................................... 200

Figure 67. Process chain of knowledge transfer networks.............................................. 230

Figure 68. Structure of knowledge transfer networks ................................................... 233

Figure 69. Network structure for the priority sector of mechanical and systems engineering

\section{Boxes}

Box 1. Assessment of PAT- funded industrial research projects........................................... 43

Box 2. The incubators in Trentino (B.I.C.) of Trentino Sviluppo .......................................... 57

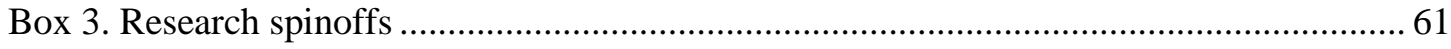

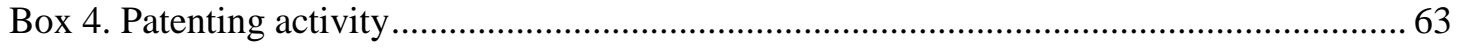


Box 5. Weaknesses in the relationship between industry and research institutes

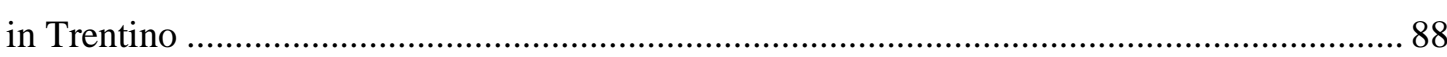

Case study: The Trentino technology cluster for energy and the environment,

"Habitech" 


\section{EXECUTIVE SUMMARY}

The general objective of the OPENLOC Project (Innovation Policy and its Effects on Locally Embedded Global Dynamics) is to create a new institutional and economic framework in which Italian local systems, starting from those located in the Autonomous Province of Trento, can tackle the entry into global networks since they are embedded in specific environmental, socio-cultural and economic contexts. With reference to this framework, the project seeks to examine the present configuration of both the formal (research centres) and the informal (routine communication between the enterprises and the public and private bodies) networks of institutions characterising the Autonomous Province of Trento, together with other local systems that are tackling global dynamics through adequate innovation policies ${ }^{2}$.

The OECD LEED Centre for Local Development in Trento helps attain the OPENLOC project objectives by offering an analysis of the knowledge and innovation systems in two different contexts: the Autonomous Province of Trento and Land Magdeburg in Germany.

\section{Background}

New and small firms can be important engines of job creation and local development when they identify and exploit entrepreneurial opportunities. Knowledge networks, understood as a threecomponent construction of (i) knowledge generation, (ii) knowledge transfer, and (iii) knowledge application, can play a crucial role in this.

This project looks at knowledge networks in specific local contexts. Each of the knowledge network components in a locality has its own organisational structure and behaviour which can impact on how they communicate and interact with the other components. By analysing each of the components the project will seek to bring to light major favouring and impeding factors. The usual actors constituting the knowledge generation component are universities, universities of applied sciences, research organisations and firms. Knowledge transfer agents can be individuals or organisations.

At the centre of this research is the knowledge application component, in particular, local new and small firms. All three components can have local and global dimensions. Local new and small

2 Operational Project, Large Projects Call for Tenders 2006. 
firms can apply knowledge generated elsewhere and locally generated knowledge can be applied globally. The global dimension of the three components can therefore take on an important role. Public policy, aimed at enhancing knowledge networks in their existence and effectiveness, will have to take account of this.

Hence, the aim of this research project is to analyse the relevance of knowledge networks to entrepreneurship and the growth of young and small firms, the role of the different components and their interplay for network effectiveness, impeding and favouring factors, and the role of public policy. The analytical work on two case study areas - the Autonomous Province of Trento, and the economic region of Magdeburg -provide insights for policy making in entrepreneurship and innovation support in the Autonomous Province of Trento.

\section{Methodology}

\section{Organisation of the research}

The research work was organised in three phases. In the first phase, the OECD team did a mapping exercise in order to identify which sectors of the two local economies are associated with the strongest local knowledge exploitation and which should be the main focus of investigation in the second phase. The second phase was dedicated to the analysis of these local knowledge networks and their influence on local new and small firm behaviour. In the third phase the results of the analysis of local knowledge networks were translated into what public policy in general, and in particular what falls under the realm of local governments and agencies, can do to promote successful knowledge networks in their existence and effectiveness.

\section{Exploratory phase (basic mapping exercise)}

The work in this research phase prepares the experimental phase.

\section{Selection of sectors in the local economy}

The mapping exercise was undertaken to support the identification of those sectors of the local economy where new and small firms are using external knowledge with a positive impact on innovation and productivity. Important selection criteria were the participation of the sector in a local knowledge network, and its impact on new and small firms' innovation and productivity within the sector.

Inventory of policies and measures

The exploratory phase also included the preparation of an inventory of all policies and measures that influenced, in the case study area, the existence and operation of knowledge networks. 


\section{Interviews}

A number of interviews, with key actors of the local innovation system in the two regions, were conducted by the OECD Secretariat and experts. The lists of interview partners are provided in the Annex 1 attached to this report.

\section{Experimental phase (analysis of local knowledge networks)}

Firm surveys

The firm surveys in the selected sectors of the local economy under review form the main component of the experimental phase. The OECD Secretariat developed a specific questionnaire containing open-ended and multiple-choice questions following the research questions and indicators outlined below. The survey was built in a way to allow for comparison among the two case study regions. The Annex 2 contains the two survey forms English.

\section{Recommendations for public policy intervention}

The overall objective of this research project is to provide insight information for policy making in entrepreneurship and innovation support in the Autonomous Province of Trento. The results of the analysis of knowledge networks has been developed into recommendations of how public policy in general, and local governments and local actors in particular, can enhance the existence and effectiveness of knowledge networks with regard to the participation of local new and small firms.

\section{Case study reports}

Two final reports, on the Autonomous Province of Trento and the Magdeburg Region, have been prepared drawing on the key findings of the exploratory and experimental research phases. They have been developed following the same methodology and have a similar structure. However, in order to give a detailed display of the differences between the reviewed regions, the reports are presented separately.

This introduction contains the summary of the Trentino and the Magdeburg case studies with key issues from firm evidence and is followed by the two complete reports.

\section{Research questions}

The below listed research questions are at the centre of the analysis of local knowledge networks in the reviewed territories. They were used as the basis for interviews with key actors during the exploratory phase, and were taken into account for the development of the questionnaire used for the firm survey part. 
1. What is the nature of the local knowledge networks most used by new and small firms? Where, and what kind of knowledge is being generated how is it being transferred and where is it applied?

2. What are the main global ${ }^{3}$ actors in these local networks? What is the role of new and small firms in other countries and/or regions in exploiting the knowledge generated locally? What is the role of organisations and firms in other countries and regions in generating knowledge that is absorbed locally? What mechanisms are at play?

3. What are the blockages amongst the existing actors and mechanisms? What are gaps and weaknesses amongst actors that are potentially hindering knowledge generation, transfer and application?

4. What influence do research organisations/universities capabilities have on the generation and transfer of knowledge to new and small firms?

5. What influence do firm capabilities have on absorption of external knowledge?

6. What is the current role of public policy in enhancing (i) knowledge transfer and (ii) knowledge application to by local new and small firms? What are the main opportunities to strengthen the knowledge network?

\section{Indicators}

In addition to the information emerged from the discussion with local actors on the above questions, a set of indicators was defined for the analysis of knowledge networks in the reviewed regions.

The indicators should provide information on the current state of knowledge network activity, blockages, gaps and weaknesses amongst the existing actors and mechanisms as well as on opportunities and unused potentials.

The following list of indicators, organised around the three components, which were provided as a first orientation, have been further developed during the course of the research in the two regions according to the availability of information and data.

\footnotetext{
${ }^{3}$ Global refers to actors from other countries or other regions from the same country.
} 
Knowledge generation: knowledge generated in (i) universities and research organisations, and (ii) private and public sector firms, which is transferred to local new and small firms.

Issues: joint/contract research, student/graduate/researcher exchange activities, consultancy services, licenses, patents

- Amount and nature of research co-operation between local knowledge generators and local new and small firms.

- Amount and nature of research co-operation between local knowledge generators and local large firms.

- Amount and nature of research co-operation between local knowledge generators and global new and small firms.

- Amount and nature of research co-operation between local knowledge generators and global large firms.

Knowledge transfer: locally active knowledge transfer agents that transfer knowledge generated locally or globally to local new and small firms.

Issues: information, training, fairs, financing

- Number of information events per year and participation rate of local new and small firms (and compared to participation rate of local large firms).

- Number of training sessions organised per year and participation rate of local new and small firms

- Number of local new and small firms of benefiting from international fair attendance co-/financing (and compared to participation rate of local large firms)

- Number of local new and small firms benefiting from public innovation finance schemes (and compared to participation rate of local large firms).

Knowledge application: locally or globally generated knowledge applied by local new and small firms. Issues: $R \& D$ expenditure, degree of innovation, relational capital

- Percentage of turnover invested in research and development expenditure

- Number of patents, licenses and percentage of turnover due to sales of innovative products and services

- Percentage of new employees hired (within last 5 years), skills levels and previous sector experience.

- Co-operation with local firms in fostering product and service innovation (distinguish between small and large firms).

- Co-operation with global firms in fostering product and service innovation (distinguish between small and large firms).

- Co-operation with customers in fostering product and service innovation.

\section{Summary of the Trentino Case study with key issues from firm evidence}

The development of a local system of innovation, and its underlying networks, is particularly effective in a context that is characterised by a strong degree of financial and organisational autonomy, as it is in the case of the PAT. The presence of these conditions encourages the generation of collective learning processes and technological development, as well as the effective co-ordination of resources 
within knowledge networks and the integration of the local system into national and international networks in order to enhance their competitiveness. Social and economic literature highlights some key elements for the development of knowledge flows within local innovation systems, such as the presence of local institutions specifically targeting innovation and knowledge transfer issues, policy flexibility, intensive networking activities integrating local and global systems and facilitating Knowledge exchange, and collective learning processes. Finally, a strategic element is the presence of a well-established, creative and motivated entrepreneurial core.

The summary sets out the case study review findings, covering the main challenges and opportunities of the Trentino Innovation System, followed by the main findings of the business perspective concerning i) knowledge generation, ii) knowledge transfer, and iii) knowledge application. The full report provides a deeper analysis and offers a set of detailed recommendations for the three main actors, who stand at the centre of the dynamics of knowledge generation, transfer and acquisition. These actors are:

- Research Centres (University of Trento, Edmund Mach Foundation, Bruno Kessler Foundation);

- Autonomous Province of Trento; and,

- $\quad$ Enterprises.

\section{Challenges and opportunities}

\section{Strengths of the Trentino Innovation System}

- In the past 40 years, Trentino registered an increase in the number of policies favouring research and public investment in R\&D (about 3\% of the budget of the PAT and over 2000 researchers).

- The reform of the research system which was performed by the law 14/05 helped to clarify the roles of the various players.

- The small dimension of the local research system favours coordination and flexibility. This also helps to focus on selected niches of excellence.

\section{Opportunities}

- Use the opportunities offered by the research reform (reinforce relationships between research centres, develop governance and system management via the foundations, structure the incentives system and the assessment of human resources, etc.).

- Capitalise on the large investments in research and innovation that have come to maturity over the past decade. 


\section{Weaknesses}

- In the private sector, product innovation is slower than process innovation.

- Difficulty in cooperation between research players and in creating critical mass.

- Limited researcher mobility within the research system, owing to different incentives and career paths.

- Notwithstanding the quantity of innovation and knowledge elaborated at a theoretical level by foundations and public research institutions, business investments in innovation are below the national average.

- Difficulty in defining a shared industrial innovation policy.

- Low business dynamics, low turnover and horizontal mobility of human resources.

\section{Threats}

- The local research system is small, therefore national and international competition is a threat. Targeted planning is required.

- The cuts in public funding for the innovation system are increasing.

- The ongoing crisis limits the attention on network policies and privileges targeted areas.

\section{The Trentino business perspective on knowledge networks}

\section{Description of the enterprises reviewed}

The analysis of the survey's results aims at identifying the business perspective on the knowledge networks in Trentino. The interviewed companies are mostly small and rather young business: almost half the companies were founded between 2000 and 2009. Only about 10\% began to operate before 1970. In most cases, over half of these companies were set up by a group of partners, and - a highly significant fact that gives a clear picture of the local situation - none of the companies that took part in the survey has a woman or a foreigner among its founders. Entrepreneurship level among young people (company founders under thirty-five) is also low at only $4 \%$. Companies in Trentino are mostly one-man businesses (74\%) and only 3\% are part of an international group. For $26 \%$ of the companies, the percentage of university graduates in the past 5 years is under $20 \%$ of the total number of new hires; for $24 \%$ of the companies, this percentage is over $80 \%$ of the total, and these are mostly companies active in new technologies. These data indicate a polarisation with high tech companies at one end of the spectrum and companies that have a very low percentage of university graduates at the other (29\% of companies report no graduates at all among their personnel). Also, $62 \%$ of the graduates received their degree at the University of Trento. As for turnover, 56\% of companies invoice less than 2 million Euros and 12\% over 50 million Euro. 
There is a structured relation between the public and the private sector mainly due to the transfer of financial resources. $44 \%$ of the interviewed companies reported having received public findings for $\mathrm{R} \& \mathrm{D}$ in the past five years. The ratio between Trentino business and the capitalisation of intellectual property is extremely low: each year, about $18 \%$ of the companies develop new patents whereas $56 \%$ use licences.

\section{Cooperation with the research centres}

The analysis reveals that $51 \%$ of the companies has benefitted from the research system in Trentino. It can therefore be considered a major asset, even if the number of enterprises involved has significant room for growth. The research also shows that the majority (59\%) of technological projects and innovation were possible thanks to the support of provincial funds for research and innovation.

In order to improve the existing partnerships with the research system, the surveyed firms accord great importance to the contribution of highly qualified human resources and to their capacity to influence the focus of research in Trentino. Positive changes regarding these two elements would favour the development of efficient partnerships on specific projects.

An untapped potential in developing organisational forms of knowledge networks, such as consortia and districts, clearly emerges from the survey, along with the will to maintain an ample autonomy in developing innovation strategies.

\section{Knowledge generation}

From the point of view of Trentino companies, innovation is a 'learning by doing' process that starts from an awareness that grows within the firm and aims to improving the business. In a subsequent stage, support is sought from outside the company. Internal experience is considered to be the main source of new knowledge generation. Many companies consider relationships with the research world to be very important. For these companies, in-house innovation and that generated from relationships with external research institutes are complementary elements of a single strategy. The average percentage of new knowledge generated within the company in the past five years compared to the knowledge acquired from external sources is $36 \%$. Trentino companies reckon that external resources play a central role in developing innovation and this acknowledgment is an important lever in setting innovation policies based on knowledge networks.

\section{Knowledge transfer}

The transfer of innovative knowledge within a system involves a complex set of mechanisms. The human capital element is a factor that unites many of these transfer processes, from the flow of graduates into business, to the creation of research spin-off companies or the establishment of new high-tech firms etc. Such processes gain strength if they are part of a framework into which are 
embedded incentive schemes, both financial and organisational.

The recruitment of skilled personnel and the knowledge arising from relations with clients are the most efficient knowledge transfer strategies implemented by the surveyed enterprises. The survey shows how local enterprises place little value on the world of research as a source of knowledge acquisition. This is partly explicable by sluggish bureaucracy and different attitudes towards research between the academic and business communities. However, not even research centres (institutes or foundations), seem to be viewed positively by entrepreneurs.

Reflecting on that distrust, it could be argued that Trentino firms seem to value knowledge acquisition processes that do not involve antecedents or commitments of time and resources, preferring in-house tools (skilled personnel and customer interaction) that enable knowledge to develop as a positive outcome of these players' activity but not necessarily constituting their primary role.

Informal relations appear to be, along with having graduates working in-house, a sort of premise, especially in the early stages of the relationship. Only after that do firms consider it appropriate to embark on active cooperation at a higher structural level. However, firms do not form an institutional association between the business and research worlds. More frequently, institutional relations are established later, following a formalised relationship between individuals, as a positive outcome of personal contacts, be they informal or institutional. Also, the survey shows that there is little mobility between the world of research and that of industry.

As regard to companies that have no dealings with research entities, the main reason given is the divergence between the timescales upon which the research world and industry function. Firms are also convinced that the knowledge produced by universities is too theoretical. This widespread perception among companies generates distrust and brings down the number of collaboration initiatives.

\section{Knowledge application}

Trentino businesses have a distinctive approach to the exploitation of technological knowledge: one of the strong points is their good use of it in the field of processes (process innovation, introduction of in-house ICT), whereas they are still weak when it comes to product innovation and applied research. The evidence shows also that marketing innovation (considered as the ability to introduce significant changes to product design, packaging, positioning and promotion), receives low consideration by the surveyed firms.

A key issue, with important policy implications, concerns the relationship between the innovative activity of enterprises and their degree of internationalisation. The results of a study conducted in Trentino in 2008 (Mariotti 2008) shows that the companies that carry out innovation activities and 
those that innovate their products perform the best in terms of internationalisation. Therefore, good performance on international markets can be considered as a result that can be obtained through, among other things, good innovation policies. However, the question posed in the survey on business strategy reveals certain misgivings on the part of firms about the link between innovation and internationalisation. These findings should be weighed up in the light of the recent global economic downturn. While recognising a link between innovation and the processes of internationalisation, firms do not consider the former to be a key investment during moments of economic weakness.

Finally, the survey investigated on how firms rate the PAT's industrial and innovation policies. Trentino's business world holds a positive view of the funding allocated to research and innovation. The quality of information sharing maintained by the PAT is considered mostly fair or good, as it is its capacity to develop local networks (e.g., clusters, business networks). Likewise, the PAT's ability to impose high quality standards for public sector procurement is well received. On the other hand, firms hold a negative view of policies aimed at strengthening their competitiveness and internationalisation, as well as of policies for developing staff skills through training courses.

\section{Policy recommendations}

A system seeking a role in the knowledge economy must increase the dynamics in its own subsystems ranging from enterprise turnover to researcher mobility to the public policies transformation elements. It is possible to achieve an overall stability of the system in the knowledge economy through actions seeking to ensure greater internal dynamism and a willingness to take risks. The social guarantees and stability traditions positively characterising the Trentino must favour the taking of social and entrepreneurial risks, not inhibit it.

From the enterprise point of view, a difficulty emerges in developing strategies based on knowledge networks. One of the main reasons is linked to the fact that the structuring of the relationships with the knowledge world is still in its early developmental phase. From this perspective it can be assumed that the investment promoted by the other players over the last decade can produce effects at the cooperative relationship level in a very short time span.

As regards the research system, the last decade focused on the fine-tuning of legislative and "macro" organisational instruments by means of the establishment of Foundations, agreements between the PAT and the NRC and the shifting of the control on the University to the PAT. Now there is a new phase based, on a greater focus, on the processes and organisational dynamics, on the "micro" level in which the governance of the processes is structured in a punctual manner at different levels. The Report highlights the fundamental importance of human capital in the innovation policies and the knowledge networks. The research system has the greatest responsibility on this issue which lies at the heart of the development policies of individual institutions. 
The PAT is facing a complex challenge. As it seeks to enhance greater collaboration between the actuators by governing the system, it should simultaneously try to increase the responsibility of the controlled subjects if it wants to ensure optimal operation. In designing policies, a distinction must be made between "excellence" and "economic development". If such distinction is lacking, it leads to unrealistic expectations which may constitute a boomerang for the important development phases. The industrial research phases, characterised by strong territorial economic impacts do not necessarily pursue excellence in research. The objective of investment in industrial research is development not excellence as was often thought in the past. Therefore, policies must define the levels at which they operate, the objectives, the appropriate instruments and enhance expectations linked to the specific contexts.

An efficient promotion of innovation policies that take into account knowledge networks should envisage appropriate focus elements, a new institutional governance as well as formats and cooperation mechanisms that do not hinder competition. The design of network policies is characterised by a growing attention to their impact on the market. This does not imply a single dimension; it implies the creation of appropriate links between the development of basic research, applied research projects, technology transfer processes and the support for market penetration so as to develop virtuous knowledge flows and the recognition of the autonomy and specificity of the single mentioned areas.

\section{Summary of the Magdeburg Case study with key issues from firm evidence}

Small and new local enterprises are known to have a significant influence on the creation of new jobs and, accordingly, on the development of the regional economy. The current regional study of Magdeburg explores to what extent knowledge transfer, controlled via regional networks, matters to small and new local enterprises. The focus of this study is on the analysis of knowledge-transfer networks as to their existence, their structure, and their relevance for small and new local enterprises in the regional economy of Magdeburg, in particular within the priority sectors identified by the city itself:

- Mechanical and systems engineering,

- Healthcare, and

- Environmental technology and recycling management.

The summary aims to highlight the case study review findings, starting from the composition of the socio-economic background of the Magdeburg region, followed by the key statements obtained from interviews with anonymous expert concerning i) knowledge transfer and identification of network structures, ii) the role of small and new local enterprises, and iii) the general political framework. 


\section{Socio-Economic Background}

In 1990, Saxony-Anhalt, located in the former German Democratic Republic, was established as one of the five New States of the Federal Republic of Germany. Comparing R\&D data among EastGerman states, Saxony-Anhalt ranks on average fourth, but there are big opportunities for growth. The area of investigation, for the purpose of this study, is the economic region of Magdeburg. In particular, the city of Magdeburg, located in the geographical center of Europe, offers a multitude of useful logistic connection, it can be considered as a service-oriented regional commercial center structured for the $97.4 \%$ by micro and small sized enterprises. Despite an almost stable population the city accounts a declining unemployment rate.

\section{Science and research}

The economic area of Magdeburg features a large number of scientific institutions. The resident universities and research institutes of the Alliance of Scientific Organizations mainly engaged in basic research, applied research, as well as research and technology exchange are:

- Universities: Otto-von-Guericke University Magdeburg (OvGU), Magdeburg-Stendal University of Applied Sciences (HS MD-SDL). Both universities have centralized structures to support knowledge transfer between the universities and local as well as regional commercial enterprises (TTZ, TWZ).

- Joint initiatives: Competence Network for Applied and Transfer-Oriented Research (KAT), a joint initiative of the universities in the state of Saxony-Anhalt and the Ministry of Education and Cultural Affairs.

- Research institutes of Alliance: Max-Planck-Institute for Dynamics of Complex Technical Systems (MPI), the Fraunhofer Institute for Factory Operation and Automation (IFF), the Leibniz Institute for Neurobiology (IFN) and the Helmholtz Center for Environmental Research (UFZ).

\section{Industry description}

The Association for Economic Services of Magdeburg (GWM) is a service offered by the city to companies in the region, within the three priority sectors, with the responsibility of providing information between science, politics and business, in order to:

- match suitable partners in the priority sectors;

- facilitate the implementation of cooperation agreements and projects; and

- strengthen the competitiveness of enterprises in the priority sectors within the region of Magdeburg. 


\section{Mechanical and systems engineering}

The mechanical and systems engineering sector is not a closed network; there are also significant external contributions at the state level by the automotive cluster and the cluster for special mechanical and systems engineering (SMAB). It also can benefit of a lot of available infrastructures provided by several centers and institutes, and in particular the newly established Institute for Competence in Auto Mobility (IKAM), which sets innovation as a priority.

\section{Healthcare}

The healthcare industry priority sector for the economic region of Magdeburg comprises a variety of industrial and value-adding sectors. Medical researches are provided by universities and research institutes. The biotechnology and medical engineering cluster at state level, networks and sectoral companies contributed to the potential of Magdeburg's healthcare priority sector in the fields of biotechnology, medical engineering and pharmaceutics. As a result of the cluster potential analysis in Saxony-Anhalt, medical engineering has been identified as a cluster with state-wide potential. All firms and institutions that are part of the healthcare priority sector have access to innovative infrastructure facilities.

\section{Environmental technology and recycling management}

In recent years, the areas of environmental technology and recycling management have become important industries in the economic region of Magdeburg and, the sectors of energy supply, water supply, sewage and waste disposal, as well as pollution control, were all combined into one priority sector. Active firms of the environmental technology and recycling priority sector have access to specialized infrastructure facilities.

\section{Knowledge transfer and identification of network structures}

According to the interviewed experts, in the Magdeburg region, the knowledge transfer networks result from the implementation of specific R\&D projects, in the context of federal funding and by the actions of industry-specific associations. The transfer occurs through transfer intermediaries (i.e., cluster management at the state level) or through the project coordinators of the priority sectors, the practical application then lies with the local firms.

The need for transfer intermediaries, responsible also of initiating and steering communication processes, results from the small-scale economic structure of the region. As a rule, not every individual firm has the capacity to apply R\&D processes in-house, but this performance capacity can be achieved by the union of several firms within the network. Moreover, the firms also have access to the infrastructure of universities and research facilities participating in the network. For the implementation of the $R \& D$ process, facilitation is required, which is performed by the transfer 
intermediaries (i.e., transfer offices created within the universities to support the knowledge exchange process).

Stagnation means regression is the core message; enterprise sustainability and growth can only be achieved through innovation based on executed R\&D processes. Scientists are regarded as having the necessary know-how to initiate start-ups, planned from the start with an orientation towards growth, through innovation based on existing R\&D process structures. As a reinforcement of this particular form of knowledge transfer, the Ministry of Economics and Labor of Saxony-Anhalt has promoted university founder networks as part of a state-wide start-up campaign, in order to support researchers on their path towards entrepreneurial independence.

\section{The role of small and new local enterprises}

The corporate landscape in Saxony-Anhalt and, in particular, in Magdeburg is shaped primarily by SMEs. Networks, particularly for micro and small businesses, ensure a supportive project environment for access to R\&D topics and enable them to access new customers and markets through innovations and thus reduce their dependence on individual customers. Micro and small-size enterprises refrain from participating in R\&D because of several structural problems. According to the interviewed experts, they are:

- the firms' lack of the necessary understanding of the need for R\&D altogether;

- the firms' lack of capital and human resources;

- the time needed for getting involved in R\&D is generally missing; and,

- rivalry and competition among cooperating firms when it comes to implementing R\&D processes.

The use of internships, and undergraduate and graduate work was unanimously identified by interviewed experts as a standard tool of knowledge transfer between universities, research institutions and industry. Both the local universities (OvGU, HS MD-SDL) have centralized structures for this task. The experts also identified information events (seminars, workshops, symposia) as a qualified instrument of knowledge transfer involving all areas ( $R \& D$, transfer, application). By creating a common language for business and science, this type of management can promote knowledge transfer through active communication with firms.

A main conclusion of the expert interviews is that only the $0.3 \%$ of firms operating in SaxonyAnhalt is continuously involved in $R \& D$, meaning that the existing potential of the $R \& D$ processes as growth option is far from being exhausted. The economic digression inspired a reorientation: firms recognized the potential of $R \& D$, but they still hold too many reservations regarding the cooperation with researchers. Experts also noted that the success of knowledge transfer crucially depends on the initiator. If the initiative for knowledge transfer comes from the entrepreneur, the probability of 
success is estimated to be significantly higher than if the initiator is a researcher.

\section{General political framework}

According to the interviewed experts framework conditions that enable local and regional firms to implement their own R\&D processes are necessary. However, they also agreed that Saxony-Anhalt has sufficiently many well-structured grant programs to allow a sustainable establishment of R\&D processes within the corporate landscape.

The most important and active players within the knowledge transfer networks such as the Central Innovation Program for the Small-Firms Sector (ZIM) of the Federal Ministry of Economics and Technology (BMWi), the Federal Ministry of Education and Research (BMBF), the Federal State itself, and also by the use of specific programs and funds of the European Union (EFRE, ESF).

Experts also agreed that politics can only provide the environment for R\&D processes, while the incentive to use them for taking advantages must clearly come from the firms themselves. In general, it was found a common lack of sensitivity: still too few companies take advantage of existing funding programs.

The state of Saxony-Anhalt offers an extensive financial product portfolio comprising grants, loans, guarantees, and equity capital, which is available to existing and also to new firms, to finance $\mathrm{R} \& \mathrm{D}$ processes at all stages of development.

\section{Policy recommendations}

A standardised terminology would be advisable for a clearer understanding of the network structures, there is no detailed classification of economic sectors according to the WZ 2008 yet, at the state as well as the municipal level. This desideratum relates to the desire for increased transparency of investigated networks in the economic region of Magdeburg.

A communication strategy should be developed through the initialization of a dialogic process involving all R\&D-relevant players, i.e. surveyed companies identified different institutions as the main contact point for the acquisition of R\&D knowledge (CIC, 62\%; GWM, 20\%; IGZ, 27\%), and a lot of them still have not cooperated with the research sector for gaps in information and communication process.

The development of a knowledge transfer concept for universities is recommended in order to fill the existing deficits handling the transfer of research knowledge. The role of mediators between research and industry played by their transfer offices is still not well recognized by economic players.

A detailed breakdown of the priority sectors is recommended in order to increase transparency and obtain a detailed overview of the relevant players within the three clusters of the knowledge 
transfer process: Saxony-Anhalt, industry-specific associations, and R\&D project networks. Networks represent a dynamic rather than a fixed system which need for a periodic updating. A micro-study is also recommended to identify and present all the available communication structures, using methods of network analysis.

Analysis revealed that there is a need for improving the central coordination of R\&D projects between academia and industry and the joint use of the existing infrastructure of science and industry within the networks. Based on these results, a further development of networks is recommended by including a detailed analysis of the process chain, the visual depiction of the structure, and the development of a communications strategy. Other priority sectors (i.e food industry is the largest economic sector in Saxony-Anhalt) may be implemented. It is conceivable that science-based $R \& D$ potential may need to be established or be imported into the economic region of Magdeburg.

The analyses carried out that $R \& D$ funding is of prime importance for the implementation of $R \& D$ processes. Furthermore, it is essential to ensure secure long-term financing of the network coordination, because the dynamics in the implementation of $R \& D$ in networks is critically dependent on the activity and stability of the actors concerned.

\section{Conclusions}

Magdeburg and Trentino Alto Adige are peculiar cases of knowledge networks in Europe. Trentino Alto Adige is an alpine region, in the bottleneck between Italy and Austria-Germany, while Magdeburg is geographically a flatter area in a relatively more central area of its Country. The German case addresses the knowledge transfer processes in an urban area; the Italian case addresses the same processes in a mountain and largely rural area. While Unemployment is a main topic of the economic agenda of Magdeburg (13.6\% rate), Trentino today is an almost no unemployment area, even though it was a very poor and emigration area in the $19^{\text {th }}$ century.

Moreover, both of them are characterized by common aspects:

- Both are situated a little bit far from where the main national economic flows are concerned;

- The industrial research is a developmental opportunity and the number of firms involved in $\mathrm{R} \& \mathrm{D}$ programmes is limited;

- The establishment of the Universities and the economic role they may play is a relatively recent topic in the territorial development agenda;

- The relative importance of the public sector in the economic environment is very important;

- From the knowledge network perspective, the technology transfer processes and network are mainly local, even though the local universities and research centres are highly respected 
international institutions;

- Strong public financial policies supporting $R \& D$, even if with even generic in purpose and not focused on specific knowledge networks;

- Being mainly characterized by small companies, both areas rely upon transfer intermediaries and provision of high quality infrastructures;

- Both areas have policies focused on attracting external companies into the local knowledge networks, however, these policies, sometimes very expensive, do not present a uniform degree of success.

Furthermore, two very young knowledge networks were identified considering, also, the age of the actors and the structured relationships among them. Magdeburg and Trentino knowledge networks are at the early stage of their developmental curve. Magdeburg has a bias in terms of main cluster toward mechanical engineering, Trentino towards ICT. The structure of the knowledge network is more formalized, and linked with State level policies. During the last decade, both Magdeburg and Trentino developed significant efforts toward clustering in the green economy environment.

The network structures recognized show some differences between the two cases. In Magdeburg network structures are based on a multilevel institutional infrastructure (funding and guidelines provided at the federal level, and the cluster management at local level), while in Trentino, where the national level is historically very weak in $R \& D$ and innovation policies, they are concentrated at the Autonomous Province level (most of the policies concentrated at Province level are also well connected at the EU level).

As the analysis revealed, the role of knowledge transfer intermediaries as facilitators of knowledge processes, in such industries based on SMEs, is critical for the success of the knowledge networks. These processes are well developed in both areas, especially in Trentino, even if there are significant opportunities for improvement.

The empirical analysis revealed also that SMEs have the domestic market as their core market, but identified two different points of view: process innovation is the focus of the Italian companies, while product innovation is the focus of the German ones.

Furthermore, knowledge networks investigated identified, as the main obstacles for cooperation, the gap between research and industry priorities and time to market issues, followed by lack of knowledge and information: the knowledge exchange, mainly developed at local level, remains highly informal (i.e. supply chain relationships, and other industrial network structures). A microeconomic analysis of the knowledge networks is highly recommended to investigate further elements of micro knowledge flows, as well as key elements of the dynamics of knowledge networks.

Being these informal networks the strongest knowledge network infrastructures, in both areas, 
awareness and communication processes, based on dialogic relationships among the actors, are highly recommended.

Trentino and Magdeburg case studies show, also, the SMEs necessity for the design of incentive systems that allow companies to better absorb resources, and in general optimize the flow of human and capital resources within the poles of the knowledge networks; but also the necessity to avoid the bureaucratic and administrative obstacles they have to face.

Building or further developing specialized agents, such as local knowledge bridging institutions, is a relevant opportunity, but the relatively small size of these knowledge networks. Local bridging institutions, rooted into national organizations, are highly recommendable, provided that they do not lose flexibility and market drive. From this perspective the two cases are part of significantly different national environments. The facilitation of the financial and skilled labour within the private-public poles of the network need in fact to be more and more a structured process, with incentive systems, management and an overall governance, as building blocks of a clear strategic policy.

In this scenario, policy designers should, on one hand, support the consolidation of existing knowledge chains, processes and communication flows. In fact, the two knowledge networks are relatively young and the experiences of the last decade are critical to optimize the incentive and coordination system, as well as control the opportunistic behaviours. The local governments have important leverages to play with the systems, in particular Trentino. On the other hand, network strategies should not hamper internal and external competition as well as internal dynamism and risk attitude. Both Trentino and Madgeburg give culturally high value to social stability and job security. This is a great value, as long as it does not create unwanted mechanisms that hamper growth and optimal dynamic allocation of resources.

Knowledge networks tend to be sectoral and industry specific (i.e. mechanic engineering in Germany, ICT in Trentino, etc), while innovation is more and more developing applicable solutions building upon multi-sectoral knowledge and expertises. Besides, important industries of the two regions might be more involved into knowledge networks (i.e. food industry in Magdeburg and tourism in Trentino). There are important experiences, but the potential of structured innovation is not completely leveraged, which is a great opportunity to build policies for bigger industries integration.

Finally, public policy makers should ensure long term sustainability of knowledge transfer networks, and strategies should be structured to overcome the life of the single projects developed within to give more added value supporting to local companies. 
PART 1: THE TRENTINO CASE STUDY 


\section{TRENTINO CASE STUDY}

The general objective of the OPENLOC Project (Innovation Policy and its Effects on Locally Embedded Global Dynamics) is to create a new institutional and economic framework in which Italian local systems, starting from those located in the Autonomous Province of Trento, can tackle the entry into global networks since they are embedded in specific environmental, socio-cultural and economic contexts. With reference to this framework, the project seeks to examine the present configuration of both the formal (research centres) and the informal (routine communication between the enterprises and the public and private bodies) networks of institutions characterising the Autonomous Province of Trento, together with other local systems that are tackling global dynamics through adequate innovation policies ${ }^{4}$.

The OECD LEED Centre for Local Development in Trento helps attain the OPENLOC project objectives by offering an analysis of the knowledge and innovation systems in two different contexts: the Autonomous Province of Trento and Land Magdeburg in Germany.

\section{Subject-Matter of the Report}

The report analyses the knowledge networks in the territory of the Autonomous Province of Trento (PAT). More specifically, the study examines the nature of the knowledge produced by the main players operating in the territory, the relationships existing between them, the tacit and coded knowledge flows, the contract types, the institutionalisation level of the relationships and the system's evolution over the last decade.

Socio-economic literature highlights a few elements which are of tantamount importance for the development of the knowledge flows within the local innovation systems, including an innovation and knowledge-oriented local institutional apparatus, a network of flexible policies, an important nucleus of creative and motivated entrepreneurs and an intense networking activity integrating short local networks with the global network and also capable of facilitating the exchange of knowledge and collective learning processes. The development of a local innovation system and the underlying networks it implies finds the maximum expression in contexts characterised by highly-developed financial and organisational autonomy as is the case for the Autonomous Province of Trento. This enhances collective learning processes, technological development, resource coordination within the networks and knowledge chains and allows the integration of the local system in the national and international context, thus helping to increase its competitiveness.

4 Operational Project, Large Projects Call for Tenders 2006. 


\section{Methodology}

\section{Structure}

The report structure includes a presentation of the issues linked to the knowledge networks in the context of the Autonomous Province of Trento. The nature of the processes and the local innovation systems are analysed starting from such networks.

Part 1 includes a short list of the main studies and reports prepared by local and national experts and policymakers on the issue.

The report then continues with an analysis of the characteristics of the Trentino entrepreneurial environment and the political and institutional profiles linked to local economic development. One of the main points examined is the organisational structure of the knowledge network in Trentino. The characteristics of the different players coming from the research, Provincial and business community are examined together with the type of relationships they have established and the degree of openness of the system to the outside world.

The networks are analysed according to their three development phases: knowledge generation, transfer and application. For each of these phases the theoretical perspective is examined, followed by a reasoned analysis of the replies obtained in the interviews and meetings with the Trentino experts of innovative policies (hereinafter referred to as "experts") and an empirical study is carried out at certain businesses located in the Province. A questionnaire containing both open-ended and multiple choice questions on issues concerning the three phases of development of the knowledge networks were forwarded to businesses that were selected with the help of Trentino Sviluppo, the agency founded by the Autonomous Province of Trento to promote sustainable development, greater entrepreneurship and the innovation capacity of the Trentino system.

Starting from the empirical results contained in the report, the conclusion elaborates suggestions for the development of innovation policies and the strengthening of the efficiency of the knowledge networks for the local policy-makers.

\section{Objectives in brief}

The report sets down the following specific objectives:

- the mapping of the main knowledge networks of interest to the Autonomous Province of Trento (types of networks, players, relationships and key elements characterising the local innovation system);

- an analysis of the functional characteristics of the Trentino knowledge networks with special attention being paid to the nature of the processes generating new knowledge, the transfer of 
knowledge and the application/exploitation of innovative knowledge processes;

- an analysis of the results of the questionnaire forwarded to the enterprises in the region;

- a study of policy implications, the preparation of points to be further examined and brought forward by the political players in the territory.

\section{Indicators}

A set of indicators were created to analyse the knowledge networks at local level. Such indicators were used in the interviews with the experts and in the questionnaire forwarded to the enterprises.

The interviews with the experts tackled mainly qualitative issues concerning:

- the type of relationship between the players in the local system and the degree of structuring;

- the origin and development of such relationships;

- the degree of formalization of the relationships and their structuring, if any;

- the main learning and transfer channels for the new knowledge;

- the main global players (coming from other regions and/or countries) in the local relationships and the role of local enterprises at a global level;

- the main obstacles and weaknesses in the generation, transfer and application of knowledge;

- the role of universities and research centres in knowledge generation and transfer to enterprises;

- the enterprises' capacity to absorb knowledge coming from outside the company;

- the policy implications, the role played in the system by the Autonomous Province of Trento and the main opportunities for further strengthening.

The questionnaire to collect qualitative and quantitative information concerning the generation, transfer and application of new knowledge within the local innovation networks was administered to approximately 300 enterprises located in the PAT. Assistance was provided by the agency for local SMEs development, Trentino Sviluppo, which made available a database of enterprises operating in different sectors engaged in innovation activities. A total of $23 \%$ of enterprises replied to the questionnaire. The group of selected enterprises also contained companies hosted at the Business Innovation Centre (BIC) of Trentino Sviluppo and academic spin-offs that contribute to strengthen the overall technological profile of the respondents. The following indicators were used:

- new knowledge generation modalities;

- new knowledge acquisition sources and types of business-research partnerships;

- $\quad$ problems and opportunities linked to the development of the knowledge networks; 
- role and value of consortia and technological clusters;

- new knowledge application modalities;

- public policy assessment. 


\section{THEORETICAL ASSUMPTIONS AND AN OVERVIEW OF THE MAIN REPORTS ON THE ISSUE}

Over the last ten years many theoretical studies have been carried out on enterprises and knowledge networks; the local innovation systems and the relationship between socio-economic environments and the innovation processes.

The local economic environment can be depicted as a network of relationships within the social, economic and cultural contexts in which the players operate (Rauch, Casella, 2001). The attention then shifts from the characteristics of the players constituting the network to the characteristics of the relationship between them. The "knowledge network" concept may refer to the inter-institutional relationships or to the personal relationships between the members of the local communities of practice. It interacts with the performance of the local innovation systems (Boschma and Ter-Wal 2007).

Recent economic literature highlights the role of "relational capital" as a social process of localised knowledge creation (Cappello, Faggian, 2005) ${ }^{5}$. The knowledge distribution channels in a territory depend on the relational capital structure of the area. An analysis of the knowledge networks allows the enrichment of the interpretative structures linked to the cluster approaches, the regional innovation systems and the local knowledge spillovers (Ter-Val and Boschma, 2009). Such analysis also highlights the relationships with players that are outside the network thus stressing the value of social construction (Giuliani, 2007).

From a dynamic point of view, it is possible to trace the interaction of the network evolution, knowledge dynamics and the innovation processes. The absorption capacity of new knowledge by enterprises is an important element in determining their positioning within the network. Generally, network evolution corresponds to changes in the players constituting the network itself. A mapping of the relationship between the key players within the system and the external partners is possible. Such mapping allows the emergence of situations characterised by cognitive lock-in effects in which there are difficulties in the relationships with external subjects. Such analysis owes much to the study of the geographic proximity relationships. It also tackles other issues regarding the way in which the agents

5 The term "relational capital" can be defined as: "The relationships that are established between enterprises, institutions and individuals as a result of a common belonging and collaboration capacity that can be found in environments characterised by a homogenous social and institutional substrate. 
coordinate their actions (issues tackled by the industrial economy and by the organization economies), the way they communicate, the way they learn (cognitive science) and how networks are born, develop and die over time (evolution economy) (Boschma 2005). The study of the Trentino area highlights the coexistence of many such dimensions at different levels of intensity which give rise to a complex framework of relationships.

\section{Main Reports on the Issue}

At the end of the 1990s, within the European Union's "Fifth Framework Programme", the former Istituto Trentino di Cultura (ITC) prepared a survey entitled "Regional Innovation and Strategy for Technological Transfer". Such study marked the first time regional innovation systems were examined. It identified some of the problems of the territory and included a commitment by the local institutional system to actually tackle them ${ }^{6}$.

The following study on "Science and Technology in Trentino" (Fraunhofer-Institut, 2003) emphasized the transformations within the Trentino knowledge networks. It is an important reference document based on the information available before the reorganisation of the research system (Provincial Law No. 14 dated August 2, 20057) and the impact of the economic crisis. Although the last decade has been characterised by great dynamism in the innovation and research sector, the report highlighted that the recommendations made at the time correspond to the problems existing today. The Report photographs the Trentino system characterised by solid informal networks and institutional relationships, a rich innovation infrastructure, an excellent funding system and a group of relatively stable enterprises. Among the main weaknesses which are listed is the lack of collaboration between research and industry and a tendency to take advantage of public sector incentives without well defined and communicated strategic priorities. Additionally, the study also highlights a limited industrial base and an insufficiently developed entrepreneurial and technological culture ${ }^{8}$.

During the same year, the Research Observatory of the Autonomous Province of Trento published the report entitled "Scientific Research in Trentino" laying down proposals for change following a first assessment and interviews with the key players.

In 2006 the PAT participated in the TeRIS project financed by the European Union's "Sixth Framework Programme", with a report on the "Trentino Regional Innovation System". Such report

\footnotetext{
${ }^{6}$ For example, between 1999 and 2003 the overall PAT funding available to organisations in the training, research and innovation sectors increased by $160 \%$.

${ }^{7}$ For further details See Paragraph 3.3 of the Research and Innovation System Adjustment Law.

${ }^{8}$ Fraunhofer-Institut, The Science and Technology Base of the Autonomous Province of Trento: Capacities, Trends and Opportunities, 2003.
} 
contains different approaches in the interpretation of the regional innovation system by the stakeholders. The report highlights the need for an alignment of the objectives by the different players.

In 2008 the Autonomous Province of Trento presented the "Airaghi Commission" Report, an impact and evolution assessment of the strategic development of the local research and innovation system (Airaghi and La Cave, 2008). The report states that the impact at international and provincial level is greater than at national level. It suggests a governance system for the regional innovation system leading to the creation of a coordination instrument to bring together the different players. The report also indicates a few strategic elements for the development of the innovation system, such as:

- A ranking of the internationalisation and local development objectives according to their importance;

- A development focus on specific sectors;

- Export of knowledge outside the local context;

- Definition of process monitoring and assessment indicators;

- Development of synergies and collaboration between the Trentino players;

- Establishment of key collaboration sectors between the institutions of the system (PhD's, European Design Centres, lure researchers from abroad). 


\section{EVOLUTION OF THE PROVINCE'S RESEARCH AND INNOVATION POLICIES}

\section{From the 1960s to the 1990s}

The Trentino industrial policies, born before the innovation policies, developed during the 1960s, i.e. during the "economic planning" season. The main objective was to support development and employment in the depressed areas by attracting industrial investments capable of realigning the province's competitiveness to that of the other industrialised European regions. Development issues were linked to the luring of capital which was considered the key factor in order to tackle the employment issues.

The first company restructurings in the 1980s and the change in the cultural climate vis-à-vis small enterprises led to a great transformation of the original model. The interest shifted from attracting large enterprises to attracting small enterprises and to business actions within the knowledge economy. Simultaneously, strategies seeking to attract institutional subjects promoting international research were carried out and the distinction between industrial policy and research and innovation policy decreased.

The panel of experts that were interviewed for this report highlighted the characteristics of an industrial policy seeking to create and maintain employment levels. However, to overcome the economic crisis of the last few years a special focus is needed on the development paths and on new models of virtuous relationships between the players. The experts' assessment shows that there is awareness that the era of large companies attracted by public funding (for example Grundig and Michelin) is over. The following phase which began in the 1980s led to the development of small companies with a new perspective which paid great attention to the risks of having a single type of industry. In the 1980s and 1990s these industrial trends were accompanied by increased investments in the ICT sector, based on the US model. Simultaneously, the civil service also introduced ICT. The difficult economic situation over the last three years has highlighted how important it is to create networks between the local players.

\section{The Last Decade}

The last decade, characterised by the review of the company incentive system for the Trentino enterprises, the reordering of research activities, the birth of the "Habitech" Trentino Technological Cluster and the recent transfer of the University under Provincial control, constitutes a very important phase for the governance and development of the knowledge society and the networks operating 
within. During this period the industrial policies and the innovation and research policies start to converge. Such process is further confirmed and consolidated by the explicit commitments by the Provincial Administration upon its election in 2008. The Programme Mandate of the Province's President, Mr. Dellai, envisages project development based on innovation in which the knowledge networks can play a central role in many different fields:

1. ensure continuity to the reorganisation activities of the research and innovation system carried out during the previous term;

2. enhance agglomeration processes to attain an adequate dimension bearing in mind the resources available in the overall system;

3. extend the experience acquired by the Trentino Technological District on energy and the environment (Habitech) to other sectors of the Trentino economy;

4. specialise Trentino Sviluppo (the local development agency) so that it can act as a link in the Research/Innovation chain.

\section{Law for the Review of the Research and Innovation System}

The main document characterising research and innovation policies in the last decade is Law $14 / 05^{9}$ concerning the review of the system. This law introduced a new phase in the dynamics of the knowledge networks in the Trentino region. The direct and indirect impacts of such law are now starting to become visible.

${ }^{9}$ Provincial Law No. 14 dated August 2, 2005 approved by the Autonomous Province of Trento reviewed the entire Trentino research and innovation system as well as the Province's role in the governance and advocacy of the system. The main intervention planning instrument for the development of the system is the Multiannual Research Programme. The first measure is the reorganisation of the two existing research centres, the Istituto Trentino di Cultura (now the Fondazione Bruno Kessler) and the Istituto Agrario di San Michele all'Adige (now the Fondazione Edmund Mach). In particular, it envisaged their transformation from public bodies to foundations. The second measure concerns the research projects purchased by the Province. These projects shall be selected by means of a call for tender. The outcome of the projects shall be the property of the Province and the rights of use, if any, shall be shared with the private subjects at market conditions. The third measure consists of the review of Article 5 of Provincial Law No. 6 dated 1999 regarding the existing advantages for research and development. Two Provincial consultancy and assessment bodies are in charge of defining the strategic priorities as regards the granting of contributions and the research assessment. The Technical-Scientific Committee for research and innovation (Art. 23), expresses its own opinion on the scientific research projects and the industrial research projects which are presented and prepares proposals concerning the Multiannual Research Programme. The Assessment Committee (Art.24) assesses the efficiency of all the Provincial interventions. 
The main element of the norm is the capacity of the research and innovation system to interpret and express the knowledge, research and innovation needs coming from the territory, identify punctual solutions and assess the results of the actions undertaken. As stated in the report accompanying the draft law dated April 2004, such objectives can be carried out by abandoning the direct management of research and envisaging for the PAT the role of system integrator capable of expressing the needs of the territory and of indicating to the research sector and other sectors the priorities and paths which can be shared by all.

Regarding the knowledge networks, the reform emphasizes the composite character of the Trentino research system in which there are many collaborating and competing players. There are also very good possibilities of receiving funding for a research chain or cluster. Such funding was explicitly introduced by a change in Law 6/99 carried out by the Provincial Council in December $2006^{10}$.

\section{Multiannual Research Programme and Provincial Development Plan (XIII ${ }^{\text {th }}$ Legislative Term)}

In 2006 the instruments which the Provincial government had identified with the law for the review of the Research System were fine-tuned, i.e., the direction, support and assessment of the participating parties in conformity with the autonomy principles of the subjects themselves. 2006 was the year in which the review of the public research bodies was carried out with the creation of the Fondazione Bruno Kessler which replaced the Istituto Trentino di Cultura abolished in March 2007. Starting in January 2008 the Fondazione Edmund Mach replaced the Istituto Agrario San Michele and the Centro di Ecologia Alpina.

At the end of 2006 there was also the approval of the first Multiannual Research Programme for the 2006-2008 period. The programme highlighted the thematic areas considered to be a priority, the general lines of intervention and the implementation instruments (conventions between the different tiers of government, tenders to obtain funding for research projects, incentives for applied research) as well as an increase of public funding following the coming into force of the new provincial law and the activation of the Single Research Fund. In May 2006 the Provincial Development Plan for the XIII $^{\text {th }}$ Legislative Term was also approved. It set down the following objectives for the regional innovation system:

- A greater internationalisation of the research system;

- An increase in the percentage of non-PAT public and private funding;

- The definition and implementation of a research assessment system (quantitative indicators

\footnotetext{
${ }^{10}$ Trentino had never tackled the cluster issue as such previously. Its partner for industrial policy had always been the individual enterprise owing to the overall lack of specialisation of the local system.
} 
and peer review);

- The promotion of synergies between the research system and the local development policies also in view of luring enterprises (for example the Microsoft Research Centre)

\section{The New Provincial Development Programme}

The knowledge network theme constitutes the subject-matter of the 2010-2012 Budget Report of the Autonomous Province of Trento, allocating research policies 84 million euro in $2010^{11}$. The new Provincial Development Programme approved in March 2010 is based on the territorial capital ${ }^{12}$ concept and it strengthens the network theme by setting down some priorities:

- the definition of an Agreement between the PAT, university and Mach and Kessler Foundations to coordinate research at a provincial level, attain results of international importance and establish the collaboration modalities between the different bodies thus favouring European embedding including in the Euroregion;

- further qualify public investments in research and strengthen the collaboration with private enterprises;

- promote the creation of an ICT cluster in the provincial territory through specific actions and the introduction of efficient collaboration instruments between the research system, the public sector and business;

- consolidate the "Habitech" Trentino Technological District project including the "Manifattura Domani"13 Project and promote a system of alliances and collaborations

\footnotetext{
${ }^{11}$ The President of the PAT, Planning and Financial Report of the 2010 Budget, page 29. Trento, October 30, 2009.

${ }^{12}$ The OECD has drawn up a list of factors determining the territorial capital including both tangible and intangible assets. "Such assets include the geographical location of an area, its size, the availability of production factors, climate, tradition, natural resources, quality of life or agglomeration economies resulting from its cities. It may also include its incubators, industrial clusters or other business networks which allow a reduction in transaction costs. Other factors may include: "interdependencies not linked to the market" such as covenants, habits and informal rules allowing the local players to work together in uncertain conditions or the solidarity networks, mutual assistance and collaboration networks in the development of new ideas which often develop into small and medium sized enterprises operating in the same sector (social capital). Lastly, on Marshall's footsteps, there is an "intangible" factor, "something in the air" which we can call the context or environment resulting from a combination of institutions, rules, practices, producers, researchers and public policy-makers which make creativity and innovation possible” (OECD, 2001, page 15).
}

13 The requalification of the "Manifattura Tabacchi" of Rovereto. It had previously been a tobacco processing plant and it is now "green innovation-oriented". Its priorities are sustainability in the construction and renewable 
including outside the PAT to create a "metacluster" on sustainability issues;

- review the financial incentives and prefer those initiatives that enhance innovation, the creation of business networks, size consolidation, the creation of new enterprises and internationalisation;

- enhance innovative entrepreneurship and the creation of new enterprises stemming from research activity (research spin-offs).

\section{Trentino Investments in the "Research and Development" sector (R\&D)}

As can be seen from the Development Programme Table for the XIV ${ }^{\text {th }}$ legislative term $^{14}$, the public system plays a prevailing role in R\&D in the Trentino region. In 2006 the public share of R\&D in Trentino was $69.8 \%$ as compared to $47.5 \%$ at national level and $34.8 \%$ in Europe (the EU objective is $33 \%$ ). The incidence of public and private expenditure in R\&D as a percentage of regional GDP during the same period was $1.2 \%$ in Trentino as compared to $1.1 \%$ at a national level and $1.9 \%$ at EU level (the EU objective is $3 \%$ ). If one looks solely at the private R\&D share, in 2006 it amounted to $0.3 \%$ of Trentino's GDP as compared to $0.6 \%$ at national level and $1.2 \%$ at EU level. Differently from the trend recorded at national level, the Trentino Provincial funding for research has increased since 2000.

In 2006, the PAT included 2091 researchers, 850 of them employed by public research bodies, 657 by the University of Trento and 489 by local enterprises. The people employed in $R \& D^{15}$ amounted to $4.2 \%$ of the residents as compared to $3.3 \%$ at national level and $5 \%$ at EU level.

The objectives linked to the interventions in the R\&D sector can be summarised as follows:

- identify research and higher education areas in which it is possible to obtain outcomes of international relevance while concentrating efforts and investments to avoid unproductive dispersions;

- the internationalisation of researchers and teachers to increase the attraction on the most important scientific and academic markets and the construction of a network of shared alliances with the best examples of national and international research;

- the development of an alliance network for the promotion of a research and training Euroregion including the Austrian-German area and that of north-eastern Italy involving both research institutions and the business community;

energy sectors.

\footnotetext{
${ }^{14}$ Provincial Council Decision No. 2608 dated October 30, 2009.

${ }^{15}$ Provincial Development Programme. See note 11.
} 
- qualify oneself as a credible and privileged interlocutor in the vanguard industrial reality and simultaneously support the entrepreneurial and production fabric in Trentino, while interpreting the innovative processes and paying special attention to the finalisation of research;

- supply indications and instruments which are useful in building a civil and political society capable of uniting the future and one's original identity, efficiency and closeness to citizens' new needs, development capacity and trust in its sustainability.

The local experts that were interviewed for the preparation of this report expressed their views on the evolution of Trentino industrial policy, the gradual approach to the research policies, the industrial policies and the knowledge network policies The first aspect which emerges from the study is the slow, albeit constant, development of the centrality of the knowledge network policies supported by the growing centrality of the research and innovation policies on one side and the economic crisis on the other. The difficulties resulting from the economic downturn which has characterised the last three years have helped increase the awareness of the importance of creating networks between the local players.

Another important aspect which emerged from the interviews is the consideration that the network policies are characterised by a better impact in terms of costs and benefits as compared to the costly policies based on incentives to single individuals which do not ensure greater employment at a local level and are incapable of influencing business strategy decisions.

\section{Box 1. Assessment of PAT- funded industrial research projects}

The last decade has witnessed a great transformation in the research and industrial innovation incentive processes starting from the assessment of the projects presented to the PAT. Up until 2006 the projects were assessed by the University of Trento which examined the fairness of the expenditure and its relation to the research and development sector.

Starting in 2005, Law No. 14/05 introduced a Technical-Scientific Committee (TSC) and a review of the general assessment criteria. The reviewed criteria include the production activity within the PAT, the relationship with the territory, the presentation of joint projects between enterprises and research centres. The TSC carries out an ex ante assessment of Law No. 6/99 projects and then an ex post assessment of the outcome upon the completion of the project.

The bigger projects also envisage an in itinere monitoring. In 2008 at the end of the legislative term, the TSC issued an assessment document on the impact of the operations funded by the law. Among the key points, it highlighted that the assessment of individual projects is inefficient for an analysis of the impact on the territory unless it is accompanied by industrial policies of reference. The research policy must be part of a context in the framework of territorial development. The industrial policy, on the contrary, historically tends to favour individual 
enterprises outside of any context. The cross-sectional innovation, internationalisation and research strategies find in aggregation a prerequisite of sustainability over time. Such processes better fit into the system if they are governed in an aggregated manner by the enterprises.

The PAT seeks to carry out a strategy embedded in the territory. Consequently, the research and industrial development activity must be linked to productive investments. If the contribution offered exceeds 500.000 Euro the enterprise must ensure employment for at least three years. Almost all the projects started during the second legislative term shall end in late 2010 and it shall thus be possible to carry out an assessment.

The quality of the projects presented between 2006 and 2009 improved following the introduction of an external referee and an assessor. The new norms introduced allowed for a better assessment of the results. Out of the 2000 or so contribution requests the PAT receives yearly, approximately 30 to 40 are research projects. The greatest advantage is reserved to the priority sectors set down in Law No.14/05: sustainable construction, renewable energy and research spin-offs. From 2006 onwards few applications were made concerning sustainable construction. Trentino is characterised by a large construction sector with a low added value.

Law No.14/05 brings Trentino up to par with the most advanced European regions. Some adjustments however have to be brought:

- Since there is abundant funding, applications tend to envisage high budgets. For many SMEs the applications are ambitious and the project management and outcomes are rather complex.

- The funding instrument is inadequate to support innovation in craftwork businesses. Small enterprises usually do not have any employees whereas this is the main cost item envisaged in the law.

- The contribution for the assignment of researchers to the businesses was used only for the FBK spinoff. Very few applications were made over the last decade.

- In industrial research projects assessment, in addition to the scientific, economic and financial assessment one must also introduce a market-related assessment of what one wishes to develop. At present, this component is often missing and a purely "technical" assessment is carried out (TSC) based on parameters related to the financial and economic aspects (preparatory body). 


\section{TRENTINO KNOWLEDGE NETWORK: SOCIAL AND ECONOMIC EMBEDDING}

The separation between the different players dealing with research has often led to the multiplication of activities and difficult relationships with the production world. This in turn risks jeopardizing an adequate level of international competitiveness. Such criticality is at the basis of the coordination role attributed to the Autonomous Province of Trento by Law No. 14/05 which reviewed the law on research.

\section{Entrepreneurial Fabric: Dynamism and Interaction}

The Trentino economy is based on a strong network of relationships between the most important chains of the PAT (construction, tourism and agri-foodstuffs industry). However, the common territorial base constituting the real competitiveness element of the area does not stimulate the dynamics typical of industrial clusters in which the sharing of the industrial scene acts as a stimulus for the development of innovation dynamics and continuous adjustment. According to one interpretation (Camagni and Zaninotto, 2002), the reduced economic dynamics in terms of entry and exit of entrepreneurial subjects from the system is what reduces the business' and chains' capacity in Trentino to explore new frontiers. The local economy presents structural limitations to mobility owing to the characteristics of the relationship between businesses and the territory and the geographical fragmentation which does not facilitate competition. Moreover, the entry barriers reduce competition and the entrepreneurial turnover.

Table 1. The Trentino production system

\begin{tabular}{ll}
\hline \multicolumn{1}{c}{ Strengths } & \multicolumn{1}{c}{ Weaknesses } \\
\hline $\begin{array}{ll}\text { Production vocation of the PAT, organised in three } \\
\text { main sectors (construction, tourism and agri-foodstuff }\end{array}$ & $\begin{array}{l}\text { Very traditional sectoral structures and industrial } \\
\text { vocation which make it difficult to reallocate the } \\
\text { industry) }\end{array}$ \\
$\begin{array}{ll}\text { production factors in more advanced sectors and limit } \\
\text { the absorption capacity of highly-qualified human } \\
\text { rood productivity dynamics in the specialisation }\end{array}$ & $\begin{array}{l}\text { Lack of production organisations similar to "industrial } \\
\text { clusters" }\end{array}$ \\
sectors & $\begin{array}{l}\text { Limited number of specialisation sectors presenting } \\
\text { High level of investment per worker in many sectors }\end{array}$
\end{tabular}


Strong presence of small enterprises including in the specialisation sectors

Entrepreneurial dynamism above the national average particularly in the specialisation sectors
Limited competitiveness in the specialisation sectors

In most sectors with a high investment per worker, including in the specialisation sectors, there is a low investment performance

Limited presence and performance of the service sector in the services offered to business.

Limited entrepreneurial dynamics in Trentino may be a consequence of the geographical peculiarities and the financial, trade and labour markets. A study carried out by the Autonomous Province of Trento's branch of the Italian Trade Association (Rulliani, 1989) analysed the Trentino entrepreneurship. It did not simply highlight the lack of entrepreneurship; it linked it to the organisational and entrepreneurial formulas based on specialisation, integration and connection capacities. Other studies promoted by "Assindustria" the Business Association (Buzzi, 1996, Schizzerotto, 1996) in the mid-90s highlighted that the entrepreneurs appreciate the activity carried out by local institutions (PAT and local banks) more than the local research activity (University and Research Institutes). To enhance entrepreneurial requalification and innovation a proposal was made to open the local markets to competition, change the distribution of the risk linked to entrepreneurial dynamics and facilitate access to the large international market networks of goods and technologies (Camagni and Zaninotto, 2002). Attention was also paid to the creation of local hubs of the aforementioned networks.

Another approach in analysing territorial characteristics, entrepreneurial dynamics and the links between them is the so-called territorial benchmarking. Starting from an analysis methodology based on an individual enterprise it enriches it by focusing on the location of the business. The efficiency of a territory is subdivided into territorial efficiency and relational efficiency referring to the presence of relationships with other players who transfer knowledge - ensure management efficiency - thanks to the use of successful administrative practices. Such analysis methodology integrates tangible assets (services, infrastructure) and intangible assets (knowledge, synergies, collaboration). By applying such methodology to the Trentino case one sees that the overall industrial performance is based more on the management efficiency of the single enterprises than on the territorial system. Such attitude implies the absence of specialisation areas capable of facilitating the creation of strong territorial bonds between the enterprises (Camagni, 2002). The data is also confirmed by cluster analyses on the main groupings of small Trentino businesses. In analysing the factors of territorial efficiency it is clear that the competitive model is not structured around a network mechanism, indeed, it is structured on the non-strategic collaborations which impact mostly on the costs. 
Lastly, to understand the system dynamics it is extremely important to analyse the cooperative phenomena in the region. Out of a total population of approximately 500,000 inhabitants, the Trentino region has more than 200,000 partners distributed in 550 cooperatives. In other words, approximately two-thirds of the Trentino families belong to a cooperative ${ }^{16}$. A fundamental role is played by the FT Coop, the Trentino Federation of Cooperatives, an organisation for the representation, assistance and review of the cooperative movement on the territory. It comprises 515 cooperatives that are active in all the production sectors with approx. 255,000 partners and 180 workers (2009). The FT Coop offers services and consultancy, favours the creation of new cooperatives, looks after the functional adjustment of the plants and structures and is committed to supporting an efficient entrepreneurial activity including through mergers and groupings capable of ensuring a better management for the associated cooperatives. The Federation represents and protects the interests of the associated cooperatives before the private and public institutions and seeks to protect their identity. Moreover, to support the development of cooperatives, the Federation promotes draft laws and measures. The co-operation activity results in positive outcomes in terms of production, labour and resource organisation and allows them to come together and act as a system in homogenous fields of activity.

\section{Political and Institutional Aspects}

The local knowledge networks cannot do without considering the elements which are embedded in the Trentino institutional context. An important characteristic of territorial governance is the extended use of concerted processes. The experts who were interviewed highlight that the concerted activity at political and institutional level which has strictly strategic objectives risks being significantly absorbed by the resource allocation processes. The Trentino system is represented as a two-tier network: an informal network focusing on the enterprises and another at the summit in which the institutional, association and research authorities interact. The second tier, bearing in mind the importance of the PAT in the system, strongly centralises the decision-making system and it is resource allocation-focused.

Such a well-defined system leads to greater attention being paid by the categories to the institutional representation activity, differently from what happens in other neighbouring regions such as the Veneto Region in which the subjects themselves also express an efficient service offer for the production fabric. The need for a greater role of the actual players of the local production and innovation system emerges. A concerted system which pays great attention to the horizontal relationships risks not leaving them sufficient space. Moreover, paying attention to procedures shared by the governing system leads to the enhancement of those projects that are aligned with the political priorities and not necessarily to the best projects. Often the institutions select big programmes which

\footnotetext{
${ }^{16}$ www.ftcoop.it
} 
are inappropriate vis-à-vis the resources which the local system can make available.

The concentration of investments is perceived as being a problem. In the last three years there has been a considerable improvement but the objectives are still quite articulated ${ }^{17}$. Additionally, the university, research and innovation policies do not refer to the same figure within the Autonomous Province of Trento government and any attempt at a greater rationalisation is therefore quite difficult. The construction of networks in the business community in the Trentino region offering advantages thanks to the economies of scale is characterised by scarce collaboration owing to sectoral fragmentation and competition.

To summarize, the relational problems between players in the knowledge network existing at national level are even more evident in the Trentino region, also due to a problem of rarefaction. Enterprises request a type of innovation which is not necessarily vanguard innovation, whereas research, by its very definition, must progress along the line of knowledge. Businesses want real solutions and research centres are not always capable of supplying the responses. Only rarely do such centres adopt local businesses as interfaces of the PAT.

The relationship between the big players in the system such as Trentino Sviluppo, the Foundations and the University implies an interaction between quite different worlds. Although collaboration has improved, the relationships cannot do without considering the embedding in the social, economic and institutional profiles capable of enhancing their potential.

17 It has been noted that a "small" reality such as that of Trentino runs the risk of dispersion in seeking to simultaneously obtain several objectives such as the absorption of the University in the PAT policies, the establishment of the new Biology Faculty, the development of a new investment cycle in ICT, the Sustainable Building Cluster which in turn is organised in several areas, perspectives etc. 


\section{TRENTINO KNOWLEDGE NETWORKS: ORGANISATIONAL STRUCTURE}

The investment in research and development activities by the Trentino system is significant, particularly as regards the presence of important public research institutions (Foundations) which do not exist in other Italian regions. Indeed, they help to increase the relative weight of public research outside the universities (Table 2 and Table 3 ).

Table 2. R\&D expenditure per institutional sector (value at current prices in thousands of Euro)

\begin{tabular}{llllcll}
\hline Year & \multicolumn{1}{c}{$\begin{array}{c}\text { Public } \\
\text { institutions }\end{array}$} & $\begin{array}{c}\text { Trento } \\
\text { University }\end{array}$ & $\begin{array}{c}\text { Private non } \\
\text { profit }\end{array}$ & Enterprises & Total & $\begin{array}{c}\text { GDP } \\
\text { Incidence }\end{array}$ \\
\hline $\mathbf{2 0 0 2}$ & 58041 & 41322 & 738 & 35569 & 136030 & 1,03 \\
$\mathbf{2 0 0 3}$ & 70273 & 49578 & 1328 & 24585 & 145764 & 1,07 \\
$\mathbf{2 0 0 4}$ & 66457 & 50782 & 3320 & 26052 & 146611 & 1,04 \\
$\mathbf{2 0 0 5}$ & 69638 & 50967 & 4848 & 31626 & 157079 & 1,09 \\
\hline $\mathbf{2 0 0 6}$ & 69638 & 56669 & 7868 & 45981 & 178108 & 1,19 \\
\hline
\end{tabular}

Source: Margherita Dei Tos, "Research in the Trentino Region 2000-2007" Trento Civil Service Statistical Service

Table 3. R\&D expenditure: 2007 comparison (value at current prices in thousands of Euro)

\begin{tabular}{|c|c|c|c|c|c|c|}
\hline & $\begin{array}{c}\text { Public } \\
\text { institutions }\end{array}$ & University & $\begin{array}{c}\text { Private non } \\
\text { profit }\end{array}$ & Enterprises & Total & $\begin{array}{c}\text { GDP } \\
\text { Incidence }\end{array}$ \\
\hline Trentino & 66127 & 58609 & 4841 & 53132 & 182709 & 1,16 \\
\hline $\begin{array}{l}\text { North- } \\
\text { Eastern Italy }\end{array}$ & 729569 & 1055229 & 52101 & 2182033 & 4018932 & 1,15 \\
\hline Italy & 2644257 & 5495244 & 637211 & 9454656 & 18231368 & 1,18 \\
\hline UE15 & 27063712 & 49227025 & 2321321 & 143529045 & 222141102 & 1,93 \\
\hline UE27 & 28961404 & 50986167 & 2347630 & 146721608 & 229016808 & 1,85 \\
\hline
\end{tabular}

Source: Margherita Dei Tos, "Research in the Trentino Region 2000-2007" Trento Civil Service Statistical Service 
Highly educated human capital that can be used in knowledge-based activities is above the national average. The number of university graduates in scientific and technological fields amounted to $12.9 \%$ in 2006 , in line with the EU average (12\%) and above the national average $(12.2 \%)^{18}$. From the skill quality point of view, the Trentino students in Science, Math and Reading according to the OECD-PISA study obtain better results as compared to the rest of the country and indeed the OECD average. The knowledge linked to the quality of human capital is therefore higher than the Italian and international average from the quality point of view. The Trentino region is quickly narrowing the education gap typical of the past generations.

The Trentino Research system is unbalanced in favour of the public sector as clearly shown in Table 4, which highlights the weakness of the private sector in the development scenarios of hightechnological-content knowledge networks.

Table 4. Trentino research system: strengths and weaknesses (2006)

\begin{tabular}{|c|c|c|c|c|}
\hline Strengths & Indicators & Trentino & Italy & EU 15 \\
\hline \multirow{2}{*}{$\begin{array}{l}\text { High level of public } \\
\text { investment in } R \& D\end{array}$} & $\begin{array}{l}\text { Public Share of R\&D } \\
\text { EU Objective: } 33 \%\end{array}$ & 69,8 & 47,5 & 34,8 \\
\hline & $\begin{array}{l}\text { Incidence of expenditure } R \& D / G D P \\
\text { EU Objective: } 3 \%\end{array}$ & 1,2 & 1,1 & 1,9 \\
\hline $\begin{array}{l}\text { High presence of } \\
\text { people working in } R \& D\end{array}$ & $\begin{array}{l}\text { People working in R\&D per } 1000 \\
\text { residents }\end{array}$ & 4,2 & 3,3 & 5,0 \\
\hline Weaknesses & Indicators & Trentino & Italy & EU 15 \\
\hline $\begin{array}{l}\text { Limited private } \\
\text { investment in R\&D }\end{array}$ & $\begin{array}{l}\text { Private R\&D Share } \\
\text { EU Objective: } 66 \%\end{array}$ & 25,8 & 48,8 & 64,3 \\
\hline $\begin{array}{l}\text { Limited Results in the } \\
\text { Research activity }\end{array}$ & $\begin{array}{l}\text { Patents (European Patent Organisation) } \\
\text { per million inhabitants }\end{array}$ & 46,4 & 78,6 & $\begin{array}{l}106,0 \\
(E \cup 27)\end{array}$ \\
\hline
\end{tabular}

Source: Provincial Development Programme, 2010

The regional innovation system is young and it comprises institutional research subjects that have been created very recently. Consequently, their experience in structured collaboration is still in the early phases. The processes that lead to the construction of territorial innovation networks are usually characterised by incremental phases requiring long periods of time and the sedimentation of skills and

\footnotetext{
${ }^{18}$ Source: Provincial Development Diagram for the XIV ${ }^{\text {th }}$ Legislative term, Decision No. 2608 dated Oct. $30,2009$.
} 
experiences. The system includes subsystems in which the relationships are better developed: the internal relationships within the technological cluster (for example the relationship between the foundations and their spin-offs) and the institutional relationship between the University and the Autonomous Province of Trento as the principal for applied research. The experiences are different and it is quite difficult to place them within the same regional innovation complex if they are not carried out in a multidimensional manner.

The survey highlights that informal relationships based on personal relationships prevail and that they define the implementation strategies which are then formalised in a bottom-up process. The development is linked to the evolution of the system towards a greater opening of the subsystems capable of exploring the development opportunities which have not yet been grasped owing to cultural or institutional rigidities.

The afore-mentioned Fraunhofer Institut Report (2003) on the Trentino research system highlighted some of the networking characteristics within the scientific and technological community including the recent institutionalization of cooperation initiatives, the simultaneous presence of both collaboration and competition elements (for example to obtain PAT funding), the possibility of extension so as to attain the critical mass which would otherwise be impossible through the development of knowledge network systems. Researcher mobility within the research system is very limited owing to the different incentives and career paths.

Notwithstanding the quantity of innovation and knowledge elaborated at a theoretical level by foundations and public research institutions, business investments in innovation are below the national average. A problem thus exists concerning the modalities with which the knowledge and innovation which is produced can be transferred and used by the businesses.

\section{Players}

\section{Network Players - the Research Centres}

For researchers in Trentino, emphasis on networking strategies is a recent topic of interest. The research system in Trentino is more highly developed as regards basic research, which in sectors such as physics, information technology and cognitive sciences is markedly international in character. This strength characterizes the system as a national and international asset that may however have more difficulty in interacting with local partners ${ }^{19}$.

\footnotetext{
${ }^{19}$ Specifically, physics is an area of added value for Trentino both nationally and for Italy on the world scene. The competitiveness of research in ICT has been favored by at least two decades of investment in this sector, and this has meant a remarkable increase in the number of researchers over time.
} 
If on the one hand the distinguishing traits and the excellence of research in Trentino are objectively present in certain fields of knowledge, it is also true that institutions cannot be removed from their local, regional, socio-cultural and economical contexts. Since the Nineties, the idea of creating a horizontal research network in Trentino, to take advantage of the marked local dimension of the businesses in the area, has been developing constantly. A vertical dimension is also required, in order to keep the system rooted within the region, to maintain both social capital and the legitimacy which such a central system requires within the PAT. This local entrenchment has however been only partly successful.

The network of operators who interact with the research system varies from sector to sector. There are areas in which relations with local businesses have become structured and developed over the years, for example in ICT. There are other sectors, such as hydraulic engineering, for example, where the main partners for the research world are the public administration and engineering companies.

\section{The University}

The University is at the top of the national listings for several parameters which are pertinent to this report, such as, for example, the level of financing from outside sources ${ }^{20}$. It remains, however, a medium-sized institution, with difficulties in attaining the critical mass required to satisfy its ambitions. This problem is made worse by the lack of focus on the part of national research institutions which rarely possess the human and economic resources needed for any progress to higher levels of knowledge (new technologies, new products). To overcome this obstacle, the research institutions have been turned into Foundations, with new missions, and the University of Trento has made changes in its knowledge and innovation networks.

The University of Trento was born in the Sixties from the Istituto Trentino di Cultura. The first department was Sociology, which trained the management levels for the local public administration. In later years an engineering department was created, to meet the needs of the local businesses. A sizeable flow of graduates has been moving into the workplace since the Eighties, which is something new, in local history. And these people, currently at the helm of the companies in Trentino, are natural liaisons for the research system. Patent research is a recent topic of interest for the University as such. Today, there are twenty active patents ${ }^{21}$. The University of Trento has a spin-off, "Mountain Hearing" (with $9 \%$ of company shares) and two start-ups (one in consulting for R\&D and another in bio-tech, "K4sint s.r.l."). In absolute terms, the number of spin-offs is insufficient; however, the University recently laid out regulations for spin-offs and start-ups (July 2007). The number has been rapidly

\footnotetext{
${ }^{20}$ See CENSIS Report on University Ranking (2001 - 2006).

${ }^{21}$ Università degli Studi di Trento. Data updated to July 2010.
} 
increasing in recent months. The University of Trento is also active in knowledge transfers: it networks with the Universities of Bolzano and Innsbruck and with the Milan and Turin Polytechnics.

\section{The Foundation System}

The research network in Trentino is distinguished by the presence of two Foundations, besides the University and several public research centres. Since 2005, the public research institutions of the Autonomous Province of Trento have become foundations, even though the PAT continues to provide over $60 \%$ of funding.

The Fondazione Bruno Kessler (FBK) set up in 2007, formerly the Istituto Trentino di Cultura, began operating in the science and technology sector in the late Eighties. The Istituto Trentino di Cultura, whose largest shareholder was the PAT, did not have structured technology transfer activities. The charter that changed the Institute to a Foundation laid greater emphasis on knowledge transfer and on giving back added value to the local community (local businesses became part of the Foundation's mission). The goal is to work from the start with the end users of the research, to reduce time to market parameters and begin a new phase emphasizing capitalization of the research: licences, patents, new business incubation, spin-offs etc.

The emphasis on the society of knowledge and the development of local know-how is considered a guarantee of social mobility, a qualitative element in protecting against economic downturns. The main characteristic of the FBK's activity is the pursuit of world-class standards in research, lest the research itself become meaningless. Another element is an increasing attention to local issues ${ }^{22}$.

The Fondazione Edmund Mach (FEM), which was founded in 2008 on the basis of the former Istituto S. Michele, is part of the public administration's strategy of supporting agriculture for reasons both political and pertaining to social cohesion and has the chance to become an international forum of excellence on the key issues in which it is a leader and also to further important innovative applications at a local level. Some of the experts interviewed expressed the opinion that the FEM risks being overly attentive to the research programs offered by the European Union and that it might be improved by a greater focus on its mission, for example as a university for mountain-specific issues working in close contact with the municipalities.

The system in Trentino, besides the University, the FEM and the FBK also has an important

\footnotetext{
${ }^{22}$ The FBK has developed four key actions for knowledge transfer in the region: i) facilitating employees who wish to go into business for themselves, with three-year sabbaticals, secondments and postings to outside companies, etc.; ii) chances for FBK researchers to activate spin-offs with existing companies iii) services for companies (only marginal) and consulting services free of cost to companies within the network on the world-level state of the art of specific technologies.
} 
series of other research centres that play an important role in the knowledge network in Trentino. These include:

Centro per la Fisica degli Stati Aggregati (CeFSA) [Centre for the Physics of Aggregate States]

It is part of the Istituto di Fotonica e Nanotecnologie [Institute for Photonics and Nanotechnology] with branches in Rome, Milan and Trento. The centre is connected to the Istituto di Biofisica del CNR [Biophysics Institute of the National Research Council]. It has a staff of about thirty researchers with financing equally distributed between local, national and European resources. It works with the FBK, which provides research infrastructure and, in a less structured manner, with the FEM. The centre does not have a patent policy, like the CNR to which it belongs. It is, however, very active in promoting international mobility for researchers.

\section{Centro Microsoft (Cosbi)}

The Microsoft Research - University of Trento Centre for Computational and System Biology, a research centre born of the scientific partnership between the two institutions and co-funded by the PAT, has as its mission the understanding of systemic biological processes, thanks to the most recent developments in computer sciences. The centre works on developing algorithms for biological systems. Born thanks to the excellent work done by the local research team, its research relationships are mostly with large pharmaceutical companies at a global level. Work with local businesses is limited, partly due to the specific nature of the research activity done at the centre. The centre's ability to attract public and private financing for research in Trentino is remarkable and continues to increase, thanks to its growing ability to finance itself by working on medium and large-sized research commissions, European projects, etc.

\section{Create-Net}

Create-Net is a non profit organization founded by the University of Trento and the FBK for the pursuit of excellence in telecommunications. The centre is active in European projects and in local knowledge networks. It has potential for spinoffs. It is a member of the "RISE TRENTO" 23 " consortium along with the FBK and the University of Trento.

Centro Europeo per gli Studi Teorici in Fisica Nucleare [European Centre for Theoretical Studies in Nuclear Physics]

A European research institution created in 1993. It is managed through the FBK and its scientific work is done with the European Science Foundation. The ECT pursues scientific excellence at an international level, focusing especially on the positive local impacts. Its purview is long-term research.

\footnotetext{
${ }^{23}$ See paragraph 5.1
} 


\section{Euricse (European Research Institute on Cooperative and Social Enterprises)}

This foundation includes the University of Trento, the PAT and other partners who operate as public or private cooperatives in the field of scientific research. Euricse supports theoretical and applied research, training and consulting activities, and promotes knowledge and innovation in the sector of cooperative and socially oriented companies and other non-profit organizations in the manufacturing sector. The Institute means to enhance the role played by these parties and their impact on economic and social development by supporting their growth and improving their efficiency. It works on issues of national and international importance, guided by the principles of openness and cooperation.

\section{Centro OCSE LEED per lo Sviluppo Locale [OECD LEED Centre for Local Development]}

As an integral part of the OECD, the Organisation for Economic Cooperation and Development, the mission of the Centre in Trento is to build and develop capabilities in the national and local administrations of OECD member and non-member states. It offers assistance in the planning, implementation and evaluation of local development strategies for entrepreneurship, innovation, small and medium-sized businesses, tourism, local governance, social inclusion and assessment. The Centre in Trento, besides research activity, also promotes exchanges between member and non-member states, between national and local organizations, between the OECD and other actors operating at a sub-national level.

\section{CNR-ISTC}

This laboratory uses an interdisciplinary approach which ranges from cognitive sciences to IT, to artificial intelligence, linguistics, philosophy and logic. Research applications are focused on biomedicine, company process management, legal issues, IT security and the semantic web, as an important regional asset concerning the creation of the "semantic valley", a sort of themed technological cluster announced in December 2009.

\section{CNR-ITIA}

The Istituto di Tecnologie Industriali e Automazione [Institute for Industrial Technologies and Automation], founded at the start of the decade thanks to the framework agreement between the PAT and the National Research Council, carries out research and development in manufacturing technology, using mechatronics. Within its own excellent innovation network, the Institute works with businesses (that is, the end users of the products of research) and other research institutions at a local, national and international level. It creates and applies new knowledge for innovations in products, manufacturing processes and business services. 


\section{CNR IVALSA}

The Institute for the promotion of timber and arboreal species works on studies that range from biomass to construction science to diagnostics. It is active in research projects, especially cooperating with the University of Trento and other specialized European centres. It also operates locally thanks to its laboratories and its consulting and certification activities. The Institute has become a key player in the new regional policy on bio-construction which is based on a network of cooperative efforts between Trentino Sviluppo, the PAT and private companies working in timber construction. The "Sofie Veritas" project, 70\% of which at first was funded by the PAT, began as part of this network ${ }^{24}$. After the research phase the project prescribes a training and certification phase managed by the CNR [National Research Council] and work on the part of the companies to promote the brand and the construction of the homes.

The relationship network also includes the Distretto tecnologico trentino per l'energia e l'ambiente "Habitech" [Trentino technological cluster for energy and the environment, "Habitech"] which promotes the European LEED certification system ${ }^{25}$. The relationships pursue the harmonisation and the integration of the two LEED and CNR certifications, and are part of the network operating to certify "Case Legno Trentino", which includes all the parties working to certify all homes in Trentino, not only those built of wood. The round table was founded by the PAT, which is promoting the activity.

\section{Network Players - the Autonomous Province of Trento}

The strategic objective of the PAT is to increase the size of local companies. The administration tries to stimulate such growth by developing company networks. Also, the PAT co-funds company groupings free of charge and applies favourable policies for cooperative syndicates that guarantee financing to businesses and clusters.

\section{Trentino Sviluppo}

This is an in-house local development agency within the PAT and is the main knowledge transfer agency. The PAT, as a response to the needs of the business world, is trying to re-orient the agency, which has traditionally worked in real estate and financing, toward business services, in order to

\footnotetext{
24 "Sofie Veritas" is a limited company consortium working in the timber construction sector. At present its shares are $51 \%$ privately owned and the remaining $49 \%$ is owned by Trentino Sviluppo.

${ }^{25}$ The LEED (Leadership in Energy and Environmental Design) certification system is a standard applied in over 10 countries and developed by the U.S. Green Building Council (USGBC), a non-profit organization that furthers and provides a global approach to sustainability, recognizing virtuosity in key areas of human and environmental health.
} 
facilitate the creation of partnerships. At an academic level it is felt that Trentino Sviluppo can be a useful process facilitator in network development. Trentino Sviluppo also manages business incubation in its "Business Information Centres (B.I.C.).

\section{Box 2. The incubators in Trentino (B.I.C.) of Trentino Sviluppo}

Business incubation strategies are set out within technology transfer policies because they help translate the accumulated technological knowledge into business activities. The B.I.C. in Trentino are an important aspect of local industrial policy: they are a physical and technological platform furthering the development of company networks and the relationship between these networks and the research system. The presence of incubators throughout the region facilitates the dialogue between the business and research sectors and among the businesses themselves and allows clustering processes to take place. For this reason, an office of the "Habitech" Trentino technological cluster has been set up at the incubator in Rovereto. The B.I.C. incubation system plays an important role in creating innovative companies and in technology transfers. Most of the new companies are in Trentino. About $20 \%$ are companies that have their headquarters in other regions (mostly Lombardy and Veneto) and have decided to open a branch office in the incubators. These are spin-outs (independent companies born from a parent company) or small research centres interested in the University of Trento and in the system of business incentives in Trentino. Two of the new companies born from the Engineering Dept. of the University of Trento are also located in the BIC and are working in consulting and research: the University is their primary client and they will gradually move onto the market. The available assets are remarkable: $96,000 \mathrm{~m}^{2}$ of available space, $80 \%$ of which is in use.

Table 5. Incubators in Trentino

\begin{tabular}{ll}
\hline B.I.C. in Trentino & 6 \\
\hline Companies currently located there & 86 \\
\hline Number of employees & 690 \\
\hline Survival rate & $93 \%$ \\
\hline Revenue of the companies located in the BIC & $>100$ milion $€$ (estimate) \\
\hline Av rage length of stay & 4,18 years \\
\hline Conventional area & $73829 \mathrm{~m}^{2}$ \\
\hline
\end{tabular}

Source: Trentino Sviluppo Dec. 2009

Almost $50 \%$ of the companies located in the BIC are active in mechanical engineering and ICT $(30 \%$ mechanics, $18 \%$ ICT), whereas the other sectors are highly diversified. The companies in the BIC are somewhat slow to grow. The average yearly rate of new companies is also rather low (about $9 \%$ in the past three years). 


\section{Informatica Trentina}

Informatica Trentina is the main organizer of company networks and relations in the ICT sector and is the in-house agency for public services and business services, besides Trentino Network, which works with VOIP networks and technology (calls with an analogical or broad-band connection). Thirty per cent of the resources that Informatica Trentina (IT) receives from the PAT are transferred to local businesses.

\section{Tourism web site}

Another networking project promoted by the PAT is the tourist web site which includes all the businesses operating in the tourist sector. It is born from the provincial tourism agencies which have been private companies since 2000 , kept alive by their operators and networked by Trentino spa, a spinoff owned by the PAT with private shareholders, which makes reservations.

\section{Network Players - Businesses}

The companies in Trentino do not have the strong tradition found in the other Italian regions of developing strategies based on company networks. Experts agree that in spite of improvements compared to the early years of the past decade, there is as yet no real system of relations. This is due in part to the low level of company investment in innovation, which is in any case linked to stimuli and mediation on the part of the PAT. The public sector provides fundamental funding to promote the creation and development of networking activities, but the slow pace of public administration does not allow for competitive progress in the projects.

The links between companies and with the field of research are developed in certain specific sectors, such as ICT, but they are isolated networks that are not part of a system. The traditional areas of the Trentino economy are more vulnerable to economical and structural problems that greatly complicate the development of innovative networks ${ }^{26}$.

Exports from Trentino are based on a few medium-sized companies that export over $50 \%$ of their turnover to Europe and the United States. The issue of knowledge networks might also include the possibility of structuring associated networks for foreign markets: this is a new area for the Provincial

\footnotetext{
${ }^{26}$ The sector of porphyry quarrying and processing, for example, is undergoing a complex transition from one generation to the next. The risk is that this will lead to the loss of a product culture that will remain part of the know-how of a generation of entrepreneurs identified with short, family-based networks. The porphyry quarry area has hundreds of micro-companies, twenty of which are in some way structured and about half of which are active internationally. The sector is innovative, when it comes to machinery, to testing, to design, to mixing stone with wood, but these innovations rarely find much application.
} 
Development Plan.

To conclude, the type and institutional frame work of the relations is quite complex and has continued to evolve, especially over the past decade. There are large projects here such as the Microsoft Centre, Habitech and the broadband project ${ }^{27}$ that, however, even today, do not have enough contact with the business sector.

\section{Types of Relationship}

\section{Research Relationships - Other Players}

The association between the University and the PAT is structured around the PAT-University of Trento framework agreement which defines areas of cooperation and the pertinent budgets. In practice however, personal relationships between faculty and technical structures in the region prevail. The University has solid connections with the local bodies and regional agencies, for example in environmental engineering. The nature of the University's associations with companies varies greatly within the University itself. Such connections are handled by the University's office for business relations which was set up in 2001. In 2008 the offices for technology transfers and the office for scientific research, which were originally separate, were merges and focused on the entire innovation cycle, from the first idea of a project to the possible birth of an innovative enterprise. The University is also active in multiple university networks for the development of new businesses and for knowledge transfers (University of Bolzano, Innsbruck and Polytechnics).

The affiliation between the University of Trento and the FBK was set up and structured in 2008, thanks also to the guidelines set out by the PAT. There is active cooperation with the FBK especially on provincial calls for bids so as to optimize acquisitions and use of shared scientific equipment. Certain areas (for example biology) have also been identified in which more structured cooperation can be developed, such as the international promotion of the research system in Trentino.

A recent project activated by a cooperation between the FBK, the University of Trento and

\footnotetext{
${ }^{27}$ Since 2006, the Autonomous Province has chosen to invest heavily in broad-band technology, as is emphasized in all the main regional planning documents, not as a technological goal, but to further the social and economic growth of a region with many peripheral areas for which, therefore, digital infrastructure is a particularly sensitive topic. The aim is to progressively overcome the digital divide and align the region with the most advanced connectivity standards defined by the European Union. In the first years, the public administration worked to create a main connecting infrastructure over $700 \mathrm{~km}$ long to connect the valleys that are typical of the region. In 2010 it was decided to set up a mixed public-private company to complete regional broad-band coverage, the goal being to offer 20-Mega connectivity via a new-generation network by 2013 and $100 \%$ coverage of the population in Trentino by 2016 .
} 
Create-net is the Trento RISE consortium which works in the ICT sector. Trento RISE ${ }^{28}$ has become a partner of the European Institute for Technology and Information (EIT) and over the next five years will be able to count on public-private financing to the tune of a billion Euro.

Both the Foundations and the University find privileged business partners in spin-offs. These new entrepreneurs often continue with their didactic and research activities, whereas the spin-offs can field new graduates. The academic world has also strengthened its connections with Trentino Sviluppo, which has had an office at the University since 2007 and is now growing thanks to the seed money grants managed by the company.

In this case again, however, the knowledge networking associations are structured starting from the researchers' networking activities and become institutionalized at a later point. The institutional aspect of these links is not, in itself, an indicator of heightened efficiency of the system. There are relationships that are highly productive, thanks to their extreme informality. At times, the institutional aspect is functional to the participation in a European project ${ }^{29}$. It may take only a few weeks to submit a candidacy but behind this activity there are normally months of partnership between the organizations involved.

${ }^{28}$ A new and important institution active both locally and internationally is, for example, the EIT, the European Institute of Technology, which creates knowledge-based communities and links them with companies, specifically in ICT. In 2010, the research bodies in the ICT sector in Trentino set up Trento RISE, which is a consortium for the entire research, innovation and training system in the areas of IT and telecommunications and which has recently won out over stiff international competition to become a partner of the Istituto Europeo della Tecnologia e dell'Innovazione (EIT). This will allow Italy to play a leading role in the strategic ICT sector in coming years in Europe. The EIT can count on public-private funding for over a billion Euro in the next five years for the ICT sector (EIT ICT Labs). Members of the consortium are FBK, Università di Trento, CREATE-NET, Graphitech, ISTC-CNR and CELCT.

${ }^{29}$ In 2006 the office for European Integration and Humanitarian Aid of the Autonomous Region of Trentino-Alto Adige/Südtirol was founded to manage the implementation of regional laws pertaining to European integration, by supporting and funding activities in this area. 


\section{Box 3. Research spinoffs}

An important technology transfer channel is that of research spin-offs. These companies are born of the capitalization of the results of scientific research and the researchers' intention to start a business. From the presence of spinoff systems linked to the most important research centres it is possible to obtain a wealth of information about the maturity of the structure of the relations between research and industry. Also, through spinoff processes, research produces businesses that can become privileged technology transfer channels and key parties in the relationship between research and business at a local level. In Trentino, this dynamic has certain peculiarities due to the fragility of the part of the business system that interacts with the research world. Since the Foundations were set up, the spin-off policy has become strategic and central to the agenda of innovation in Trentino. By 2008 the FBK had given rise to the creation of 13 spinoffs based on its research. Today, there is a remarkable network for the period from 2009 to 2011 . The Foundations do not carry out structured business incubation, which is Trentino Sviluppo's job, even though there is an informal support structure for the start-up phases. Trentino Sviluppo is only responsible for the incubation phase but it is not a technological body with the ability to evaluate the projects from a scientific point of view.

The FBK and FEM foundations play a central role facilitating relations between players in the field of research and those in larger knowledge networks. This cooperation between the foundations is fairly recent. The FBK, Mach Foundation and Trentino Sviluppo are planning the launch of a joint initiative to create new businesses and are working on common projects at an international level. These are flagship projects in which everyone uses their best resources. Trentino Sviluppo offers its experience in evaluating business plans, in information and training of businesspeople for preincubation and business incubation, whereas the Foundations support internal technological scouting and technical evaluations. This important transformation occurred after the Foundations' missions were re-defined due to a change in mind-set caused by the turnover of the heads of the research areas.

The Trentino technological cluster for energy and the environment cooperates with the Foundations for technological development in several sectors. In the biomass sector, Habitech works with the FEM, and with the FBK in microelectronics (new-generation photovoltaic cells) and on control systems for solar technology. The University of Trento also works with Habitech in several sectors, including photovoltaic, fuel cells and standards. The Trentino technological cluster also cooperates with research institutions outside the PAT, including the Milan Polytechnic. The relationship between the Foundations, the University, Habitech and CNR Ivalsa is one of the more promising areas for scientific and technological cooperation at the provincial level, now that the Autonomous Province of Trento has set the direction for future developments.

After becoming a Foundation, the FBK devoted itself to redefining the key relationship with the 
provincial administration via a framework agreement with the PAT in which research ${ }^{30}$ is separate from real estate matters. The relationship is evolving toward a progressively greater level of structuring and accountability of management.

The dynamics between research players and Trentino Sviluppo play out at several levels. A first level has to do with the creation of new research-based businesses, since Trentino Sviluppo manages the six incubators in Trentino. A second level is the management of the seed money fund that can be used for the first phases of development of innovative companies. The first selection of new, interested companies was completed in 2010. A third level concerns the capitalization and marketing of technology. Trentino Sviluppo's activities are in marketing and gate-keeping between research and businesses. The technology transfer activities of the Foundations, the University and the nominally similar activities of Trentino Sviluppo are different and potentially complementary, if organized from this standpoint.

The local Foundations are the heart of the local innovation system with a fundamental mission to connect local stakeholders institutionally, scientifically and industrially. They are also a fundamental hub in the system of "long networks" in Trentino, meaning the totality of players that act as communication links between innovative processes both inside and outside the local system, able to promote collective learning processes by putting the innovative knowledge acquired from the outside of the system into context, and able as well to further the promotion of knowledge that has been developed internally.

\footnotetext{
${ }^{30}$ About $50 \%$ of human resources for research are stable employees, 50\% have research contracts or doctoral grants. Source: Management FBK.
} 


\section{Box 4. Patenting activity}

Trentino is a region in which the development of patents has always been of minor importance. An analysis carried out between 1990 and 2000 by the Fraunhofer Institut (2003) found an average of 18,6 patents a year. Compared to the national average of 2,755 requests per year for patents, the percentage in Trentino is $0.7 \%$ which lines up with the percentage of the population of the province as compared to the entire country. Technological specialization is especially strong in information technology, food processing and chemical engineering (specialization index over 60\%). Food chemistry, handling and civil engineering are also over $40 \%$. It is interesting to note that this specialization in applied technology, which can be seen through an analysis of the individual patents, was aligned, in the Nineties, with a specialization in science, measured using the Science Citation Index, in key sectors such as IT and civil engineering. In other sectors such as optics and materials science, specialization above the national average did not translate to a comparable level of specialization in patent development activity, which is noticeably lower than the Italian average. The FBK had 9 patents in 2008. Four more were being negotiated or approved. Of the patents approved 7 belonged to FBK. The others were jointly owned with the University of Trento or other research organizations. Seven further patents at that date had been developed by individual researchers, and three patents were potentially able to be a starting point for business spin-offs.

The reform promoted by Law No. 14/2005 sets up a patent fund at Trentino Sviluppo financed by the Autonomous Province of Trento. The multi-year program for research gives Trentino Sviluppo a mandate to manage the patents and the intellectual property rights that belong to the PAT (for example all results obtained in projects financed by the PAT) with the aim of furthering the capitalization of knowledge. The PAT's strategy recently evolved to allow the Foundations to keep ownership of the patents developed by them. The Foundations are now considered the most appropriate parties to put the results of their research on the market. Trentino Sviluppo has therefore lost its position as the only existing interface between publicly financed patents and the markets.

\section{Relationships with the PAT - Other Players}

The PAT has worked over the past decade to draw up administrative documents, framework agreements and service contracts able to improve the level of structure and accountability in relations with the various bodies that implement the policies in the region (Trentino Sviluppo, the Foundations, Informatica Trentina, etc.). Trentino Sviluppo is the main institution that handles relations with industries. The PAT pursues a strategy of facilitations and incentives for individual companies and business networks. Public development policy includes, among these facilitating bodies, Trentino Sprint of the Chamber of Commerce, the local branch of Enterprise Europe Network ${ }^{31}$,

${ }^{31}$ Enterprise Europe Network is a new European business support network to further entrepreneurial activity and company growth in Europe. It is part of the Commission's integrated policy to further entrepreneurial 
Finest/Informest ${ }^{32}$ and the consortia (in the construction and quarrying sectors, etc.).

In 2007, Trentino Sviluppo opened a contact point operating by appointment at the University of Trento, to promote the development of new businesses by young university students. The projects being activated with the University include partnerships with the Centro Mente-Cervello ${ }^{33}$ and with BizTech $^{34}$, concerning the relationship between ICT and business, in which Trentino Sviluppo cooperates with operational know-how. The tendency is to increase the degree of structuring of these relationships, under the direction of the PAT. This type of networking and facilitating technology transfers at a local level would seem to be still in its infancy. Since Trentino Sviluppo is not a technological institution, a partnership with local research bodies is required, in a global design in which roles and strategies still need to be clearly defined.

The relationship between the research system in Trentino and the PAT on the one hand and businesses on the other has been the subject of several studies, including a User Survey (Bonaccorsi, 2007). The analysis of the relationships between the departments of the PAT and the research centres in Trentino showed that of the 23 relationships evaluated, $40 \%$ were between departments of the PAT and the University of Trento. This is highly significant, considering that the University is a national

activity and company growth in Europe. It supports small and medium-sized businesses in any sector so that they may take the best possible advantage of the opportunities of the single market. It has been active since January $1^{\text {st }}, 2008$ and was created as indicated by the European Commission by merging the two preexisting networks (Innovation Relay Centre and Euro Info Centre) into two consortia set up by regional macro-areas. As far as the Province of Trento is concerned, it is a member of the FRIEND Europe consortium with the Province of Bolzano, Veneto and Friuli Venezia Giulia, meaning the north-eastern part of the country. The Province of Trento's official partner for the project is Trentino Sviluppo, former manager of "Irene", the Innovation Relay Centre, which is supported by the Chamber of Commerce via Trentino Sprint, the former regional office of the Euro Info Centre.

${ }^{32}$ The Autonomous Province owns $1.18 \%$ of Finest, the financing company of the northeastern regions which is active in economic cooperation with countries in Eastern Central Europe and the Balkans. It is also part owner of Informest, an agency for economic cooperation with southeastern Europe.

${ }^{33}$ The CIMeC (Centro Interdipartimentale Mente/Cervello - Interdepartmental Centre for the Study of the Mind and the Brain - of the University of Trento in Rovereto) is an interdisciplinary centre created by the Departments of Educational and Cognitive Sciences, Physics, Engineering and Information Sciences and directed by Professor Alfonso Caramazza.

${ }^{34}$ A recent institution which is part of studies in Net Economy is BizTek (Net-Economy Start-up Centre), a laboratory aimed at supporting groups of students in developing business ideas based on particularly innovative technological solutions that can be brought to the attention of possible external financers. 
body (the study refers to the period prior to the recent passage of the university to the $\mathrm{PAT}^{35}$ ) and therefore not local like the other players involved in the study. This is also due to the fact that the University carries out complete research studies, whereas other institutions focus mainly on specific areas of science and technology Many of the joint operations analyzed last several years, are based on teams which have usually been formed for this reason, and involve a remarkable organizational effort on the part of everyone involved.

\section{Relationships with Businesses - Other Players}

Businesses in Trentino began to have structured relationships with the research system on the basis of Law 6/99, the "Legge unica sull'economia" [single law on the economy]. Companies cooperate in particular with the FBK in IT and with the university of Trento in material science and environmental engineering. Law No. 6/99 provides for the participation of all types of companies; it was also used for a call for bids concerning the Trentino technological cluster; the participants were associations of businesses, instead of individual companies, including craftsmen.

The main learning channel for companies can be found in the relationships created along the distribution chain. In local innovation processes there is always a certain leadership that provides the initial impulse ${ }^{36}$. Trentino, as has already been said, is too small a region to contain entire distribution chains. This creates an objective obstacle to the development of business networks contained within Trentino, but it allows the definition of extra-regional knowledge flows that the networks can benefit from.

There is a remarkable number of research centres connected to large industries (Fiat, Ducati, Microsoft, etc.). The most recent example is the Microsoft Research Centre, born of the cooperation between Microsoft and the University of Trento ${ }^{37}$. The Centre has developed a network technology

\footnotetext{
${ }^{35}$ Based on an agreement between the Italian government and the Province of Trento which was signed on November $30^{\text {th }} 2009$ in Milan by the president of the PAT and the Ministers of Economy and Laws Simplification, the Province will handle matters concerning universities which had previously been the concern of the national government. The agreement was formalized within the framework of the budget law for 2010 (art. 2, par. 22) and delegates to the Province all functions pertaining to the University of Trento, including financing.

${ }^{36}$ This system is also typified by vertical relationships that are far more solid and institutionally connected than the horizontal connections. In the chain of distribution for the timber industry, for example, a cluster of companies has formed over the years, based on personal relationships. In parallel a more institutional system of relationships has grown up that works with institutional intermediaries such as the artisans' union and the service centers.
}

\footnotetext{
${ }^{37}$ The Microsoft research center includes 40 people (half of whom are not Italian). The management personnel comes mostly from the industry, the research component comes from numerous International universities.
} 
that works with businesses through partnership contracts. However, it has a global reach, and therefore does not cooperate much with local businesses, which are mostly small and cannot absorb technologies developed by the Centre. Institutions like the Microsoft Centre are not usually geared to companies that are not themselves active in research or at the very least in technological development. However, the Microsoft Centre, thanks to its global relationship system, could help solve certain specific problems for the local businesses.

The difficulty of working with local businesses is an issue common to all research centres. First of all, there is reluctance to network on the part of the businesses themselves. This is confirmed by the experience of both Habitech and the CNR with "Sofie Veritas" ${ }^{38}$. The common strategic goal runs up against competition. There is also a tendency to avoid business risk, if the investment is not protected in some way. In the strategic partnerships between research institutions and businesses in Trentino, the most common relationship is built around a single funded project. The rare cases in which cooperation continued after the project had been completed can be considered best practices in the creation of knowledge micro-networks in which public funding acted as facilitator.

\section{Flows Inherent to the Relationships: The Importance of Human Resources}

The main flows between players in the system take place between qualified human resources. The mainstay of these processes is human capital. This is especially true, within the framework of innovation policies, for spin-off companies and for projects funded by seed money, in which a flow of qualified human resources is created between the research system and the new business. In the case of the FBK, the key factor for the flow between the University and the FBK are the doctorate scholarships. There were 41 such scholarships in 2009 and 100 are expected for 2010.

The FBK's mission is the transfer of knowledge and approach methodologies, rather than technical data. The technology is embedded in the people. To speak of a technology transfer in this case is limiting: the main goal is to obtain lasting results by transferring human resources. The FBK's client portfolio is based on about fifty contacts with businesses in Trentino and on about two hundred contracts with companies outside the region, mostly abroad. At the national level there are relationships with the largest industrial groups (such as ENI, Finmeccanica, Fiat, ST Microelectronics) and the client portfolio practically doubled from 2000 to 2010. The relationships with parties inside the knowledge networks develop within formal relationships, defined by contracts as set forth by Law

\footnotetext{
${ }^{38}$ In the case of the Sofie Veritas consortium, the creation of a network system between the companies was impacted by the difficulty in finding a producer of wood panels to close the distribution chain, since the consortium works with wood as its raw material. The panels are sold abroad, without using forests in Trentino. It is hard to find an entrepreneur who would assume the risk of producing panels for the needs of the distribution chain.
} 
6/99, by European projects, agreements, individual cases of direct contracting or supply contracts. In training, which is an integral part of the FEM's mission, there is a solid tradition of using human resources trained within the economy of the Trentino region. Research and technology transfer are more recent activities, so that there is no history, as yet, of meaningful flows between the FEM and local companies. It is plausible to assume that in the near future, research, consulting and training will become increasingly important.

In the case of the Trentino technological cluster "Habitech", the main element is the flow of know-how between the participating companies. The introduction of the LEED certification can itself be seen as a step forward towards the activation of knowledge flows between companies. These require careful management in the areas of cooperation and competition, because businesses cooperate and accept partnerships under the condition that they maintain exclusive possession of their knowhow.

The best companies tend not to take part in joint projects, to avoid sharing knowledge. The Habitech cluster activates different types of flows: in human resources - some of which are company resources that come to Habitech for training; financial flows, which are activated by contractually regulating the relations with the partner companies; and technological flows concerning the most important projects for which Habitech asks participants to sign Non Disclosure Agreements (NDA) ${ }^{39}$. In the case of CNR Ivalsa, training activities are an important channel for knowledge transfers. All professional groups take part in training, from artisans to architects to engineers. The courses are organized directly by the CNR or by agencies that do training and use CNR personnel for teaching.

\section{Incentives and Barriers in Relationships between Players}

As has been said, connections between organizations are typically highly fragmented, with personal relationships playing a main role. The development of institutional bodies has often led to the facilitation of relationships, increasing free encounters and cooperation. However, there are also other obstacles to the structuring of relationships and networks, such as communication barriers between players, unequal timing and differing goals from one player to the next.

Formal channels often do not work by themselves: to activate cooperation, facilitators who take over the job of intermediating knowledge and language prove to be very important, as shown by the experience of the Trentino technological cluster Habitech. Also, at an institutional level, empirical evidence shows that the incentive of public funding by itself is not enough to stimulate investment in research and private development. Other resources should be increased at the same time, especially managerial abilities capable of governing such situations (Fraunhofer-Institut, 2003).

\footnotetext{
${ }^{39}$ Non-disclosure agreements in which the parties agree that a disclosure of the information mentioned in the agreement would be a violation of the agreement itself and a cause for specific penal action.
} 
As far as businesses in Trentino are concerned, there are two critical characteristics that should be pointed out:

- Trentino has mostly medium-technology companies. There is not much chance of technology transfers. The most important companies in this field generally locate their decision centres elsewhere.

- A more typically cultural obstacle is the extreme caution exhibited by businesses in Trentino when faced with innovation, dividing entrepreneurs into those who resist innovations, those who sit on the fence and those who accept the challenge.

There is a radical difference in the learning processes for new knowledge. Large businesses have their own sources and contacts with universities and consultants. In small companies, on the other hand, innovation processes are characterized by a higher level of fortuity and business associations assume a meaningful role.

\section{System Openness, National and International Integration}

A regional innovation system can perform well if the links between its subsystems do not generate lock-in effects which would keep those within the system from benefiting from outside partnerships and cooperation.

The research system in Trentino is highly internationalized, especially in its areas of excellence. Among the most active players in this sector, there are the University of Trento (networking with the universities of Bolzano and Innsbruck) and the FBK with European research projects. The openness rate of the university system in Trentino increased 10 percentage points, from $71.8 \%$ in 1996-97 to $81.8 \%$ in $2007-2008^{40}$. However, the process of research internationalisation is still slow and the effects on the local system are uncertain. Of course, international research centres bring resources to a region, but any other conclusion is premature. Closely linking activities that often have a global reach to local effects is a distortion, and conceptually incorrect, if the real preference is for a European benchmark rather than competing with the rest of Italy for research.

The University also acts as a fundamental international link and interface for businesses. The local businesses interviewed express their wish to work at an international level: the University can help this intention. It is not able, however, to act as a driving force on projects for local businesses, a

\footnotetext{
${ }^{40}$ It calculates the ratio between residents from outside the Province enrolled in the University of Trento and residents of the Province enrolled in universities outside the Province, compared to the total number of students enrolled at the University of Trento. Data from 2008 “Osservatorio Permanente per Economia, Lavoro e Domanda Sociale" (permanent observatory for economy, labor and social needs).
} 
role that the PAT could further support and encourage ${ }^{41}$.

The importance of the international dimension of research, not only in science and technology but also in economic and social sciences is confirmed by the fact that the OECD (Organization for Economic Cooperation and Development) set up an office in the city of Trento in 2003, the result of a cooperation between the OECD Council, the Italian government and the government of the Province. The mission of the OECD Centre in Trento, which is the only office of this organization in Italy, as has been previously mentioned in these pages, is to gain and spread knowledge in the field of local development in OECD Member and non-Member States.

CNR Ivalsa is also involved in many international projects which are generally funded by the European Union. The international prestige of the Institute has greatly increased thanks to the impulse given by the new management, which has led to a system of global relationships in wood engineering.

One key question is whether the research centres in Trentino, which are relatively speaking more international than the average local business, can be nodes in long global networks that can be useful for the businesses as well. In some sectors of the local economy, such as timber or information technology, there is empirical evidence to support this idea, though in an early phase, especially in the period 2008-2010.

\footnotetext{
${ }^{41}$ Enterprises are not often encouraged to participate to European projects as funding for research are tailored to local needs (law 6/99).
} 
Table 6. Regional innovation systems SWOT

Strengths

- In the past 40 years, Trentino has seen an increase in policies favouring research and public investment in R\&D (about 3\% of the budget of the PAT and over 2000 researchers).

- The reform of the research system has helped to clarify the roles of the various players.

- The small dimensions of the local research system favour coordination and flexibility. This also helps to focus on selected niches of excellence.

\section{Weaknesses}

- In the private sector, product innovation is slower than process innovation.

- Difficulty in cooperation between research players and in creating critical mass.

- Low flexibility in the management of human resources in research (reform of Law 14/05).

- Difficulty in defining a shared industrial innovation policy

- Low business dynamics, low turnover and horizontal mobility of human resources

Threats
- Use the opportunities offered by the research reform (reinforce relationships between research centres, develop governance and system management via the foundations, structure the incentives system and the assessment of human resources, etc.).

- Capitalize on the large investments in research and innovation that have come to maturity over the past decade.
- The local research system is small, therefore national and international competition is a threat. Targeted planning is required.

- Cuts in public funding for the system. 


\section{KNOWLEDGE NETWORKS: THE TRENTINO BUSINESS PERSPECTIVE}

Regional knowledge networks cannot be analyzed without considering the entrepreneurs, whose role it is to absorb innovations and translate them into economic value for the system, generating virtuous development for the knowledge network.

The aim of the study which was carried out on several businesses in the PAT was to record the companies' attitude toward the Trentino knowledge network. There are no recent local studies on this topic and most of the information available concerns the period from the end of the Nineties to the first years of the new century.

The questionnaire was administered to about 300 companies in the Autonomous Province of Trento. To determine the participants, the Trentino agency for the local development of small and medium-sized businesses, Trentino Sviluppo, was asked to assist and did so by providing names and contact information for companies in different production fields but sensitive to issues of innovation, growth, and the circulation of knowledge. Of these, $\mathbf{2 3 \%}$ answered $^{42}$. Among the sample we also find companies located at the Business Innovation Centres (B.I.C.) of Trentino Sviluppo and the university spinoffs.

\section{Description of the Companies Participating in the Study}

\section{Sector of Activity and Company Characteristics}

The companies interviewed are mostly small businesses: 54\% have less than 10 employees, $16 \%$ have between 11 and 25 employees, $9 \%$ between 26 and 50 and $21 \%$ have 50 employees. Almost half of these companies were founded between 2000 and 2009 and are, therefore, young businesses. Only about $10 \%$ began to operate before 1970. In most cases, over half of these companies were set up by a group of partners, and - a highly significant fact, and one that gives a clear picture of the local situation - none of the companies that took part in the survey has a woman or a foreigner among its founders. Entrepreneurship among young people (company founders under thirty-five) is also low at only 4\%. Companies in Trentino are mostly one-man businesses (74\%) and only 3\% are part of an international group. For $26 \%$ of companies, the percentage of university graduates in the past 5 years is under $20 \%$ of the total number of new hires; for $24 \%$ of companies, this percentage is over $80 \%$ of the total, and these are mostly companies active in new technologies. These data indicate a

\footnotetext{
${ }^{42}$ In five cases the questionnaire was filled out during visits to a company and in the other cases the answers arrived by e-mail or by fax.
} 
polarization with high tech companies at one end of the spectrum and companies that have a very low percentage of university graduates at the other (29\% of companies report no graduates at all among their personnel). Also, $62 \%$ of the graduates received their degree at the University of Trento.

Figure 1. Number of workers employed by the interviewed companies

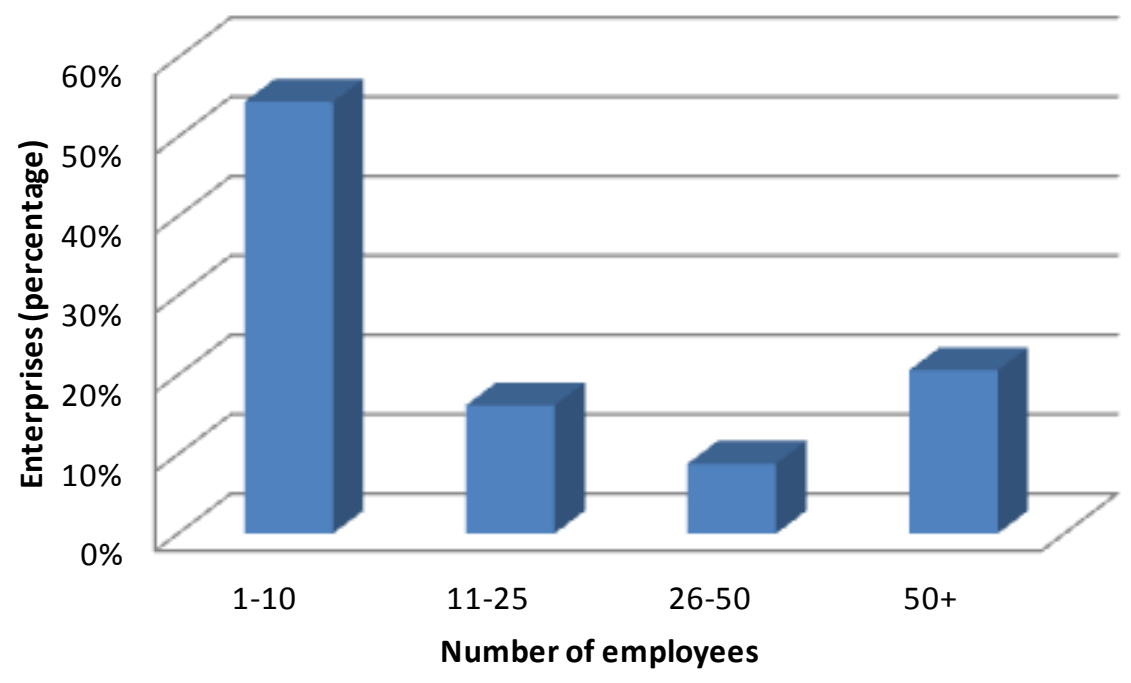

Source: Work-up of the data gleaned from the OECD questionnaire Le reti di conoscenza in Trentino [Knowledge networks in Trentino] OCSE, 2010

Figure 2. Number of graduates hired over the last five years

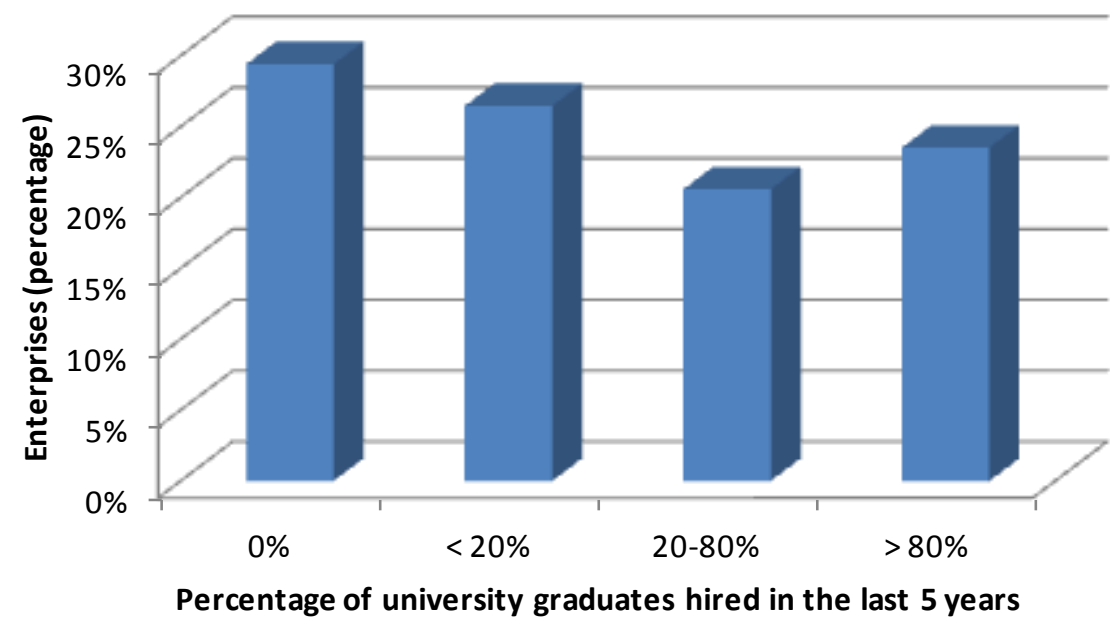

Source: Work-up of the data gleaned from the OECD questionnaire Le reti di conoscenza in Trentino [Knowledge networks in Trentino] OCSE, 2010 




Source: Work-up of the data gleaned from the OECD questionnaire Le reti di conoscenza in Trentino [Knowledge networks in Trentino] OCSE, 2010

As for turnover, $56 \%$ of companies invoice less than 2 million Euro, $22 \%$ between 2 and 10 million, $10 \%$ between 10 e 50 million and $12 \%$ over 50 million Euro. Concerning the distribution of turnover in national and international markets, $42 \%$ of companies in Trentino report part of their turnover as coming from markets abroad. This amount, however, is equal on average to $13 \%$ of total turnover.

Figure 4. Turnover

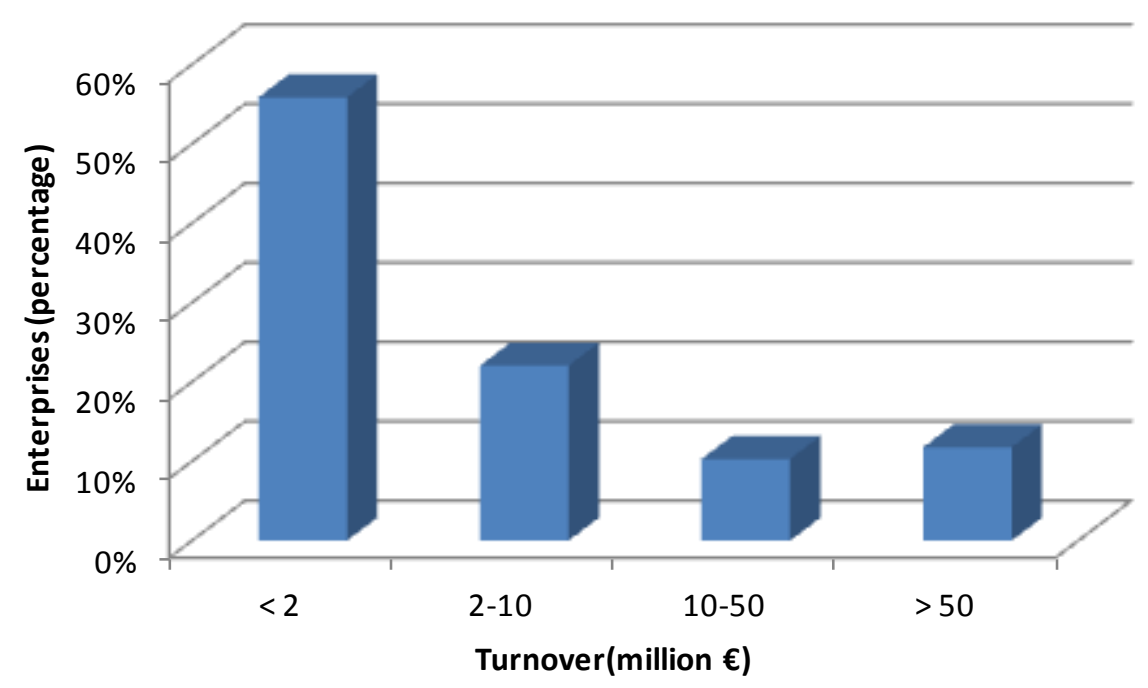

Source: Work-up of the data gleaned from the OECD questionnaire Le reti di conoscenza in Trentino [Knowledge networks in Trentino] OCSE, 2010 
As follows the main sectors of activity of the companies interviewed.

Figure 5. Company sectors of activity

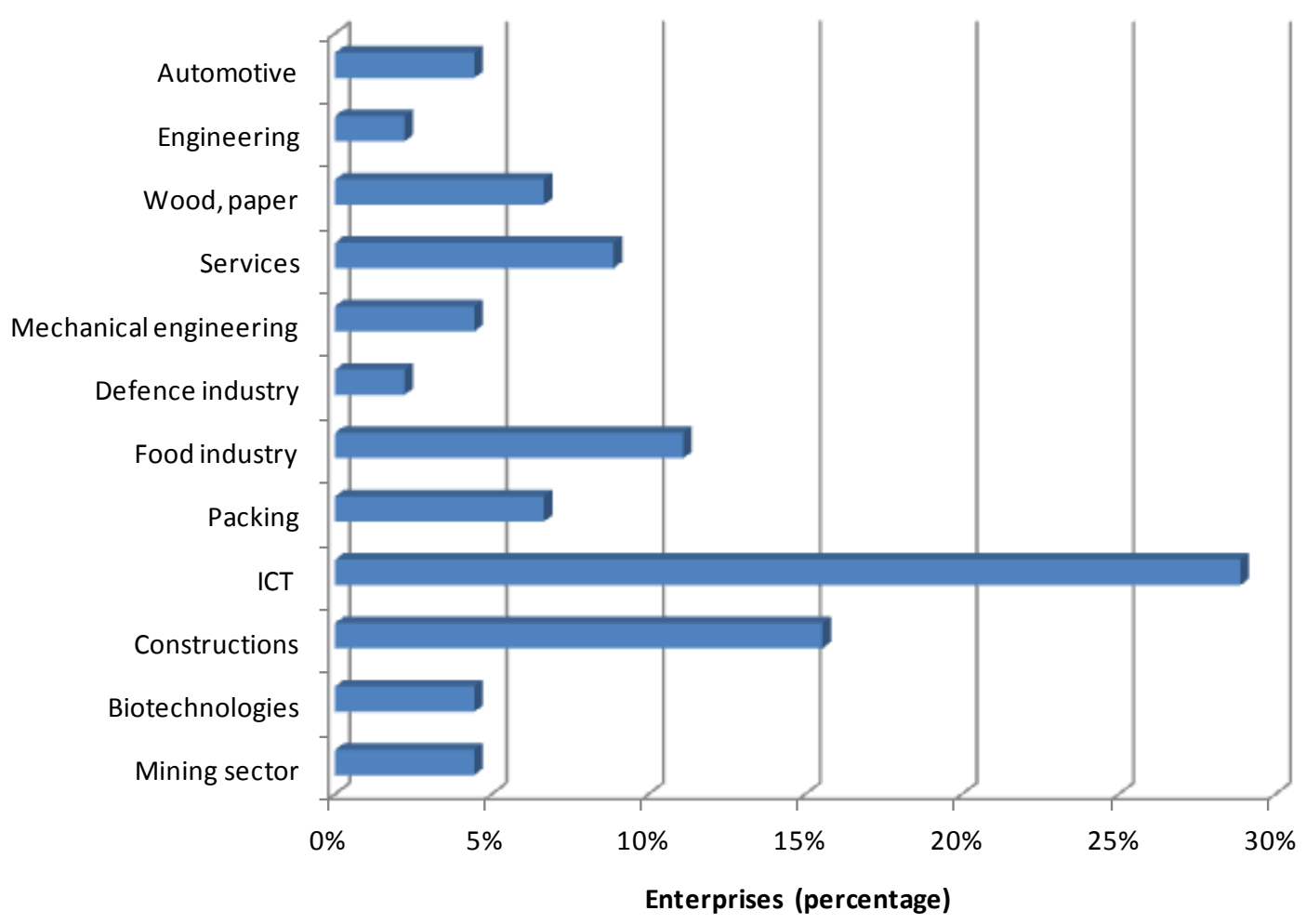

Source: Work-up of the data gleaned from the OECD questionnaire Le reti di conoscenza in Trentino [Knowledge networks in Trentino] OCSE, 2010

The percentage of investments in $\mathrm{R} \& \mathrm{D}$ as compared to turnover is zero for $24 \%$ of companies, over $10 \%$ for $22 \%$ and ranges from 1 to $10 \%$ in other cases. Almost half $(44 \%)$ of the companies reported having received public funding for $R \& D$ activities in the past five years. This is a very high number that indicates the existence of structured relations between the public and private sectors concerning the transfer of financial resources. 
Figure 6. R\&D investments (\% of yearly turnover)

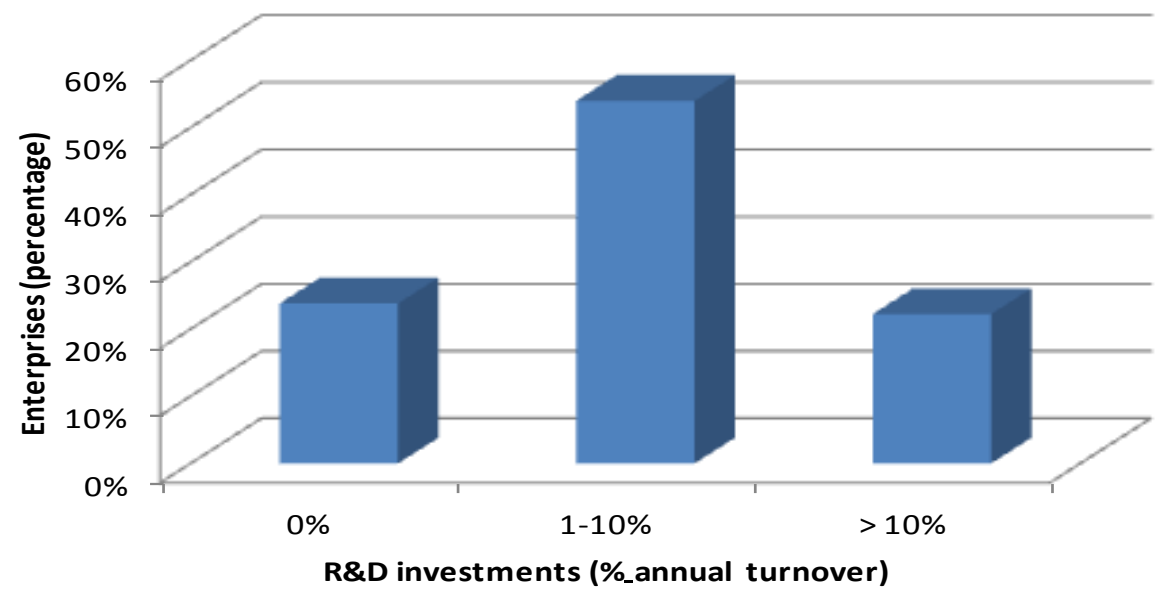

Source: Work-up of the data gleaned from the OECD questionnaire Le reti di conoscenza in Trentino [Knowledge networks in Trentino] OCSE, 2010

The medium-high technological level of a significant part of the sample also emerges from an assessment of intellectual property management: each year, about $18 \%$ of companies develop new patents, whereas 56\% use licenses. The trend is growing, though slowly: the ratio between Trentino businesses and the capitalization of intellectual property is still extremely low.

Figure 7. Patents developed over the last five years



Source: Work-up of the data gleaned from the OECD questionnaire Le reti di conoscenza in Trentino [Knowledge networks in Trentino] OCSE, 2010 


\section{Businesses, leadership and internationalisation}

Even though a large number of businesses were recently founded (12\% of the companies were founded in the Nineties and $47 \%$ in the past decade), only in $\mathbf{3 \%}$ of the cases was the founder under 35 years of age. This fact concerning the average age of company founders might derive from the difficulty of starting a business as a young entrepreneur in the Autonomous Province of Trento. Something similar can be said about participation in international networks: only $3 \%$ of companies report being part of foreign groups.

\section{Cooperation with the research centres}

The companies also reported on the difficulty, or ease, of cooperation with the Trentino research system. It is interesting to observe that it has become easier, if only slightly, to work with the research centres, meaning the Foundations, rather than the University of Trento. The transformation into Foundations, the PAT's focus on knowledge transfers, the analysis of technology transfers in Trentino and the activation of virtuous internal procedures have started to produce results.

Figure 8. Collaboration with universities

\section{In general, based on your experience, is working with universities difficuly?}

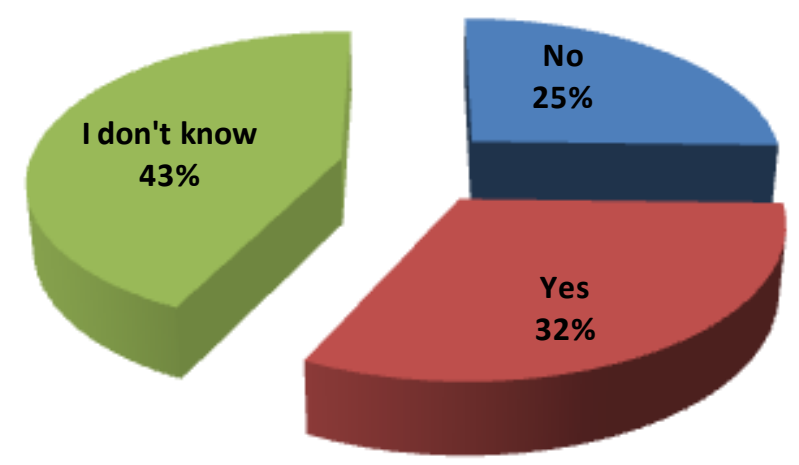

Source: Work-up of the data gleaned from the OECD questionnaire Le reti di conoscenza in Trentino [Knowledge networks in Trentino] OCSE, 2010

The research system in Trentino has benefited $51 \%$ of the companies. It can therefore be considered an important asset, even though the potential number of businesses involved has significant room to grow.

A smaller number of companies answered the query as to whether they would be able to create technological projects and innovation if there were no access to provincial funds for research and 
innovation. Fifty-nine per cent answered in the negative: this indicates that innovation processes are rooted in funding on the part of the PAT.

The next question pointed out the obstacles to be overcome to improve existing forms of cooperation. The companies interviewed feel that the opportunity to influence the areas on which to focus research in Trentino and the production of highly qualified human resources are both of primary importance. These changes would allow the implementation of efficient partnerships for operative projects. The answers given also denote an unexpressed potential in creating forms of organization aimed at developing knowledge networks such as consortia and clusters. The lesser interest shown by the companies in the development of joint university-business laboratories and in a central coordinating body for the transfer of technology indicate their preference for ample autonomy in developing innovation strategies.

Table 7. Which of the following improved conditions would benefit your company most?

The possibility for businesses to influence the choice of sectors in which research is done in Trentino

An improved capability on the part of universities to produce qualified human resources

$64 \%$

The development of clusters or consortia that can help to further the interests of my company

The development of areas (such as laboratories) that can be used jointly by researchers and businesses

The presence of a body to coordinate technology transfer activities

$47 \%$

Source: Work-up of the data gleaned from the OECD questionnaire Le reti di conoscenza in Trentino [Knowledge networks in Trentino] OCSE, 2010

\section{Knowledge Generation}

The primary material in the network system is human resources, including the young people who move from the university to the productive world, talent attracted from abroad, foundation or university personnel interested in going into business, etc. Another important aspect in the functioning of knowledge networks is the mountainous geography of Trentino, which distinguishes between activities that are concentrated in the lowlands and those that form in the Alpine valleys. In these valleys there have been recent and interesting experiences of networking among individuals that can be shaped into a system ${ }^{43}$.

\footnotetext{
${ }^{43}$ One example is the project promoted by Trentino Sviluppo which from 2006 to 2009 promoted the creation of 95 new companies with 2359 people and 150 towns involved. The project started in 2006 under the team led by Sergio Remi with the aim of promoting entrepreneurship and self-employment in the mountainous areas
} 


\section{Knowledge Generation Through Joint Research}

Estimates on the application of knowledge are closely linked to the evaluation of the results and the impact of research in Trentino. With Provincial Law No. 14/05 the PAT created a TechnicalScientific Committee (CTS) for steering and consulting activities and a Research Evaluation Committee (CVR). In the three years following the enactment of the law, the CVR structured its assessment approach and produced its first results. The Committee monitors industrial research projects, develops templates and indicators and uses both the surveys on research and development and public perception from ISTAT [National Institute of Statistics], and a group of international experts. The model defines three areas where the impact assessment indicators can operate. These are: framework agreements, research institutions and financial instruments. These areas are analyzed according to five dimensions: Generation of New Knowledge, Policy, Administration and Management, Economy, Culture, Society and Citizenship, Environment and Sustainability ${ }^{44}$. The CVR also formulates policy suggestions such as the need to clarify the issue of the relationship between Foundations and Development Agencies. For example, concerning the issues that can emerge when the responsibility for capitalizing on a patent or creating value from an intellectual property is separated from the activity of the individual researchers or institutions that have produced that patent or property, problems may arise that can potentially jeopardize the entire capitalization process. What appears here is the difficulty in utilizing the full potential of results that one does not own from a technological point of view.

\section{European Research Projects}

European research projects are an important instrument to evaluate the generation of applied knowledge and the level of research internationalisation, since such projects are normally the result of partnerships between the academic and industrial worlds at a European level. They are also an indicator of knowledge transfer, inasmuch as the projects shared between universities and businesses allow such a flow.

As of 2006, what was to become the FBK has already presented 106 project proposals to the European Union, especially in the field of information technology, 15 of which had been funded and 2 were awaiting an answer, with an assigned budget of 5.5 million Euro ${ }^{45}$. In the same period, what

of Trentino. See also "Fare Impresa in Montagna. La domanda di auto imprenditorialità nelle aree obiettivo

2 della Provincia di Trento". Trentino Sviluppo, Quaderni del Territorio, vol. 2, 2008, a cura di Sergio Remi.

${ }^{44}$ For more information on the impact assessment model used by the Research Evaluation Committee, please see the report detailing activities from 2006 to 2008 (web: www.uniricerca.provincia.tn.it).

${ }^{45}$ Source: FBK. It should be noted, as the newspaper Sole 24 Ore did (7/1/2010), that $1 \%$ of Italian academics work in 
would later become the FEM had presented 18 projects to the European Union with a success rate of $10.5 \%$ and global funding of 300,000 Euro. The University of Trento, in 2006, had also presented 130 proposals: 47 of these were approved and 2 were in the evaluation phase with grants for 7.9 million Euro. These are significant numbers that denote a highly internationalized system where the effect on the region is an important aspect.

\section{Dynamics in Knowledge Generation: Human Capital}

The enrichment processes from which knowledge generation dynamics originate require a lot of time to be metabolized by the system and become fully operative. The FBK's strategy, in particular, emphasizes human capital, facilitating the passage from university to applied research and from here to the business world. It is the FBK that allows a large number of young people, mostly from Trentino, to gain experience in applied research after university. This opportunity is helpful in any later work experiences with a company. The absence of an applied research centre acting as a link between the academic and business worlds would make such mobility processes far more complicated. From the point of view of the companies in the Trentino system, it emerges that innovation is a process of learning by doing, born of an awareness that grows within the company and aims to improve its internal procedures. In a subsequent phase, support is sought from outside the company.

The Trentino technological department for energy and the environment "Habitech", by codifying processes and languages, creates a more favourable substrate for generating innovation, which is born of the interaction between many parties. In the case of "Sofie Veritas", the relationship between company and research is successful also because it is very market-oriented. The process activated by "Sofie Veritas" was born from the interaction between CNR Ivalsa and several businesses with the support of the $\mathrm{PAT}^{46}$. The businesses took part in the process by supplying technical specifications.

Trentino, but that these people are able to attract, on average, $4.5 \%$ of the EU resources that flow to Italy for research. In the sixth framework program, the University of Trento was a partner in 64 research projects. In 2008 the University of Trento came in eleventh for the volume of EU projects that had been funded.

${ }^{46}$ At the start, only two companies were involved, which later became thirteen. These include six timber construction companies, two technical institutes, a public body, four other companies in the timber sector that however are not active in construction. Today the consortium primarily credentials new companies interested in the innovation process. 


\section{Knowledge Generation from the Point of View of the Companies Sampled}

Table 8. New knowledge generation modalities

\begin{tabular}{lc}
\hline From the company's inside experience & $95 \%$ \\
\hline From inside R\&D activities & $80 \%$ \\
\hline Developed through interactions with research centres & $57 \%$ \\
\hline Developed through interactions with international commercial partners (medium to large-sized & $46 \%$ \\
businesses) & $46 \%$ \\
\hline Developed through interactions with local commercial partners (medium to large-sized businesses) & $46 \%$ \\
\hline Developed through interactions with local commercial partners (micro and small businesses) & $40 \%$ \\
\hline Developed through interactions with others (associations, chambers of commerce) & $38 \%$ \\
\hline Developed through interactions with international commercial partners (micro and small businesses)
\end{tabular}

Source: Work-up of the data gleaned from the OECD questionnaire Le reti di conoscenza in Trentino [Knowledge networks in Trentino] OCSE, 2010

A company's inside experience is, tellingly, considered the main source of generation dynamics. This applies both to companies that have relationships with external parties in developing innovative dynamics and to other companies. In other words, in generation dynamics, inside company experience is not an alternative element, it plays a complementary role to external relationships. Many companies consider relationships with the research world to be very important. For these companies, innovation born of inside research and that generated from relationships with external research institutes are complementary elements of a single strategy. Analyzing the value given to new scientific knowledge in interactions between company partners it emerges that, both locally and internationally, the size of the company correlates with the chances it has to learn. In other words, it denotes the importance of leading medium or large businesses that belong or are connected to regional innovation systems.

The next topic suggested to the companies is an evaluation of the percentage of new knowledge generated within the company in the past 5 years as compared to the knowledge from external sources. The average percentage is $36 \%$. The companies acknowledge that in their development model, external resources play a central role in developing innovation. This acknowledgment is an important lever in setting innovation policies based on knowledge networks.

\section{Knowledge Transfer}

The transfer of innovative knowledge within a system involves a complex set of mechanisms. The human capital element is a factor that unites many of these transfer processes, from the flow of 
graduates into business, to the creation of research spin-off companies or the establishment of new high-tech firms etc. Such processes gain strength if they are part of a framework into which are embedded incentive schemes, both financial and organizational.

\section{Graduate job opportunities}

Providing job opportunities for Trentino graduates is the province's main pillar of knowledge dissemination. Research projects undertaken jointly by universities and businesses, which provide some of the primary data analyzed when studying local knowledge networks, indicate that such networks can only take root if they have a bedrock of technologically skilled human resources forming the core of the production system's absorptive capacity

Producing graduates is a process associated with knowledge generation, while the flow of graduates into local businesses and other organizations pertains to that of knowledge transfer. The question of the quality and quantity of openings for graduates within the province's firms or organizations, on the other hand, is a matter of knowledge exploitation and application. The fact that the topic of graduate job openings has been placed in this section is, therefore, arbitrary, but allows for a more comprehensive appraisal.

A primary indicator of knowledge transfer efficiency is the length of time new graduates spend seeking employment. If they spend less than 6 months, this indicates a system in which there is a consistent correlation of quantity and quality between supply and demand, which makes it possible to optimize the flow of knowledge ${ }^{47}$. An interesting study ${ }^{48}$ (Borzaga and Valline, 2003), albeit carried out prior to the recent economic crisis and before the digital economy transformed the labour market, shows that $63.8 \%$ of new graduates found employment within 3 months, a figure that increases to $72.8 \%$ among those who began job-hunting after a period of inactivity. For a period of 6 months, the figures rise to $81.3 \%$ and $88.1 \%$ respectively. Only $7.3 \%$ of the graduates of the first group and $4.9 \%$ of the second spent more than 12 months looking for work (thereby entering the realm of "long-term unemployment"). Whereas in the early $80 \mathrm{~s}, 50 \%$ of graduates found work by entering public competitions, by the mid 90s, public competitions (20.5\%) had been overtaken by direct requests from employers $(20.7 \%)$, followed by job applications sent to firms or public sector bodies $(15.3 \%)$ and employment found through the help of friends, relatives and acquaintances $(12.5 \%$, a steep increase compared to the $1.3 \%$ found in 1983 ).

\footnotetext{
${ }^{47}$ Borzaga and Valline (2003).

48 The survey involved 1,402 University of Trento graduates, residents or not of the Province, and graduates originating from Trentino who studied at the universities in central and northern Italy most attended by those opting to study outside of Trento, and covered four academic years: 1982/3, 1986/7, 1990/1, 1994/5.
} 
Another point of interest is the study's analysis of the sector and place of work. In 1982-83, 60\% of graduates were divided equally between the education and health sectors. In the mid 90s, education had fallen to $17.3 \%$ and health to $5.8 \%$. Industry, on the other hand, had risen from $3.8 \%$, to $15.9 \%$ and finance from $8.8 \%$ to $16.1 \%$. These figures corroborate a lasting trend in Trentino's industry and services during the 80 s and 90 s of absorbing skilled human resources.

The study revealed that Trentino has a considerable capacity to absorb graduates, defying the common perception of the province as a "brain drain". $72.4 \%$ of the 1,400 graduates interviewed worked within the Autonomous Province of Trento, a percentage rising to $94.2 \%$ for Trentino residents who graduated in Trento, and $80.0 \%$ for students from Trentino who graduated at other universities. Young Trentino students who graduate in Trento present the lowest rate of geographical mobility: only 5.8\% work outside the Autonomous Province of Trento. The percentage of graduates with a propensity to work abroad is negligible.

Lastly, one of the factors influencing decisions to seek new employment, which is an indicator of potential mobility within the local network, is limited opportunity for professional growth or poor career prospects (deemed important or very important by respectively $46.1 \%$ and $45 \%$ of interviewees). Trento's job market of the $80 \mathrm{~s}$ and $90 \mathrm{~s}$ absorbed local graduates, and businesses contributed greatly to raising the number of recruitments through direct job applications. This increase in private sector demand offset the reduced number of public sector opportunities.

\section{New knowledge acquisition: sample firms' perspective}

In this section, the focus of attention is knowledge acquisition, but not necessarily innovative knowledge. External relationships are central to the processes of innovation for the Trentino firms interviewed. They were therefore asked who or what are their most important sources for acquiring knowledge (Table 9).

Table 9. Firm's knowledge acquisition sources

\begin{tabular}{lc}
\hline Recruitment of skilled personnel & $83 \%$ \\
\hline Customers & $82 \%$ \\
\hline Professional technical and scientific courses & $63 \%$ \\
\hline Trade fairs, shows and exhibitions & $62 \%$ \\
\hline Purchase of equipment, material, parts or software & $58 \%$ \\
\hline Technical and commercial press, databases & $58 \%$ \\
\hline International trading partners & $54 \%$ \\
\hline Trade associations and representative bodies & $54 \%$ \\
\hline
\end{tabular}




\begin{tabular}{ll}
\hline Technical, environmental standards and quality certification & $54 \%$ \\
\hline Local trading partners & $49 \%$ \\
\hline University of Trento & $43 \%$ \\
\hline Consortiums, clusters, business parks & $43 \%$ \\
\hline Liaison bodies (e.g. Development agencies, Chamber of Commerce) & $43 \%$ \\
\hline Professional conferences & $43 \%$ \\
\hline Research centres in Trento (Kessler, Mach Foundations etc) & $40 \%$ \\
\hline Other universities in Italy & $37 \%$ \\
\hline Offices of local, provincial or central government & $35 \%$ \\
\hline Competitors in same line of business & $34 \%$ \\
\hline Groups to which firm belongs & $32 \%$ \\
\hline Research centres in Italy & $31 \%$ \\
\hline Overseas research centres & $23 \%$ \\
\hline Other overseas universities & $18 \%$ \\
\hline
\end{tabular}

Source: Data processed from results of OECD questionnaire Knowledge Networks in Trentino, OECD, 2010

The highest number of affirmative answers ${ }^{49}$ was given to: "Recruitment of skilled personnel" (83\%) and "Customers" (82\%).

Customers play a key role for firms in acquiring significant knowledge. Especially in the case of SMEs, business solutions are geared towards the requirements and responses of customers and often the final product or service is the result of an exchange between customer and supplier (public or private sector). This bears out an awareness that was gained some years ago and incorporated into Trentino's industrial policy, namely that a demand for high quality from the public sector is a valuable asset for increasing a region's technological levels and competitiveness. Public sector spending accounts for $48 \%$ of the local GDP, which means it is important to promote policies of high quality procurement. One has only to think, for example, of the public sector housing policies that have been developed alongside private sector technological innovation projects, thanks to, among others, the "Habitech" environmental and renewable energies cluster.

Another source deemed important is that of advanced professional training through technical courses. Trentino's framework for professional technical training boasts some centres of excellence -

\footnotetext{
${ }^{49}$ Firms were asked to answer yes or no if each source of knowledge acquisition was significant or not.
} 
including the courses given by the Ivalsa CNR (National Research Centre) or the Fondazione Edmund Mach - and a system that plays a key role in helping Trentino's small businesses to acquire knowledge, comparable to the quality and impact on local systems of the vocational training schemes in place in Germany. Next in line comes "Trade fairs, shows and exhibitions", always a key element in border regions like Trentino (particularly in certain sectors such as that of porphyry stone and the food and wine industry), followed by "Purchase of equipment, materials, parts or software". Over $40 \%$ of the companies interviewed look to consortiums, clusters and business parks for acquiring knowledge, as well as to trade associations. Furthermore, the firms interviewed consider international trading partners to be a far more important source than national ones. Presumably, knowledge of international markets, which can be acquired only through cooperation with foreign players, is more sought after. Thus, there is a link between knowledge policies and internationalisation policies, which the Provincial Development Plan and local government have stated in their programme that they wish to further integrate.

The table brings to light the fact that firms place little value on the world of research as a source of knowledge acquisition, whereas intuitively this should, on the contrary, be one of the main focal points in this context. For sure, sluggish bureaucracy and differing attitudes towards research between the academic and business communities are factors to consider. However, not even research centres, be they institutions or foundations, seem to be viewed positively by entrepreneurs: this applies to centres both in Trentino as well as in the rest of Italy and abroad. Likewise, little value is given for the purpose of knowledge acquisition to other players such as local and provincial agencies and institutes or the trade groups to which the company belongs. Reflecting on that distrust, we can note that Trentino firms seem to value knowledge acquisition processes that do not involve antecedents or commitments of time and resources, preferring in-house tools (skilled personnel and customer interaction) that enable knowledge to develop as a positive outcome of these players' activity but not necessarily constituting their primary role.

Just under $50 \%$ of the companies responding to the questionnaire stated they benefited from collaboration with research entities, the remaining having no dealings with them. More detail was then obtained on the nature of the relationship had by those companies declaring an active involvement. 


\begin{tabular}{|c|c|}
\hline $\begin{array}{l}\text { Informal relationships (personal contact etc.) with university teachers, researchers and/or lab } \\
\text { technicians }\end{array}$ & $85 \%$ \\
\hline Student or young graduate internships within the firm & $52 \%$ \\
\hline $\begin{array}{l}\text { Research or collaboration contracts with individual university teachers/ researchers (other than } \\
\text { institutional relations) }\end{array}$ & $45 \%$ \\
\hline Supervision of / consultation on bachelor, masters or PhD degree theses & $42 \%$ \\
\hline Contracts with research centres funded or co-funded by the Autonomous Province of Trento & $42 \%$ \\
\hline $\begin{array}{l}\text { Contracts with research centres funded by the firm (e.g.: university departments, Foundations, } \\
\text { Liaison Offices, etc.) }\end{array}$ & $27 \%$ \\
\hline Staff who are former researchers & $27 \%$ \\
\hline Tests / patent testing & $27 \%$ \\
\hline Contracts with research centres funded or co-funded by regional, national or EU government & $24 \%$ \\
\hline Collaboration from university teachers / researchers working in-house (full or part time) & $18 \%$ \\
\hline Joint use of research centres' laboratories / instruments & $15 \%$ \\
\hline Collaboration with research spin-off companies & $15 \%$ \\
\hline Company staff working (full o part time) at the University & $12 \%$ \\
\hline
\end{tabular}

Source: Data processed from results of OECD questionnaire Knowledge Networks in Trentino, OECD, 2010

Informal relations appear to be, along with having graduates working in-house, a sort of premise, especially in the early stages of the relationship. Only after that do firms consider it appropriate to embark on active cooperation at a higher structural level, such as contracts with the various Foundations within the PAT (Autonomous Province of Trento) or the supervision of bachelor and PhD degree theses. Even in this case, however, relations are personal in nature ("Research or Collaboration Contracts with individual university teachers / researchers (other than institutional relations)"), in other words, they do not form an institutional association between the business and research worlds. More frequently, institutional relations are established later, following a formalized relationship between individuals, as a positive outcome of personal contacts, be they informal or institutional.

If we look at the wide gap between the figures for contracts funded or co-funded by the Autonomous Province of Trento and those for contracts funded by the company, we can see that Trentino firms are little inclined to make structural investments in research, and that they are more prepared to accept contract-based initiatives that are financially supported by the PAT. 
Lastly, it is worth reflecting on the low percentage found of university teachers working in-house for firms or for research spin-off companies. This figure shows once again that there is little mobility between the world of research and that of industry. More specifically, we should speak of an underinvestment on the part of companies in developing relations with research entities, even the kind of relationship (such as cooperation with research spin-off companies) that could generate real benefits for the business.

Companies that have no dealings with research entities were asked their reasons for this (Table 11). The main motive given is the divergence between the timescales upon which the research world and industry function. Firms are also convinced that the knowledge produced by universities is too theoretical. The responses reveal a certain scepticism of the research milieu, not only in terms of its content and objectives, but also in the institution itself, which they consider to be sluggish and complex. Excessive red tape slows the process down, so that it cannot keep up with the faster time-tomarket companies need in order to remain competitive. It is therefore plausible that businesses are not turning to the academic or research centres because they do not deem them to be an efficient investment. However, research is by definition necessary to a company: it must be pursued through the acquisition of know-how, in-house systems or through consortiums, which work at a pace more in line with the firms' business needs.

Table 11. Why the company is not involved in institutional collaboration with the research sector

Research and business work to different timescales (time-to-market)

The knowledge produced by universities/ research centres is too theoretical

$60 \%$

Universities / research centres require too much bureaucracy

$53 \%$

The firm already has advanced in-house know-how

$53 \%$

It is not easy to find the right person to contact

Too many in-house issues to be interested in research

$43 \%$

The firm relies on the companies with which it is partnered (mother company, clusters, consortiums) for its know how

The firm does not have the financial resources available

The firm is not aware of the opportunities for collaboration

$33 \%$

Source: Data processed from results of OECD questionnaire Knowledge Networks in Trentino, OECD, 2010

Some of the barriers to collaboration are behind the fact that industry continues to be multisectoral and generalist, while research concentrates on more and more specific subject areas. This means that company innovators cannot rely on Trentino-based research entities alone: for more 
complex procedures, they have to look to centres further afield, outside of the local system but if possible belonging to Trentino's research network. The purpose of local knowledge networks is not to be all-encompassing, but rather to coordinate a system of stakeholders who interact and develop together. When local expertise is not available, they can thus refer to a wide network of researchers or entrepreneurs able to select and to bring such expertise back to the local level. When interviewed, both the Microsoft Research Centre and the FBK (Bruno Kessler Foundation) said they were willing to act as a technological antenna to enable Trentino companies to enter global knowledge networks.

The last question in this section concerns the main barriers to achieving high standards of quality in the technology transfer between the research world and businesses in Trentino (Table 12). Here again, diverging priorities and time-to-market pressure were the reason for industry's lack of interest in research. This widespread perception among companies generates, in turn, distrust and brings down the number of collaboration initiatives. If these initiatives were boosted by economic incentives and projects were promoted by the Autonomous Province of Trento, this could stimulate a reform of the research world, streamlining and speeding up the system, making it more attractive to Trentino's businesses. Another weakness to emerge from the survey relates to information. Despite numerous recent proposals, specifically aimed at computerizing public administration, the business community complains of a lack of information on research programs, which hinders the achievement of high standards of quality in technology transfer. Here again, it would be desirable for the APT to intervene in order to close the gap between business and research in the information sector.

Table 12. Barriers to achieving high quality standards in the technology transfer between research and business in Trentino

\begin{tabular}{lc}
\hline Inadaptability to business needs & $71 \%$ \\
\hline Lack of information available on research programmes & $69 \%$ \\
\hline Time-to-market pressure & $67 \%$ \\
\hline Different objectives (e.g. publications against products) & $64 \%$ \\
\hline Inaccessibility: world of research is closed & $50 \%$ \\
\hline Different unwritten codes of behaviour & $34 \%$ \\
\hline
\end{tabular}

Source: Data processed from results of OECD questionnaire Knowledge Networks in Trentino, OECD, 2010 


\section{Box 5. Weaknesses in the relationship between industry and research institutes in Trentino}

The issues of the research world's lack of market orientation and its non-compliance with firms' time-tomarket needs are also found in the survey on University-Industry relations in Trentino (Bonaccorsi, 2007). The results shown in the following table highlight the problems firms have with bureaucratic-administrative issues, costs, and the amount of human resources that can be dedicated to individual projects at the same time so as to be able to focus on the most pressing needs.

Table 13. Weaknesses in industry-research institute relationship (\%)

Reaction/development time too long, unsuited to industry

Bureaucratic- administrative problems

Above-market costs / unsuited to industry, differing financial requirements between research world and business world

Insufficient human resources available

Insufficiently geared to production, not market-oriented, not business-oriented

Low level of focus on specific sectors

Different problem-solving approach

Limited technical resources

Lack of communication between research bodies and firms

The question doesn't arise

Unable to answer as collaboration only just begun or underway

Total replies
$20.6 \%$

$11.8 \%$

$8.8 \%$

$8.8 \%$

$8.8 \%$

$2.9 \%$

$2.9 \%$

$2.9 \%$

$2.9 \%$

$14.7 \%$

$14.7 \%$

$100.0 \%$

A recent analysis of these dynamics was carried out by the Trentino CVR (committee for evaluation of research), in its 2006-2008 activities report: "In the period 2001 - July 2005, 163 different research projects were presented, involving 116 companies overall (over the period 1,637, companies were surveyed, in other words the investigation covered $7 \%$ of companies based in the province), representing a total turnover of $€ 205,168,000$. The sum of investment in research undertaken under provincial law 6/99, calculated on the basis of total eligible expenditure amounted to $€ 69,684,978^{50}$. Hence the need to monitor the impact of business research subsidized under provincial law 6/99, which was drawn up in order to establish guidelines for a debate on the validity of actions already taken and those to be undertaken with a view to support and strengthen a research-oriented

\footnotetext{
50 “La Ricerca Scientifica in Trentino: rilevazioni 2004”, a cura dell’Osservatorio Provinciale della Ricerca.
} 
entrepreneurship in Trentino, in line also with the EU objective of "a common strategy on science and technology in the service of society". An initial analysis had already been made by the provincial Observatory on Research in order to highlight certain characteristics of companies that had access to funds. (...). At the conclusion of the study it was found that Trentino companies who undertook in the period under consideration research co-funded by local government improved their performance in terms of value added, increased their propensity to invest in research and reduced their economic and financial risk profile. Overall, the survey painted a picture of $R \& D$ on the rise but which still needed to undergo a systematic restructuring in order to achieve the institutional objectives and enable individuals who undertake research to gain a real competitive edge over their competitors."

Source: Bonaccorsi, 2007

\section{Knowledge Application}

Trentino businesses have a distinctive approach to the exploitation of technological knowledge: one of their strong points is their good use of it in the field of processes (process innovation, introduction of in-house ICT), whereas they are still weak when it comes to product innovation and applied research (Table 14).

Table 14. Strengths and weaknesses in the exploitation of technological knowledge by Trentino companies

\begin{tabular}{|c|c|c|c|c|}
\hline Strengths & Indicators & Trentino & Italy & EU 15 \\
\hline High levels of process innovation & $\begin{array}{l}\% \text { of firms having introduced process } \\
\text { innovations (2004) }\end{array}$ & 17,9 & 15,5 & 13,7 \\
\hline $\begin{array}{l}\text { Good development of in-house } \\
\text { network applications }\end{array}$ & $\begin{array}{l}\% \text { of firms with a broadband connection } \\
\text { (2008) }\end{array}$ & 86,2 & 81,1 & 86 \\
\hline $\begin{array}{l}\text { Good use of online business } \\
\text { services }\end{array}$ & $\begin{array}{l}\% \text { of firms using online financial } \\
\text { services }\end{array}$ & 92,8 & 85,9 & $\mathrm{~N} / \mathrm{A}$ \\
\hline Weaknesses & Indicators & Trentino & Italy & EU 15 \\
\hline Low levels of product innovation & $\begin{array}{l}\% \text { of firms engaging in product } \\
\text { innovation (2004) }\end{array}$ & 6,7 & 5,2 & 9,8 \\
\hline $\begin{array}{l}\text { Limited numbers of staff employed } \\
\text { in high tech sectors }\end{array}$ & $\begin{array}{l}\% \text { of staff employed in high tech sectors } \\
(2007)\end{array}$ & 4,2 & 4,4 & $\mathrm{~N} / \mathrm{A}$ \\
\hline Low levels of in-house R\&D & $\begin{array}{l}\text { In-house R\&D staff out of total } \\
\text { workforce (2005) }\end{array}$ & 18.3 & 40.4 & 54.4 \\
\hline
\end{tabular}

Source: Adapted from the Provincial Development Plan, 2010 
This section's data, drawn up by the Statistics Office of the Autonomous Province of Trento, allow for an investigation into some of the main ways Trentino firms apply knowledge and innovation $^{51}$. To this end, an interesting comparison can be made with the figures the Italian Institute of Statistics (ISTAT) came up with in 1996 (Mariotti, 2003).

The first part of the analysis looks at indicators of innovation and research of Trentino firms by product sector. Then, the same indicators are broken down by company size, divided into industry, construction and services. The 1996 survey found that the percentage of Trentino firms able to market new products, or products with improved functionality, was below the national average (index number 88.7), as was their propensity to innovate products and processes (index number 89.7). On the other hand, the percentage of firms that had innovated only their production processes was above the national average (index number 176.3).

The 2004 survey presents significantly different findings: index numbers relating to product innovation are higher than the national average both for industry (index number 167.0) and, albeit to a lesser extent, construction and services. With regard to process innovation, the figures for the construction industry remain similar to those of 1996 (index number 174.6), while they are lower for industry and stand at a percentage significantly below the national average in the services sector (index number 80.9). Regarding the simultaneous innovation of both product and process, the earlier figure below the national average remains the same only for the construction sector, while it is significantly higher for industry (index number 146.6) and in particular for services (index number 210.4). Concerning the innovation of services, phenomena such as the introduction of the Euro, the explosion of the new economy in 2000 and the advent of the Internet in the tourism sector, have likely contributed significantly to the change in trend, by promoting new and integrated dynamics, affecting both the nature of the service and its delivery method. This growth trend was the object of increasing government attention during the same period with regard to energy and the environment, leading to specific policies on these issues in the years immediately following.

Performance in the more hi-tech sectors remains weak. In the machinery and electrical and electronic equipment sector, the 1996 innovation expenditure index of 18.9 rose to 36.7 in 2004 . This figure is still below the national standard for a sector in which Trentino boasts a strong research presence, and not just theoretical. In the chemical sector, the figure increased from 71.0 to 99.0 indicating here again a slight improvement, but still remaining below the national standard.

\footnotetext{
${ }^{51}$ Data updated on the basis of the 2002-2004 ISTAT figures. In that survey, all firms with more than 10 employees were evaluated, while the 1996 survey analyzed only firms with more than 20 employees. The 2002-2004 survey is also the only one for which ISTAT supplied regional data including production units located in the region but headquartered elsewhere.
} 
With regard to the size variable, the survey carried out in the mid 90s reveals that the innovation gap within Trentino businesses could be ascribed to financial companies with over 250 employees. In particular, large Trentino firms showed a propensity well below the national average towards more complex product and process innovations (index number 20.8), introducing innovations more often simpler innovations, pertaining only to products (index number 141.2) or only to processes (index number 105.0). Slightly higher than half the national average is the percentage of large Trentino companies that in 1996 had undertaken research and development activities (index number 58.1).

By the middle of the following decade, the data given here broken down into size and sector (industry, construction and services) reveal that large industrial enterprises are still way below the national average for product and process innovation (index number 46.7), while they appear to be focusing increasingly on the innovation of one product (index number 334.3) and at the same time a reducing their commitment to the innovation of process only (index number 77.2), which is where the most profound transformations of the 90 s occurred.

The category of firms with more than 250 employees showed, in the 1996 survey, a very low level of innovation, even taking into account the amount of total expenditure, (index number 28.4), just over a quarter of the national average. By 2004, the index had risen to 58.7, in the industrial sector, and to 169.7 in the services sector, although this is largely due to the purchase of machinery, an area heavily subsidized by the local public sector. The problem of large enterprises does not improve even if the data is broken down the by activity: findings show a wide gap with the national average, a gap that was only partially closed by 2004. The same applies to firms belonging to the smaller size category: the purchase of equipment is the only area of expenditure where small and medium-sized enterprises have values higher than the national index numbers for industry.

Innovation capacity in Trentino lies, therefore, mainly in small businesses that are not agglomerated into more dominant groups. A study of the Trentino firms with the highest innovation performance (Mariotti, Mutinelli, Della Lucia, 2003) confirmed the above findings, even among toplevel enterprises.

\section{Link between company innovation activities and internationalisation}

A key issue, and one with important policy choice implications, revolves around the link that becomes established between a company's innovation activity and its degree of internationalisation. One aspect of this issue concerns the presence in the area of multinationals, which act as bridges to foreign markets for local businesses. In the case of the Autonomous Province of Trento, the Report on the internationalisation of local firms (Mariotti, 2006) confirms the role of foreign multinationals in the province's economic fabric. The Report reveals that multinationals act as an important spur for domestic firms to begin exporting and at the same time, as a means of reinforcing and extending the flow of their exports through vertical (i.e. inter-sectoral) spillovers. In the case of horizontal (intra- 
sectoral) spillovers, the dominant aspect is that of competition, which inhibits firms' export capacity.

One highly interesting study (Mariotti, 2008) spotlights the connection between innovation activities and high levels of internationalisation for Trentino companies. It examines a sample of 215 local enterprises, accounting for approximately $60 \%$ of Trentino's exports ${ }^{52}$. The companies that carry out innovation activities and those that innovate their products are found to perform the best in terms of internationalisation. The non-innovative groups always perform the worst, while groups that carry out innovative activities exclusively aimed at improving production processes obtain intermediate level results. It would therefore seem to make sense to consider good performance on international markets as a result that can be obtained through, among other things, good innovation policies.

However, the question posed in the survey on business strategy reveals certain misgivings on the part of firms about the link between innovation and internationalisation.

Table 15. Relationship between innovation and internationalisation

\begin{tabular}{lc}
\hline Innovation has made it possible to access new market niches at international level & $54 \%$ \\
\hline Innovation has facilitated internationalisation & $46 \%$ \\
\hline Internationalisation has facilitated the development of innovation & $46 \%$ \\
\hline Innovation has made it possible to gain a new international market position at a time of crisis & $39 \%$ \\
\hline Innovation and internationalisation are independent from each other & $34 \%$ \\
\hline
\end{tabular}

Source: Data processed from results of OECD questionnaire Knowledge Networks in Trentino, OECD, 2010

These findings should be weighed up in the light of the recent global economic downturn. During the latter crisis, investment in innovation did not guarantee or facilitate Trentino companies in gaining a position in international markets. While recognizing that there is a link between innovation and the processes of internationalisation, firms do not consider the former to be a key investment during moments of economic weakness.

\section{New knowledge application: sample firms' perspective}

This section of the questionnaire attempts to establish what are the main kinds of innovative processes to interest the sample firms. The first question was aimed at assessing the types of innovations the sample firms have been involved in over the past 5 years. It focuses on product

\footnotetext{
${ }^{52}$ The classification distinguishes between groups that perform innovative activities, groups that do not carry out R\&D but which have innovated their products in the 2002-2004 period, groups that do not carry out R\&D but which have introduced process innovations and lastly groups that do not perform any innovative activities.
} 
innovation, process innovation, managerial innovation and marketing innovation, recognized in the literature as the main types of business innovation. Product, process and managerial innovation all obtained substantially the same score, indicating that the sample firms are interested in all these areas.

Marketing innovation, that is to say the ability to introduce significant changes to product design, packaging, positioning and promotion, obtained a significantly lower score, as can be seen in Table 15. Presumably this is due in part to the nature of the firm's line of business, which is not necessarily in contact with an end market. However, it is striking that $79 \%$ of the firms have introduced new products and services, while only $46 \%$ have developed an innovative approach to marketing. This figure is cause for concern with regard to the ability of the products made by Trentino firms to access international markets, particularly in the light of Trentino's loss of international market shares in recent years.

The sample firms were then asked what four types of innovation are the most relevant for the company. The findings show that firms introduce product and process innovation simultaneously, but that they consider product innovation to be more important (54\%).

Table 16. Types of innovation introduced by the firm

2. Has the firm developed innovative managerial processes (significant changes to business practices, workplace reorganisation, external relationships, etc.)?

3. Has the firm carried out any process innovations (significant changes to production or distribution through technical changes, new instruments or software used, etc.)?

4. Has the firm developed innovative marketing strategies (significant changes to product design, packaging, positioning, promotion, etc.)?

Source: Data processed from results of OECD questionnaire Knowledge Networks in Trentino, OECD, 2010

\section{Business’' Assessment of Industrial Policy and Innovation Issues}

Innovation policies and the development of networks foster "reactions" among the system's stakeholders, providing them with strategic, financial and managerial incentives. It is useful, therefore, to see how firms view the PAT's industrial and innovation policies. A few key issues, covering the main content of these policies, were selected and firms were asked to provide a detailed assessment of each issue, so as to glean a more nuanced picture.

The results illustrated in Figure 10 confirm that Trentino's business world holds a positive view of the funding allocated to research and innovation. The quality of information sharing maintained by the APT was rated mostly fair or good, as was its capacity to develop local networks (e.g., clusters, 
business networks). Likewise, the PAT's ability to impose high quality standards for public sector procurement was well rated. In line with the other findings of this report, firms hold a negative view of policies aimed at strengthening their competitiveness and internationalisation: $80 \%$ of answers hovered around "poor" and "fair". The question of policies for developing staff skills through training courses according to the needs of the company received the most negative ratings.

Figure 9. Firm's assessment of the PAT research and innovation activity

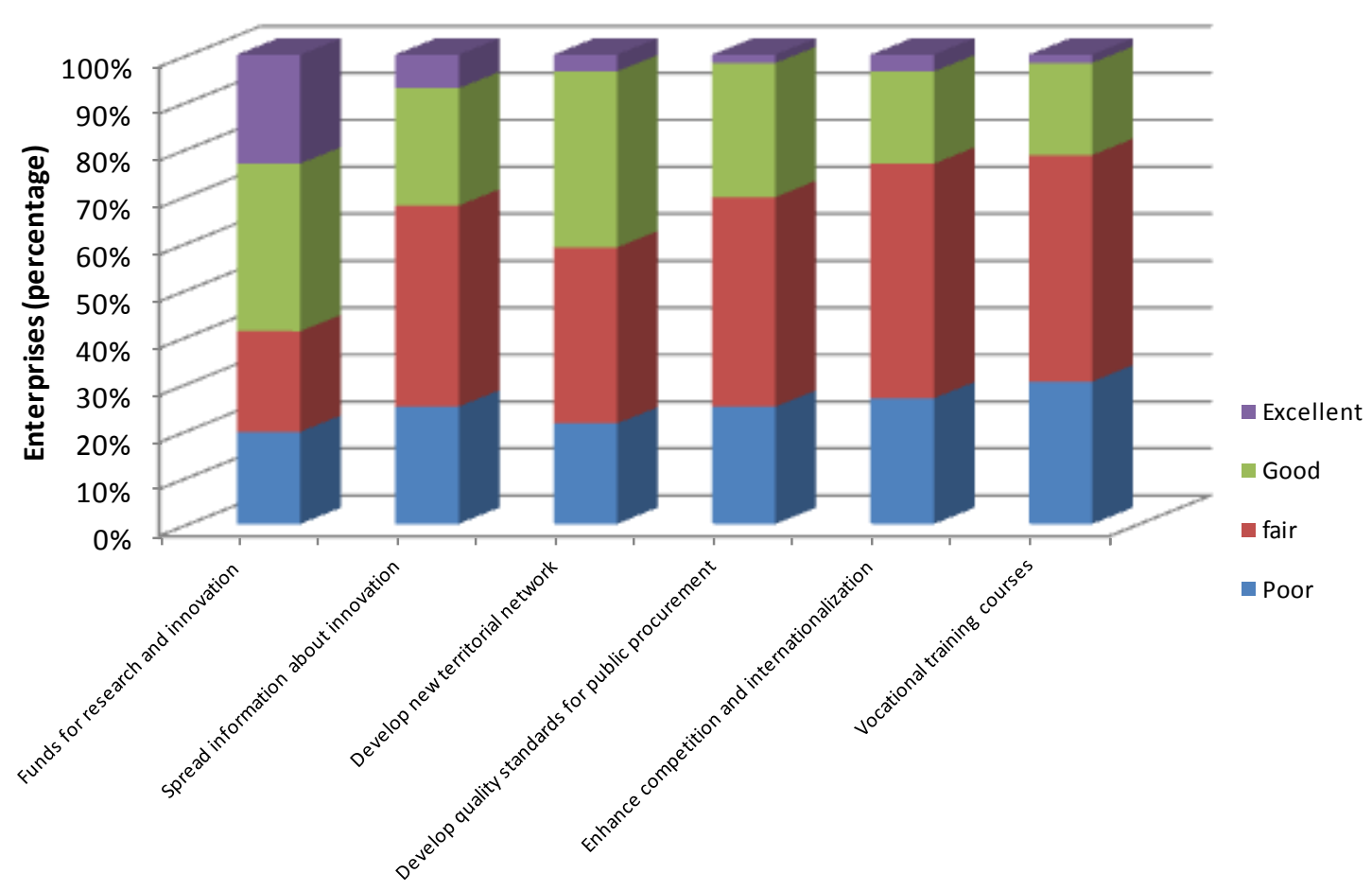

Source: Data processed from results of OECD questionnaire Knowledge Networks in Trentino, OECD, 2010

The results framework demonstrates that there are critical situations that must be addressed. One of these is the need to strengthen the virtuous link between innovation policies and policies to support international development, one of the sectors to suffer most from the current economic crisis.

At the end of the section of the survey consisting of quantitative questions, interviewees were asked to comment on two issues that are of importance for local government policy and of strategic value for the province, as is clear from the Provincial Development Plan. The first issue is whether or not it would be of any use to set up a reward system for access to research and innovation funds directly proportional to a company's export capacity. The firms' response is predominantly negative (70\%). The current system of incentives for research seems thus to be perceived as an area that does not require strategic modifications. The second question put to the firms focuses on whether or not the PAT should reserve a quota of public spending for goods or services that incorporate new technology, given the well-known fact that public sector demand for high quality plays a key role in regional 
innovation development. The firms' response to this question was largely positive (85\%).

The second part of the questionnaire was dedicated to free comments from the firms, to serve as suggestions to the PAT in its support and promotion of innovation. Points were grouped into the following topic areas.

\section{Goals intrinsic to the research system}

- $\quad$ set concrete targets for the research system, introduce metrics and measure results;

- improve relationships and synergies between companies and universities or research centres, guiding the latter towards the pursuit of financially profitable results for Trentino's enterprises;

- $\quad$ publish the results of research more widely;

- choose research areas to support economically that correspond as closely as possible to local industry;

- promote the horizontal mobility of researchers and employees between companies and research (exchanges or leases).

\section{Goals related to relationships with firms}

- better select which SMEs should be targeted for public investment, focusing on those with a greater aptitude for innovation;

- $\quad$ rovide incentives for companies to agglomerate in order to overcome constraints related to size;

- $\quad$ pay more attention to private enterprise;

- develop and strengthen an industrial fabric based on businesses able to support themselves and be competitive on the market;

- identify homogeneous groups of SMEs and promote group audits of the companies, guiding them at the same time towards new products and processes.

\section{Goals related to human resources, flows and training}

- facilitate the exchange and flow of human resources between research and advanced training environments and the business world;

- create a closer linkage between university and employment, given graduates' difficulty in entering the job market, extend the number of hours of internships included in the curriculum of specialized university courses; 
- encourage specialist training at all levels of higher education and university;

- encourage job creation;

- develop a system of further vocational training that is more demand side than supply side.

\section{Goals intrinsic to the Province}

- maintain closer ties with the PAT's more outlying businesses;

- maintain more contact with the various sectors of industry;

- help overcome social and entrepreneurial exclusion.

\section{Goals related to political and administrative procedures}

- help small businesses by easing up bureaucratic procedures;

- $\quad$ simplify the regulations of law 6/99 and generally reduce the red tape surrounding funding;

- increase available funds;

- $\quad$ adjust to the industrial world's time-to-market needs;

- facilitate the commercialisation of innovative products starting by adopting them within the PAT and do more to promote use of innovative products and services by the provincial administration;

- manage the incentives system responsibly, avoiding a 'handout' mentality;

- co-operate with the banking system by providing forms of credit for companies that use patents, conduct research, and work in synergy with the University.

Significant ideas to emerge include a cross-section interest in developing knowledge network policies to oversee complex processes, especially at the level of firms, or in building relationships between research and business, in the recognition that knowledge networks can be a central asset for business development in Trentino.

\section{Experts' Assessment of Industrial Policy and Innovation Issues}

Besides the policy assessment obtained from firms, interviews were carried out with experts on the effectiveness of policies for the development of networks, as applied to the context of Trentino.

\section{Creation of joint research-industry laboratories}

Experience of such laboratories is very limited: the BICs (Business Innovation Centres) have experimented with them in the past, but Trentino's economic agents - starting with companies themselves - still show no inclination to establish a formally structured relationship. The FBK 
(Fondazione Bruno Kessler) does have joint laboratories with its spin off companies, but setting up such labs with existing firms is more problematic: past investments in research collaboration with local stakeholders has yielded positive results. The commitment of large companies, the experts observe, should be to invest, and not just to obtain PAT resources. There is no collaboration between the Fiat Research Centre and the FBK; The FEM (Fondazione Edmund Mach) has no joint laboratories, its experimental activities being carried out to order.

\section{Human capital mobility}

Research contracts with the Foundations include incentives for "safeguarded" transfers into the business system. This stems from the understanding that the most important strategy to foster technology transfer is to ensure the mobility of human capital between research and industry. However, cases of this happening have, to date, been sporadic, although such phenomena often have long periods of "incubation" and the possibility cannot be ruled out that there will be a significant growth in the coming years. It remains to be seen if these cases of transfer from research into industry are of a temporary or a permanent nature. In the case of a permanent transfer, ongoing career support is important. In the case of transfers for a limited time, the central issue is the researcher's subsequent return to the university environment, which nowadays rewards only publications or possibly 'impact factor' achievements. For example, the policy of continuous international level human capital acquisition, one of the priorities of FBK, requires the Foundation to be mindful in terms of output too, since its total allocation of human resources is basically stable. In the case of the FEM, project-based associations between the foundation and industry provide a natural bridge for the mobility of researchers.

\section{Support for innovative start-ups.}

The seed capital competition announced in 2009 is producing positive results in terms of the number of applicants (54): it remains to see the quality of the business ideas put forward. Alongside the Autonomous Province of Trento, the University of Trento is developing a strategy that facilitates new business ventures. FBK also stresses the importance of such a policy. In 2009, the FBK helped create 4 spin-offs, and up till now, in 2010, there have been nine candidacies. As for the FEM, the seed capital competition has helped set up a new consultancy firm.

\section{Creation of technology clusters and similar consortiums.}

An example of this trend is the recent creation of Semantic Valley, albeit sponsored by the public sector (Informatica Trentino). The focalization of policy on high-tech clusters has, however, given cause for concern. On the side of industry, there are fears that this policy might reduce the appropriateness of supporting Trentino's industrial base, consisting of over 1000 industrial enterprises, thereby weakening the whole system and its employment capacity. On the side of research, on the 
other hand, the concern is that in a market as "small" as Trentino, research decisions could be influenced excessively: sector-based clusters are more effective in large markets.

\section{Funding for joint university-industry research projects.}

The PAT has recently taken measures to extend its incentives system, at first aimed only at projects centred on priority areas such as energy, to all projects involving this type of collaboration. The FEM has opted to develop a tariff-list based on the Foundation's strategies, rather than on projects financed by the public sector.

\section{Funding for other modes of knowledge acquisition / transfer.}

Appreciable results have been achieved by the regional development agency Trentino Sviluppo's temporary management projects, in which retired managers visit firms to help them in their company check-ups (Blue Eagles project). It is a commonly shared view that companies should not limit themselves to research projects, though other initiatives, such as study days, are not widespread. Companies that avail themselves of consultation services get greater satisfaction than those that rely on research projects.

\section{Support for local networking initiatives.}

The local development agency Trentino Sviluppo launched a project in 2006 called "Cento Nuove Imprese" (One Hundred New Businesses). Under this project - which evolved from a package of coordinated development agreements known as the Patti Territoriali (territorial pacts) - 174 workshops have been held in towns throughout the province and as many information evenings on how to set up a business venture. A total of 2,359 people (average age of $36,48 \%$ women) have attended and 606 business ideas been put forward up till March 2010. There have been 80 training days held, and 180 business plans developed with the support of Trentino Sviluppo experts, 100 of which have led to concrete results in the form of a proper company, with its own VAT registration number, being opened. Assistance to those wishing to go into business, or to check the feasibility of a business idea, begins with meetings held usually in the evening in local town halls, to find out via questionnaires what kind of business those attending wish to enter into. The would-be entrepreneurs are then given a private interview in order to ascertain their business motivation on a case-by-case basis. This is followed by meetings with experts to assist the hopefuls in drawing up a job plan to give them a better grasp on the importance of business planning, targeting topics such as business strategy, administration and finance, testing plans and feedback. When the technical side of the assistance is completed, it is up to the would-be entrepreneurs to determine, according to the specific needs of each, if, how and when they decide to start up their new business. Only then does the last phase of the development agency's assistance begin, the so-called 'introductory' phase, in which the soon-to-be businessmen and women are introduced to provincial services local authorities and trade associations 
to apply for the necessary licences, permits, and other legal requirements.

Another important initiative in support of local private-public networking is the promotion of province-based ICT networks. The Autonomous Province of Trento has invested in developing computer skills within Trentino businesses. Skill development initiatives have been launched, involving the main regional training agencies of the professional associations. The Chamber of Commerce makes it obligatory to submit financial statements electronically. Networking initiatives, such as "maestri artigiani" an association of master craftsmen, have been promoted.

\section{Box 6. Case study: The Trentino technology cluster for energy and the environment, "Habitech"}

Trentino's Technology cluster "Habitech" was founded as a result of a new way of thinking about development processes that arose mid-decade along with a renewed determination to enhance innovative sectors (sustainable construction, distributed energy production and energy efficiency in particular) in harmony with the province's traditional industries (tourism and timber). The technology cluster was created in an attempt to leverage local assets, tapping into a new globally development trend, that of the green economy. It comprises some 40 companies and develops relationships along three axes: LEED-Green Building Council, services to individual members and integrated projects.

The cluster facilitates interaction and manages its network of enterprises by coordinating the various parties - architects, engineering companies, general contractors, equipment suppliers and universities. Without the cluster and without leading local companies, such alliances would be difficult: Habitech develops a common language. It oversees relationships between companies and creates a collaborative environment. The Trentino technology cluster invests in the codification of a language shared by all parties, which is essential for the transfer of knowledge: this is the LEED standard, the Green Building rating system. The mechanism of organizational learning that drives Habitech is commitment combined with a model of knowledge codification and certification. This constitutes not only a guarantee of respect for the internal business processes, but also a model of sustainable construction.

The Cluster sponsors a variety of innovation strategies:

- System activities that are of value for all members, including for example knowledge building, good practices and projects linked to building certification;

- Projects based on tourism and sustainable mobility like the Primiero Oil Free Zone, information workshops throughout the province focusing on the production of biogas generated by animal waste, biogas for remote heating and production of hydrogen;

- Construction of sectoral macro-projects, such as the project it presented under "Industry 2015" (government bill on competitiveness and industrial policy);

- Development of institutional relations to promote policies of sustainability that can enhance quality production within the cluster's firms; 
- Coordination of projects based on funding provided under Law 6 / 99.

In order to study a concrete case of a business agglomeration aimed at supporting a knowledge network, the companies interviewed were asked to assess the concept of technology clusters.

The first question, intended to ascertain the extent of firms' participation in clusters, $40 \%$ of companies said they participate or are interested in Habitech, $33 \%$ of firms said that there are no clusters for their line of business, and $21 \%$ of firms consider themselves too small to be part of a cluster. Worthy of note is the response from microenterprises, which feel that participation in a business cluster is something for more structured firms. In reality, a cluster should be able to focus directly on smaller companies, and create economies of network in which smaller companies benefit. Companies that stated they are part of or are interested in joining the Habitech cluster were asked what benefits they derived or expected to derive. The responses showed a high level of interest in B2B knowledge of companies with similar profiles, a prerequisite for building sectoral projects. This was followed by an interest in better access to business contacts and better understanding of technical standards: issues pertaining to the knowledge networks and the potential for development the cluster model offers.

\section{Table 17. Benefits derived or expected from participation in the "Habitech" technology cluster}

\begin{tabular}{lc} 
Better knowledge of firms with similar profiles & $76 \%$ \\
\hline Better access to commercial contacts & $67 \%$ \\
\hline Better access to public funds (EU and national) & $57 \%$ \\
\hline Better understanding of technical and environmental standards and procedures, and quality & $52 \%$ \\
certification & $38 \%$ \\
\hline Joint participation in open competitions & $24 \%$ \\
\hline Possibility of using licences &
\end{tabular}

Source: Data processed from results of OECD questionnaire Knowledge Networks in Trentino, OECD, 2010

The experience of the Habitech technology cluster highlights the potential for catalyzing processes aimed at consolidating local knowledge networks and facilitating further development by overseeing processes in a strategic way. It also underlines the need to control the life cycle of network processes and to find participants' elements of interest at each stage (creation, development and maturity of the network). 


\section{CONCLUSIONS: IDEAS FOR INNOVATION POLICIES}

The Trentino innovation system comprises many different players and institutional and organisational levels that must be taken into consideration when transforming the ideas contained in this report into policy suggestions. The policies adopted by the individual players have their own margins of freedom, albeit within the PAT-managed framework. Such margins have enabled the establishment of Foundations and the implementation of network mechanisms that the PAT can govern only in part. An attempt has been made to collect political innovation lines linked to the issues of the enterprise network and adapt them to the different players involved in the system. A system seeking a role in the knowledge economy must increase the dynamics in its own subsystems ranging from enterprise turnover to researcher mobility to the public policies transformation elements. It is possible to achieve the overall stability and guarantees of the system in the knowledge economy through actions seeking to ensure greater internal dynamism and a willingness to take risks. The social guarantees and stability traditions positively characterising the Trentino must favour the taking of social and entrepreneurial risks, not inhibit it.

From the enterprise point of view a difficulty emerges in developing strategies based on knowledge networks. One of the main reasons is linked to the fact that the structuring of the relationships with the knowledge world is still in its early developmental phase. From this perspective it can be assumed that the investment promoted by the other players over the last decade can produce effects at the cooperative relationship level in a very short time span.

Table 18. SWOT analysis of Trentino innovation policies and knowledge networks: the enterprise system

Strengths to be enhanced

- Habitech Technological Cluster experience

- Presence of a small, albeit qualified number of companies capable of working with research Opportunities worth exploiting

- Network contracts focused on the knowledge sector

- Introduction of new funding modalities for companies for advanced services (vouchers)
Weaknesses to be overcome

- The strategic development projects are usually proposed by the public sector

- Limited entrepreneurial dynamics

\section{Threats}

- Insufficient penetration of Trentino companies in the markets with the fastest growth rate

- Loss of relative positions vis-à-vis export 
As regards the research system, the last decade has focused on the fine-tuning of legislative and "macro" organisational instruments by means of the establishment of Foundations, agreements between the PAT and the NRC and the shifting of the control on the University to the PAT. Now there is a new phase based on a greater focus on the processes and organisational dynamics, on the "micro" level in which the governance of the processes is structured in a punctual manner at different levels. The Report highlights the fundamental importance of human capital in the innovation policies and the knowledge networks. The research system has the greatest responsibility on this issue which lies at the heart of the development policies of individual institutions.

Table 19. SWOT analysis of Trentino innovation policies and knowledge networks: foundation and research bodies

Strengths to be enhanced

- International leadership in well defined sectors

- Highly educated human capital

\section{Weaknesses to be overcome}

- The life-cycle of the funded projects is too long and not strong enough. There is a risk of losing the research economic enhancement opportunities

\section{Opportunities worth exploiting}

\section{Threats}

- An advanced interpretation of the relationship

- Loss of the critical mass if there is no focus between the Provincial planning and the • Latent conflict autonomy/responsibility typical of Universities and Foundations;

- Improve the relationship with Trentino Sviluppo by enhancing the complementary elements

- Create a "One-stop shop" for research with a well developed back office

The PAT is facing a complex challenge. As it seeks to enhance greater collaboration between the actuators by governing the system, it must simultaneously try to increase the responsibility of the controlled subjects if it wishes to ensure optimal operation. 
Table 20. SWOT analysis of Trentino innovation policies and knowledge networks: the PAT

Strengths to be enhanced

- Strategic commitment on innovation and research policies

Weaknesses to be overcome

- Improve the facilitating and networking operations between the subjects in the system, starting from those it controls

- Integrate the policies within the Administration's areas

\section{Opportunities worth exploiting}

Threats

- Transform Trentino Sviluppo into the true chief - The ongoing crisis limits the attention on the support of the Trentino networks by supporting network policies and privileges individual situations strong processes rather than replacing other players. Qualify its human resources

In designing policies a distinction must be made between "excellence" and "economic development". If such distinction is lacking, it leads to unrealistic expectations which may constitute a boomerang for the important development phases. The industrial research phases, characterised by strong territorial economic impacts do not necessarily pursue excellence in research. The objective of investment in industrial research is development not excellence as was often thought in the past. Policies must define the levels on which they operate, the objectives, the appropriate instruments and enhance expectations linked to the specific contexts.

The main aspects concerning the PAT's role which emerge are:

- Focus the interventions on a few "macro-projects";

- Use contractual instruments such as the Framework Agreements between different tiers of government including multilateral agreements, to structure and consolidate a strategic vision;

- Promote collaborations, network policies and develop a strong assessment culture;

- Develop policy implementation instruments capable of enhancing the knowledge networks starting from the stimulation of human capital mobility within the networks;

- Improve the integration between research policies and industrial policies within the macro development projects.

Innovation policies based on enterprise networks require the development of appropriate 
legislative instruments ${ }^{53}$ and efficient administrative and regulatory schemes. Such policies often have to intervene on the entire chain in addition to the individual network projects. An evolution from policies rewarding individual projects to policies rewarding the integration of projects is recommended. Macro-projects that pay attention to the application context, supply chains comprising the integration of "sub-chains" that are apparently very distant from each other (for example wood and ICT) within which project clusters can develop.

An efficient promotion of innovation policies that take into account knowledge networks should envisage appropriate focus elements, a new institutional governance as well as formats and cooperation mechanisms that do not hinder competition. The design of network policies is characterised by a growing attention to the impact actions have on the market. This does not imply a single dimension; it implies the creation of appropriate links between the development of basic research, applied research projects, technology transfer processes and the support for market penetration so as to develop virtuous knowledge flows and the recognition of the autonomy and specificity of the single areas mentioned.

\footnotetext{
${ }^{53}$ Law 6/99, though used for network projects, is not however a piece of law conceived for networks of companies.
} 


\section{LIST OF THE INTERVIEWS WITH THE EXPERTS}

\begin{tabular}{|c|c|}
\hline BENEDETTI Marco & Director, Casa Sofie Consortium \\
\hline BETTOTTI Sergio & $\begin{array}{l}\text { General Director, Department for innovation, research and ICT, } \\
\text { PAT }\end{array}$ \\
\hline BONACCORSI Andrea & Professor, University of Pisa \\
\hline CAFAGGI Fabrizio & Professor, European University Institute \\
\hline CALANDRA BUONAURA Carlo & $\begin{array}{l}\text { Professor, University of Modena and Reggio Emilia } \\
\text { President of the commission for research, PAT }\end{array}$ \\
\hline CAMAGNI Roberto & Professor, Politecnico of Milan and PAT consultant \\
\hline CAPRA Luca & $\begin{array}{l}\text { Director, Entrepreneurship and development area, Trentino } \\
\text { Sviluppo }\end{array}$ \\
\hline FAMBRI Giovanna & Responsible for statistical service, PAT \\
\hline FRANCH Maria Giovanna & External relations, Ivalsa-CNR \\
\hline GURISATTI Paolo & President, Habitech - Energy and environment cluster \\
\hline INGUSCIO Massimo & Director, Deparment of Materials and Devices, CNR \\
\hline LAZZARI Gianni & Director, Habitech - Energy and environment cluster \\
\hline LONER Diego & Responsible, Promotion of technological districts project, PAT \\
\hline MARIOTTI Sergio & Professor, University of Milan and PAT consultant \\
\hline MICHELINI Michele & $\begin{array}{l}\text { Deputy director, Finance, research and development, APIAE, } \\
\text { PAT }\end{array}$ \\
\hline MIGLIARESI Claudio & Professor, University of Trento \\
\hline MOLON Graziano & Director, Trentino SPRINT \\
\hline NULLI Michele & Director, University and research service, PAT \\
\hline PONTALTI Michele & $\begin{array}{l}\text { Responsible for technological transfer, Edmund Mach } \\
\text { Foundation }\end{array}$ \\
\hline PRIAMI Corrado & $\begin{array}{l}\text { President and CEO, "Microsoft Research - University of Trento, } \\
\text { Centre for Computational and Systems Biology" }\end{array}$ \\
\hline
\end{tabular}


RAVAGNI Vanessa

SALVATORI Gianluca

SPAGNI Paolo

TRIGILIA Carlo

ZANINOTTO Enrico

ZANOTTI Andrea

ZEN Mario

ZOLEZZI Guido
Responsible for technological transfer, University of Trento

Former local minister for research and innovation, PAT

President, Manifattura Domani

General Director, Department for Industry, PAT

Professor, University of Florence

Professor, University of Trento

President, FBK - Bruno Kessler Foundation

Responsible for technological transfer, FBK - Bruno Kessler

Foundation

Professor, University of Trento 


\section{BIBLIOGRAPHY}

Airaghi A., Lacave M. (2008), Evaluation of the impact of the activities promoted by the Kessler and

Mach Foundations on the Provincial System in Trentino in the period 2005-2007 with particular reference to the provisions of the 2007-2008 planning and financial agreements signed with the Province.

Bonaccorsi, A. (2007), Il sistema trentino della ricerca, WP4 User Survey, Comitato provinciale per lo sviluppo.

Borzaga, C., B. Valline (2003), Gli Sbocchi Occupazionali dei Laureati nella Provincia di Trento, Quaderni della Programmazione, N.4.

Boschma, R (2005), Proximity and Innovation: a critical assessment, Regional Studies 39:1,61-74, Routledge

Boschma, R. and Ter Wal, A.L.J. (2007) Knowledge Networks and Innovative Performance in an Industrial District: the Case of a Footwear District in the South of Italy', Industry and Innovation 14 (2): 177-99.

Boschma, R and Ter Wal, A.L.J. (2009), Applying social network analysis in economic geography: framing some key analytic issues. Ann. Reg. Sciences, Springer .

Buzzi. C. (1996), Economia, Risorse Umane e Sviluppo Sociale in AAVV. Gli imprenditori del Trentino, Valori, Opinioni, Immagini, Confindustria, Trento.

Camagni, R. (2002), Benchmarking Territoriale, Quaderni della Programmazione, n.3.

Camagni, R., E. Zaninotto (2002), Competitività del Sistema Produttivo. Quaderni di Programmazione, Competitività, N.1., Cappello, Faggian 2005

Fraunhofer-Institut (2003), The Science and Technology Base of the Provincia Autonoma di Trento: Capacities, Trends and Opportunities

Fraunhofer-Institut (2003), The Science and Technology Base of the Provincia Autonoma di Trento: Capacities, Trends and Opportunitie.

Giuliani, E., Il concetto di 'rete efficiente': una comparazione internazionale dei rapporti tra Istituti di 
Ricerca Pubblica e Impresa nel settore del vino, in Salvini A. (a cura di), Analisi delle reti sociali. Teorie, metodi, applicazioni, FrancoAngeli, Milano, 2007.

Mariotti, S. (2003), Innovazione e Nuove Tecnologie: Analisi e Politiche. Quaderni della Programmazione, N.2.

Mariotti, S. (2008), Le Relazioni tra internazionalizzazione e innovazione delle imprese della provincia di Trento. Quaderni della Programmazione, N. 22.

Mariotti, S. a cura di (2006), Competitività e internazionalizzazione del sistema locale delle imprese, Trentuno ed., Trento.

Mariotti, S., Mutinelli M., Della Lucia M. (2003), Innovazione Tecnologica e Ricerca nell'Industria Locale, Quaderni della Programmazione, N.2.

OECD (2001), OECD Territorial Outlook, Paris

Rauch, J., Casella,A.(2001), Networks and Markets, Russell Sage Foundation, New York.

Rullani, E. (1999), La Realtà Locale nello scenario economico del Paese e del Nord Est. Oltre il Nord Est, Confindustria Trento.

Schizzerotto, A. (1996) Le Origini Sociali, la Carriera e la Posizione Professionale Attuale, in AAVV. Gli imprenditori del Trentino, Valori, Opinioni, Immagini, Confindustria, Trento. 
ANNEX I: THE QUESTIONNAIRE

\section{QUESTIONNAIRE}

Public policies and local development: public innovation policies and local fall-out of global dynamics (OPENLOC)

\section{TRENTINO KNOWLEDGE NETWORKS}

The questionnaire seeks to examine the existence and efficiency of the Trentino knowledge networks, assess the propensity of local enterprises to innovation and collect the impressions on the role of local public policies for innovation.

The report with the results of the study shall be available at the end of the project. The information collected shall be subjected to the same treatment as statistical data and used solely for the study.

\section{A. COMPANY PROFILE}

1 Name and legal status of the company (state whether a joint stock company, limited company, cooperative, limited partnership, general partnership etc.)

2

Company established in: (year)

3

Company founded by:

multiple answers available

$\square$ man $\square$ woman $\square$ under $35 \square$ not Italian $\square$ a group of partners

4

Does your company belong to a group?

select one

$\square$ yes, an Italian group $\square$ yes, a foreign group, $\square$ no

5 Sector of activity:

select one

$\square$ Aerospace industries $\square$ Automotive $\square$ Biotechnology $\square$ Chemicals $\square$ Construction $\square$ Defence industries 
$\square$ Electrical engineering $\square$ Food industry $\square$ Footwear $\square$ Furniture $\square$ Healthcare Industries $\square$ ICT $\square$ Leather

$\square$ Legal metrology and pre-packaging $\square$ Maritime industries $\square$ Mechanical engineering $\square$ Mining, metals and minerals

$\square$ Pressure equipment and gas appliances $\square$ Radio and telecommunications terminal equipment (R\&TTE)

Textiles and clothing $\square$ Tourism $\square$ Toys $\square$ Wood, Paper, Printing $\square$ Other (please specify)

$6 \quad$ Number of employed workers:

select one

$1-10 \square 11-25 \square 26-50 \square>50$

7 Percentage of university degree employees hired in the last 5 years?

Warning: the sum of b) $+c$ ) must total 100

a) \% total

b) $\%$ of graduates who obtained their degree at the University of Trento

c) $\%$ of graduates who obtained their degree at other universities (in Italy or abroad)

8

2009 Turnover:

select one

$\square<2(\mathrm{mln} €) \square 2-10(\mathrm{mln} €) \square 10-50(\mathrm{mln} €) \square>50(\mathrm{mln} €)$

9 Subdivision of the 2009 turnover:

Warning: the sum of $b)+c)$ must total 100

a) \% local market (Province of Trento)

b) \% national market (outside the Province)

c) \% international market

10 Percentage of turnover invested in Research and Development (over the last 5 years)

Enter the number only. Do not enter the "\%" symbol

11 Has your enterprise obtained any public funding for research in the last 5 yea?

$\square$ Yes $\square$ No

12 Has your enterprise ever filed an application for a patent?

$\square$ Yes $\square$ No 
Yes $\square$ No

\section{B. CREATION OF NEW KNOWLEGE GENERATED WITHIN THE COMPANY}

14 Which creation modalities for new knowledge are important for the activity of your company?

The term new knowledge refers to any progress in the enterprise's know-how and in general any acquisition of NEW knowledge capable of solving company problems, develop new products/processes, the structuring of new opportunities and/or new approach perspectives to the challenges the enterprise must tackle.

$$
\begin{aligned}
& \text { Not } \\
& \text { important }
\end{aligned}
$$

a) Generated thanks to internal R\&D activities

b) Stemming from the experience within the enterprise

c) Elaborated through interactions with local trade partners (micro and small enterprises)

d) Elaborated through interactions with local trade partners (medium and large enterprises)

e) Elaborated through interactions with international trade partners (micro and small enterprises)

f) Elaborated through interactions with international trade partners (medium and large enterprises)

g) Developed through interactions with research bodies

h) Elaborated through interactions with others (associations, Chambers of Commerce)

\section{ACQUISITION OF NEW KNOWLEDGE}

1. Local trade partners 
2. International trade partners

3. Group the enterprise belongs to

4. Competitors in the business area

5. Customers

6. University of Trento

7. Other universities in Italy

8. Other universities abroad

9. Trento research centres (Kessler and Mach Foundations etc.)

10. Italian research centres

11. Foreign research centres

12. Local, Provincial and or Central Government offices

13. Intermediation Bodies (ex: Development Agency, Chamber of Commerce)

14. Trade and representative associations

15. Consortia, Districts, Enterprise Groupings etc.

16. Acquisition of equipment, materials, components or software

17. Professional conferences

18. Fairs, shows, exhibitions

19. Specialised, technical-scientific courses

20. Technical and trade magazines, data banks

21. Technical and environmental standards and quality certifications

22. Hiring of qualified personnel

17 Which three of those listed below have been the most important sources of knowledge acquisition for your enterprise in the last five years?

(Select the number of the item stated in the previous question. For Example 6= Trento University)

$\square 1 \square 2 \square 3 \square 4 \square 5 \square 6 \square 7 \square 8 \square 9 \square 10 \square 11 \square 14 \square 15 \square 16 \square 17 \square 18 \square 19 \square 20 \square 21 \square 22$

18 Does your enterprise collaborate with research organisations (Universities, research institutes etc.)

$\square$ Yes $\square$ No 
If so, which?

1. Contracts with research centres funded by the enterprise (ex: university departments, foundations, liaison offices etc)

2. Contracts with research centres funded or co-funded by the PAT

3. Contracts with research centres funded or co-funded by the Regional, National or EU governments

4. Research contracts and collaborations with individual professors/researches (outside institutional relationships)

5. Informal relationships (personal contacts etc) with teachers, researchers and/or laboratory technicians

6. Supervision/collaborations for university dissertations, masters or $\mathrm{PhDs}$

7. Joint use of laboratories/instruments belonging to research centres

8. Collaborations with research spin-off enterprises

9. Tests/patent checks

10. Collaborations (full time or part-time) of enterprise employees at the university

11. Collaborations (full time or part-time) of professors/researchers at the enterprise

12. Employees who are former researchers

13. Stages (students or young graduates) within the enterprise

Reasons why your enterprise is not involved in institutional collaborations with the research world:

1. The company already has advanced internal know-how

2. The company uses the know-how of related companies (parent company, cluster, consortium)

3. I am not aware of collaboration possibilities

4. It doesn't have financial resources available

5. It doesn't have human resources available

6. Universities/research centres require too much red tape

7. It is not easy to find the right contact

8. The knowledge produced by the university/research centres is too theoretical

9. Research shows little interest in the problems raised by enterprises

10. Research and enterprises have different times to market 
In general, according to your experience it is difficult to work with:

The University

Research centres

22

Do you think your company is advantaged by the Trentino research system?

$\square$ Yes $\square$ No

23 Do you think that your company would have been able to activate technological/innovative projects as has been the case even without access to Provincial innovation and research funds?

\section{$\square$ Yes $\square$ No}

24 What is the main reason for the missed advantages?

25 Which of the following improved conditions can help your enterprise obtain the greatest advantage?

1. Development of cluster organisations or consortia that can also promote the interests of my enterprise

2. Universities better able to produce qualified human resources

3. Development of spaces (laboratories, for example) that can be used jointly by research bodies and enterprises

4. Possibility the production world has to influence the choice of the research areas in Trentino upstream.

5. Presence of an organism that can coordinate the technological transfer activities the research world and enterprises in Trentino?

1. Few available information on the research programmes

2. Difficulty of access: the research world is very closed

3. Unwritten behavioural codes

4. Different time scales 
5. Different objectives (for example publications instead of products)

6. Incapacity to adapt to the company's requirements

27

Are you participating in a technological cluster (for example Habitech?)

select one

$\square$ Yes

$\square$ No, but I do intend to participate

$\square$ No, there are no interesting clusters for the type of activity carried out by my enterprise

$\square$ No, my enterprise is too small

$\square$ Other (please specify)

Which of the following benefits have you obtained (or do you expect to obtain) from your participation in a technological cluster?

1. Joint participation in public tenders

2. Better access to public funds ( national and EU)

3. Better knowledge of companies with a complementary profile

4. Better access to trade contacts

5. Better understanding of the procedures and technical, environmental and quality certification standards

6. Possibility of using licences

\section{ENTERPRISE APPLICATION OF THE INNOVATIVE KNOWLEDGE}

1. Developed innovative (new or greatly improved) products and services?

2. Introduced process innovations (significant production and/or distribution changes thanks to changes in techniques, instruments and/or software used, etc)?

3. Developed innovative marketing methodologies (significant changes in design, packaging, positioning, product promotion etc.)?

4. Developed innovative organisation processes (significant changes in the way business is carried out, workplace organisation, external relations etc)?

Which type of innovation among those mentioned above is the most important for your enterprise? 
select one
$\square$ Product Innovation
Process Innovation
Marketing innovation
Organisational innovation

31

How many patents has your enterprise developed over the five past years?

2005

2006

2007

2008

2009

2010 Forecasts

32

In your enterprise's experience what is the relationship between innovation and internationalisation?

1. Innovation has favoured internationalisation

2. Internationalisation has favoured the development of innovation

3. Innovation and internationalisation are independent

4. Innovation has enabled repositioning on international markets at a time of crisis

5. Innovation has enabled my enterprise to enter new market "niches" at international level

\section{E. INNOVATION POLICY OF THE AUTONOMOUS PROVINCE OF TRENTO: OPINIONS}

What do you think of the Autonomous Province of Trento's interventions on research and innovation in:

Unsatisfactory Satisfactory Good Excellent

1. Funding enterprise research and innovation

2. Disseminating information on innovation by means of publications, conferences, the web etc.

3. Development of territorial networks (for ex.: clusters, enterprise networks

4. Development of high quality standards in PAT procurement

5. Strengthening competition and internationalisation in enterprises 
6. Obtaining qualified personnel by means of training courses in keeping with the enterprise's needs

1. The more the company exports the more it is entitled to access $R \& D$ funds

2. The PAT must reserve part of its public purchases to products and services incorporating new technologies

35 In your opinion what can the Autonomous Province of Trento do better to support and promote innovation? 
PART 2: THE MAGDEBURG CASE STUDY 


\section{MAGDEBURG CASE STUDY}

\section{Introduction}

Small and new local enterprises are known to have a significant influence on the creation of new jobs and, accordingly, on the development of the regional economy. The access to knowledge-transfer networks is crucial for these enterprises, in order to protect and further develop their long-term innovation ability and competitiveness. Indeed, it is only their investment in and their application of research-generated knowledge that enables enterprises to pursue product and process innovation.

The current regional study of Magdeburg, the capital of the East German state of Saxony-Anhalt, explores to what extent knowledge transfer, controlled via regional networks, matters to small and new local enterprises. For this purpose, it is necessary to disclose the organizational structure and to indicate how different regional networks are interlinked with each other, whether they generally interact or operate in isolation. Moreover, for each knowledge-transfer network, it is important to identify the most influential factors and describe its geographical range.

For Saxony-Anhalt the main economic objectives are job security as well as new job creation through startup companies and growth of existing businesses. The aim of the study is to derive statements concerning the relevance of identified knowledge-transfer networks, i.e., whether these have a significant impact on the emergence and growth of small and new innovative enterprises in the economic region of Magdeburg and, thereby, contribute to the achievement of the economic policy objectives. In addition, recommendations for optimizing knowledge-transfer networks will be compiled.

\section{Terminology}

In the context of the present study it is important to specify the following terminological expressions.

Small and new local enterprises: Enterprises are assigned to this group if the corporate headquarters are located in the economic region of Magdeburg and one of the following conditions applies: The firm has no more than 50 employees or was founded no longer than five years ago.

Knowledge transfer: This refers to a three-step process, through which usable knowledge is generated by research and development and then transferred through different channels to be made available to enterprises.

Knowledge-transfer network: This refers to a group of interconnected people, resources, and relationships, which are combined in order to generate, gather, share, and use knowledge. 


\section{Methodology}

For the development of the initial exploratory phase, the design of the study methodically relies on qualitative empirical social research.. For the economic region of Magdeburg, the study focuses on priority sectors, identified and defined by the city itself:

- Mechanical and systems engineering

- Healthcare

- Environmental technology and recycling management

The study begins with a brief socio-economic description of the state of Saxony-Anhalt in comparison with the other New Federal States in Eastern Germany, with a particular focus on research and development (R\&D) within enterprises. Then the general socio-economic conditions for the regional economy of Magdeburg will be presented, including a brief overview of the research environment.

The focus of this study is on the analysis of knowledge-transfer networks as to their existence, their structure, and their relevance for small and new local enterprises in the regional economy of Magdeburg, in particular within the priority sectors. The analysis comprises, first, an exploratory phase, based on expert interviews, and, second, an enterprise survey. Based on the results of the expert interviews, the three priority sectors to be examined will be characterized by describing their main protagonists with brief portraits. In addition to the collection and analysis of empirical data, the study will point out the thematically relevant public funding programs. The objective of the subsequent compilation of the results from the expert interviews and the enterprise survey is the identification of existing network structures. This includes an assessment of their relevance for small and new local enterprises with regard to research and development as a basis for sustainable corporate success and growth. Finally, recommendations for optimizing the effectiveness of knowledge-transfer networks with respect to the economic policy objectives will be elaborated.

\section{Exploratory phase}

Core of the exploratory phase was the oral consultation of experts by means of computer-assisted interviews (CAPI). ${ }^{54}$ The selection of experts was based on a prior analysis of key players among the regional knowledge-transfer networkers. ${ }^{55}$ Based on own research and initial consultations with the city of Magdeburg's Association for Economic Services (GWM), a list of 37 experts was compiled. These experts were regarded as playing an active role in the three industry-specific knowledge-transfer networks under investigation, the focus being on research and development as well as on transfer.

\footnotetext{
${ }^{54}$ Hamman and Erichson (2000, p. 97).

${ }^{55}$ Häder (2010, p. 72).
} 
The questionnaire for the expert interviews featured a comprehensible structure, ${ }^{56}$ with 26 questions in following three areas:

- Knowledge transfer and the identification of network structures

- The role of small and new local enterprises

- The general political framework

To minimize the influence of the interviewers during the expert interviews, the surveys were based on a neutral strategy. ${ }^{57,58}$ Furthermore, all questions were designed to be open-ended, in order to avoid limiting the experts' responses and to obtain as much information as possible. ${ }^{59}$ The transcribed expert interviews provided the basis for the identification and description of the relevant protagonists and institutions within the individual knowledge-transfer networks. The evaluation was based on an inductive approach, while simultaneously employing methods of network analysis. ${ }^{60}$

Parallel to the expert interviews, a questionnaire on Entrepreneurial Finance was developed, in order to assess the role of financiers in and their access to the identified knowledge-transfer networks. The 25 questions were largely identical to those of the expert interviews, with a selective focus on financing. Design, execution and evaluation were carried out according to the previously described methods. The interviewees came from both public and private financial institutions.

\section{Survey of enterprises}

The second step of the empirical research was a survey of local enterprises using an online computer survey. ${ }^{61}$ The objective of this quantitative empirical research as a survey method was the collection of a sufficient amount of data under standardized conditions. The basis of the enterprise survey was a corporate database. The following criteria were necessary for inclusion of an enterprise in the database:

- The corporate headquarters were located in the economic region of Magdeburg

- The enterprise's main business activity was focused on one of the designated priority sectors

For the identification of relevant companies, the following specific aspects were considered:

\footnotetext{
${ }^{56}$ Häder (2010, p. 194 pp.).

${ }^{57}$ Neutral strategy means that the interviewer records the answers without adding an own evaluation.

${ }^{58}$ Häder (2010, p. 190).

${ }^{59}$ Hamman and Erichson (2000, p. 106 pp.).

${ }^{60}$ Häder (2010, p. 69).

${ }^{61}$ Hamman and Erichson (2010, p. 97).
} 
- The company profile in the GWM industry specifications

- The company's affiliation with thematically relevant network structures (economic cluster of Saxony-Anhalt, industry-specific associations)

- The direct reference to the company in an expert interview

- The direct involvement of the company in collaborative $\mathrm{R} \& \mathrm{D}$ projects

The database created on this basis consisted of nearly 275 companies that could reasonably be expected to have an affinity towards $R \& D$. An extension of the database was carried out by the Magdeburg Chamber of Industry and Commerce (CIC), taking into account the necessary criteria. Companies that were not recorded in the first round, but which could be associated with the key industries on the basis of the CIC industry key, were added subsequently.

The objective of the survey was to derive statements concerning the relevance of research and development for small and new local enterprises in the economic region of Magdeburg. Moreover, the survey examined the extent to which the networks identified in the exploratory phase play a significant role for these enterprises. In addition, existing barriers to the knowledge-transfer process were characterized from the perspective of the respective enterprises, and options for optimizing the knowledge transfer were elaborated.

The questionnaire of the enterprise survey comprised 32 questions in the following categories:

- Company Profile

- Knowledge transfer and $\mathrm{R} \& \mathrm{D}$ processes within the enterprise

- General economic and political framework

The questionnaire for the quantitative survey contained only closed questions, in order to ensure comparability of data. By specifying all the possible answers, the questionnaire was fully structured. The evaluation of the enterprise survey was carried out by means of electronic data processing software. 


\section{STATE OF SAXONY-ANHALT}

\section{Socio-economic background}

In 1990, Saxony-Anhalt, located in the former German Democratic Republic, was established as one of the five New States of the Federal Republic of Germany. With an area of $20447.64 \mathrm{~km}^{2}$, it is the eighth largest state in Germany. Saxony-Anhalt has 2,381,872 inhabitants. This corresponds to 116 inhabitants per $\mathrm{km}^{2}$ and 2.9 percent of the German population. ${ }^{62}$ In 2009 , the number of employed persons was at 1,010,100 million; the average unemployment rate was 13.6 percent. ${ }^{63}$

Saxony-Anhalt currently has a Gross Domestic Product (GDP) at current prices of 51.5 billion EUR, which corresponds to a GDP per employee of about 51,000 EUR. ${ }^{64}$

Figure 10. The state of Saxony-Anhalt with counties and county boroughs

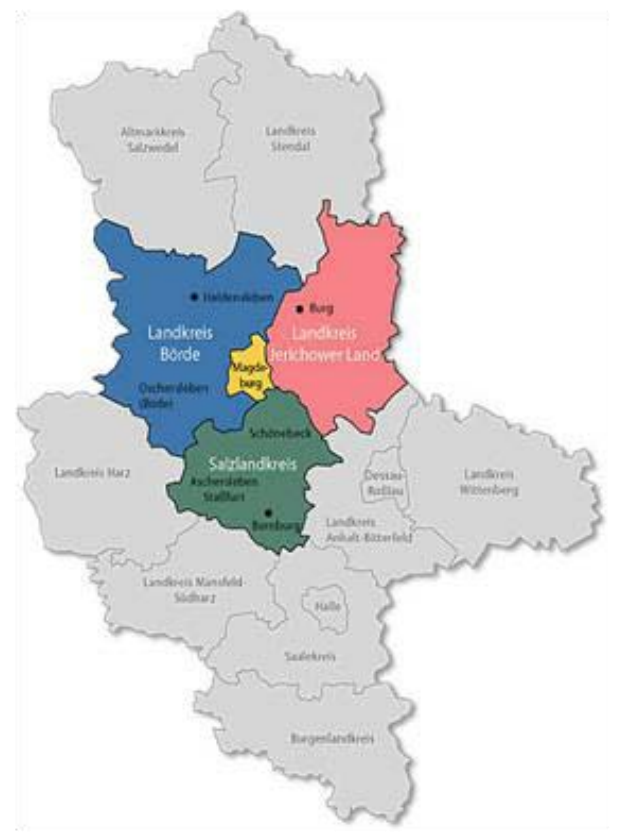

Source: www.sachsen-anhalt.de

Figure 10 shows the county structure of Saxony-Anhalt and the location of Magdeburg, the state

\footnotetext{
${ }^{62}$ www.statistik-portal.de.

${ }^{63}$ Statistisches Bundesamt.

${ }^{64}$ Staatskanzlei Sachsen-Anhalt.
} 
capital. Magdeburg, a county borough, is surrounded by three larger counties. For the purpose of this study, the closely located towns of Barleben and Osterweddingen (Landkreis Börde), and Schönebeck (Salzlandkreis) are regarded as belonging to the economic region of Magdeburg.

\section{Comparison of R\&D data between East-German states}

The analysis of Eastern Germany with regard to R\&D data cannot be considered as being representative for all of Germany, as there are major differences in all relevant $R \& D$ areas between the New Federal States and the Old States (i.e., Germany before unification in 1990). For example, in the German economy as a whole, 85.3 percent of R\&D expenditures must be attributed to large companies (i.e., with more than 500 employees). In contrast, in the New Federal States, large companies account for only 46.7 percent of R\&D expenditures. Moreover, in 2008, R\&D expenditures in the New States (including East Berlin) totaled to 2.3 billion EURs, a share of only 4.3 percent of total German R\&D expenditures. ${ }^{65}$

Despite the low overall R\&D expenditures of the New Federal States, a comparison of their R\&D data yields conclusions on the framework conditions and, more generally, the importance for and of $R \& D$ in Saxony-Anhalt. Since there are no relevant and usable R\&D data for the economic area of Magdeburg alone, Saxony-Anhalt must be considered as representative for the economic area of Magdeburg in terms of $R \& D$ data analysis. One may assume that Magdeburg, as a major regional $R \& D$ center, indeed, plays a special role within the $R \& D$ assessment at the state level, but it has yet to be empirically proven.

\section{Number of enterprises involved in $R \& D$}

As the following Figure 11 illustrates, in 2008, there were 254 companies in Saxony-Anhalt with continuous R\&D involvement. ${ }^{66}$ This corresponds to 13 percent of the total number of companies continuously involved in R\&D in the New Federal States. In addition, 61 companies conducted R\&D on a temporary ${ }^{67}$ basis, which implies a share of 12 percent over all New Federal States. In terms of the number of companies involved in R\&D, Saxony-Anhalt ranks fourth among the five New Federal States.

\footnotetext{
${ }^{65}$ Konzack, Herman-Koitz and Horlamus (2009, p. 8).

${ }^{66}$ Firms with continuous R\&D involvement have their own full-time R\&D staff and carry out R\&D over several years. Konzack, Herman-Koitz and Horlamus (2009, p. 22).

${ }^{67}$ Firms with temporary R\&D involvement have either provided one-off project-related R\&D services, or R\&D activity proceeds with interruptions (without R\&D costs). Konzack, Herman-Koitz and Horlamus (2009, p. 22).
} 
Figure 11. Distribution of companies continuously and temporarily involved in R\&D in the New Federal States in 2008



Source: Source: Konzack, Herman-Koitz and Horlamus (2009, p. 57)

\section{Size of $R \& D$ staff}

In 2008, there were 2,279 R\&D staff members working in companies with continuous $R \& D$ involvement in Saxony-Anhalt (cf. Fig. 12). The term R\&D personnel in this context describes employees in companies working full-time in R\&D or providing services for R\&D. ${ }^{68}$ As the comparative data reveal, Saxony-Anhalt, again, ranks fourth among the New Federal States.

\footnotetext{
${ }^{68}$ Konzack, Herman-Koitz and Horlamus (2009, p. 22).
} 
Figure 12. Number of R\&D Personnel working in companies with continuous R\&D involvement in the New Federal States in 2008

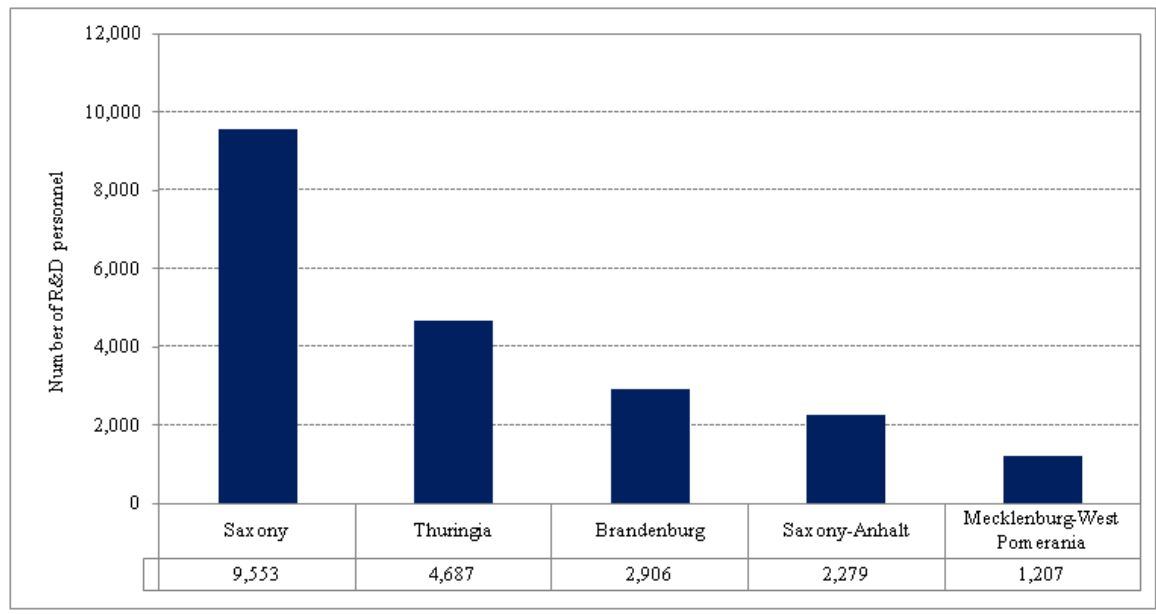

Source: Konzack, Herman-Koitz and Horlamus (2009, p. 32)

\section{Sales figures of companies involved in $R \& D$}

The comparison of aggregate sales of companies with continuous R\&D in the New Federal States (cf. Fig. 13) reveals that Saxony-Anhalt, with approximately 6.6 billion EUR, ranks second behind Saxony in 2008. The relatively strong position of Saxony-Anhalt is due to the fact that in 2008 the state achieved the highest productivity per R\&D employee (273,000 EUR) ${ }^{69}$

Figure 13. Sales of companies in the New Federal States with continuous R\&D in 2008

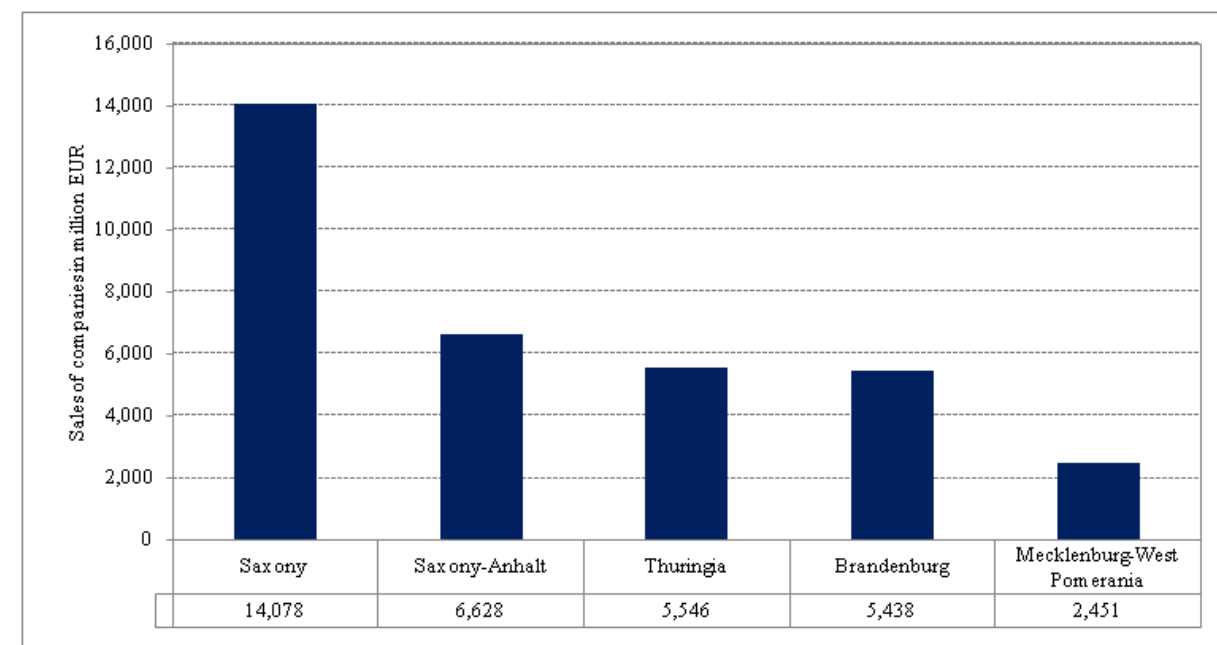

Source: Konzack, Herman-Koitz and Horlamus (2009, p. 43)

\footnotetext{
${ }^{69}$ Konzack, Herman-Koitz and Horlamus (2009, p. 47).
} 


\section{$R \& D$ expenditures of companies involved in $R \& D$}

As shown in Figure 14 below, the R\&D expenditures of companies with continuous R\&D involvement in 2008 in Saxony-Anhalt amounted to 166 million EUR. Only Mecklenburg-West Pomerania recorded a lower overall level of R\&D expenses. In the comparison of the five New Federal States, Saxony-Anhalt, thus, ranks fourth.

Figure 14. R\&D expenditures of companies with continuous R\&D involvement in the New Federal States in 2008

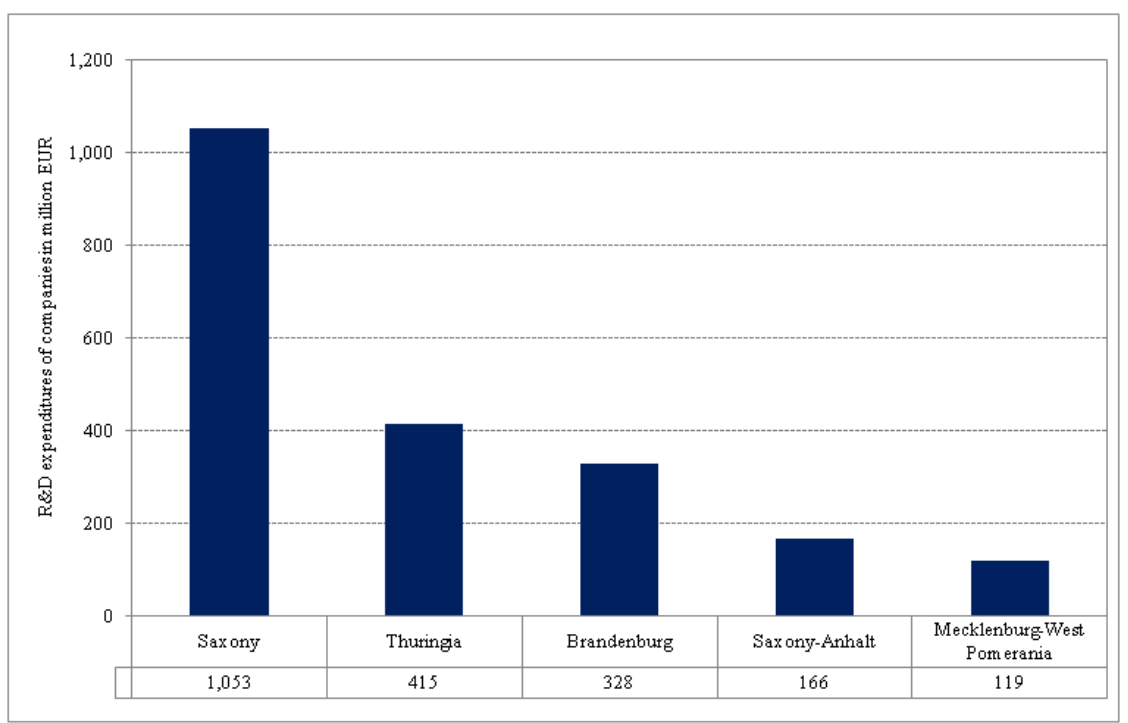

Source: Konzack, Herman-Koitz and Horlamus (2009, p. 38)

In terms of research funding for individual R\&D employees, Saxony-Anhalt, with 73,000 EUR, ranks fifth in the state comparison. In Brandenburg, the individual R\&D employees, at 113,000 EUR each, had the highest individual budget for research funding in 2008.

\section{$R \& D$ intensities}

From sales and R\&D expenditures of companies with continuous $R \& D$ involvement in 2008, one can derive information concerning cost-related R\&D intensity. ${ }^{70}$ Saxony-Anhalt features a cost-related $R \& D$ intensity of 2.5 percent, which is the lowest among the New Federal States and far below the average of 7.3 percent. With regard to the staff-related R\&D intensity ${ }^{71}$ of companies with continuous R\&D involvement in 2008, Saxony-Anhalt, at 9.4 percent, has the lowest value of the New Federal States. By comparison, Thuringia - with 13.5 percent - has the highest staff-related R\&D intensity.

\footnotetext{
${ }^{70}$ Defined as the ratio of R\&D expenditures and sales. Konzack, Herman-Koitz and Horlamus (2009, p. 48).

${ }^{71}$ Defined as the number of R\&D staff relative to overall staff. Konzack, Herman-Koitz and Horlamus (2009, p. 47).
} 


\section{THE ECONOMIC REGION OF MAGDEBURG}

\section{Socio-economic considerations}

\section{Geography}

Magdeburg is the state capital of Saxony-Anhalt and has a recorded history of more than 1,200 years. The county borough is geographically divided into 39 different districts (cf. Fig. 15).

Figure 15. Magdeburg, the state capital of Saxony-Anhalt (subdivided into districts)

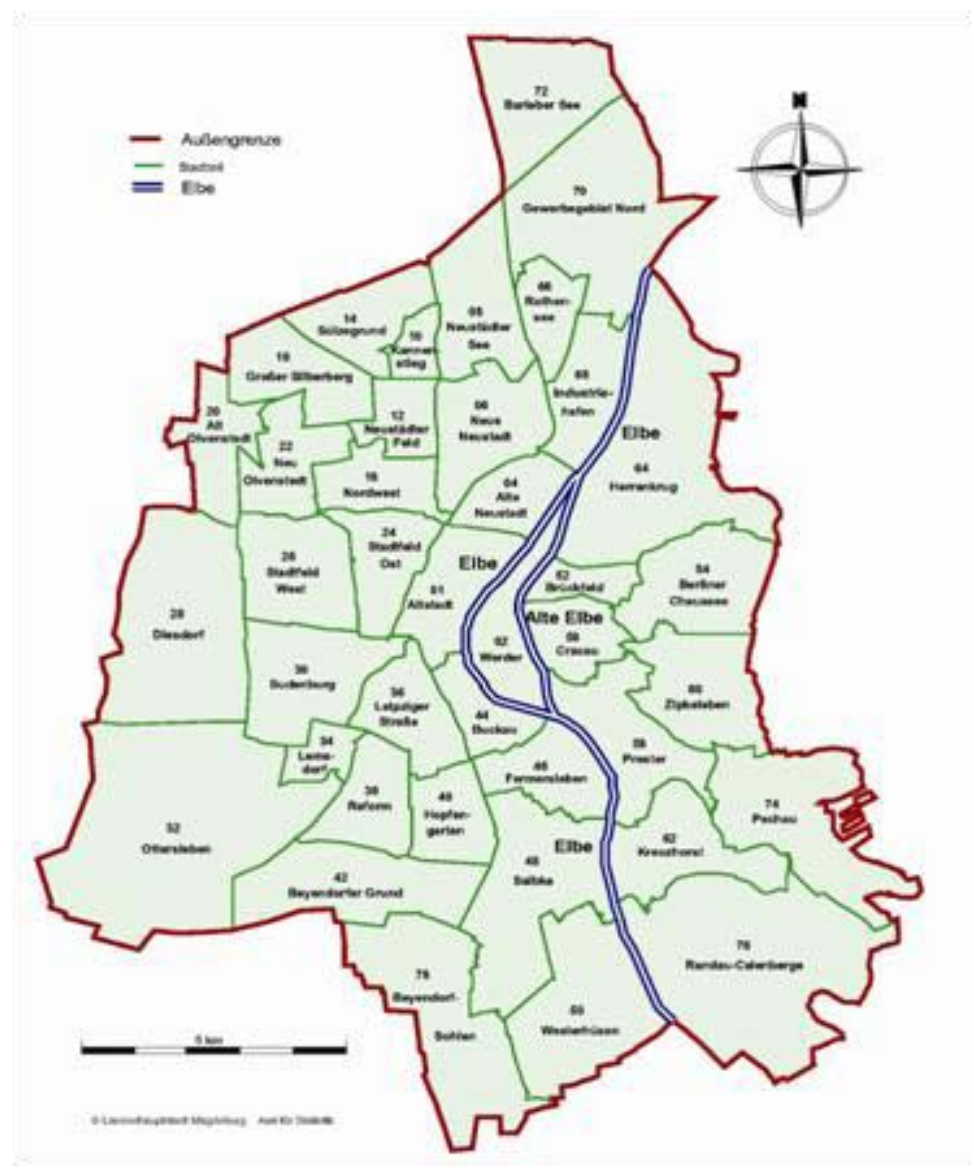

Source: Magdeburger Statistische Blätter Issue 73 (2010, p. 10)

Magdeburg covers an area of $201.6 \mathrm{~km}^{2}$. The city limits, bordering on the surrounding districts, reach a total length of $88.8 \mathrm{~km} .{ }^{72}$ The different types of land use and their proportional percentage

${ }^{72}$ State Agency for Topographical Surveying and Geoinformation, Magdeburg Statistische Blätter, Issue 73 (2009, p. 12). 
relative to the total area of Magdeburg are displayed in Figure 16. The areas for trade/ services, and commerce/industry constitute one sub-group of buildings and open spaces with a total area of 15.15 $\mathrm{km}^{2}$.

The area of investigation, for the purpose of this study, is the economic region of Magdeburg, which covers the geographical area of the city of Magdeburg and, in addition, selected economic regions directly adjoining and strongly related to the city, such as the towns Barleben, Osterweddingen, and Schönebeck.

Figure 16. Overview of the various areas: itemizing actual use

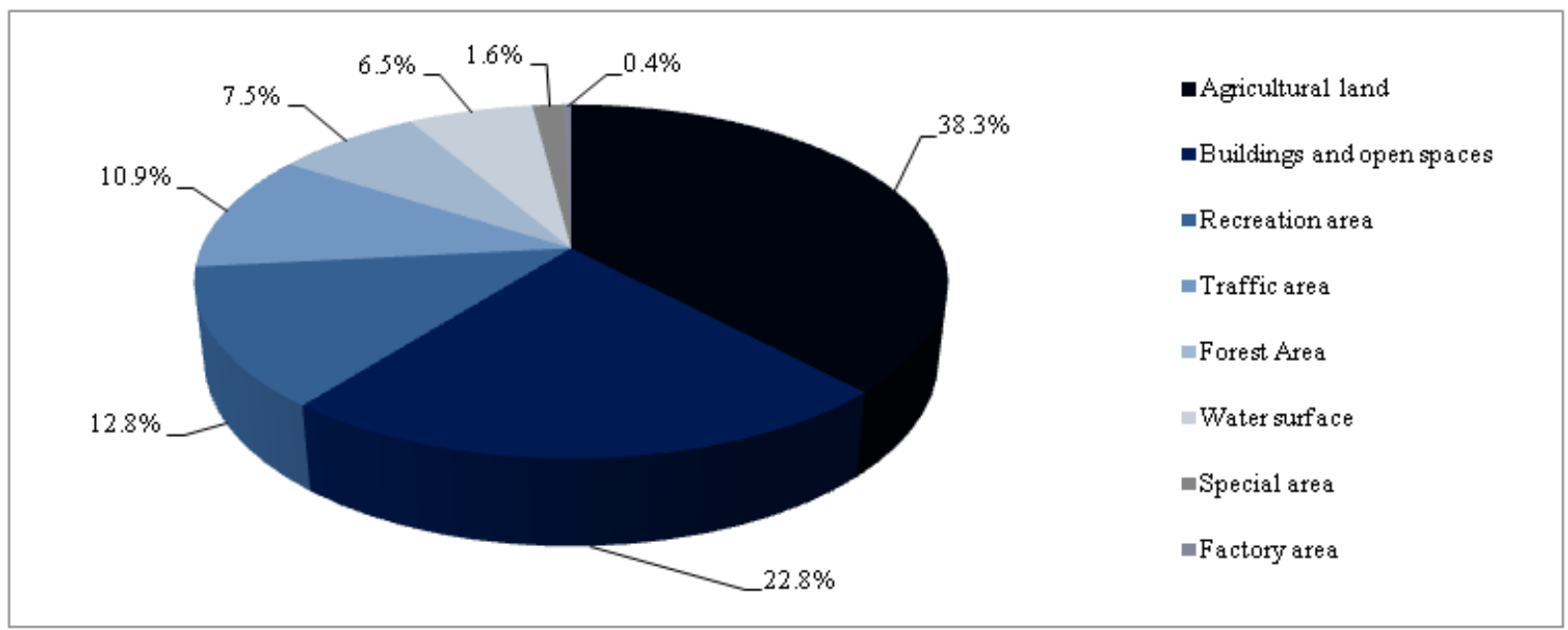

Source: Magdeburger Statistische Blätter Issue 73 (2009, p. 13)

\section{Infrastructure}

Magdeburg, located in the geographical centre of Europe, offers a multitude of logistic connections. There is direct access to the most frequented east-west highway in Europe (A2), with the Magdeburg junction (A2-A14) as a major intersection for north-south traffic. The city of Magdeburg is also the most important rail traffic hub in northern Saxony-Anhalt.

North of Magdeburg, the Midlands Channel crosses the River Elbe before it connects to the ElbeHavel Channel east of the Waterway Intersection. With a length of $324.4 \mathrm{~km}$, the Midlands Channel is the longest artificial waterway in Germany. It is the most important east-west waterway and, on a European scale, the central waterway leading from western to Eastern Europe. The port of Magdeburg is the largest inland port of the New Federal States, with a port handling volume in 2008 of 3,086,559 t. Accordingly, the freight traffic centre in Magdeburg-Rothensee, an interface between rail, highway, and waterways, is becoming increasingly important.

Magdeburg Airport is suitable only for small aircraft, helicopters and gliders. The closest major 
airports are Leipzig/Halle, Berlin-Tegel, Berlin-Schönefeld, and Hanover. ${ }^{73}$

\section{Population}

Within the past 5 years, the city of Magdeburg has maintained a relatively constant population of about 230,000, as Fig. 17 illustrates. This is due to an even fluctuation balance. The negative balance of births and deaths was offset by the positive balance of immigration and emigration, as the following Tab. 21 shows.

Figure 17. Development of the population of Magdeburg 2004-2008

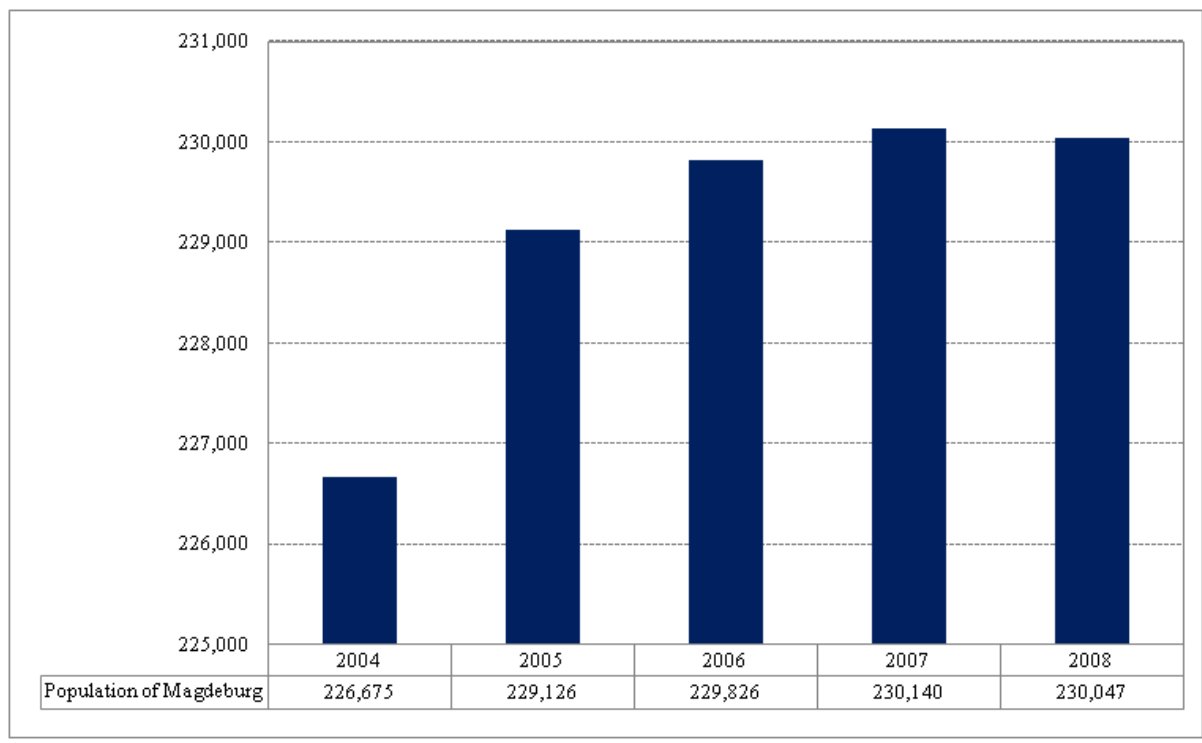

Source: Magdeburger Statistische Blätter Issue 73 (2009, p. 27)

The cause is an even fluctuation balance. The negative balance of births and deaths was offset by the positive balance of immigration and emigration, as the following Table 21 shows.

Table 21. Population fluctuation of Magdeburg 2004-2008

\begin{tabular}{llllll}
\hline Fluctuation balance & $\mathbf{2 0 0 4}$ & $\mathbf{2 0 0 5}$ & $\mathbf{2 0 0 6}$ & $\mathbf{2 0 0 7}$ & $\mathbf{2 0 0 8}$ \\
\hline People moving in & 9,454 & 12,120 & 10,093 & 10,243 & 10,429 \\
Births & 1,712 & 1,763 & 1,789 & 1,854 & 2,041 \\
Upturn & $\mathbf{1 1 , 1 6 6}$ & $\mathbf{1 3 , 8 8 3}$ & $\mathbf{1 1 , 8 8 2}$ & $\mathbf{1 2 , 0 9 7}$ & $\mathbf{1 2 , 4 7 0}$ \\
Deaths & 2,595 & 2,502 & 2,437 & 2,641 & 2,590 \\
People moving away & 9,431 & 8,930 & 8,746 & 9,143 & 9,971 \\
Downturn & $\mathbf{1 2 , 0 2 6}$ & $\mathbf{1 1 , 4 3 2}$ & $\mathbf{1 1 , 1 8 3}$ & $\mathbf{1 1 , 7 8 4}$ & $\mathbf{1 2 , 5 6 1}$ \\
\hline
\end{tabular}

Source: Magdeburger Statistische Blätter Issue 73 (2009, p. 29)

${ }^{73}$ Brochures on the key sectors of the Department of Economic Affairs of the City of Magdeburg. 
In Magdeburg, 132,000 households were reported in 2008, with an average household size of 1.74 persons. The average age of the population was 45.4 years, with a slightly increasing trend. The population structure in 2008 was 51.66 percent female and 48.34 percent male. ${ }^{74}$

\section{Employment and the economy}

Despite the relatively stable number of inhabitants in the period of 2004 - 2008 in Magdeburg, the number of unemployed has fallen steadily to 16,267 in 2008 , which is associated with a declining unemployment rate. The annual averages are shown in Figure 18. For the unemployment rate, the frame of reference is the labour force. ${ }^{75}$

Figure 18. Number of unemployed and unemployment rate on average 2004-2008

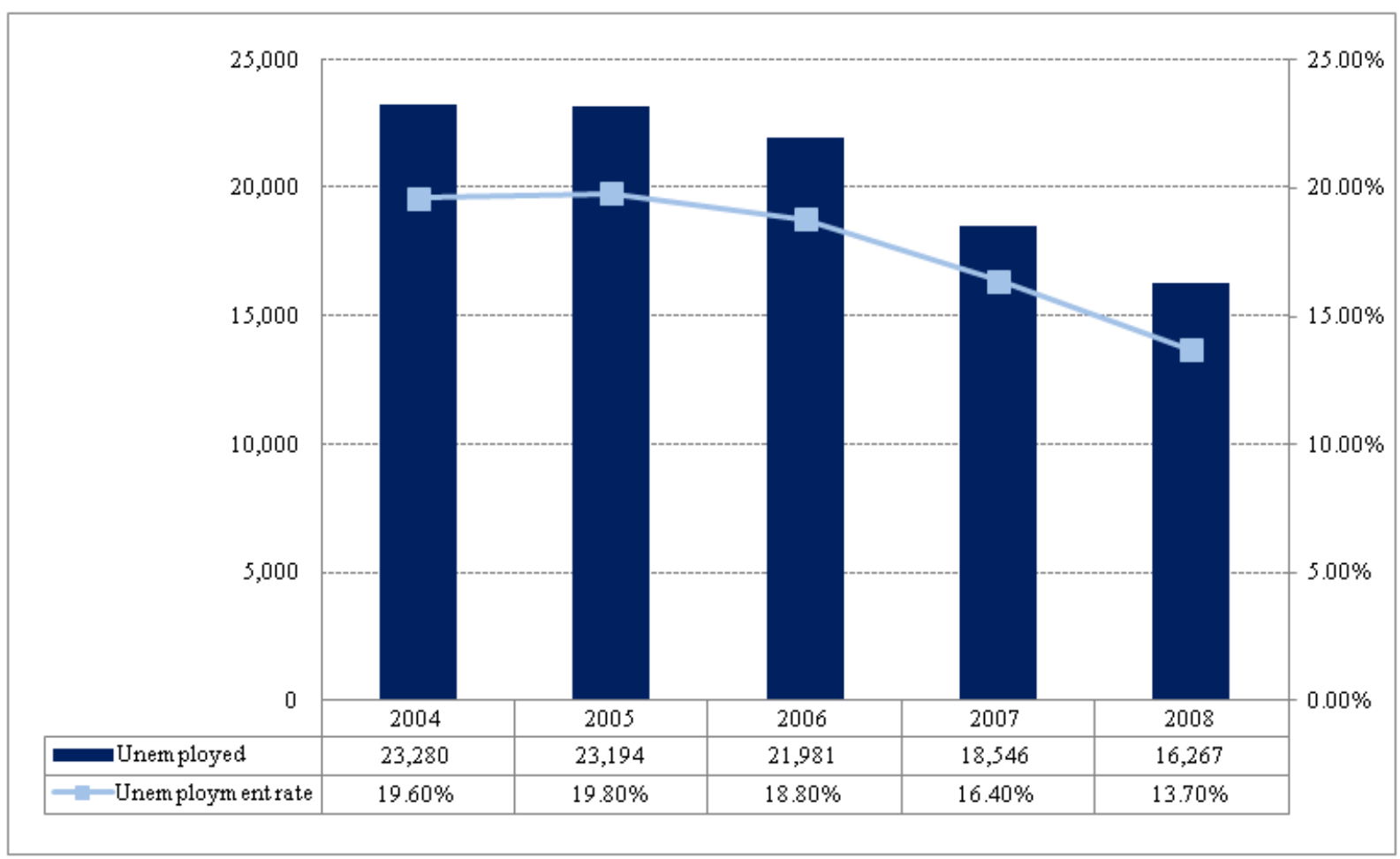

Source: Federal Employment Agency, Magdeburger Statistische Blätter Issue 73 (2009, p. 174)

Both, the absolute numbers of employed persons, ${ }^{76}$ as well as the number of salaried employees ${ }^{77}$

\footnotetext{
${ }^{74}$ Statistical Office of Magdeburg, Magdeburg Statistische Blätter, Issue 73 (2009, p. 44 pp.).

${ }^{75}$ The labour force comprises all persons residing in Germany who, during the period under investigation, perform activities that directly or indirectly generate funds or who are seeking such activities (self-employed, assisting family members, salaried workers), regardless of the attained income and without consideration of actually worked or contracted working hours. The labor force is composed of the employed and the unemployed. Source: Statistical Office of Saxony-Anhalt.
}

${ }^{76}$ An employee is anyone who is in a working relationship, either as a laborer, salaried employee, a civil servant, 
and the number of the self-employed ${ }^{78}$ at the location of Magdeburg have continuously increased over the last three years. An overview of the development is provided by Figure 19. Looking at the commuters among the persons subject to mandatory social insurance in the City of Magdeburg, it can be seen that Magdeburg has a positive commuter balance (surplus of 26,584 commuters, as of $6 / 30 / 2008)^{79}$ and, therefore, has a regional pull effect as a main commercial centre.

Figure 19. Absolute numbers of employed persons, number of salaried employees and number of the self-employed at the location of Magdeburg (2004-2007)

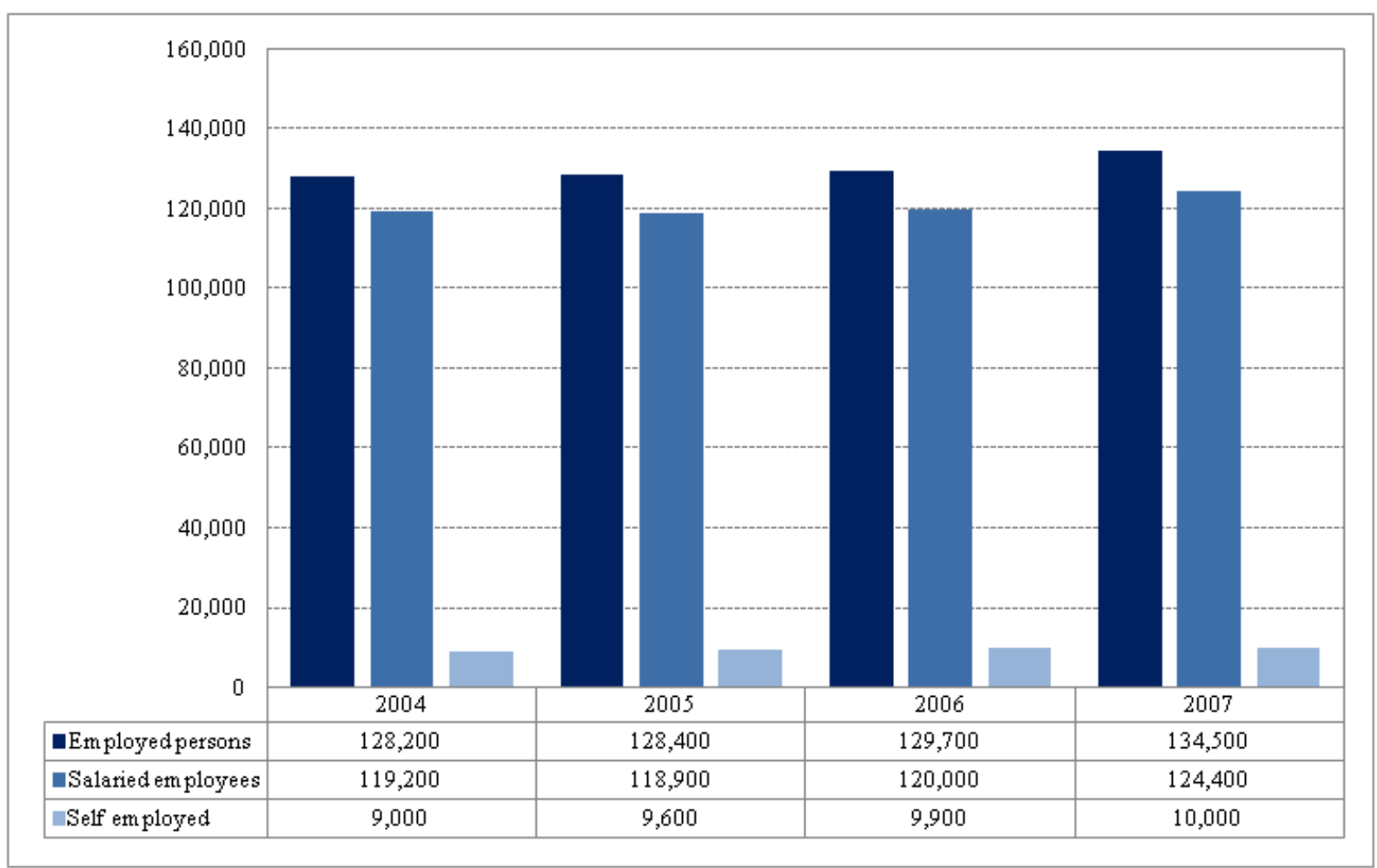

Source: Magdeburger Statistische Blätter Issue 73 (2009, p. 159)

judge, professional soldier, soldier on time, persons in the military as a result of conscription or rendering alternative civil service, trainees, interns or volunteers, and who primarily performs this activity. Homeworkers and persons with minor jobs are also included. Source: Statistical Office of Saxony-Anhalt

${ }^{77}$ An employee is anyone who is in a working relationship, either as a laborer, salaried employee, a civil servant, judge, professional soldier, soldier on time, persons in the military as a result of conscription or rendering alternative civil service, trainees, interns or volunteers, and who primarily performs this activity. Homeworkers and persons with minor jobs are also included. Source: Statistical Office of Saxony-Anhalt

${ }^{78}$ The self-employed include active owners and co-owners of sole proprietorships and private limited companies, independent farmers (including leaseholders), tradespeople, independent sales representatives, people working for their own business or on a freelance basis. Source: Statistical Office of Saxony-Anhalt.

${ }^{79}$ Statistical Office of Magdeburg, Magdeburger Statistische Blätter Issue 73 (2009, p. 170). 
The resulting share of self-employed persons based on the total number of employed persons working in the city of Magdeburg in 2007 is 7.4 percent. A higher value of 8.4 percent (May 2009) is given, if the share of self-employed is based on the place of residence of the civilian labor force. ${ }^{80}$

The percentage distribution of employed persons among the industries in Magdeburg, according to the place of work principle (2007 annual average), is illustrated in Fig. 20. Aggregating across industries, one can see that 86.4 percent of the workforce is employed in the service industry ${ }^{81}$ and only 13.5 in the manufacturing industry. ${ }^{82}$ Thus, Magdeburg can be characterized as a service-oriented regional commercial centre.

Figure 20. Percentage distribution of employed persons among the industries in Magdeburg (2007 annual average)

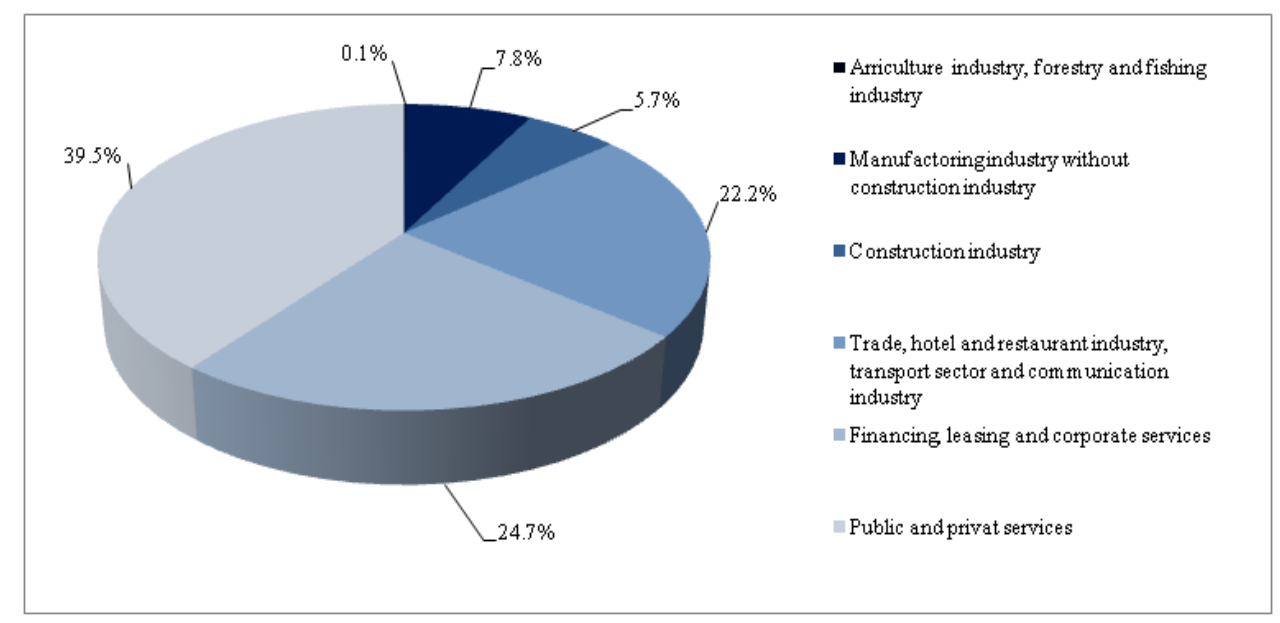

Source: Magdeburger Statistische Blätter Issue 73 (2009, p. 160)

The gross value added ${ }^{83}$ for industry sectors of Magdeburg is shown in Figure 21 for 2007. The total gross value added is 5,623 million EUR. The service sector accounts for 82.4 percent and the manufacturing industry for 17.5 percent of gross value added.

\footnotetext{
${ }^{80}$ Federal Employment Agency, Magdeburger Statistische Blätter Issue 73 (2009, p. 189).

${ }^{81}$ The service sector includes the following industries: Skilled trade, hotels and restaurants, transport and communications, financing, leasing, corporate services, public and private service providers.

${ }^{82}$ The manufacturing sector includes the following industries: Manufacturing industry (including processing but excluding construction), construction industry.

${ }^{83}$ The gross value added (GVA), evaluated in terms of production prices is the difference between production values and inputs in the individual industries. The GVA thus takes into account the subsidies received but not the taxes to be paid for products. Source: Statistical Office of Saxony-Anhalt.
} 
Figure 21. Percentage distribution of gross value added for the industry sectors of Magdeburg, (2007 annual average)



Source: Magdeburger Statistische Blätter Issue 73 (2009, p.205)

The number and distribution of the companies registered by the Chamber of Industry and Commerce (CIC) according to select industrial sectors of the economic areas of Magdeburg are illustrated in Table 22 below. In January 2009, the city had 12,438 CIC registered firms. Further 2,401 member firms were registered at the Chamber of Trade in 2008 (as on 12/31), of which 1,254 were trades subject to approval, 544 approval-free trades and 603 trade-like enterprises. ${ }^{84}$

\footnotetext{
${ }^{84}$ Chamber of Trade Magdeburg (Date: 31/12/2008), Magdeburger Statistische Blätter, Issue 7 (2009, p. 138).
} 
Table 22. Number of CIC enterprises in the city of Magdeburg, by industrial sectors

Industrial Sectors

Agriculture and forestry, fishery 18

Number of enterprises

Mining and quarrying

7

Manufacturing industry

314

Energy Supply

Water supply, sewage and waste disposal and pollution

control

58

Construction industry

Sales, maintenance and repair of motor vehicles

Transportation and storage

Hospitality industry

Information and communications

Provision of financial and insurance services

Real estate and housing services

Other

Total

12,438

Source: CIC Magdeburg (As on: January 2009), Magdeburger Statistische Blätter Issue 73 (2009, p. 134)

To further illustrate the corporate structure in the economic region of Magdeburg, Figure 22 below shows the distribution of employees subject to social insurance contributions among firms in Magdeburg, according to firm size.

Figure 22. Percentage of enterprises by employment categories

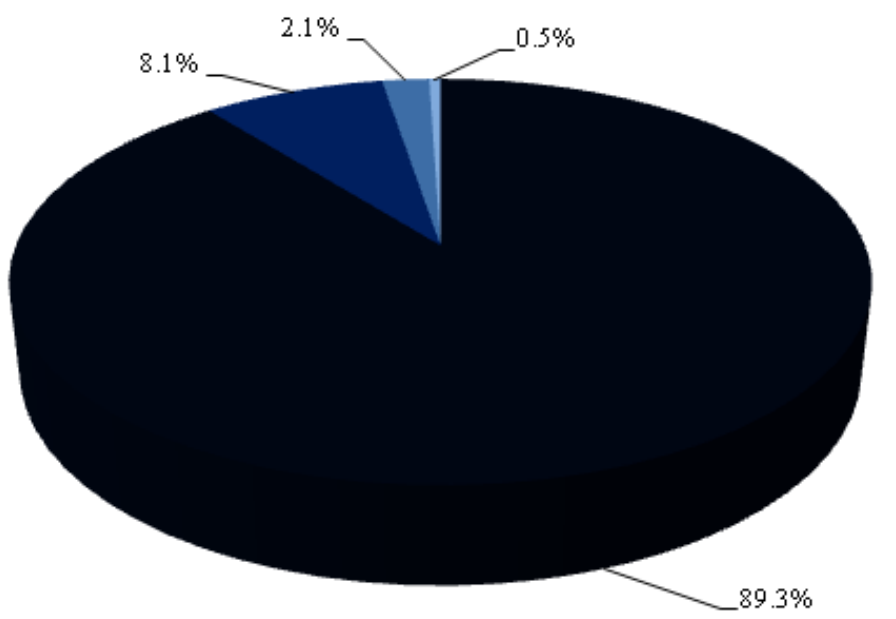

- Micro-sized enterprises

-Sm all firm s

- Medium-sized

enterprises

Large-scale enterprises 
The differentiation categories are as follows:

- Micro-sized enterprises: 0-9 employees

- Small firms: 10-49 employees

- Medium-sized enterprises: 50-249 employees

- $\quad$ Large-scale enterprises: $\geq 250$ employees

The corporate structure in Magdeburg is dominated by micro-and small-sized enterprises, which account for 97.4 percent of all businesses in Magdeburg. The small-scale corporate structure of the regional economy in Magdeburg underscores the importance of focusing the case study on small and new local enterprises.

In order to assess the economic performance of the city of Magdeburg, Figure 23 illustrates the development of the local GDP. ${ }^{85}$ In 2007 the GDP of the city of Magdeburg amounted to 6,274 million EUR.

Figure 23. Development of GDP in the city of Magdeburg 2004-2007

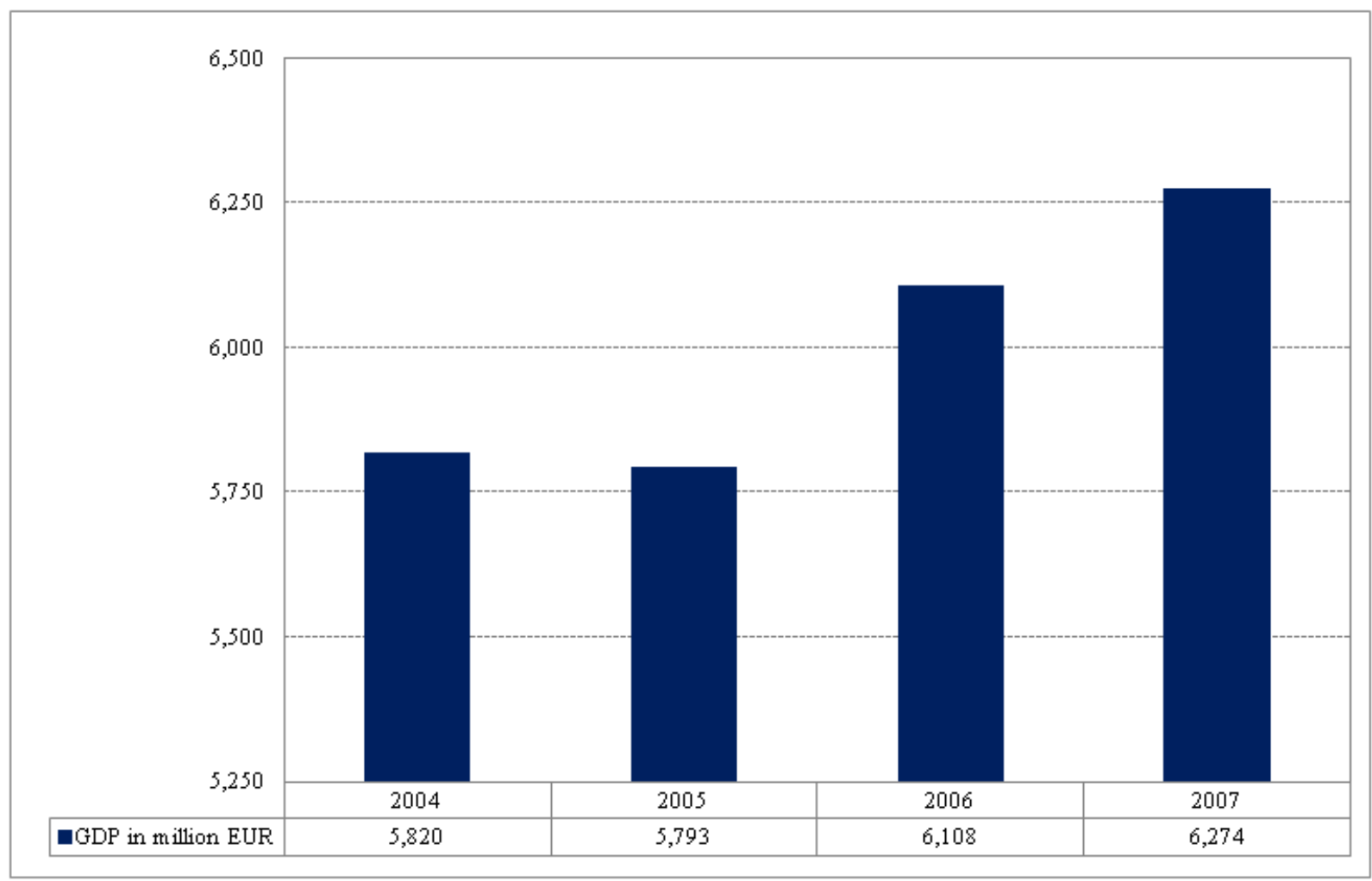

Source: Magdeburger Statistische Blätter Issue 73 (2009, p. 204)

${ }^{85}$ The GDP, valued at market prices, includes the value of goods and services produced of a defined economic area minus the goods used in production (inputs). The GDP thus includes product taxes, but excludes product subsidies. Source: Statistical Office of Saxony-Anhalt. 
The development of GDP per capita and per employee in Magdeburg for 2004 - 2007 is shown in Figure 24. In 2007, Magdeburg had a GDP per capita of 27,298 EUR and a GDP per employed person of 46,658 EUR. The GDP per capita shows a positive growth rate for $2005-2007$ similar to that of the GDP itself. In contrast, the GDP per employed person dropped slightly from 2006 to 2007.

Figure 24. GDP per inhabitant and per employed person in Magdeburg 2004-2007

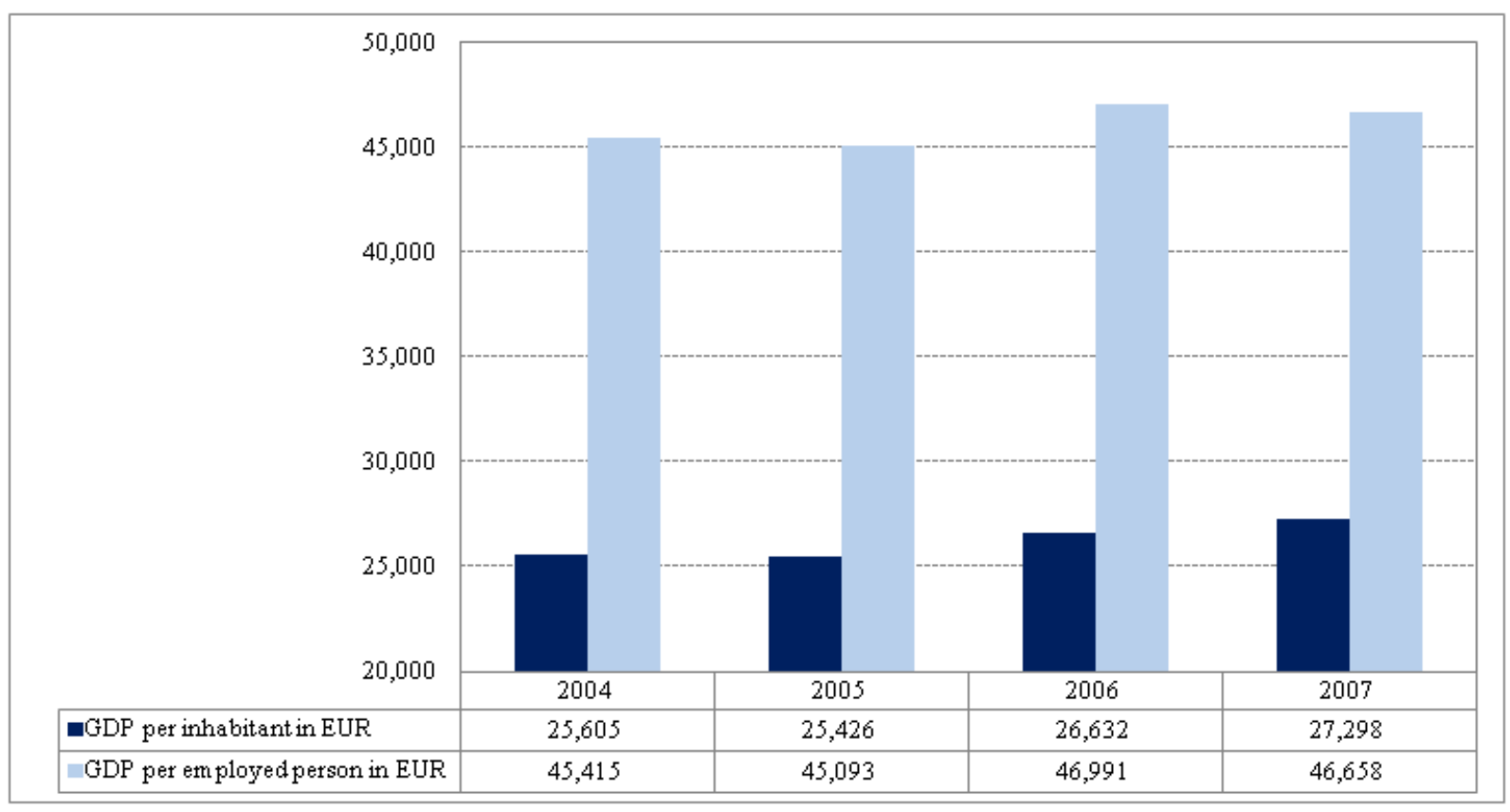

Source: Statistical Office of Saxony-Anhalt, Magdeburger Statistische Blätter Issue $73(2009$, p. 205)

\section{Science and research}

The economic area of Magdeburg features a large number of scientific institutions. The resident universities and research institutes of the Alliance of Scientific Organizations are engaged in basic research, applied research, as well as research and technology exchange.

\section{Universities}

With Otto-von-Guericke University and the Magdeburg-Stendal University of Applied Sciences, Magdeburg offers two institutions engaged in university education as well as basic and applied research. In addition, both universities have centralized structures to support knowledge transfer between the universities and local as well as regional commercial enterprises.

\section{Otto-von-Guericke-University Magdeburg}

Otto-von-Guericke University (OvGU) was created in 1993, uniting the former Magdeburg University of Applied Sciences, the Medical College and the Educational University. Today, students 
can study at nine different faculties - mechanical engineering, process and systems engineering, electrical engineering and information technology, computer science, mathematics, natural sciences, medicine, humanities, social sciences, pedagogy, and economics - and choose between 62 different study programs. The university places a strong research focus on neuroscience, dynamic systems, and automotive as fields of excellence at both the international and national level.

The Technology Transfer Center ${ }^{86}$ (TTZ), a centralized institute at Otto-von-Guericke University, currently with a staff of 10 , is a central communications and service hub for the University and the economy. With its core projects, the Research Portal Saxony-Anhalt ${ }^{87}$, the Trade Fair Portal "Research for the Future," the Research Catalog Magdeburg, and the Magdeburg job centre, the TTZ offers proven Internet platforms that support the knowledge transfer process. ${ }^{88}$

\section{Magdeburg-Stendal University of Applied Sciences}

The Magdeburg-Stendal University of Applied Sciences (HS MD-SDL) was founded in 1991. Students can choose between seven different departments, located at two sites (Magdeburg and Stendal). The departments of construction, engineering and industrial design, communications and media sciences, social services and healthcare, water and recycling management are located in Magdeburg; Applied Human Sciences and Economics are located in Stendal. Research and teaching are focused on the implementation of basic research, ranging from specific requirements in practice to product development within an extensive network of cooperative relations with the economy and with social service institutions.

The Technology and Knowledge Transfer Centre (TWZ), currently with a staff of 2, is a central institute of the university, located within the Research and Development Centre (RDC). ${ }^{89}$ It is the main point of contact for enterprises and institutions in the region, and it acts as the interface to the various departments of the university. ${ }^{90}$

\section{Students}

At both tertiary education locations ${ }^{91}$ of the city of Magdeburg, the number of students remained

\footnotetext{
${ }^{86}$ www.ttz.uni-magdeburg.de.

${ }^{87}$ www.forschung-sachsen-anhalt.de

${ }^{88}$ www.uni-magdeburg.de.

${ }^{89}$ www.fez-magdeburg.de.

${ }^{90}$ www.hs-magdeburg.de.

${ }^{91}$ Note that the total number of students at the Magdeburg-Stendal University of Applied Sciences includes those at the Stendal location, which, during the winter semester 2008/2009, made up 28 percent of the total student body at the University.
} 
almost constant at the beginning of the 2004/2005 - 2008/2009 winter semesters: at just fewer than 20,000 , with a currently slightly increasing trend. At the time of the 2008/2009 winter semester, approximately 67.5 percent of all students in Magdeburg were enrolled at the OvGU. Related to the overall population of Magdeburg, the student proportion, in 2008, was about 8.6 percent of the total population.

Figure 25. Number of students at the universities of Magdeburg during the 2004/2005-2008/2009 winter semesters



Source: OvGU and HS MD-SDL, Magdeburger Statistische Blätter Issue 73 (2009, p. 90)

\section{Competence Network for Applied and Transfer-Oriented Research (KAT)}

The "Competence Network for Applied and Transfer-Oriented Research" (KAT) is a joint initiative of the universities in the state of Saxony-Anhalt and the Ministry of Education and Cultural Affairs. The services offered by the KAT community, among others, include the conducting of market and feasibility studies, the establishment of research and development partnerships (R\&D), the implementation of $R \& D$ projects, the development and implementation of continuing education programs, the acquisition of interns, undergraduates and graduates, and the provision of laboratory equipment. The founding members of the KAT-network were the Anhalt University of Applied Sciences, Harz University of Applied Sciences, Magdeburg-Stendal University of Applied Sciences, and Merseburg University of Applied Sciences. In 2009, the Martin-Luther University HalleWittenberg, the Otto-von-Guericke-University Magdeburg, and the Burg Giebichenstein School of Arts and Design were integrated into the KAT community. ${ }^{92}$ The KAT-network conceives itself as an important partner for companies, business- and social-networks. The universities of the KAT network maintain contacts to over 400 mostly regional enterprises and institutions. In 2009, 157 major projects

\footnotetext{
${ }^{92}$ www.kat-netzwerk.de.
} 
were executed, with a total budget for the colleges or nearly 8 million EURs. By networking the four competence centers and other existing centers at the universities, such as the Technology Transfer Centre (TTZ) of OvGU, it was possible to generate a sound basis for demand-driven applied research and development. ${ }^{93}$

\section{Research institutes of the Alliance}

The Alliance of Research Institutes of Magdeburg includes the Max-Planck-Institute for Dynamics of Complex Technical Systems (MPI), the Fraunhofer Institute for Factory Operation and Automation (IFF), the Leibniz Institute for Neurobiology (IFN) and the Helmholtz Center for Environmental Research ( UFZ).

\section{Max-Planck-Institute (MPI)}

Founded in 1996 within the vicinity of Otto-von-Guericke University, the Max-Planck-Institute for the Research of Dynamics of Complex Technical Systems (MPI) serves as a bridge between basic engineering research and industrial applications. The focus is on the study and optimization of highly complex systems, which are becoming increasingly important and more widely spread in both chemical and biological process engineering. The MPI Magdeburg currently employs a staff of 234 and is complemented by visiting researchers. ${ }^{94}$

\section{The Fraunhofer-Institute for Factory Operation and Automation (IFF)}

The Fraunhofer-Institute for Factory Operation and Automation (IFF) is an independent institute of the Fraunhofer-Association. Since 1998, the IFF has been located next to the Max-Planck-Institute. In 2006 the Institute was expanded to include the Virtual Development and Training Center (VDTC) located in the Magdeburg Science harbor by the river Elbe. The VDTC specializes in the application of the latest research in the field of Virtual Reality. Solutions in the fields of Logistics, Virtual Engineering, Automation and Systems Engineering are developed at the VDTC for a variety of customers (SME, industry, research and politics). At the end of 2008, the Fraunhofer Institute had 147 employees. $^{95}$

\section{Leibniz-Institute for Neurology (IfN)}

In 1992, the Leibniz-Institute for Neurology (IfN) was established on the grounds of the Medical Faculty of Otto-von-Guericke as a basic research institute dedicated to research on the mechanisms of learning and memory. The IFN is a member of the Leibniz Association (consisting of 86 institutions

\footnotetext{
${ }^{93}$ www.kat-kompetenznetzwerk.de.

${ }^{94}$ www.mpi-magdeburg.de.

${ }^{95}$ www.iff.fraunhofer.de.
} 
that engage in research or provide an academic infrastructure) ${ }^{96}$ Based in Magdeburg, the Leibniz Institute of Neurobiology is one of the most important sites of brain research in Europe. In the Magdeburg institute, one can find the only 7-Tesla MRI in Europe, which is used exclusively for research purposes. ${ }^{97}$

\section{Helmholtz-Center for Environmental Research}

Founded in 1991, the Helmholtz-Center for Environmental Research (UFZ), with its locations in Leipzig, Halle and Magdeburg, has over 900 employees. The scientists who work at the UFZ are active in research on the causes and consequences of environmental changes. Their tasks include the visualization of complex systems and connections as well as the provision of tools and strategic plans for politics, economy and society, in order to improve decision making in this field. ${ }^{98}$

Table 23. Research institutes of the Alliance

\begin{tabular}{|c|c|c|c|c|}
\hline Name & Main research areas & $\begin{array}{c}\text { Number of } \\
\text { staff }\end{array}$ & $\begin{array}{c}\text { Knowledge } \\
\text { transfer links with } \\
\text { local firms }\end{array}$ & $\begin{array}{c}\text { Knowledge } \\
\text { transfer links with } \\
\text { local universities }\end{array}$ \\
\hline $\begin{array}{c}\text { Max-Planck- } \\
\text { Institute }\end{array}$ & $\begin{array}{l}\text { Physical and Chemical } \\
\text { Process Engineering, } \\
\text { Process Synthesis and } \\
\text { Process Dynamics }\end{array}$ & 234 & Y & Y \\
\hline $\begin{array}{c}\text { Fraunhofer- } \\
\text { Institute }\end{array}$ & $\begin{array}{l}\text { Logistics, Virtual Reality, } \\
\text { Systems Engineering, } \\
\text { Automation }\end{array}$ & 147 & Y & Y \\
\hline Leibniz-Institute & $\begin{array}{l}\text { Auditory Learning and } \\
\text { Speech, Neurochemistry } \\
\text { and Molecular Biology, } \\
\text { Neurophysiology and } \\
\text { Behavioral Neurology }\end{array}$ & 269 & $\mathrm{~N}$ & Y \\
\hline Helmholtz-Center & $\begin{array}{c}\text { Environmental } \\
\text { Technology, Terrestrial } \\
\text { Ecology, Social Science }\end{array}$ & 80 & $\mathrm{~N}$ & $\mathrm{~N}$ \\
\hline
\end{tabular}

Source: Company survey (all information in the table only refers to the present study).

\footnotetext{
${ }^{96}$ www.leibniz-gemeinschaft.de.

${ }^{97}$ www.ifn-magdeburg.de.

${ }^{98}$ www.ufz.de.
} 


\section{INDUSTRY DESCRIPTION}

The Association for Economic Services of Magdeburg (GWM) is a service offered by the city to companies in the region, with the following priority sectors:

- Mechanical and Systems Engineering

- Healthcare

- Environmental Technology and Recycling Management

A case study commissioned by the city of Magdeburg in 2001, on "Strategic reorientation of business development activities in the state capital of Magdeburg," was crucial for the definition of priority sectors.

The area of responsibility of the GWM is the provision of information between science, politics and business, in order to match suitable partners in the priority sectors and to facilitate the implementation of cooperation agreements and projects. The aim is to strengthen the competitiveness of enterprises in the priority sectors within the region of Magdeburg. For these tasks, a network management for each priority sector was installed in $2003 .{ }^{99}$ In this case study, these priority sectors will be analyzed, in the light of the economic policy mission of the GWM, with regard to the relevance of knowledge transfer networks for new and small local enterprises in the economic area of Magdeburg. With its analysis of cluster potentials in 2008, the state of Saxony-Anhalt has identified own clusters ${ }^{100}$ that, both geographically (state level/municipal level) and in terms of content, are not congruent with the priority sectors in Magdeburg. At the state level, a greater differentiation of the cluster's own industrial sectors was made than at the municipal level. For the purpose of this study, several state clusters will, therefore, be merged into the structure of the priority sectors at the municipal level of Magdeburg. For the characterization of the three main industries under investigation in Magdeburg, the following factors will be taken into account:

- Number of enterprises in the priority sector

- Value-added activities of the priority sectors in 2001 (case study "Strategic reorientation of economic development activities of the state capital of Magdeburg").

\footnotetext{
${ }^{99}$ www.gwm-magdeburg.de.

100 "A cluster refers to a geographic concentration of interconnected companies and institutions in a given industrial sector.” Cluster potential analysis of Saxony-Anhalt (2008, p. 4); own translation.
} 
- Relevant clusters at the state level

- Existing infrastructure

The value-added activities identified within the priority sectors of Magdeburg were continually developed and expanded. A significant influence was exerted by the subsequent establishment of the clusters at the state level. The R\&D projects initiated and implemented in these clusters are of crucial importance for the further development of value-added activities. At the same time, substantial investments were made by public and private institutions at the state and municipal level, in order to provide network members with the necessary research and development infrastructure. This remains an ongoing process.

\section{Mechanical and systems engineering}

Magdeburg has a long history in the field of mechanical and systems engineering. Up to the fall of the Berlin wall in 1989, Magdeburg as a business location was characterized by mechanical engineering (especially heavy mechanical engineering). Large conglomerates made up the organizational structure of this industry, which was then broken up and fragmented after German reunification. Within a short time, new structures formed, with new firms, innovative technologies and products emerging. ${ }^{101}$

Today, mechanical and systems engineering, the main industrial sector in Magdeburg, comprises approximately 120 CIC companies. According to the Chamber of Industry and Commerce key, these companies are distributed between the various fields of a given industrial sector. The CIC sector data used for this study, for the main industrial sector, mechanical and systems engineering, can be seen in Figure 26 below. Compared with the same period of the previous year, the number of CIC enterprises in this key sector has increased from 118 to 120.

\footnotetext{
${ }^{101}$ www.gwm-magdeburg.de.
} 
Figure 26. Numbers of firms in mechanical and systems engineering, the CIC main industrial sector in the economic region of Magdeburg

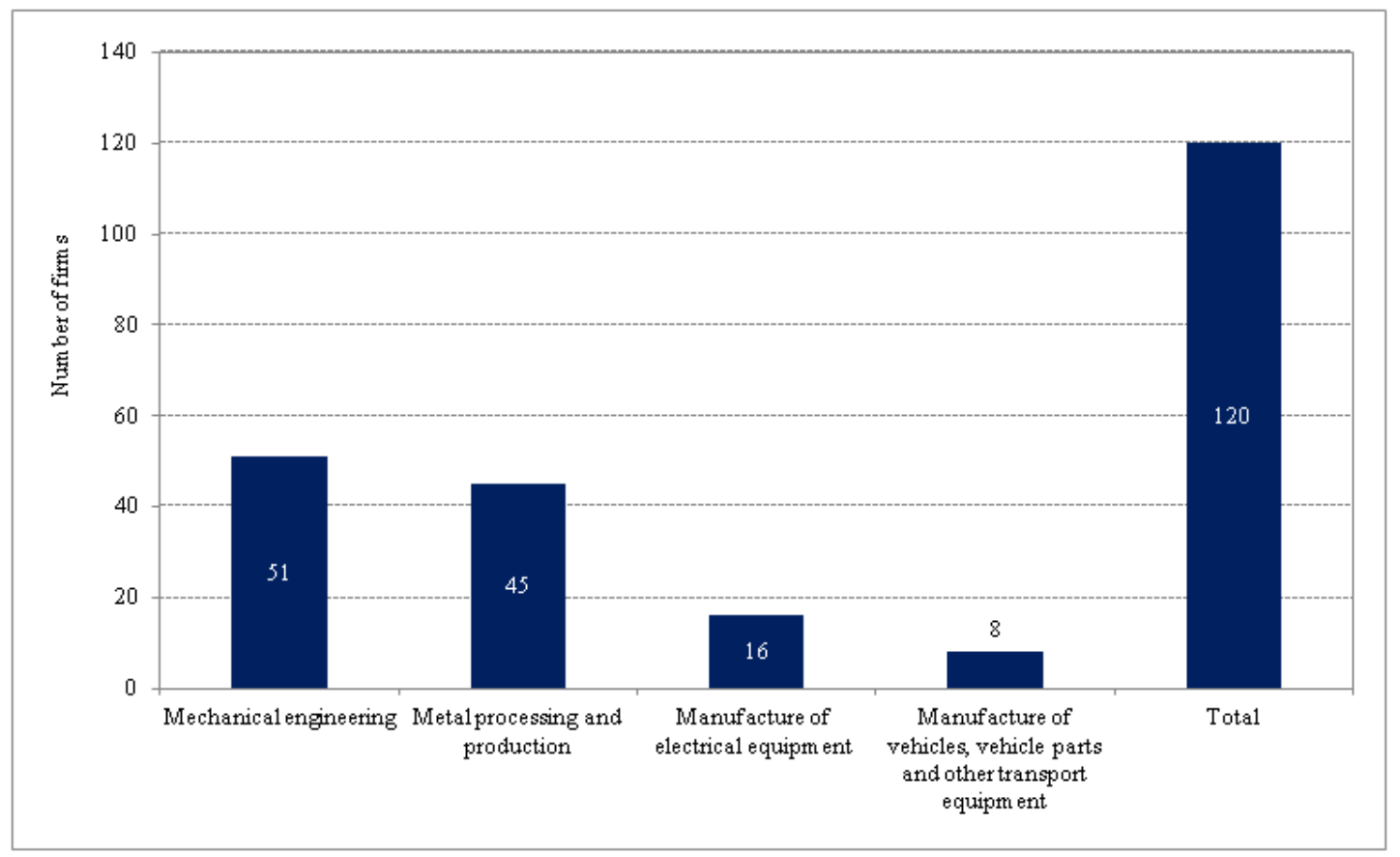

Source: CIC Magdeburg (January 2010)

The value-adding activities of the main industrial sector, mechanical and systems engineering, are shown in Figure 27. The potential for this economic sector as a priority sector was identified in 2001 and, in consequence, a network management for this priority sector was installed by the GWM in 2003 in the form of a project coordinator. The sector mechanical and systems engineering is not a closed network; there are also significant external contributions at the state level by the automotive cluster and the cluster for special mechanical and systems engineering. This has led to a continuous enhancement of the value-adding activities through specialization and differentiation.

After the presentation of the value-adding activities of the main industrial sector, mechanical and systems engineering, there will be a brief description of the state clusters in terms of their prolific focal areas, with reference to the widely used programs for the implementation of R\&D projects. In addition, an overview of the existing infrastructure, which serves as a catalyst for the implementation of these projects, will be provided. 
Figure 27. Value-adding activities of the main industrial sector, mechanical and systems engineering



Source: Source: ExperConsult (2001, p. 17)

\section{Automotive Cluster}

The Automotive cluster in Saxony-Anhalt is named MAHREG Automotive, and it comprises a competence network of automobile suppliers in Saxony-Anhalt, ${ }^{102}$ with the Saxony-Anhalt Automotive Association (SAA e.V) as its umbrella organization. MAHREG Automotive originated from a regional enterprise project (Unternehmen Region-Initiative) funded by the Federal Ministry for Education and Research (BMBF) as part of a regionally focused East German competition (Innovative Impulse für die Region). As project administrator, the SAA e.V., which is financially supported by the state of Saxony-Anhalt (GRW grant), is responsible for the cluster management. The core competencies of the automotive suppliers in the cluster are in light metal casting, high-performance composite materials, and plastics engineering. The cluster focuses on the development of innovations, their effective market implementation, and the alignment of the cluster with the demands of the international automotive market. At present, the network comprises over 170 partners from industry (suppliers, equipment suppliers and business services) and science (universities, colleges and research institutions). To ensure the sustainable positioning of the cluster and in order to strengthen the

\footnotetext{
${ }^{102}$ Innovation strategy 2013 (p. 8); Cluster potential analysis Saxony-Anhalt (2008, p. 37, 43).
} 
Magdeburg location, MAHREG Automotive is a member of the Automotive Cluster of East Germany (ACOD) and, therefore, also involved in cross-border initiatives of the automotive industry. ${ }^{103} \mathrm{R} \& \mathrm{D}$ projects that have emerged from the cluster originated from different programs, such as the innovation cluster of the Fraunhofer Gesellschaft, ${ }^{104}$ ZIM NEMO ${ }^{105}$ and innovative regional growth centers. ${ }^{106,107}$ Of these three programs ZIM NEMO is most relevant for knowledge networks for the economic region in Magdeburg, as the expert interviews (cf. Ch. 6) show.

\section{Special Mechanical and Systems Engineering Cluster (SMAB)}

The Special Mechanical and Systems Engineering Cluster (SMAB) operates statewide and is supervised by the state funded (GRW grant) the Technology Transfer and Innovation Company Magdeburg (tti), which is responsible for the cluster management. The strength of this cluster lies particularly in precision mechanical engineering and systems engineering. In addition, the cluster's structure is strongly determined by the development of centers specialized in large parts machining for the production of wind turbines, lifting and handling equipment, as well as construction machinery and mining equipment. The cluster management focuses on the reinforcement of collaboration in development and production co-operations. Accordingly, there are also joint activities between the automotive cluster and the cluster for renewable energy. At present, there are around 90 firms as well as scientific partners in the special mechanical and systems engineering cluster. ${ }^{108}$ Several R\&D programs have been initiated and supported by the cluster: ZIM NEMO ${ }^{109}$, Innovation forums ${ }^{110}$, InnoProfile ${ }^{111}$ and innovative regional growth centers. ${ }^{112,113}$

\footnotetext{
103 www.mahreg.de.

${ }^{104}$ Fraunhofer Innovation Cluster VIDET - Virtual Development, Engineering and Training for regional large-scale equipment and systems engineering, www.vdtc.de.

105 e.g., INNO-E-Mobile and MIM-NET.

106 e.g., Thale PM - Thalenser Pulvermetallurgie.

${ }^{107}$ Appendix 4, Innovation strategy 2013.

${ }^{108}$ www.cluster-smab.de.

${ }^{109}$ e.g., fluidized bed - high temperature granulation and InnFütecRS.

${ }^{110}$ e.g., electron beam technology and fluidized bed technology.

111 e.g., NaWiTec - Fluidized bed process.

112 e.g., WIGRATEC and ALFA - Allianz Faserverbunde.

${ }^{113}$ Appendix 4, Innovation strategy 2013.
} 


\section{Infrastructure}

The available infrastructure for the active firms in the main industrial sector of mechanical and systems engineering is provided by the following centers: ${ }^{114}$

- $\quad$ VDTC - Virtual Development and Training Center, Magdeburg ${ }^{115}$

- $\quad \mathrm{CCC}-$ Competence and Creativity Center, Harzgerode ${ }^{116}$

- PIZ IF Rota - Product Development and Innovation Center, Magdeburg

- $\quad$ PMC - Powder Metallurgy Competence Center, Thale ${ }^{117}$

- $\quad$ EXFA - Experimental Factory, Magdeburg ${ }^{118}$

- $\quad$ IGZ - Innovation and Founder Center, Magdeburg ${ }^{119}$

As an additional component, the newly established Institute for Competence in Auto Mobility (IKAM) will be available to companies of the automotive and the special mechanical and systems engineering cluster. Future priorities of the institute include alternative propulsion systems, automotive lightweight construction with novel materials and innovative processes, product miniaturization and electric vehicles, including fuel cells and energy storage.

\section{Healthcare}

The healthcare industry priority sector for the economic region of Magdeburg comprises a variety of industrial and value-adding sectors. The interaction of the participating economic sectors in the healthcare industry - before the introduction of a network management by the GWM as project coordinator in 2003 - is illustrated in Figure 28 below.

\footnotetext{
${ }^{114}$ Appendix 4, Innovation strategy 2013.

115 www.vdtc.de.

${ }^{116}$ www.ccc-harzgerode.de.

${ }^{117}$ www.pmc-thale.de.

118 www.exfa.de.

${ }^{119}$ www.igz-md.de.
} 
Figure 28. Value-adding areas of healthcare industry priority sector

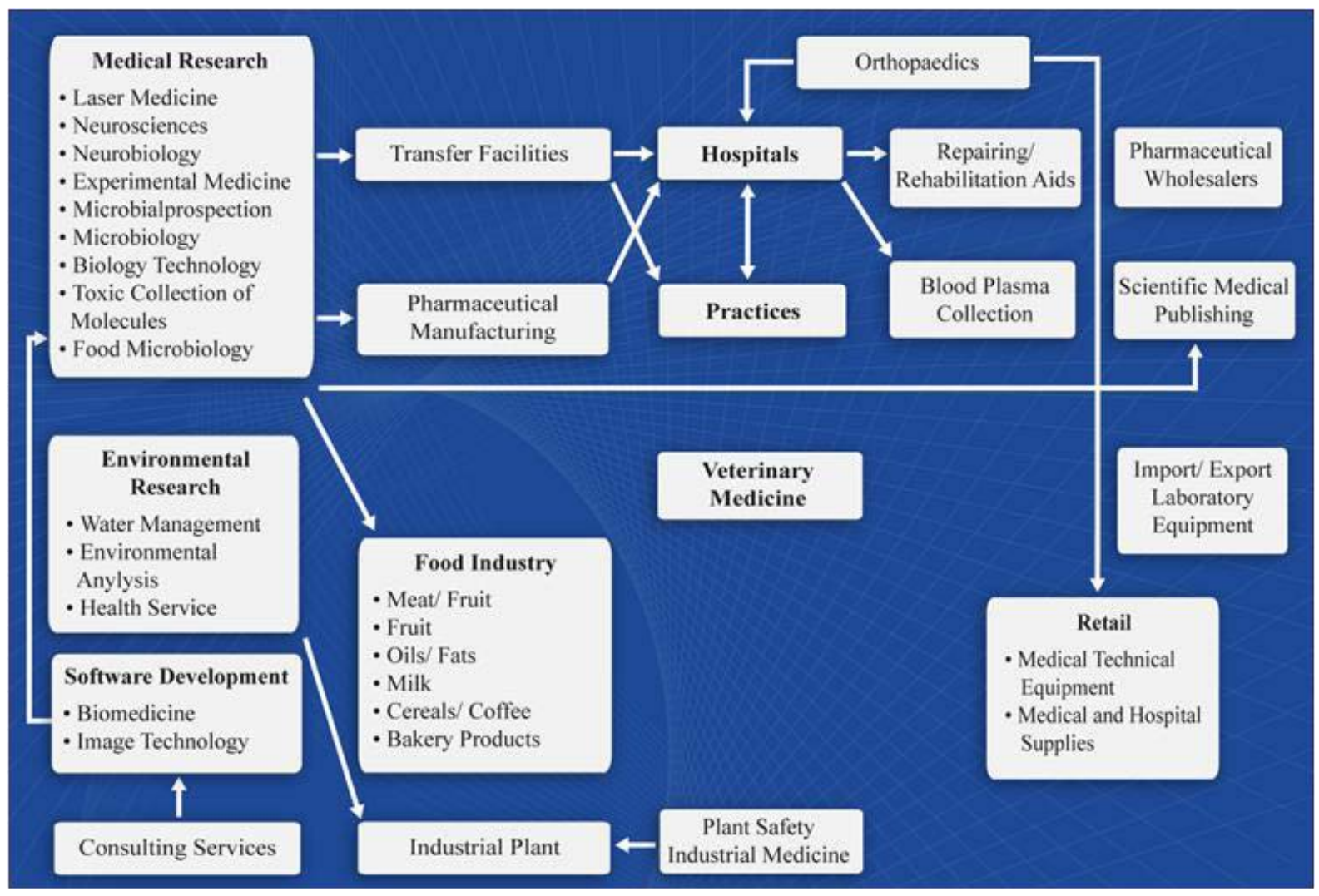

Source: ExperConsult (2001, p. 17)

Aside from the traditional fields of pharmaceutical manufacturing or hospitals and ambulances for the economic region of Magdeburg, medical research is also of fundamental importance. The institutions of basic research are among the world's leading in their fields and are also attractive training locations. The important research institutes of the healthcare industry priority sector are

- Otto-von-Guericke-University Magdeburg (Faculty of Medicine with 22 institutions, 29 hospitals and 40,000 in-patients), main areas of research: neuroscience, immunology, including molecular medicine, inflammation, medical engineering

- Magdeburg-Stendal University of Applied Sciences (Department of Chemistry/ Pharmaceutical Engineering), Research priorities: biotechnology, genetic engineering, hydrochemistry

- Leibniz-Institute, Research priority: neurobiology

- Max-Planck-Institute, Research topic: modeling and control problems in human medicine

- Fraunhofer-IFF, Development of complex robotics and handling systems for the automation of laboratory and manufacturing processes

The biotechnology and medical engineering cluster at the state level, the Network for Neuro- 
Medical Engineering (InnoMed), and the companies consolidated as PharmaMD ${ }^{120}$ have all contributed to the potential of Magdeburg's healthcare priority sector in the fields of biotechnology, medical engineering and pharmaceutics. The focused implementation of R\&D projects within these networks, in conjunction with the creation of a special infrastructure, has led to a significant development of value-adding activities. Within the healthcare priority sector, 175 companies can currently be identified for the economic region of Magdeburg (cf. Fig. 29). However, according to the CIC industry key, these also include firms offering social service. A detailed breakdown of enterprises into the fields of medical engineering, pharmaceutics and biotechnology is not available.

Figure 29. Number of enterprises in the healthcare and social service sector in Magdeburg

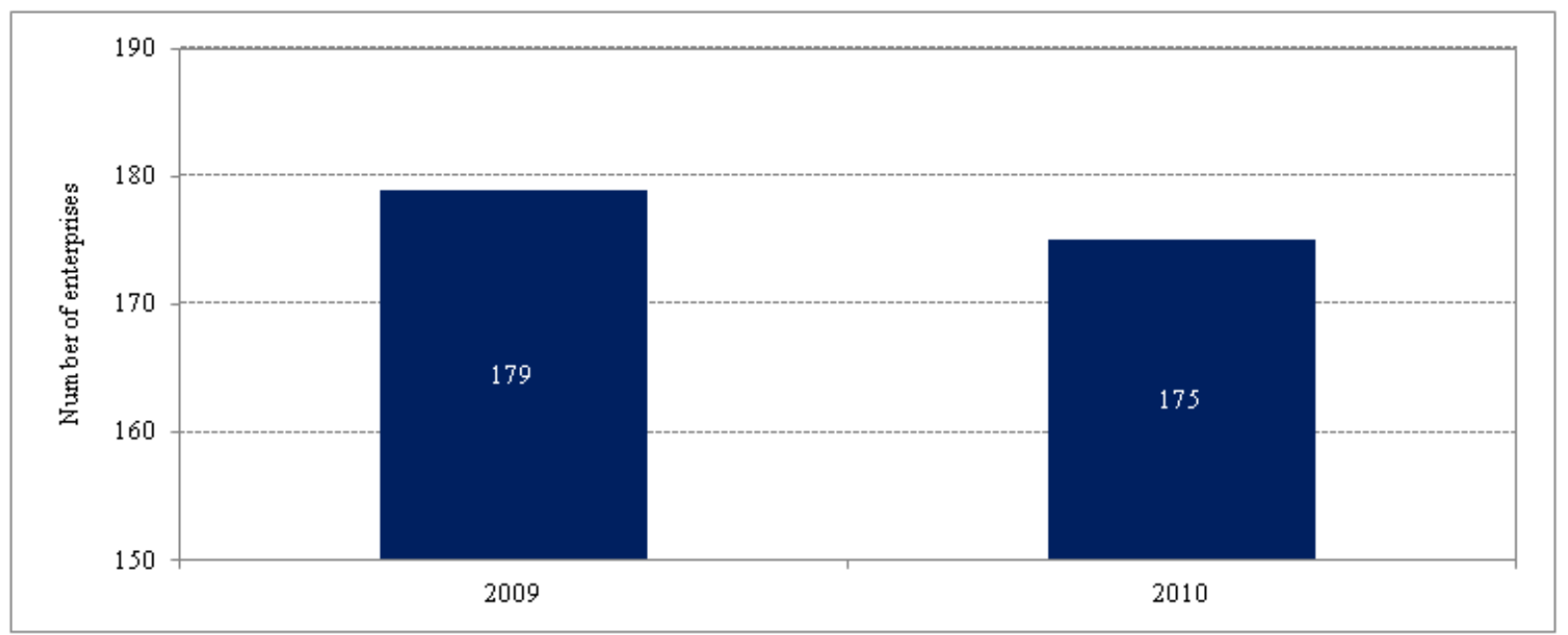

Source: CIC Magdeburg (January 2010)

\section{Biotechnology and Pharmaceutics Cluster}

As part of the implementation strategy concerning the biotechnology initiative of Saxony-Anhalt, BIO Mitteldeutschland GmbH has taken on the cluster's management since 2003. The BIO Mitteldeutschland $\mathrm{GmbH}$ is an amalgamation of around 20 firms and institutions in the field of biotechnology. The cluster management makes an important contribution to the promotion of biotechnology in central Germany and, as part of an interstate cooperation, supports the LifeScience/Biotechnology Cluster in Central Germany. ${ }^{121}$ Furthermore, the cluster management handles important networking tasks between parties in the economy, science, and politics. Biotechnology and genetic engineering can be divided into the following areas: green (food and agriculture), red (health and pharmaceutics) and white (use of cells and enzymes for the industrial production of pharmaceutical, chemical and other products). ${ }^{122}$ The specialization of the research environment in

\footnotetext{
${ }^{120}$ Innovative Regional Growth Core as part of the program “Unternehmen Region,” www.unternehmen-region.de.

${ }^{121}$ www.cluster-mitteldeutschland.de.

${ }^{122}$ www.biomitteldeutschland.de.
} 
Magdeburg is in red biotechnology. Completed $R \& D$ projects in this cluster come from the $R \& D$ programs InnoRegio, ${ }^{123}$ innovative regional growth cores, ${ }^{124}$ ZIM NEMO, ${ }^{125}$ and InnoProfile. ${ }^{126,127}$

\section{Medical Engineering Cluster}

As a result of the cluster potential analysis in Saxony-Anhalt, medical engineering has been identified as a cluster with state-wide potential. The reasons for this are the high-profile and wellinterlinked research environment and an extensive infrastructure with excellent technical equipment. One must also emphasize the available expertise in the field of neuroscience, where an internationally renowned research platform has been created. ${ }^{128}$ Other research areas are dynamic systems in biomedicine and process technology. A state-wide cluster management has not yet been implemented. However, even without this catalyst of knowledge exchange, it has been possible to complete R\&D projects within the following programs: InnoProfile, ${ }^{129} \mathrm{ZIM} \mathrm{NEMO},{ }^{130}$ Innovation Forum, ${ }^{131}$ and ForMaT. ${ }^{132,133}$

\section{Network InnoMed}

InnoMed, the Network for Neuromedical Engineering in the economic region of Magdeburg, is supported by the InnoMed e.V. Association. This network has emerged from research institutions and, since its foundation in 2000, has grown to a total of more than 40 members (mainly SME from the region). Its core responsibility is the combination of high-standard scientific competence in the field of neuroscience at the Magdeburg location with modern medical engineering developments contributed by industry partners.

Between 2002 and 2006, the establishment and development of InnoMed was supported by grants

\footnotetext{
${ }^{123}$ e.g., INNOPLANTA und INNOMED.

${ }^{124}$ e.g., recombinant proteins.

125 e.g., Innogas and CellTechBioReactor.

${ }^{126}$ e.g., Binding proteins.

${ }^{127}$ Appendix 4, Innovation strategy 2013.

${ }^{128}$ Center for Behavioral Brain Sciences (CBBS), Cluster potential analysis Saxony-Anhalt (2008, p. 64).

${ }^{129}$ e.g., INKA.

${ }^{130}$ e.g., MicroMed and VIRTOP Magdeburg.

${ }^{131}$ e.g., ASTER - Akut-Schlaganfall-Versorgung-Telemedizin im Rettungswagen.

132 e.g., TASC - Telemedical Acute Stroke Care (tasc.telestroke.net)

${ }^{133}$ Appendix 4, Innovation strategy 2013.
} 
from the Federal InnoRegio program, through which 17 scientific collaborative projects could be implemented. In addition, the state of Saxony-Anhalt, co-funded by the European Social Fund (ESF), supported pilot projects from 2001 - 2007 for post-graduate qualification in medical engineering. The objective was the further regional development of medical engineering and the creation of jobs with new task profiles. ${ }^{134}$

Currently, InnoMed e.V. is headquartered at the GWM which also organizes the project coordination of the healthcare priority sector. The resulting synergies are reflected, for example, in the implementation of innovation forums.

\section{Infrastructure}

All firms and institutions that are part of the healthcare priority sector have access to the following infrastructure facilities:

- IGZ Inno-Life (innovation and startup center in the field of healthcare and social services). ${ }^{135}$

- ZENIT (Center for Neuroscience Innovation and Technology). ${ }^{136}$

\section{Environmental technology and recycling management}

In recent years, the areas of environmental technology and recycling management have become important industries in the economic region of Magdeburg. Yet, the value-adding activities in the two sectors, as shown in Figure 30, were already outlined in a case study of 2001 titled "strategic reorientation of business development activities of the state capital Magdeburg”.

\footnotetext{
${ }^{134}$ www.innomed-magdeburg.de.

135 www.inno-life.de.

${ }^{136}$ www.zenit-magdeburg.de.
} 
Figure 30. Value-adding activities in the priority sector of environmental technology and recycling management



Source: ExperConsult (2001, p. 19)

On this basis, the GWM merged the two fields into the environmental technology and recycling management priority sector in 2003 and established a project coordination site for the economic region of Magdeburg.

The number of enterprises in the priority sector of environmental technology and recycling management in the economic region of Magdeburg is illustrated in Figure 31. According to the CIC industry key, the sectors of energy supply, water supply, sewage and waste disposal, as well as pollution control, were all combined into one priority sector. Currently, the number of enterprises categorized within this unified priority sector is 120 .

Decisive for the further development of value-adding activities within the priority sector are also the Renewable Energies Cluster at the state level, the Renewable Resources Coordination Site Saxony- 
Anhalt (KoNaRo - Koordinierungsstellungstelle Nachwachsende Rohstoffe Sachsen-Anhalt), ${ }^{137}$ the Regional Center of Competence for Renewable Resources Saxony-Anhalt (ZERE e.V.), the Network for Renewable Resources Saxony-Anhalt (NAROSSA e.V. - Netzwerk Nachwachsende Rohstoffe Sachsen-Anhalt e.V.), and the Association for the Promotion of Recycling Management (FGK e.V. Fördergemeinschaft Kreislaufwirtschaft e.V.).

Figure 31. The number of enterprises in the priority sector of environmental technology and recycling management

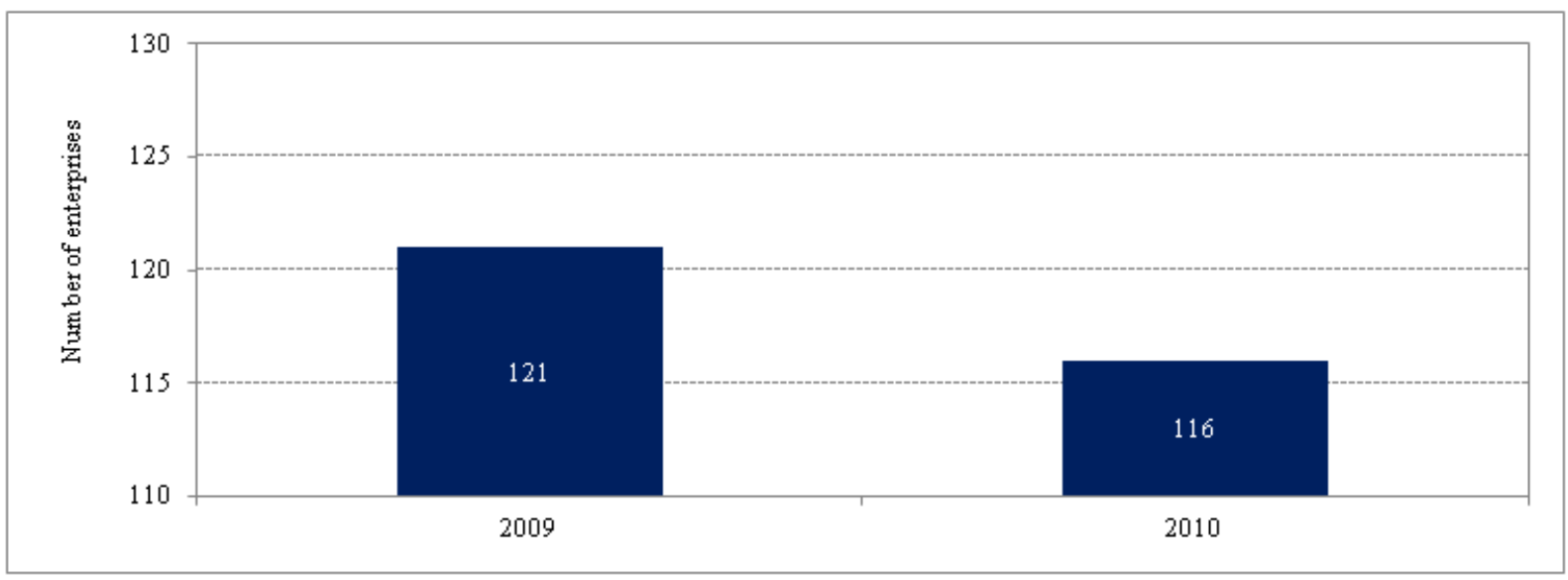

Source: CIC Magdeburg (January 2010)

\section{Renewable Resources Cluster}

The Cluster for Renewable Resources Saxony-Anhalt (CEESA - Cluster für erneuerbare Energien Sachsen-Anhalt) aims at combining various aspects of renewable resources, such as storage technologies and electricity grid management, as well as the energetic use of biomass in regional biogeochemical cycles. Cluster management is the responsibility of the ZERE e.V. as well as the ATI $\mathrm{GmbH}$, with ATI GmbH being in charge of the operative implementation. ${ }^{138}$ The cluster management is responsible for the following key tasks:

- Initiation, support, and improvement of the cooperation between industry and research institutions

- Exchange of information between firms with and without internal corporate R\&D

- Support of national and international technology exchange for the development of innovative

\footnotetext{
${ }^{137}$ KoNaRo is the point of contact for anyone dealing with renewable resources and bioenergy. Since 2003, it has been a permanent facility within the State Institute of Agriculture, Forestry and Horticulture of Saxony-Anhalt www.sachsen-anhalt.de.
}

${ }^{138}$ The cluster management is financially supported by state funds under the GRW grant scheme 
potentials

- Research cooperation with research institutions

- Execution of projects to strengthen the innovation capacity of enterprises

- Internationalisation of business activities ${ }^{139}$

$R \& D$ projects in the renewable resources sector originate from the $R \& D$ programs ZIM $\mathrm{NEMO}^{140}$ and InnoProfile. ${ }^{141,142}$ Moreover, cross-cluster activities result from collaboration with the special mechanical and systems engineering cluster.

\section{Competence Centre for Renewable Resources Saxony-Anhalt (ZERE e.V.)}

On the initiative of the State of Saxony-Anhalt, the competence centre was established in 2006 as an umbrella network for professional exchange, pooling, coordination of activities, and dissemination of innovative technologies in the field of renewable resources. Previous projects include the power supply of a business park in the town of Sülzetal as well as the technical and economic development of renewable resources in the pilot region of Harz (RegModHarz) and their integration into everyday use. ${ }^{143}$ The ZERE e.V. is also active at the international level as a member of the Central European Power Research Institute (CEPRI). ${ }^{144}$

\subsubsection{Renewable Resources Network Saxony-Anhalt (NAROSSA e.V.)}

The Association of Renewable Resources Saxony-Anhalt (NAROSSA e.V.) was founded in 2003, together with members of the Farmers Association, as a successor of the BIS NAROSSA. The special focus of the association is the utilization of renewable resources in terms of product development. The following tasks are included in its mandate:

- Facilitation of a legal framework for the utilization of renewable resources

- Employment of the legal framework in order to influence politics and the government in Saxony-Anhalt

- Organization of effective and targeted communication for the association members

\footnotetext{
${ }^{139}$ www.ceesa-org.de.

${ }^{140}$ e.g., technology competence flow stream, geothermal modular system and Solarflex.

${ }^{141}$ e.g., SiThinSolar.

${ }^{142}$ Appendix 4, Innovation strategy 2013.

${ }^{143}$ www.regmodharz.de.

${ }^{144}$ www.zere-ev.de.
} 
- Reinforcement of information transfer between industry, research, and administration

At present, the network includes 26 firms, seven research institutes, and seven private individuals. ${ }^{145}$

\section{Association for the Promotion of Recycling Management (FGK e.V.)}

The Association for the Promotion of Recycling Management (FGK e.V.) was founded in 2003; it currently has 40 members from the areas of industry and science. The core competencies of this organization are the integration of material and energy flows, technology consulting and the exchange of know-how between its members. The main topics are the use of waste and recyclable materials for energy, recycling of mineral and organic materials, alternative technologies for energy generation and recycling, consulting for association members on new waste management and developments in environmental law. ${ }^{146}$

\section{Infrastructure}

Active firms of the environmental technology and recycling priority sector have access to the following infrastructure facilities: ${ }^{147}$

- $\quad$ TEUTLOFF Zentrum für Regenerative Energien (Renewable Resource Centre) ${ }^{148}$

- $\quad$ Fraunhofer IWM IW9 $^{149}$

\footnotetext{
${ }^{145}$ www.narossa.de.

${ }^{146}$ www.fgk-magdeburg.de.

${ }^{147}$ Appendix 4, Innovation strategy 2013.

${ }^{148}$ www.teutloff.de.

${ }^{149}$ www.iwm.fraunhofer.de.
} 


\section{ANALYSIS OF EXPERT INTERVIEWS}

This chapter summarizes the key statements obtained from interviews with anonymous experts ${ }^{150}$ in the exploratory phase, and classifies these analogous to the structure of the questionnaire.

\section{Identification of network structures and the role of knowledge exchange}

\section{Description of knowledge transfer networks}

According to expert testimony, the locally identified knowledge transfer networks in the priority sectors in the economic area of Magdeburg are decisively influenced by the clusters that were initiated statewide, most of which have an established cluster management. These clusters at the state level do not operate independently, but act in an overlapping and sometimes intertwined manner. Within the clusters, there are other, smaller and focus-specific networks that form a substructure. These networks result from the implementation of specific $R \& D$ projects, primarily in the context of federal funding, on the one hand, and by the actions of industry-specific associations, on the other. With the description of the relevant clusters at the state level, including references to existing lower-level network structures (implemented R\&D projects, industry-specific associations), and the listing of the available infrastructure, it is possible to adequately depict the knowledge transfer networks within the economic region of Magdeburg. With a detailed characterization according to the industries specifications described in Ch.5, all partners, agencies, and institutions can be identified. However, conclusions concerning the positions of individual protagonists within the value chain or the complete communications structure cannot be drawn without further in-depth analysis.

\section{Network structures}

According to expert statements, it is generally possible to differentiate within the knowledge transfer networks between the structural fields of $\mathrm{R} \& \mathrm{D}$, transfer, and application. R\&D idea generation at universities and research institutes mainly takes place through basic and applied research. The transfer occurs primarily through transfer facilitators (intermediaries), such as the cluster management at the state level or through the project coordinators of the priority sectors in the economic region of Magdeburg. The practical application then lies with the firms. The need for transfer intermediaries results from the small-scale economic structure of the region.

As a rule, not every individual firm has the capacity to apply R\&D processes in-house. This

\footnotetext{
${ }^{150}$ All experts were guaranteed the anonymous evaluation of the interviews.
} 
performance capacity can be achieved by the union of several firms within the network. Moreover, the firms also have access to the infrastructure of universities and research facilities participating in the network. For the implementation of the R\&D process, facilitation is required, which is performed by the transfer intermediaries.

According to the interviewed experts, the state of Saxony-Anhalt supports the transfer of knowledge within the networks, primarily through the provision of a high quality infrastructure that can be used in an interdisciplinary manner. This includes supporting the clusters at the state level through temporary financing of the cluster management. ${ }^{151}$

\section{Further cooperation partners}

In addition to the previously described clusters at the state level, with locally operating firms (including transfer intermediaries) and research institutions, there are other cooperation partners associated with the knowledge transfer process in the economic region of Magdeburg. Within the universities, the transfer offices, described above, were created to support the knowledge exchange process. In addition, the Technology Transfer and Innovation Company Magdeburg (tti) ${ }^{152}$ acts on the mandate of the CIC Magdeburg as a point of contact for firms involved in the exchange of knowledge. The Ministry of Economics and Labor of Saxony-Anhalt provides the political framework for the support of knowledge exchange. The Investment Bank of Saxony-Anhalt and, in some cases, the Administrative Department of the State of Saxony-Anhalt is responsible for coordinating funded projects. In Magdeburg, contacts with the individual priority sectors are facilitated by the city's Department of Economics, operating through the GWM, which also assists in handling infrastructural issues.

\section{Communications processes}

According to the experts, communication processes are mainly initiated and steered by the respective transfer intermediaries (e.g., cluster management / project coordinator). The activities and the consistency of the communicating actors are vital for the perception and the importance of the cluster management / project coordination within the network. Moreover, the cluster management / project coordination screens potential partners for the implementation of $R \& D$ projects. The initiator of the project may come from all three areas of a knowledge transfer network ( $\& \& D$, transfer, application). The search for suitable project partners is characterized by a problem-oriented approach, but it also requires personal network connections. Information events, taking place both within a priority sector industry / cluster as well as across clusters and industries, bring potential partners

\footnotetext{
${ }^{151}$ A detailed description of organizational structure and public support of these networks is given in Ch. 5 .

${ }^{152}$ www.ttimd.de.
} 
together.

\section{Framework conditions}

Experts certify that knowledge transfer networks generally emerge parallel to existing industrial fields. Indeed, as the priority sectors in the economic region of Magdeburg reveal, existing industries have the advantage that synergy effects will create favourable framework conditions for the emergence of networks. However, an existing industry is not a sufficient condition. Often the development of knowledge transfer networks also requires a financial boost. The federal Unternehmen Region Initiative was instrumental in the development of local priority sectors and regional economic clusters. ${ }^{153}$ The goal was the establishment and development of primarily technological, scientific, and economic expertise in the Eastern Germany for sustainable protection of innovation in firms as a prerequisite and foundation for economic growth. ${ }^{154}$

\section{$R \& D$ and transfer know-how}

Amongst the different priority industry sectors, as well as between clusters at the state level, there exist quite different perceptions of the role of universities and research institutions within the knowledge transfer networks. According to some proponents (typically these are cluster managers), all $R \& D$ requirements should be met by enterprises, which have a more business-oriented manner of thinking and acting. Accordingly, the research sector should be involved only at certain points to fill existing gaps. In contrast, there is the opposing view (typically held by firms but also public institutions) that firms primarily follow the goal of product optimization and do not generate any fundamental innovations. Therefore, universities and research institutions are an indispensable driving force behind R\&D-based innovations. In general, universities and research institutions, including existing centres of competence, are regarded as being responsible for basic and applied research, due to their infrastructure, which is missing in many firms. The further value-adding activities in the transfer process are the responsibility of the firms within the clusters or core industries and, in particular, of the cluster managers and the project coordinators in charge of the knowledge exchange.

According to experts specifically from the public sector, the involvement of universities and research institutions in these knowledge-transfer networks is carried out via different channels. For the most part, the federal funding programs, in addition to the integration of firms, also promote the direct integration of research institutions into R\&D projects. Furthermore, universities are integrated in a subject-specific manner into the network structure of the priority sectors or the clusters through their individual departments, institutes, affiliated institutes, associate institutions and individual researchers. In addition, the Competence Network for Applied and Transfer-Oriented Research (KAT) provides yet

\footnotetext{
${ }^{153}$ Specifically, for the economic region these are mechanical and systems engineering and healthcare.

${ }^{154}$ www.unternehmen-region.de.
} 
another interface between universities and clusters/priority sectors. In line with the research priorities of universities, this network is used to initiate trans-cluster interaction between the fields of industry and science.

The patent licensing agency (ESA PVA GmbH), ${ }^{155}$ as a partner of the working group "invention commercialization" of Saxony-Anhalt, ${ }^{156}$ handles the property rights and patent licensing across industries as part of the technology transfer process. Its tasks include raising the awareness of scientists, the analysis of inventions for novelty and commercialization potential, providing support for patent law work, and the commercialization process. The objective is to protect the inventions of the scientists and, at the same time, to make them available for commercialization.

\section{Sizes of the firms}

The economic structure of the economic region of Magdeburg and in the state of Saxony-Anhalt is characterized by a highly fragmented corporate landscape. The implementation of R\&D processes within individual firms requires a specific performance capacity, ${ }^{157}$ often measured by the number of employees in the company. Many of the SMEs, especially the small and micro firms, do not have this capacity. Often, the critical mass can be generated only through networks. Through the interaction within the network, it becomes possible to provide small and micro-size enterprises access to the infrastructure required for the R\&D process. For the interaction within the networks, firm size is of secondary importance. However, large companies do have better financial and market opportunities than the SMEs. Accordingly, large companies are usually found at the end of the value-adding chain of collaborative projects within a given knowledge transfer network, whereas small and micro enterprises typically assume the role of suppliers in $R \& D$ processes.

In principle, access to the network structures of the priority sectors in Magdeburg and the clusters in Saxony-Anhalt is open to any company, without restrictions. For the economic region of Magdeburg, specifically experts from the public sector find that small and micro-size businesses are much more flexible than large companies in deciding to actively participate in networks. Partially, this is determined by the outside governance of major enterprises, for which Saxony-Anhalt and, in particular, the economic region of Magdeburg often only serves as a location for production rather than the strategic management headquarters of these enterprises.

The state Ministry of Economics and Labour indisputably focuses its settlement policy on major enterprises including their management headquarters. The main settlement argument is technology transfer.

\footnotetext{
155 www.esa-pva.de.

${ }^{156}$ The universities of Saxony-Anhalt and select research institutions have joined together to form this working group.

${ }^{157}$ The level of performance, in this context, is determined by the number of employees of a company.
} 


\section{Leading issues}

Within the knowledge transfer networks analyzed at both the local as well as state level, crosscutting focal points can be identified, which form the basis of activities within the networks. Foremost are the process and procedural innovations which, through collaborative projects, are meant to raise awareness among enterprises for the R\&D process and also ensure its long-term establishment within firms. Further along the value chain, new markets with new customer groups must be developed for any resulting innovations. Issues such as finance and joint ventures play only a minor role in the knowledge transfer networks. For example, the financing of R\&D projects is coordinated by the Cluster Management (or the cluster at the state level) and sustained by R\&D support programs. External funding partners are typically only contacted by firms directly, in case of specific requirements, rather than being involved in the general thematic discussions within the knowledge transfer networks.

\section{Catchment area and effective radius}

There is a general agreement within the knowledge transfer networks that the created value should originate within the local and regional catchment area. For the economic region of Magdeburg, this implies that the local universities and research institutions are the key generators of R\&D ideas and are, thus, the driving force of innovation for enterprises. This statement also applies at the state level. For the local and regional universities and research institutes, the catchment area for R\&D input extends to the national and international level due to a variety of research collaborations. The commercialization of locally generated value from $R \& D$ processes clearly focuses international markets.

\section{Importance of knowledge transfer for established and new firms}

Consistent knowledge transfer from the scientific to the business community has been unanimously assigned a very high, almost existential importance for the firms. Stagnation means regression is the core message; enterprise sustainability and growth can only be achieved through innovation based on executed R\&D processes. Since a large share of firms within the regional area of Saxony-Anhalt do not have the capacity for in-house R\&D processes, different measures have been taken to address this problem. Through the implementation of R\&D projects, the implemented cluster structures, including their management, aim to ensure economic performance within the network of companies and to provide access to the necessary $R \& D$ infrastructures of the universities and research institutes. The objective is to let companies use innovation as a basis for tapping into new markets with new customers, in order to encounter their dependency as suppliers. Nevertheless, experts currently attribute a lack of innovation willingness to the SMEs, especially to small and micro-size enterprises, and they see a strong necessity for catching up. Moreover, due to a lack of large companies with the capacity for own R\&D processes, science and industry must be interlinked even more closely in future. 
Parallel to the development of existing businesses, a focus of political action is on the support of innovative, technology-based start-ups from science. Scientists are regarded as having the necessary know-how to initiate start-ups, planned from the start with an orientation towards growth, through innovation based on existing R\&D process structures (see, for example, the BMWi research report No. 576 p. 11). As a reinforcement of this particular form of knowledge transfer, the Ministry of Economics and Labour of Saxony-Anhalt has promoted university founder networks as part of a statewide start-up campaign (ego.-Existenzgründungsoffensive), in order to support researchers on their path towards entrepreneurial independence.

\section{Importance of new and small local firms within the knowledge transfer networks}

\section{Utilization of network structures for the implementation of $R \& D$ processes}

The corporate landscape in Saxony-Anhalt and, in particular, in Magdeburg is shaped primarily by SMEs. With minor local differences, the proportion of companies with fewer than 20 employees is 80 - 90 percent. These companies have to organize themselves in networks, as their own research infrastructure does not permit individually and independently controlled R\&D processes. Networks, particularly for micro and small businesses, ensure a supportive project environment for access to $R \& D$ topics. Since the participating companies are mainly service providers or suppliers, the networks enable them to access new customers and markets through innovations and thus reduce their dependence on individual customers.

\section{Firm structural problems}

According to the interviewed experts, micro-and small-size enterprises refrain from participating in R\&D for several reasons. Often, these companies lack the necessary understanding of the need for $R \& D$ altogether. In addition, the specific requirements placed on $R \& D$ cooperation and the differences in terminology hinder communication between science and industry. A fundamental problem is also the firms' lack of capital and human resources. Micro and small-size enterprises, with limited financial leeway, simply cannot afford the human resources, both quantitatively and qualitatively, that would be needed for the R\&D activities. Moreover, since the managing director typically has the exclusive responsibility for all corporate divisions, the time needed for getting involved in R\&D is generally missing.

Small firms also see a significant risk with regard to the probability of success of R\&D projects. In addition, their necessary own contribution to $R \& D$ projects is often not possible. For example, the necessary skills in project management needed for the successful implementation of R\&D projects simply may not exist. Another fundamental problem for the interviewed experts, specifically from firms, is the rivalry among cooperating firms when it comes to implementing R\&D processes. 


\section{Standardization processes of knowledge transfer}

The use of internships, and undergraduate and graduate work was unanimously identified by experts as a standard tool of knowledge transfer between universities and research institutions, on the one hand, and industry, on the other. According to interviewees from the public sector, clear structures also exist for the recruitment of skilled experts in the region. Both the Otto-von-Guericke University in Magdeburg (continuing education of researchers and graduate placement ${ }^{158}$ ) as well as the Magdeburg-Stendal University of Applied Sciences (Career Centre ${ }^{159}$ ) has created centralized structures for this task. ${ }^{160}$ The standard repertoire of knowledge transfer also includes patent licensing through the patent agency (ESA PVA GmbH), where patents are filed mainly by scientists, while industry becomes more involved over the course of the commercialization process.

The experts identified information events (seminars, workshops, symposia) as a qualified and often used instrument of knowledge transfer. The initiation and organization involves all areas of knowledge transfer (R\&D, transfer, application). Typically, several partners from different sectors are involved, who support each other and contribute their specific technical expertise. According to the CIC Magdeburg, the consultation service for companies interested in technology transfer is standardized by its subsidiarity $\mathrm{GmbH}$. Questions concerning funding opportunities and networking can be directed towards the state initiative NETWORK KMU, the organization of which is located in Magdeburg. ${ }^{161}$

\section{Optimization opportunities for networking}

Central for optimizing the expansion of $\mathrm{R} \& \mathrm{D}$ processes for small and micro-size enterprises within the knowledge transfer networks is their often poor or nonexistent affinity for $R \& D$. In addition, it is criticized that the existing networks are often too fragmented and dispersed, with no visible structure and, hence, also no visibility for potentially interested parties. Moreover, companies, lacking capital and human resources, face a structural problem, thus preventing the implementation of $\mathrm{R} \& \mathrm{D}$ from the outset. In many cases, the companies lack the experience in cooperating with universities and research institutions.

Further optimization opportunities emerge at the interfaces along the process chain, involving basic research, applied research, corporate development, and market launch. With the appropriate infrastructure, the interfaces could lead to higher efficiency along the process chain.

\footnotetext{
${ }^{158}$ www.wiwa.ovgu.de.

${ }^{159}$ www.hs-magdeburg.de/service/careercenter.

${ }^{160}$ Another state-level professional recruiting portal can be found at www.pfiff-sachsen-anhalt.de.

${ }^{161}$ www.network-kmu.de.
} 
An additional option for accelerating the transfer of knowledge from science to industry is seen in the establishment of development centres in the universities. Here the focus should be on management and facilitation skills as a core competence. By creating a common language for business and science, this type of management can promote knowledge transfer through active communication with firms.

\section{Benefits of the R\&D process as a growth option}

A main conclusion of the expert interviews is that, of over 100,000 businesses operating in Saxony-Anhalt and represented by various Chambers, only 300 firms are continuously involved in $R \& D$, meaning that the existing potential of the $R \& D$ processes as growth option is far from being exhausted. However, the few companies actively participating in networks have recognized the importance of R\&D and use the resulting potential. During the economic and financial crisis, these companies have specifically dedicated their activities to R\&D, e.g., by training employees. In addition, the economic digression inspired a reorientation. Firms recognized the potential of R\&D for addressing new groups of customers in new markets, in order to escape their dependency on individual industry sectors. Nevertheless, firms still hold too many reservations regarding the cooperation with researchers. In general, the interviewed experts see an enormous need for additional innovative firms in the region. In particular, with respect to small and micro-sized enterprises, great potential is seen with spin-offs from universities and research institutions. ${ }^{162}$

Experts also noted that the success of knowledge transfer crucially depends on the initiator. If the initiative for knowledge transfer comes from the entrepreneur, the probability of success is estimated to be significantly higher than if the initiator is a researcher.

\section{Political framework conditions}

\section{Impact of the political environment on the operational work knowledge transfer networks}

According to the interviewed experts, the absence of industrial research, due to the lack of large firms, necessitates suitable framework conditions that enable local and regional firms to implement their own R\&D processes. These conditions determine the design of knowledge transfer networks, taking into account the definition of priority sectors, the formation of clusters, and infrastructure measures. To be able to operate effectively, the transfer networks require start-up funding, described in detail below, which should be provided at the state level. Thus, the political conditions have a significant influence on the development and the operational activities of knowledge transfer networks. It was stated that the political conditions must be clear in definition and structure, in order to enable an adequate quality management with the necessary monitoring of success and, thus, the efficient use of funds. To ensure sustainability, the network structures must include the economic

\footnotetext{
${ }^{162}$ Spin-offs from universities include both research spin-outs and start-ups by university employees, graduates, and students in general.
} 
sector from the start, e.g. through the participation of the experts in advisory boards. In designing the state funding structure, complementarity to federal funding programs is taken into account, in order to avoid double funding.

The interviewed experts unanimously agreed that Saxony-Anhalt has sufficiently many wellstructured grant programs to allow a sustainable establishment of R\&D processes within the corporate landscape. Possible measures for improvement and extension will be outlined further below.

\section{Relevant programs in support of the $R \& D$ process}

For the implementation of specific collaborative $R \& D$ projects within the knowledge transfer networks, especially within the clusters at the state level, the Central Innovation Program for the Small-Firm Sector (ZIM) of the Federal Ministry of Economics and Technology (BMWi) plays a crucial role. This innovation program comprises the following grant modules: ${ }^{163}$

- Cooperation Projects (ZIM-KOOP): Funding supports cooperation between SMEs as well as between SMEs and research institutions

- Individual projects (ZIM-SOLO): Funding of R\&D projects of SMEs

- Network Projects (ZIM-NEMO): Funding for external management and organizational services for the development of market-oriented networks of innovative SMEs

Also influential for the formation and further advancement of regional R\&D networks are the following grant modules of the Federal Ministry of Education and Research (BMBF), as part of the innovation initiative for a regional enterprise culture (Unternehmen Region): ${ }^{164}$

- Innovative Regional Growth Cores: Funding is provided for regional cooperation, which have (the potential for) a platform technology and also have significant unique features in their respective area of expertise

- Potential Growth Cores: The objective is to make research findings from universities and research institutions available to regional firms more quickly

- Innovation Forums: These have the task of supporting regional networks during their startup phase, in order to sharpen their thematic profile and in order to establish and strengthen contacts and cooperative ventures

- InnoProfile: Funding for systematic reinforcement of the innovative capacity of the economy through cooperation of regional junior researchers and regional business experts

- ForMaT (Market-oriented research as a team): The objective is to bring public research

163 www.bmwi-zim.de.

${ }^{164}$ www.unternehmen-region.de. 
results to the market more quickly and in a more useful form

- InnoRegio (until 2006): The goal was to develop self-supporting innovation networks and to create long term competitive locations. This program initiated the development of individual economic clusters in the region of Magdeburg (e.g., by funding MAHREG Automotive und InnoMed)

Complementary to these programs, the Federal State of Saxony-Anhalt established its own grant programs to further strengthen knowledge transfer processes and ensure a sustainable structure. The following programs are highlighted by experts as being particularly relevant: ${ }^{165}$

- $\quad \boldsymbol{R} \& \boldsymbol{D}$ directive: The aim is to promote $\mathrm{R} \& \mathrm{D}$ in individual firms as a joint venture or joint project

- Knowledge transfer directive: The objective is to improve technology transfer between innovation intermediaries and the users of technology (mainly SMEs) and also to reduce economic and technological risks

- Patent directive: The focus is on improving the legal protection of patentable ideas and research results, as well as providing support to entrepreneurs and inventors

- Network and cluster funding: The focus is the sustainable development and establishment of management structures in the clusters at the state level

In support of these tasks and for the provision of the necessary infrastructure, the State of Saxony-Anhalt, for the most part, uses the resources provided by the European Union through the European Regional Development Fund (EFRE) and the European Social Fund (ESF). In addition, the cluster funding program focuses on resources of the "Community mission to improve the regional economic structure" (GWR). The active players within the knowledge transfer networks also have use specific programs of the European Union for the implementation of R\&D projects. Primarily, e.g., the INTERREG programs, which aim to promote European territorial cooperation. Figure 32 presents an overview of the approved project applications during the period 2006-2009 that are relevant for the individual grant programs at the state level.

\footnotetext{
165 www.sachsen-anhalt.de.
} 
Figure 32. Number of applications in Saxony-Anhalt approved in the R\&D field



Source: Ministry of Economy and Labor of Saxony-Anhalt

The number of approved applications among the four support programs is depicted in Figure 33.

Figure 33. Funding per grant program in Saxony-Anhalt in thousands of EUR

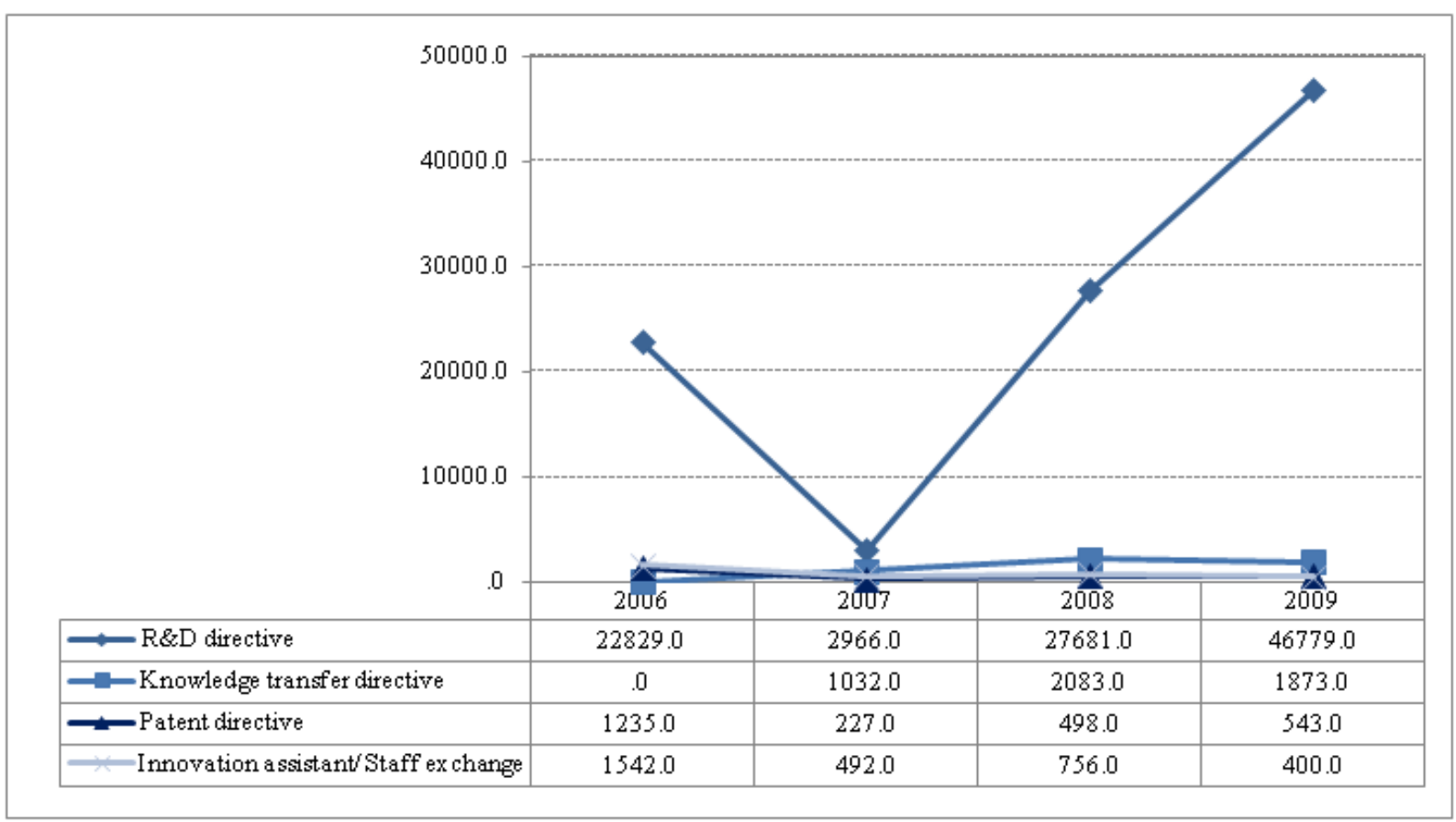

Source: Ministry of Economy and Labor of Saxony-Anhalt

For the university sector, and especially for the University of Magdeburg, there are further grant programs that play an important role. Of fundamental importance for scientists are the resources of the 
German Research Association (DFG: Deutsche Forschungsgemeinschaft) ${ }^{166}$ and the Organization of Industrial Research Associations (AiF: Arbeitsgemeinschaft industrieller Forschungsvereinigungen Otto-von-Guericke e.V.). ${ }^{167}$

The development and evaluation of these grant programs proceeds through different channels. At the Federal level, for example, the ZIM programs are evaluated by the AiF. For economic region of Magdeburg, the CIC is directly involved through the SME Promotion Act in the development of political framework conditions. Firms' interests concerning the design of the grant programs are directly addressed to the CIC. The tti GmbH has an advisory position for the design of grant schemes through its seat in the advisory board of the Innovation Officer of Saxony-Anhalt. All state programs of the Ministry of Economics and Labour are evaluated by the EU administration authority in the Federal Ministry of Finance. The individual projects implemented within these state grant programs are usually assessed by the Investment Bank of Saxony-Anhalt (IB). ${ }^{168}$

\section{Information on public support programs}

According to the interviewed experts, there are many ways in which network partners obtain an overview of the different grant programs. First, all protagonists involved in knowledge transfer undertake their own information search. For this purpose, the state of Saxony-Anhalt provides an overview (including a forwarding) of all state, Federal, or EU funding options available. At the state level, the Ministry of Economics and Labour provides information on relevant funding programs directly for the cluster managements. The cluster management then passes on the information to parties associated with the cluster. In addition, the central university facilities (TWZ, TTZ) provide information on current grant programs, e.g., through newsletters. Firms also have the option to obtain comprehensive information on grant programs from the various departments of the CIC Magdeburg and the State Initiative NETWORK-KMU. Information on EU related issues and funding opportunities is provided by the Europe Enterprise Network (EEN). ${ }^{169}$

For the funding of individual $R \& D$ activities based on the guidelines of the state of SaxonyAnhalt, any interested party can obtain information at the Consulting Centre of the Investment Bank of Saxony-Anhalt (IB). The investment bank also actively promotes these programs at information events of the priority industry sectors, the clusters and the various chambers and associations. This proactive communication strategy by the investment bank meets the publicity requirements of the ESF.

\footnotetext{
${ }^{166}$ www.dfg.de.

${ }^{167}$ www.aif.de.

${ }^{168}$ www.ib-sachsen-anhalt.de.

${ }^{169}$ www.een-sachsen-anhalt.de.
} 


\section{Value added and growth processes driven by grant programs}

Experts agreed that politics can only provide the environment for R\&D processes, in order to support and accelerate the value-creation and growth processes of enterprises. The incentive to use $R \& D$ processes for the development of new customer markets by means of innovative products must clearly come from the firms themselves. In general, it was found that still too few companies take advantage of existing programs. According to the experts, this is presumably due to lack of sensitivity. However, for the clusters at the state level, there are different assessments concerning this matter. While the economic objectives of growth and employment have been achieved quite well in the automotive cluster, the same does not hold true for healthcare industry cluster. The key message is that the success of the clusters is specifically dependent on the individuals involved. The provision of infrastructure for research support buildings (e.g., ZENIT and IKAM), is regarded as a growth catalyst for industry and enterprise growth and significantly contributes to success. It was also noted that there are individual firms continuously involved in R\&D that would not have survived or never have been founded without the funding support.

\section{Gaps in the grant instruments}

All experts agree that business development institutions in Saxony-Anhalt and, in particular, in the region of Magdeburg perform quite well. This is particularly true for the development of knowledge transfer and access options for small and micro-size enterprises. There are, however, individual suggestions for optimization, expansion, and modification. For universities, a general support of knowledge exchange, and not only in the form of actual projects, would be desirable. The monitoring of R\&D processes through a transfer unit is one of the proposals. So far, the necessary personnel to initiate these processes have yet not been funded.

In addition, there is the criticism that project funding is primarily focused on "mainstream" projects (i.e., within the general trend), while more risky projects, driven by visions and focused on non-established markets, with the potential for radical innovation, often lack the necessary capital for implementation. A further approach to improve knowledge transfer is seen in the direct funding of R\&D within the firms rather than only through project funding. Moreover, settlement policy should pay more attention to the R\&D potential of companies. The experts state that the neighbour state of Saxony could serve as a model here. Finally, capital links, primarily in a form of equity, between small and large enterprises are regarded as insufficient.

In the segment of patent funding, a gap was identified provision of engineering samples, specifically for the creation of prototypes in the range of 10,000 - 50,000 EUR. Above and below these limits, patent funding is covered by state and Federal programs. A configuration of the cluster and network support to provide access to the resources of the GRW is not considered to be very practical. 
There is general criticism of high administrative barriers. Complicated application processes, long decision-making periods and high administrative costs over the course of the project intimidate interested parties from using the available grant programs for research and development. This bureaucratic burden results mainly from the requirements of the European Union as part of its program funding approach. The Ministry of Economics and Labor of Saxony-Anhalt criticizes its insufficient means to continuously perform a scientifically sound analysis of their own funding instruments and optimize them as needed.

\section{Perspectives of experts from financial institutions}

Central to economic policy in Saxony-Anhalt are measures in support of SMEs and start-ups. For start-ups, the objective is to create the best possible framework for technology- and knowledge-based ventures. The focus is on qualification and the provision of funding opportunities. For the future, higher investments are planned for knowledge transfer, both financially as well as in terms of content.

The state of Saxony-Anhalt offers an extensive financial product portfolio comprising grants, loans, guarantees, and equity capital, which is available to existing and also to new firms, to finance $\mathrm{R} \& \mathrm{D}$ processes at all stages of development. In the following, an overview is given of the relevant institutions and funding opportunities for both priority industry sectors, including an examination of their integration into the knowledge transfer networks.

\section{Investment Bank of Saxony-Anhalt (IB)}

The IB is the central unit in Saxony-Anhalt responsible for the implementation of policy guidelines aimed at achieving the economic objectives of growth and employment. The investment bank observes existing knowledge transfer networks from an outside position and is only occasionally involved in financial issues, but it has no sectoral priorities.

In collaborative projects, the IB communicates with the cluster management at the state level, in individual projects directly with the firms. The product range comprises various aspects of financing up to a total investment of three million EUR. Over all programs, the IB has an approval rate of 50 percent. In particular, the segment of R\&D grants features a two-stage application process. In Phase 1, interested parties can apply with a project outline. Approximately 40 percent of the applications are rejected during this stage. In the application process of Phase 2, 80 percent of the positively evaluated projects of Phase 1 are then actually funded. For the evaluation of projects, the plausibility of the business model is just as important as the capabilities of the management. The grant rates decline with increasing firm size.

For start-ups, the approval rate of 75 percent is considerably higher than in the overall context. The IB has an accreditation for the KfW-startup funds, but other programs of the $\mathrm{KfW}$ are also offered. The following products are offered by the IB as part of the start-up campaign of SaxonyAnhalt (ego.): 
- ego.-Plus: Loans to knowledge- and technology-oriented start-ups

- ego.-Start: Subsidies for university graduates who plan to start their own businesses

The IB regards the academic start-up networks ${ }^{170}$ as well as its own start-up network ego.Business ${ }^{171}$ as knowledge transfer networks. The application of the guidelines for R\&D funding for SMEs is reflected in the following programs of the Bank:

- Research, development and innovation funding: Grants for the development of new products and processes in the field of industrial research and experimental development

- Knowledge and technology transfer: Grants for innovation advisory services and innovation support services

- Patent Grants: Grants to cover the costs of obtaining patents and other intellectual property rights and for expenses related to the functional proof of function of inventions

- Trade shows: Subsidies to cover trade-show expenses so that the firms can present their innovative products and services at home and abroad

- Staff exchange / Innovation Wizard: Grants for the initial recruitment of highly qualified graduates for R\&D projects or to pay for the exchange of highly qualified personnel

- Saxony-Anhalt Impulse: Loans for R\&D and innovation

- Saxony-Anhalt Growth: Mezzanine loans including those for R\&D purposes

The centralization of core funding activities with the investment bank of Saxony-Anhalt is viewed critically by the experts, as the creation of competing financial products through government intervention may lead to distortions in a functioning market.

\section{Guarantee Bank Saxony-Anhalt (BB) and the SME Investment Company Saxony-Anhalt (MBG)}

The strategy of the $\mathrm{BB}^{172}$ together with the MBG is oriented towards business development and is focused across all industries on the business environment of SMEs. The central product of the guarantee bank is a deficiency guarantee, which is used when commercially available instruments are no longer effective because of the increased risk. As part of this product, there is a direct contact with the firms' house banks that must apply for the letter of indemnity.

Overall, the rejection rate is one percent. This is preceded by a free initial inquiry to the house

\footnotetext{
${ }^{170}$ The academic startup networks are Impuls-Netzwerk Sachsen-Anhalt (www.impuls-netzwerk.de), funded 2005 2009 for Northern Saxony-Anhalt, and the Univations academic startup network (www.univations.de), funded since 2005 for Southern Saxony-Anhalt.

${ }^{171}$ www.egobusiness.de.

172 www.bb-sachsen-anhalt.de.
} 
banks, which is already a selection process. The investment bank engages in project-based communication. In addition, the guarantee bank maintains regular contacts with the state-wide start-up initiative (ego.Existenzgründungsoffensive) and the state initiative NETWORK SME. These, however, are not considered as knowledge transfer networks as they do not match the definition provided by this study.

Through the MBG, various forms of silent partnerships are assigned:

- MBG-Start-up: Equity interest in start-ups or existing SMEs in Saxony-Anhalt

- MBG-Succession: Equity interest in start-ups and succession arrangements

- MBG-Growth: Equity for growth in SMEs in Saxony-Anhalt

Furthermore, the product $\boldsymbol{B B} \boldsymbol{M B G} \mathbf{K o b i}$ allows the exploitation of benefits of both the equity interest and the letter of indemnity for financing. In addition, the BB, under the "guarantee without a bank" $(\boldsymbol{B o B})$ concept, will handle the task of what is often an elaborate credit check process on behalf of the banks. If a positive decision has been made, the letter of indemnity can be submitted by the entrepreneur to the credit bank as a surety bond. In assessing the applications, the priority is first on the management skills, and only then does a business model analysis follow.

\section{Investment Company of Saxony-Anhalt (IBG)}

The investment portfolio of the $\mathrm{IBG}^{173}$ is supervised by GoodVent Investment Management $\mathrm{GmbH} \& \mathrm{Co} . \mathrm{KG}$, which is responsible for equity interests in technology-oriented, innovative companies and projects. The commitment is primarily for start-ups but also includes experienced SME with new product and process ideas from the fields of life sciences, mechanical engineering, nanotechnology, micro-sensors and energy and environmental technology. These fields have a large overlap with the priority sectors in the economic region of Magdeburg, investigated in this study. The investment portfolio of the IBG includes the following funds: ${ }^{174}$

- IBG Innovation Fund: Investments in technology-based business models in the early phase, with fund assets of 40 million EUR in the form of open and silent partnerships

- IBG Venture Capital Fund I: Investments in technology-oriented projects of the seed, startup and growth stages, with fund assets of about 160 million EUR in the form of open and silent partnerships

- IBG Venture Capital Fund II: Orientation similar to the venture capital fund I with a fund volume of approximately 80 million EUR

\footnotetext{
173 www.ibg-vc.de.

${ }^{174}$ www.goodvent.net.
} 
In financial issues, the GoodVent Investment Management $\mathrm{GmbH}$ is involved at certain points in the activities of knowledge transfer networks. Communication proceeds primarily through the universities for specific project inquiries related to specific areas of the product portfolio.

\section{House banks}

For house banks, especially in the economic region of Magdeburg, knowledge transfer networks are not significant for the design of company policy. There is no direct contact with universities and research institutions. First and foremost, the composition of the business customer portfolio includes skilled trade companies, as well as general trade and service industries. The house banks maintain regular contact with the investment bank, guarantee bank and the KfW banking group. The application process for the products of these institutions requires the commitment of the house bank. This in turn uses these products to diversify risk within its own business portfolio. In the evaluation of funding requests local house banks focus on the design of the business plan. Plausibility, profitability and management skills of the applicant play a decisive role. With regard to $R \& D$, patents may have a supportive effect in the assessment of plausibility. Specific products for different company sizes are not available. There is an organizational differentiation with respect to total lending volume.

The SBG (Sparkassenbeteiligungsgesellschaft Sachsen-Anhalt $\mathrm{mbH}$ ), the venture capital investment company of nine savings banks in Saxony-Anhalt, located in Barleben, is an exception. ${ }^{175}$ It invests in innovative SMEs and start-ups with regional ties to Saxony-Anhalt in the form of open or silent partnerships. The SBG is a private sector catalyst for economic growth in Saxony-Anhalt.

${ }^{175}$ www.sbg-sachsen-anhalt.de. 


\section{COMPANY SURVEY}

Of the 330 companies that were addressed, a total of 84 companies returned the questionnaire. Of these, only the 55 questionnaires that had been fully completed were included in the data analysis. Thus, the response rate based on the analyzed data amounted to 17 percent. There was a preliminary data exploration, in order to reveal possible input errors in the questionnaires. ${ }^{176}$

In the following, the results are first presented using frequency diagrams and box plots, as well as statistical key figures. This forms the basis for the further development and analysis of other specific issues. Note that the results are not representative for the total number of enterprises in the economic region of Magdeburg. Rather, the analysis reveals a sample of companies that already feature an affinity towards R\&D.

\section{Company key figures}

\section{Distribution among industries}

In the questionnaire, the companies were able to undertake their own industry allocations. Their choices were not limited to the priority sectors defined by the city of Magdeburg and investigated in the course of this study. As an additional option, the companies were also able to select priority clusters implemented by the state of Saxony-Anhalt and industrial sectors specified by the OECD. An industry classification code was then used for allocation to the priority sectors of the city of Magdeburg. ${ }^{177}$

\footnotetext{
${ }^{176}$ Bühl (2010, p. 261 pp.).

177 Industry classification code: Mechanical Engineering (choices: Mechanical and systems engineering, automotive industry), environmental technology and recycling management (choices: Environmental technology and recycling management, renewable resources, energy supply and recycling, biotechnology), healthcare sector (choices: Healthcare sector, medical engineering, pharmaceutical products), other (choice: Other, information and communication technologies, food industry).
} 
Figure 34. Number of enterprises in the priority sectors

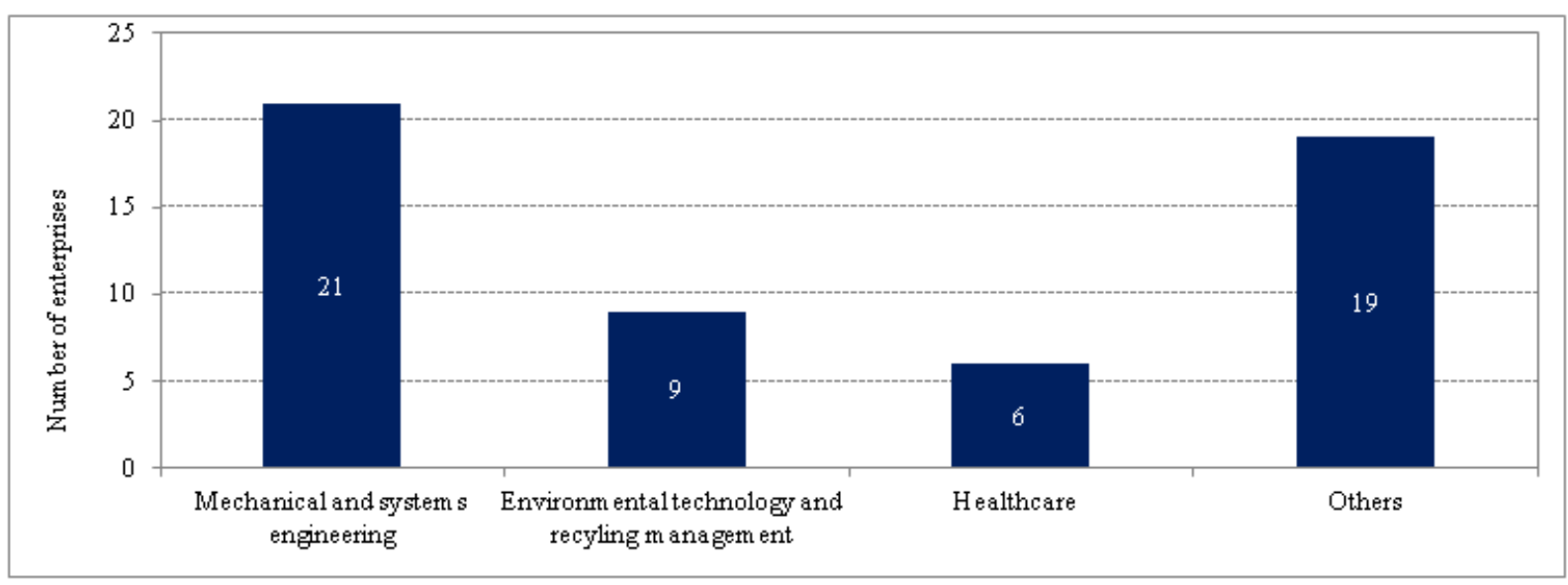

As shown in Figure 34, of the questionnaires returned, the largest proportion, i.e., 38 percent, came from companies from the priority sector of mechanical and systems engineering. The priority sectors of environmental technology and recycling management as well as the health care sector account for 16 and 11 percent, respectively. The high proportion of companies coming from other sectors results from the fact that the transfer facilities that were topically assigned to a specific sector in advance do not see themselves as being part of any of these industries.

\section{Individual and team enterprise foundation}

Figure 35. individual and team enterprise foundation

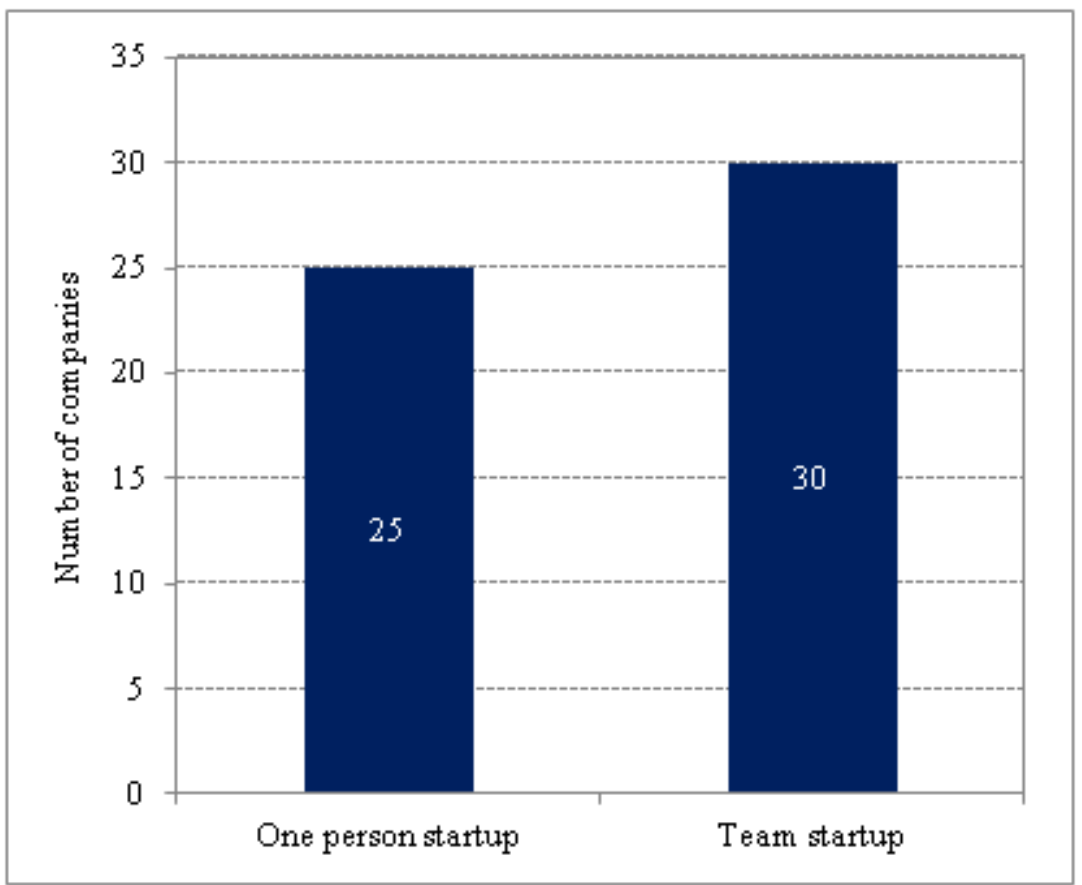

There is a preference for team as opposed to individual foundations for the industries 
investigated. As shown in Figure 35, 55 percent of new company formations were the result of a team effort, and only 45 percent were individual start-ups. Among team start-ups, the proportion of male founders was 93 percent and for one-person start-ups it was 92 percent. The proportion of founders under the age of 35 years was 16 percent for team start-ups, which is much higher than 2 percent for the individual start-ups. The average team size was 3.6.

\section{Founding motive and group affiliation}

Figure 36. Founding motive

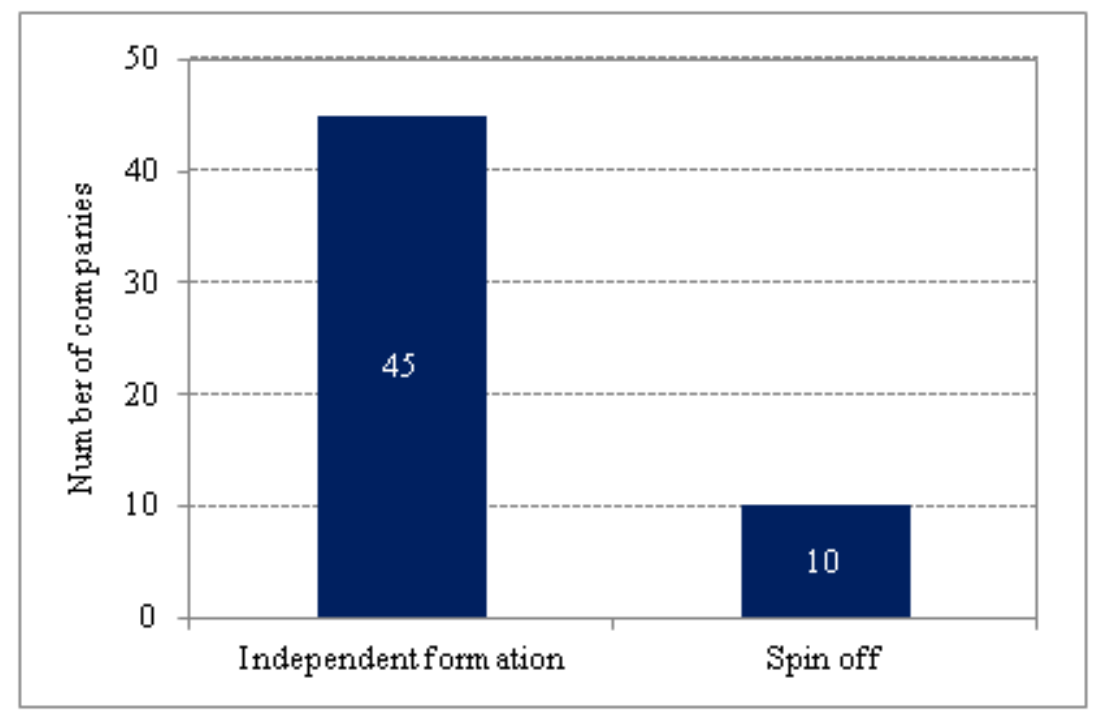

In 82 percent of the cases, companies were created as independent formations, 18 percent were founded as spin-offs, as shown in Figure 36.

Figure 37. Group affiliation

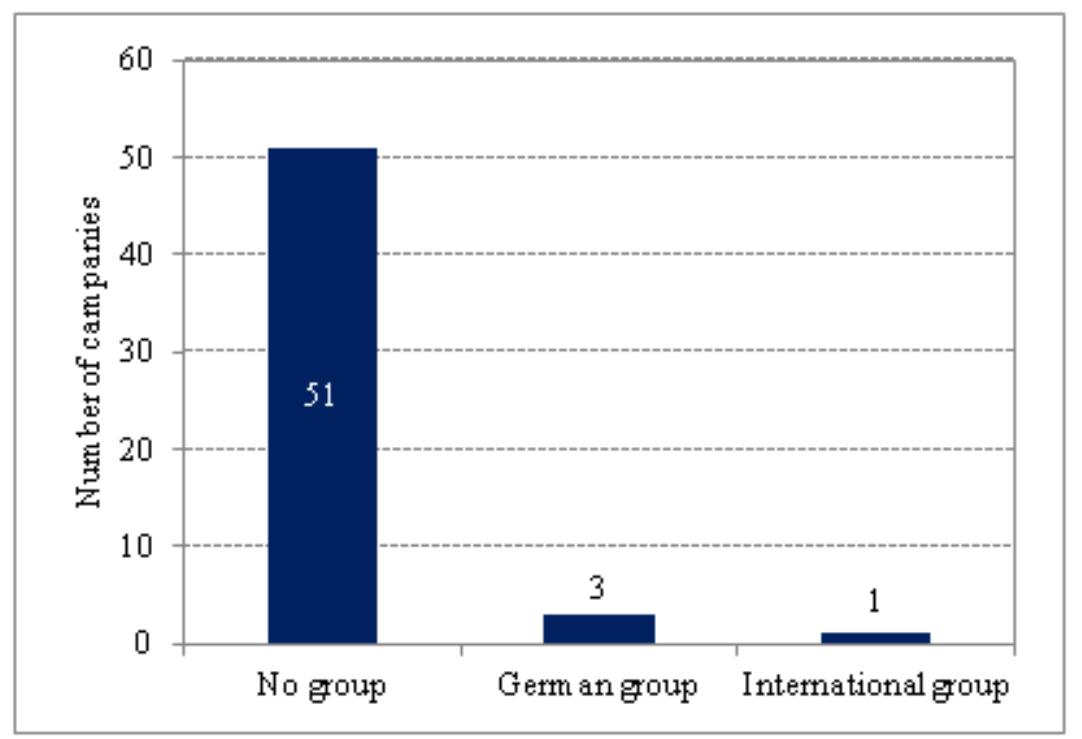

Only 7 percent of the firms have a legally relevant group affiliation. Only one company is part of an international group. 


\section{Founding year}

According to the definition in this study of new companies, with a founding date not more than five years ago, Figure 38 shows that 16 percent of enterprises fall into this category. Only one firm in the sample was founded before 1990 .

Figure 38. Founding year of enterprises

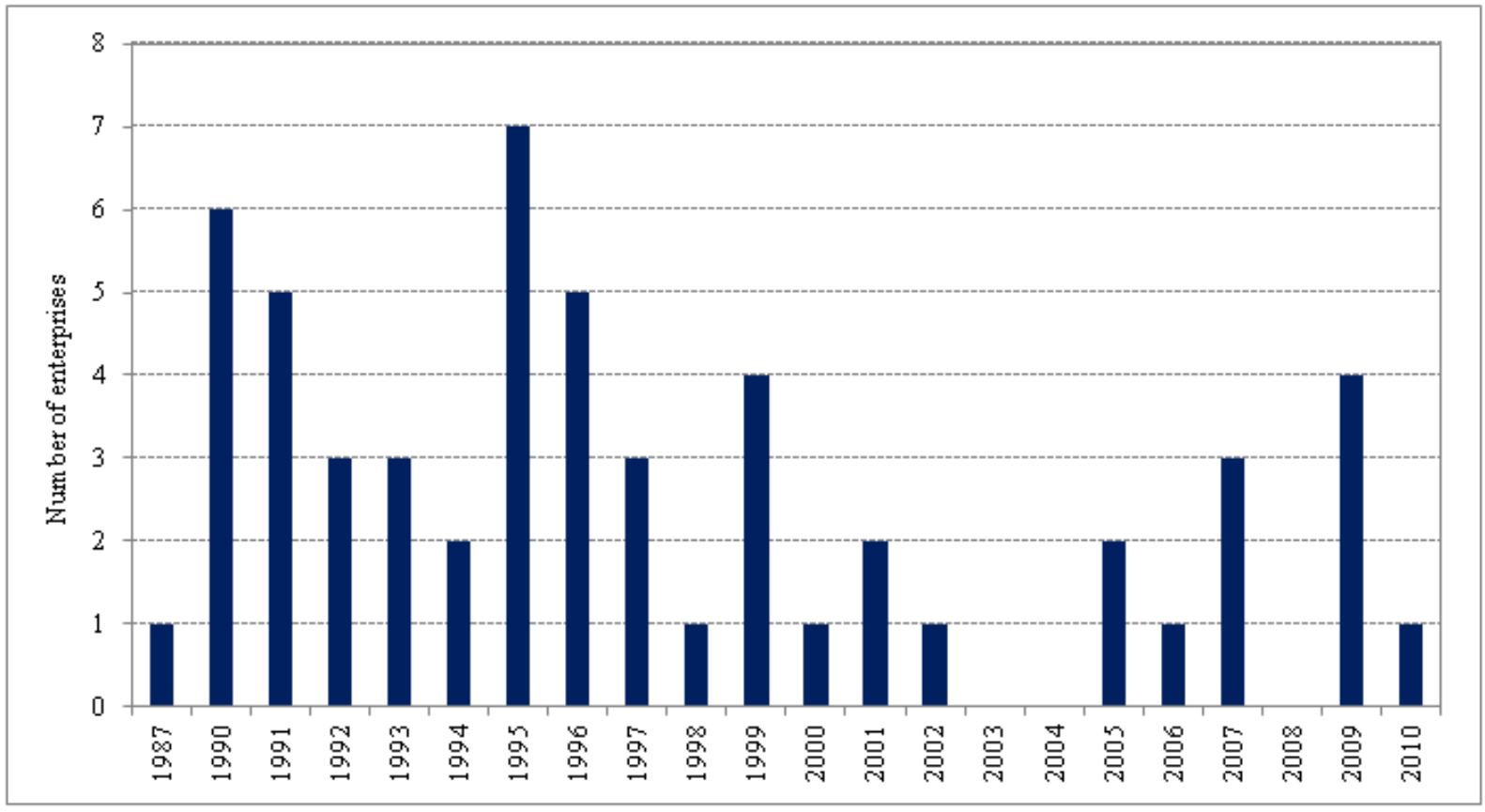

\section{Legal form}

More than 80 percent of the companies in the sample chose the $\mathrm{GmbH}$ as the legal form at the time of foundation. The legal forms of $\mathrm{AG}, \mathrm{GmbH} \& \mathrm{Co} . \mathrm{KG}$ and $\mathrm{UG}$ play only a minor role, as is shown in Figure 39. 11 percent of firms were established in sole proprietorship. 
Figure 39. Legal forms

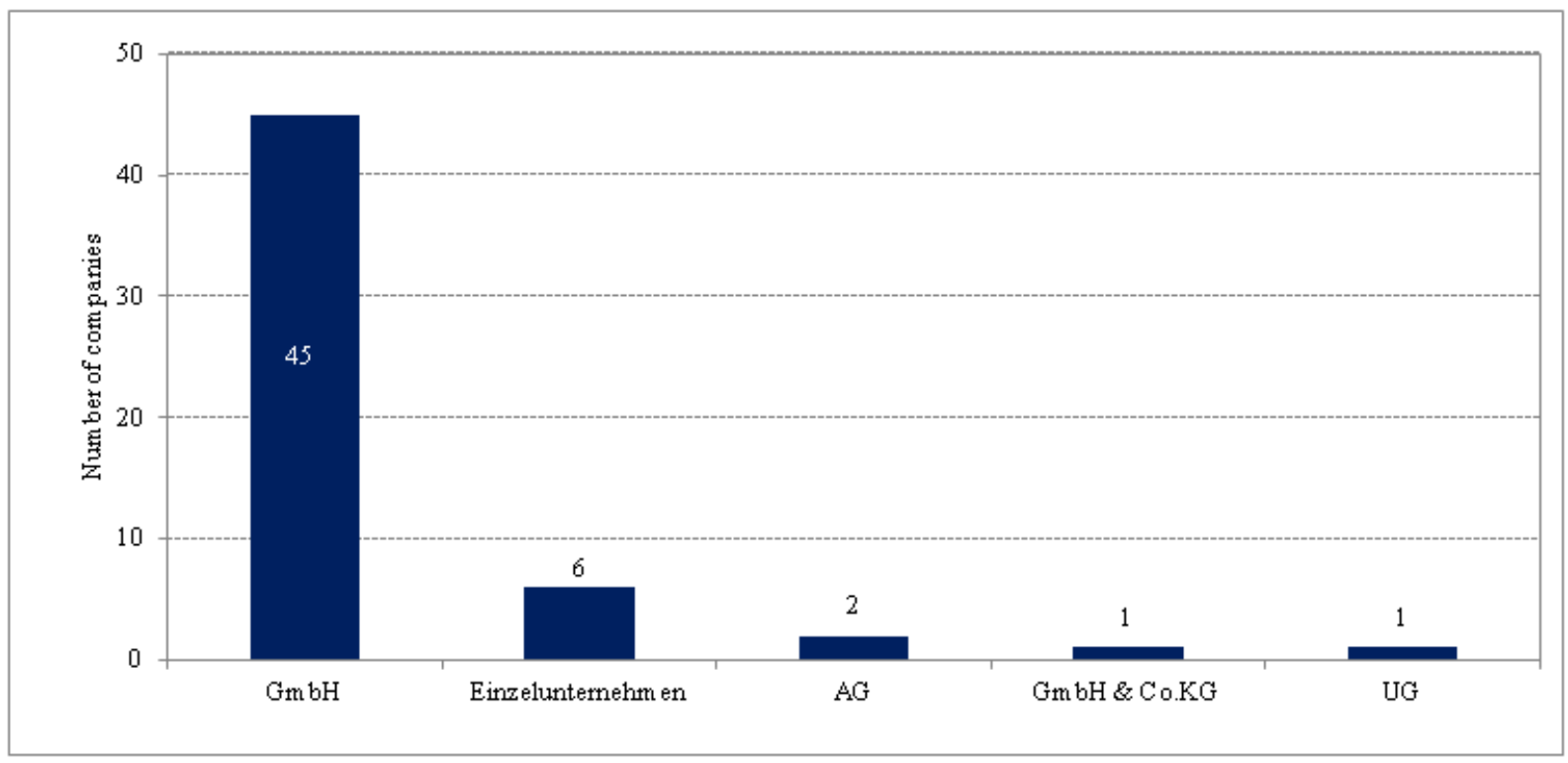

\section{Employment categories}

The differentiation of sampled enterprises by employment categories reveals that the category of micro-enterprises has a share of 51 percent. The category of small-size enterprises, with up to 50 employees, contains 36 percent of the firms. Medium-sized enterprises are represented with 13 percent. Large companies, defined in the context of the study as having more than 250 employees, do not exist in this sample. The group of small regional companies, as the sum total of micro-size and small enterprises, therefore makes up 87 percent of the enterprises of this study, as shown in Figure 40 .

\section{Figure 40. Employment categories}

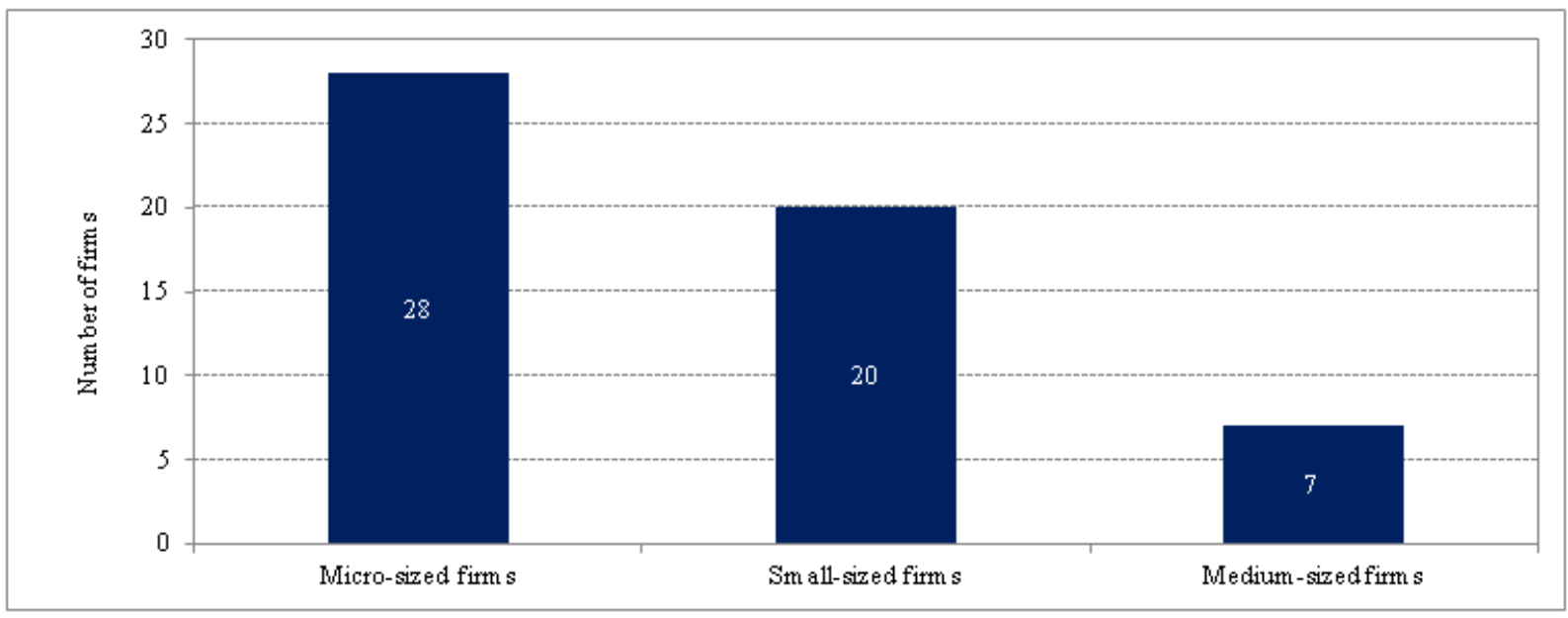

\section{Sales and market-shares}

Figure 41 illustrates the distinction of firms according to revenues in 2009. As one can clearly 
see, 91 percent of the firms investigated are in the range of up to 10 million EUR, with the main share of 62 percent of enterprises having generated less than 2 million EUR revenues in 2009. Only two companies had revenues of more than 50 million EUR recorded in 2009; and then there are three firms in the range of 10 to 50 million EUR.

Figure 41. Sales categories



Tab. 24 shows statistical parameters of the sales distribution for the firms and the various geographical markets in 2009.

Table 24. Key figures regarding sales distribution as related to geographical markets

\begin{tabular}{|c|c|c|c|c|c|c|}
\hline & Median & Mean & $\begin{array}{c}\text { Standard } \\
\text { error of the } \\
\text { mean }\end{array}$ & SD & Min. & Max. \\
\hline Local Market & 5 & 20.9 & 4.1 & 30.4 & 0 & 100 \\
\hline Regional Market & 30 & 29.8 & 3.6 & 26.9 & 0 & 100 \\
\hline National Market & 30 & 37.6 & 4.5 & 33.1 & 0 & 100 \\
\hline $\begin{array}{l}\text { International } \\
\text { Market }\end{array}$ & 0 & 9.8 & 2.7 & 20.0 & 0 & 100 \\
\hline
\end{tabular}

Figure 42 shows a strong percentage fluctuation of firms with respect to geographical markets relevant to their sales figures in 2009. In 2009, 64 percent of the firms generated no more than 10 percent of their revenues on the local market of Magdeburg. On the other hand, 4 percent of the firms 
operated entirely on the local market. The international market had no sales relevance in 2009 for 56 percent of the firms. Only one company generated its total revenue in 2009 on the international market. The largest revenues across all firms, for 2009, were generated on the national market, followed by the regional market of Saxony-Anhalt.

Figure 42. Sales distribution among the geographical markets ${ }^{178}$

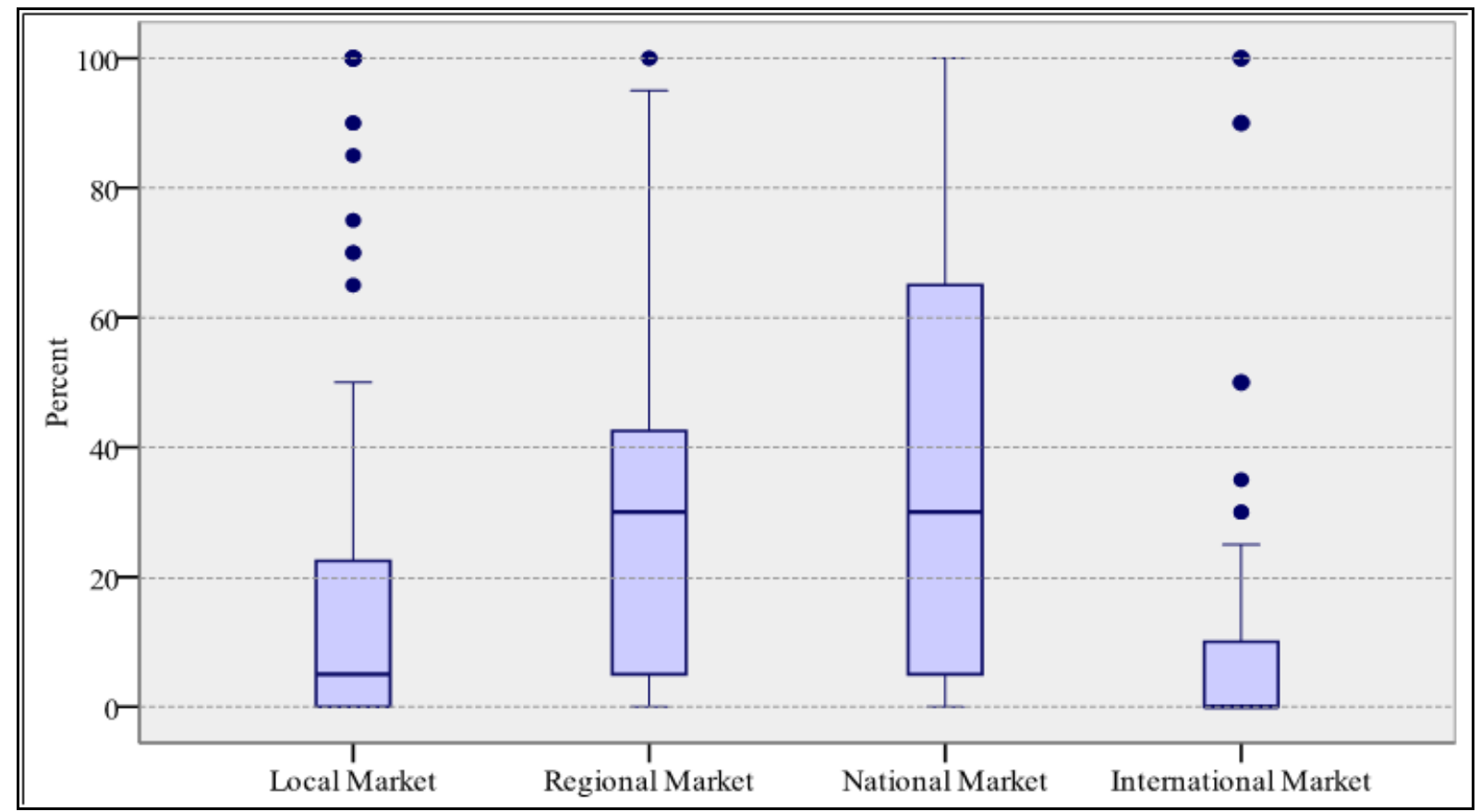

\section{$\mathbf{R} \& \mathbf{D}$ in enterprises}

\section{Number of R\&D personnel}

As an indicator of R\&D activities, there will be an initial illustration of the number of employees who are employed in R\&D in the various firms. Table 25 outlines statistical parameters for the R\&D employees in full-and part-time employment in the firms at the time of the survey.

${ }^{178}$ The dark line in the middle of the boxes is the median of the salary. Half the cases and/or lines have a higher value than the median and the other half has a lower value. The bottom of the box shows the 25th percentile. 25 percent of cases/lines have values below the 25th percentile. The upper end of the box shows the 75 th percentile. 25 percent of cases/lines have values above the 75 th percentile. This means that $50 \%$ of cases / rows are located within the box. The T-bars extending from the boxes are called sensors or whiskers. The length is 1.5 times the height of the box or, if no cases or rows with values are present in this field, the length is specified by the maximum or minimum value. 
Table 25. Key figures of R\&D personnel

\begin{tabular}{|c|c|c|c|c|c|c|}
\hline & Median & Mean & $\begin{array}{c}\text { Standard } \\
\text { error of the } \\
\text { mean }\end{array}$ & SD & Min. & Max. \\
\hline $\begin{array}{l}\text { R\&D full- } \\
\text { time staff }\end{array}$ & 2 & 3.1 & 0.6 & 4.1 & 0 & 20 \\
\hline $\begin{array}{l}\text { R\&D part- } \\
\text { time staff }\end{array}$ & 0 & 0.4 & 0.1 & 0.8 & 0 & 3 \\
\hline
\end{tabular}

All in all, across the industries at the time of the survey, there were 169 full-time R\&D employees and 20 part-time R\&D employees working in the firms. Figure 43 shows that the range of full-time R\&D employees working in the firms is between 0 and 20 , while the range of part-time $R \& D$ employees in only between 0 and 3. No R\&D full-time staff are employed by 33 percent of the firms, and 76 percent have no part-time $R \& D$ employees. There is no R\&D staff whatsoever in 29 percent of the firms.

Figure 43. Number of full-time and part-time R\&D employees

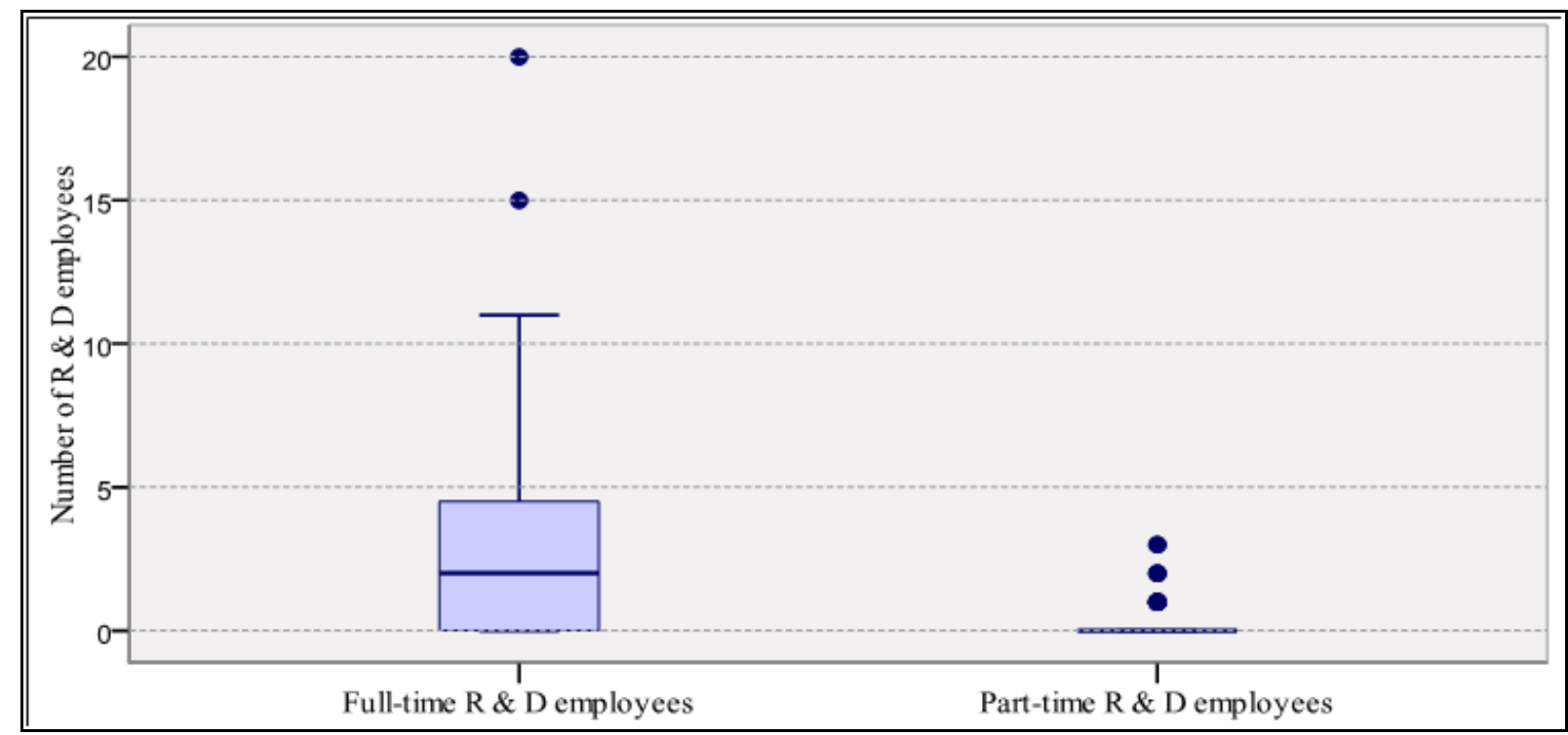

\section{Patents}

Another indicator of R\&D intensity is given by the patent activities of the firms. In the 2005 2010 period, a total of 31 patents were registered by the sampled firms. Only 29 percent of firms were active in this field. The remaining 71 percent of firms had no patent activity during this period. Figure 44 shows patents granted to the firms from the time of their formation to the time of the survey, which 
includes patents used by the companies themselves as well as those that were out-licensed. 27 percent of firms had some patents granted. The range extends from one to ten patents granted per firm. Of the patents granted, 61 percent are used by the firms themselves and 7 percent are used through outlicensing.

Figure 44. Patent activities



\section{$R \& D$ intensity}

Cost-related $R \& D$ intensity is a further indication of the $R \& D$ activities of the firms. This is shown for the year 2009 in Fig. 45. First, Table 26 outlines the preliminary statistical pa-rameters for cost-related R\&D intensity.

Table 26. Key figures of cost-related R\&D intensity

\begin{tabular}{|c|c|c|c|c|c|c|}
\hline & Median & Mean & $\begin{array}{c}\text { Standard } \\
\text { error of the } \\
\text { mean }\end{array}$ & SD & Min. & Max. \\
\hline \multicolumn{7}{|c|}{ R\&D investment as } \\
\hline $\begin{array}{l}\text { a percentage of } \\
\text { sales in } 2009\end{array}$ & 5 & 8.9 & 2.1 & 15.5 & 0 & 100 \\
\hline
\end{tabular}


Figure 45. Cost-related R\&D intensity of firms 2009



The range, of between 0 and 100 percent, of the cost-related R\&D intensity of firms in 2009 is due to the inclusion of the outlier, which in turn has a significant influence on the mean and the standard deviation. As part of the survey, 35 percent of the firms stated that they had no R\&D costs in 2009. The R\&D intensity of all firms is 8.9 percent on average. The median of the cost-related R\&D intensity is, however, 5 percent, as Figure 45 shows.

Figure 46. Changes to $R \& D$ intensity

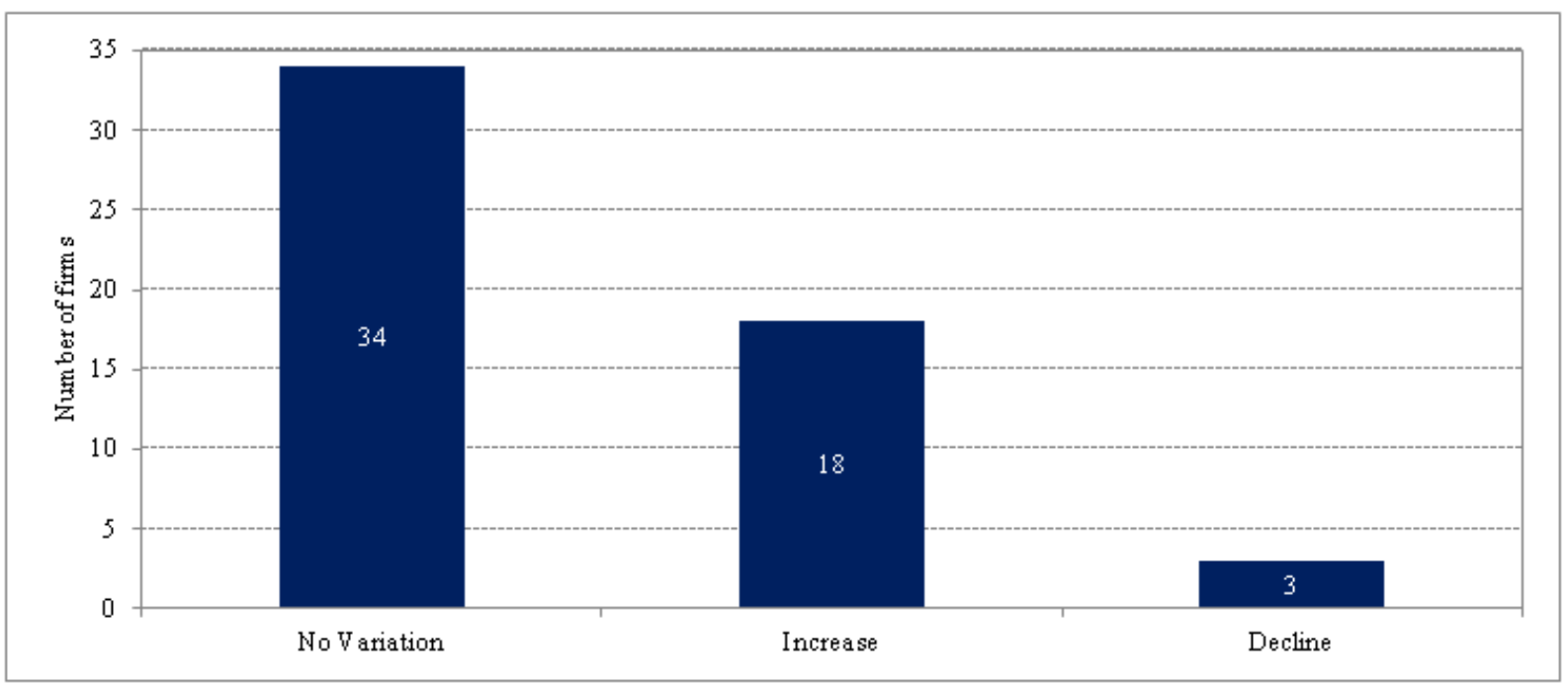

When asked about R\&D investment changes during the 2011 - 2012 period, 62 percent of the firms responded that there were no changes, as Figure 46 shows. Of those firms that had no R\&D investments to record in 2009, 21 percent plan R\&D costs for the $2011-2012$ period. 


\section{Innovation areas}

Figure 47 shows the fields of innovation in which the firms were active during the $2005-2010$ period. Multiple answers were possible to this question. 71 percent of firms were active in the area of product innovation. Process innovations were carried out by 38 percent of the firms, marketing innovations by 26 percent, and organization innovations by 24 percent. During the period under review, 15 percent of the firms reported that they had had no innovations to record in the surveyed fields.

Figure 47. Innovations executed

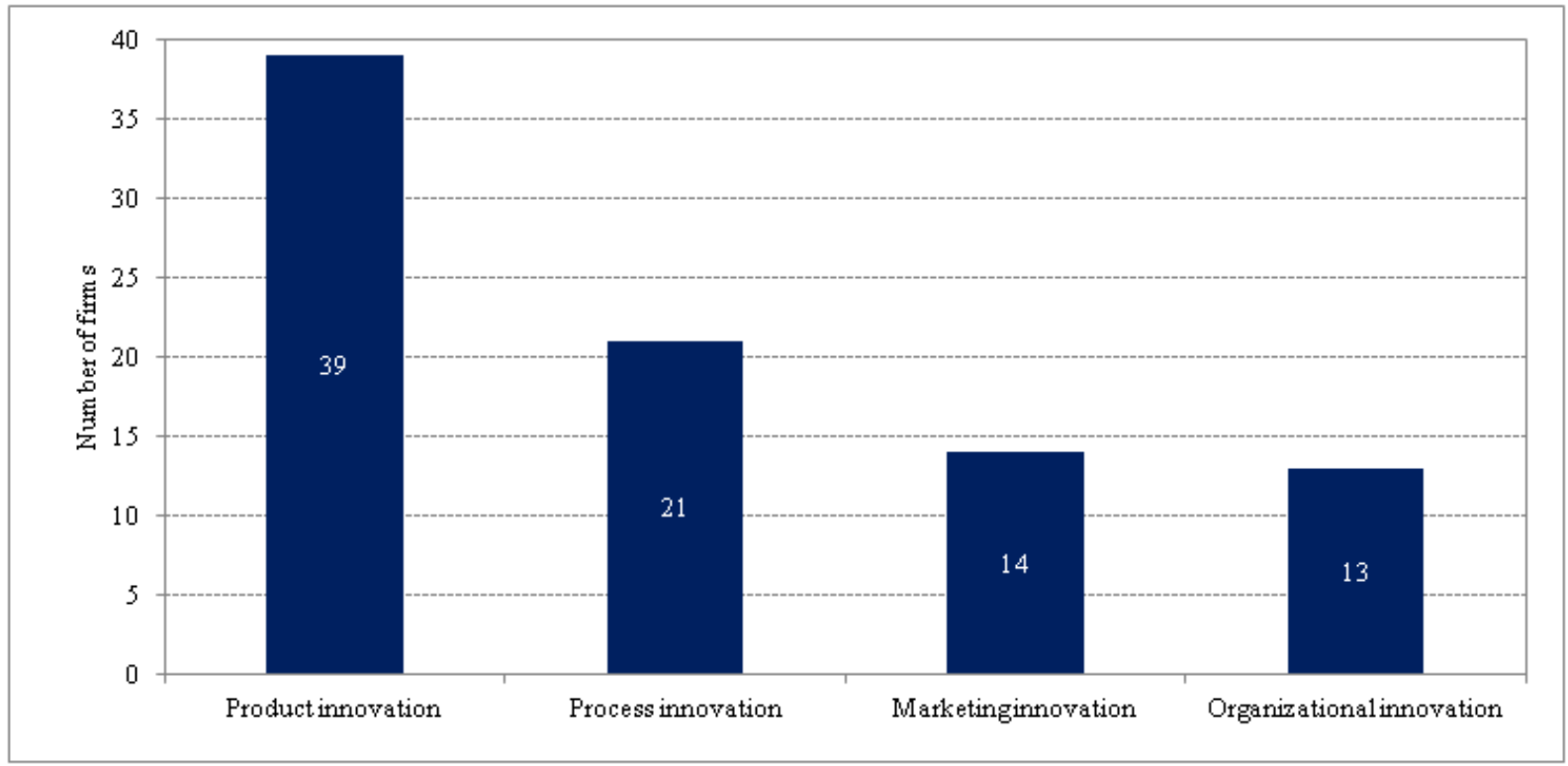

Regarding the question of which area of innovation was the most important for the firms during the $2005-2010$ period, the answers to the previous question are only conditionally confirmed. Here as well, 64 percent of the firms name product innovation as the most important area of innovation, as Figure 48 shows. The fields of marketing or organization as the main focus of innovation were named by 13 percent of the firms. This corresponds to almost identical comparison levels of innovations actually carried out by the firms between 2005- 2010. Process innovation is stated by 11 firms as being the most important innovation field. This figure is opposed to the number of innovations actually carried in the $2005-2010$ period. The reason is that 33 percent of the firms have carried out both product and process innovations, but, regarding the importance of individual innovation fields, the majority of these firms have a priority for product innovation. 
Figure 48. Priority of the innovation fields

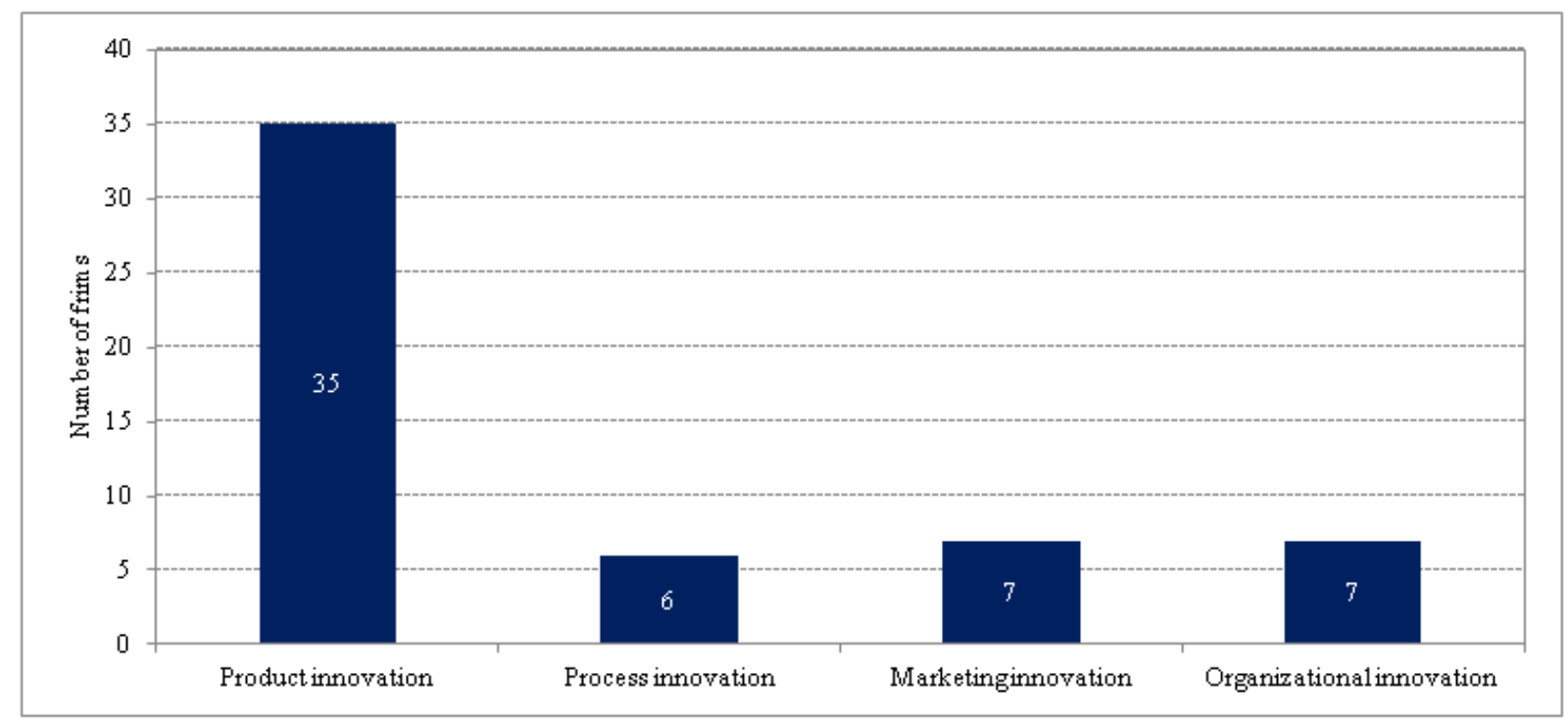

\section{Funding}

Table 27 shows statistical parameters for the different funding authorities for approved R\&D programs of the firms for the 2010 - 2005 period. The values refer to the number of approved R\&D programs and are not a measure of the subsidy volumes.

Table 27. Parameters for the different funding authorities

\begin{tabular}{lllllll}
\hline & Sum Total & Median & Average & $\begin{array}{r}\text { Standard } \\
\text { error of } \\
\text { average }\end{array}$ & SD & Min. \\
\hline Saxony-Anhalt & 32 & 0 & 0,6 & 0,2 & 1,1 & 0 \\
\hline Federal & 48 & 0 & 0,9 & 0,2 & 1,3 & 0 \\
EU & 6 & 0 & 0,1 & 0,1 & 0,4 & 0 \\
\hline Total & 86 & 1 & 1,6 & 0,3 & 2,1 & 0 \\
\hline
\end{tabular}

56 percent of the firms have used funding from $R \& D$ programs during the period under review, regardless of the funding authority. 34 percent of firms have used R\&D programs of the state of Saxony-Anhalt. Success in applying for Federal R\&D funding programs was reported by 44 percent of the firms. R\&D funding programs of the European Union, however, were used by only 9 percent of the enterprises. With regard to the absolute frequency of funding programs used, the companies 
operate quite differently. The maximum is 10 , the median 1, as Figure 49 shows.

Figure 49. Number of funding programs by funding authority



\section{$R \& D$ activities between enterprises}

Of the companies surveyed, 91 percent reported to have generated novel R\&D knowledge through interaction with other firms during the 2005 - 2010 period. The different forms of R\&D knowledge transfer through interaction between firms are also of interest, as is the intensity by which the different channels were used. Figure 50 documents the results on this issue. 
Figure 50. Forms of R\&D knowledge transfer between firms

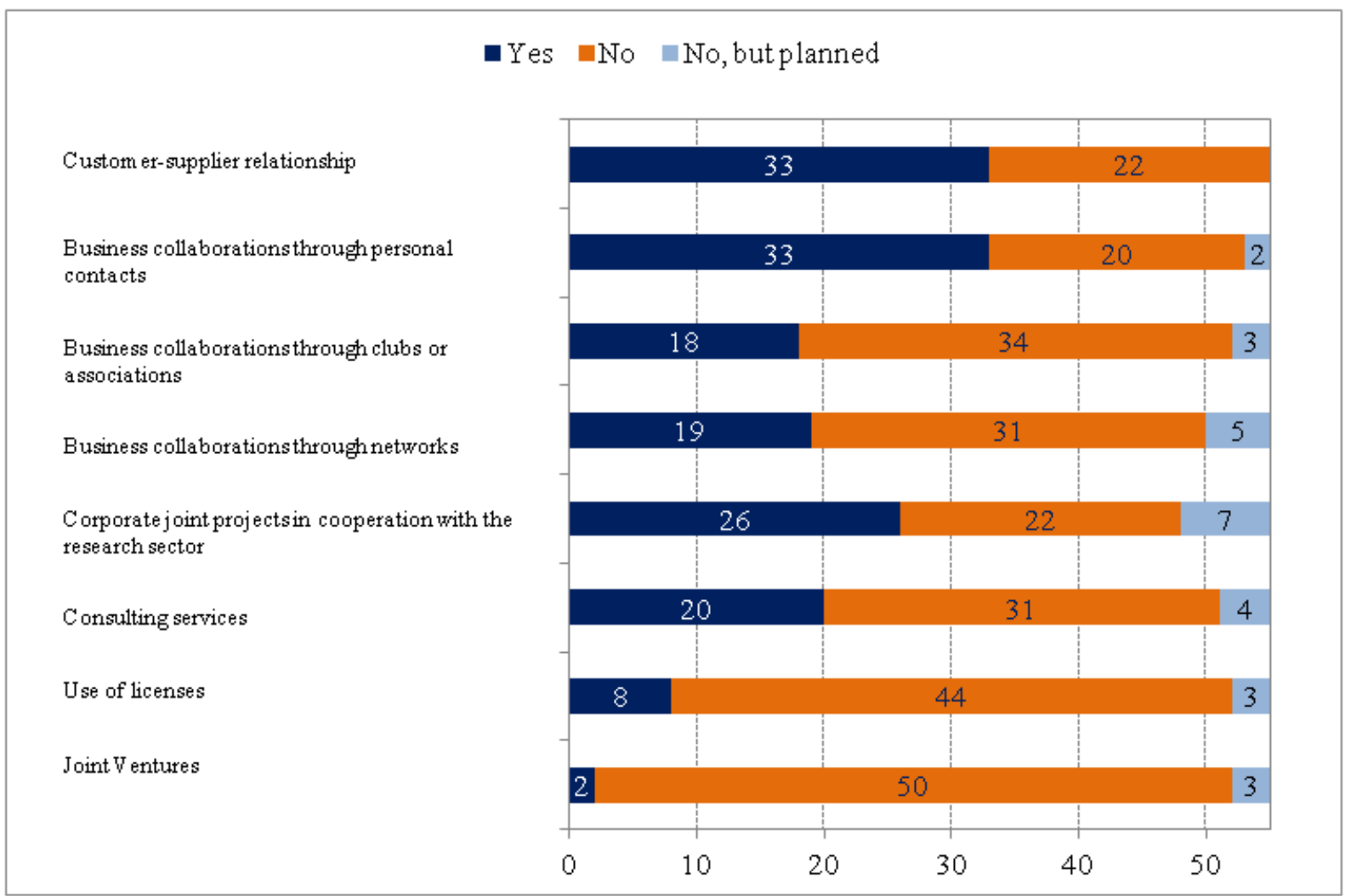

The customer-supplier relationship and cooperation through personal contacts are most frequently used by firms for the purposes of R\&D knowledge transfer. These forms of knowledge transfer are each relevant for 60 percent of the surveyed firms. 47 percent of the firms generate new R\&D knowledge through corporate joint projects in cooperation with the research sector. Another 13 percent of firms plan to use this form of knowledge transfer in the future. Less than 40 percent of the firms stated that they generate new knowledge through collaborations with other companies that were initiated by network structures. Patents and joint ventures as a form of knowledge transfer between firms a play a subordinate role. For the interaction between the firms, there are hardly any differences in terms of a geographic market differentiation. For the sampled firms, partner firms in the local market of Magdeburg, the regional market of Saxony-Anhalt, and the national market of Germany, all have approximately the same importnace for the acquisition of R\&D knowledge. Foreign firms, in contrast, are of much less importance.

\section{$R \& D$ activities between enterprises and the research sector}

Of the firms surveyed, 49 percent cooperate with the research sector in order to generate new R\&D knowledge. Figure 51 illustrates the various reasons why 51 percent of firms have not yet engaged in any type of cooperation with the research sector. 


\section{Figure 51. Reasons why firms do not cooperate with the research sector}

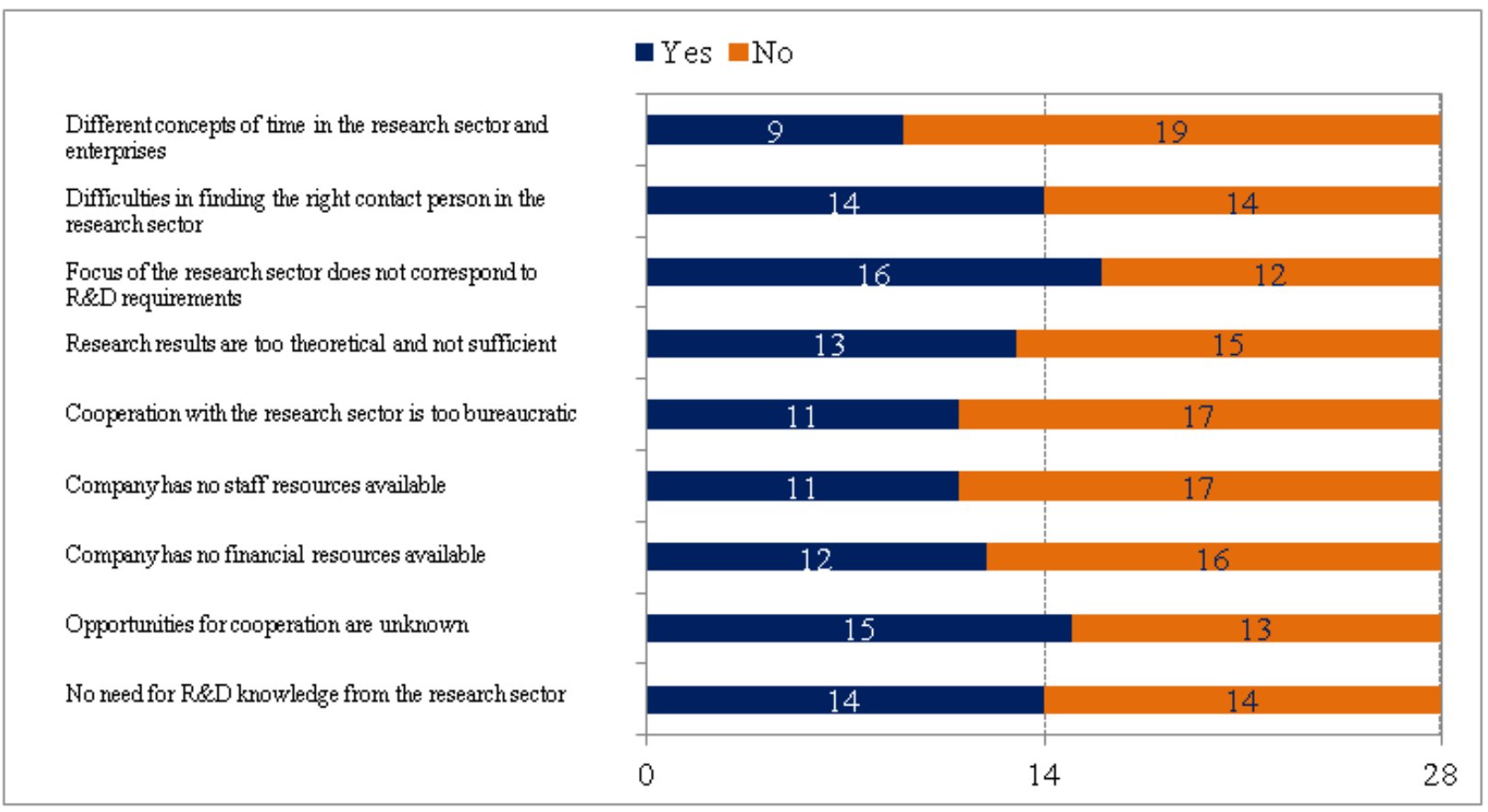

The main hurdle to cooperation with the research sector lies with the focus of the research sector, which often does not correspond to the R\&D needs of the regional enterprises. This reason was cited by 57 percent of the firms. Another barrier to cooperation between science and business that of communication. 54 percent of firms that are not presently collaborating with the research sector, for instance, reported that opportunities for cooperation were unknown to them. Furthermore, 50 percent of these firms report problems in identifying the right contact person within the research sector. On the other hand, only 43 percent of firms stated their own inadequate financial resources as a cause for missing cooperation with the research sector in order to gain new R\&D knowledge.

\section{Cooperation with the research sector}

In terms of the firms' collaboration with the research sector, a differentiated approach was taken in order to distinguish between universities and research institutes. Of the firms that do cooperate with the research sector, 78 percent of firms are working together with the universities and 59 percent with the research institutes. 22 percent of the firms cooperate with both universities and research institutes.

\section{Universities}

For the firms cooperating with the research sector, universities in the local economic area of Magdeburg play a decisive role. Of these firms, 52 percent are working together with the Otto-vonGuericke University, Magdeburg, and 33 percent with the Magdeburg-Stendal University of Applied Sciences in order to acquire R\&D know-how, as Figure 52 shows. In addition, 41 percent of the firms engage in cooperation with other universities in Germany. Other universities outside the economic region of Magdeburg but still within Saxony-Anhalt play a minor role for the firms, as do universities 
from abroad.

Figure 52. University cooperation's

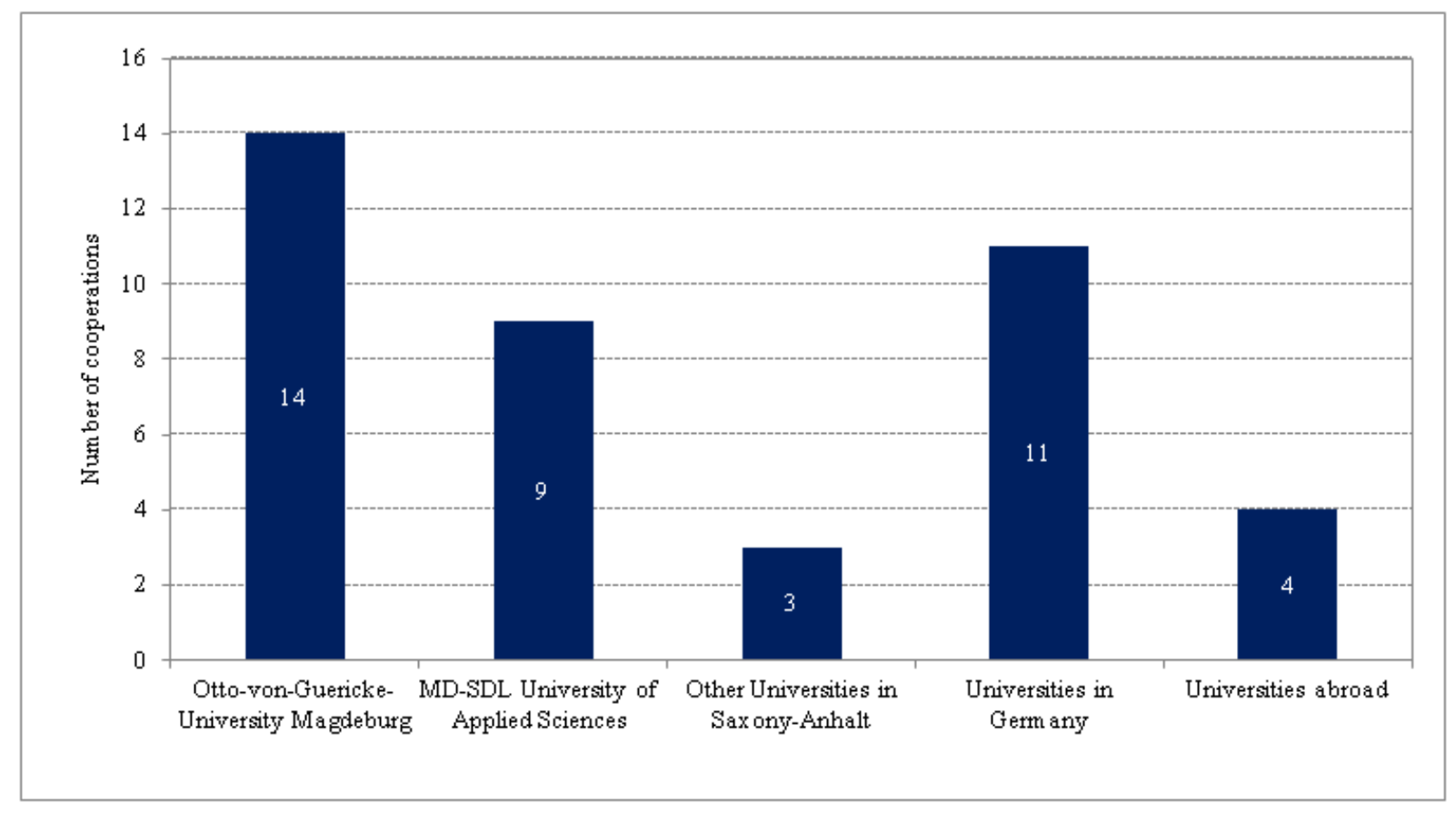

Otto-von-Guericke-University Magdeburg (OvGU)

Informal cooperation with individual scientists as a transfer option for the exchange of R\&D knowledge between the OvGU and the firms is used by 100 percent. As Figure 53 shows, a central role for the transfer of R\&D knowledge to the firms is also played by commissioned research, funded by grant programs, as well as cooperation on the basis of internships, bachelor, master, and doctoral theses. Licensing and registration of patents play only a minor role. 
Figure 53. Forms of knowledge transfer at Otto-von-Guericke University

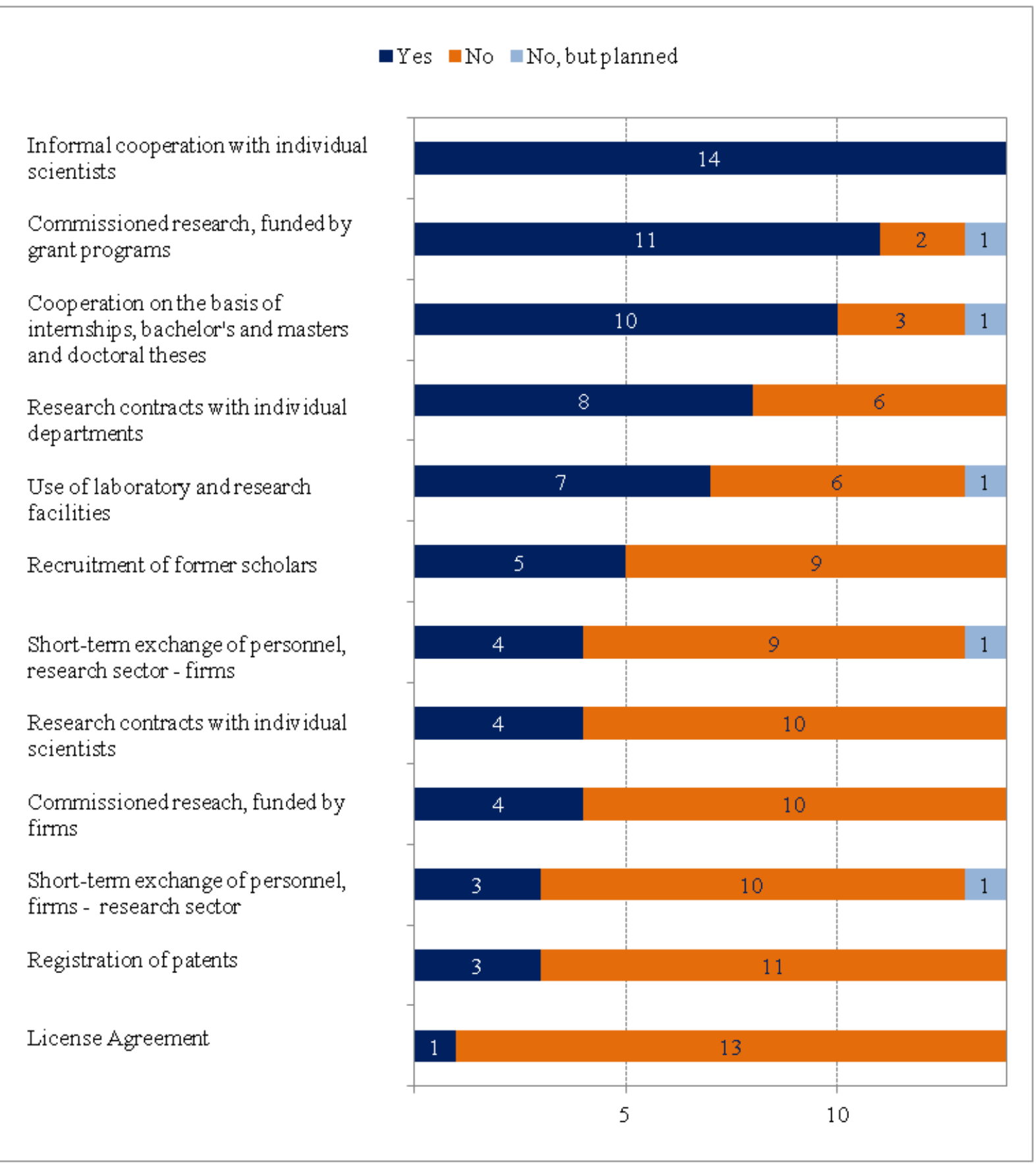

Magdeburg-Stendal University of Applied Sciences (HS MD-SDL)

Of the firms that collaborate with the HS MD-SDL, 78 percent use informal cooperation with individual scientists in order the generate new R\&D knowledge. In addition, commissioned research, funded by grant programs, as well as cooperation on the basis of internships, bachelor and master theses, are a core factor of cooperation. The results are presented in Figure 54. 
Figure 54. Forms of knowledge exchange at the HS MD-SDL

Informal cooperation with individual scientists

Commissioned research, funded by grant programs

Cooperation on the basis of internships, bachelor's and masters and doctoral theses

Research contracts with indiv idual departments

Use of laboratory and research facilities

Recruitment of former scholars

Short-term exchange of personnel, research sector - firms

Research contracts with indiv idual scientists

Commissioned reseach, funded by firms

Short-term exchange of personnel, firms - research sector

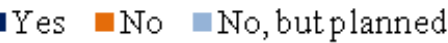

Registration of patents

License Agreement

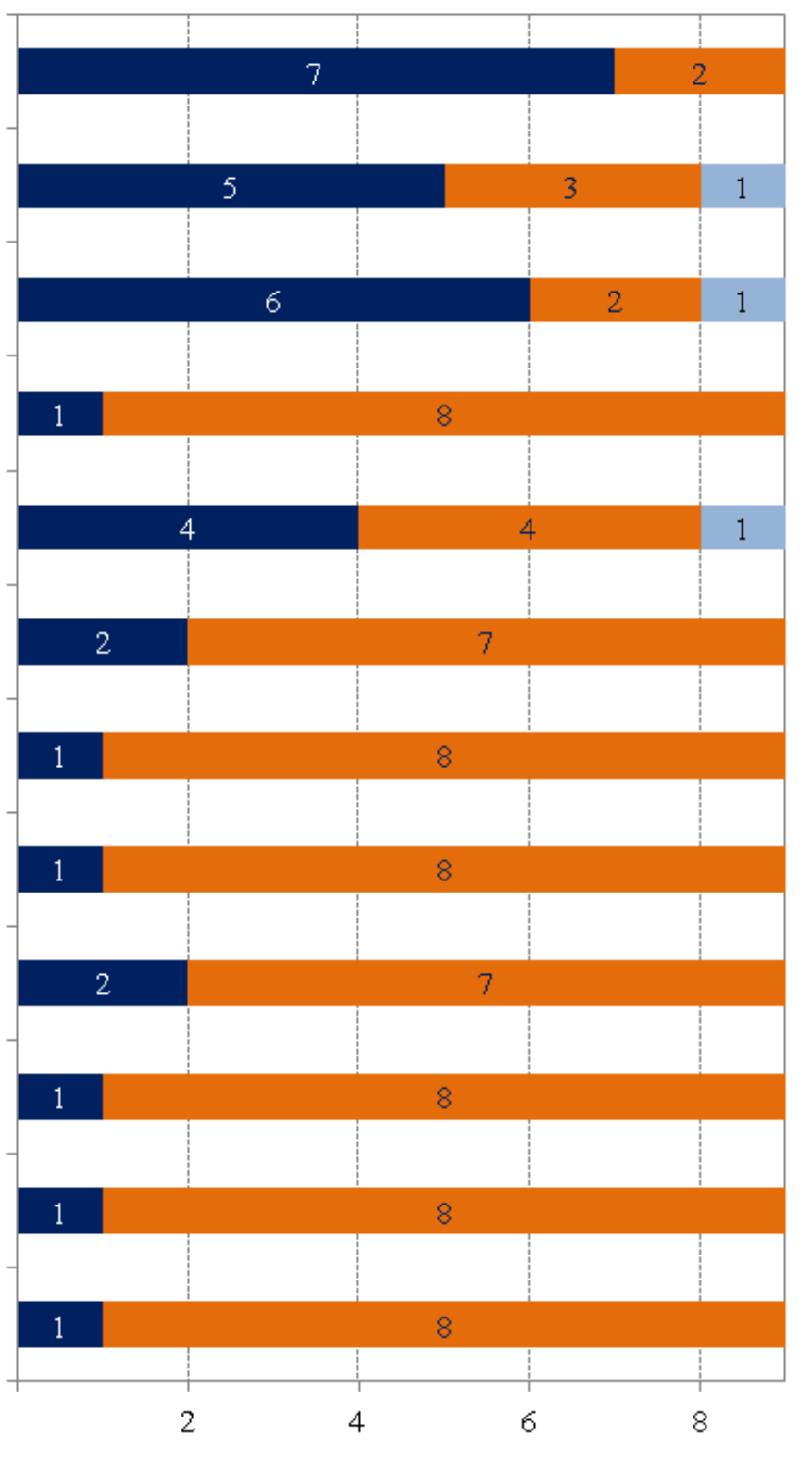

\section{Universities in Germany}

Besides the informal cooperation with individual scientists, research contracts with individual departments play an important role for firms in terms of their cooperation with universities in Germany. As Figure55 shows, no single dominant form of R\&D transfer from universities to the various firms can be identified for this geographical area. 
Figure 55. Forms of knowledge exchange with other universities in Germany



\section{Universities in Saxony-Anhalt}

Of the companies cooperating with the research sector, 11 percent are working together with other universities in the state of Saxony-Anhalt (excluding the universities in Magdeburg) in order to generate new R\&D knowledge. The predominant form of knowledge transfer is that of contract research, funded by scholarships and research contracts with individual scientists.

\section{Universities abroad}

15 percent of the sampled firms cooperate with foreign universities. This interaction takes place 
largely in the form of informal cooperation with individual scientists.

\section{Research institutes}

With respect to the cooperation of firms with research institutes, Fraunhofer IFF is of central importance for the economic region of Magdeburg, as can be seen in Figure 56. Of the total number of firms that cooperate with the research sector in order to generate R\&D knowledge, 45 percent are interacting with Fraunhofer IFF. Furthermore, 19 percent of the firms maintain contacts with other research institutes in Saxony-Anhalt and 11 percent with other research institutes in Germany. Research institutes abroad are of minor significance to the firms surveyed. The Max-Planck-Institute in Magdeburg has a low priority for the firms when it comes to the acquisition of R\&D knowledge. As for the Helmholtz-Zentrum für Umweltforschung and the Leibniz-Institut für Neurobiologie, the survey was unable to determine cooperative relations with enterprises.

Figure 56. Cooperation with research institutes

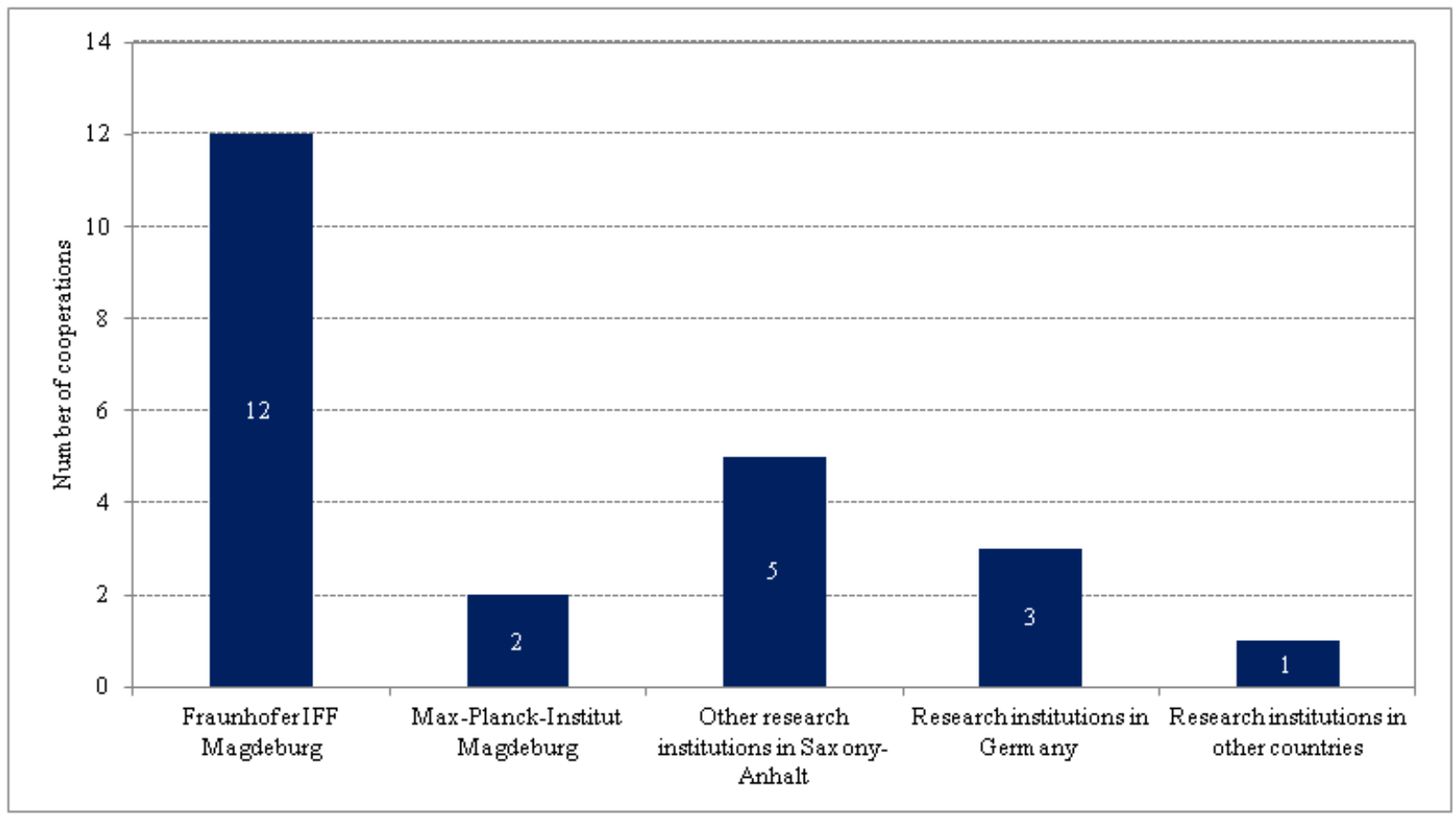

\section{Fraunhofer IFF}

Contract research funded by grant programs is the most common form of cooperation between the companies and the Fraunhofer IFF and is used by 75 percent of the firms that are working together with the Fraunhofer IFF. The form of informal cooperation with individual scientists is used by 67 percent of the firms in order to acquire new R\&D knowledge. In addition, 42 percent of the firms access the laboratories and research facilities of the Fraunhofer IFF, as is shown in Figure 57. 
Figure 57. Forms of knowledge exchange at the Fraunhofer IFF

Informal cooperation with individual scientists

Commissioned research, funded by grant programs

Use of laboratory and research facilities

Recruitment of former scholars

Short-term exchange of personnel, research sector - firms

Commissioned reseach, funded by firms

Short-term exchange of personnel, firms - research sector

Registration of patents

License Agreement
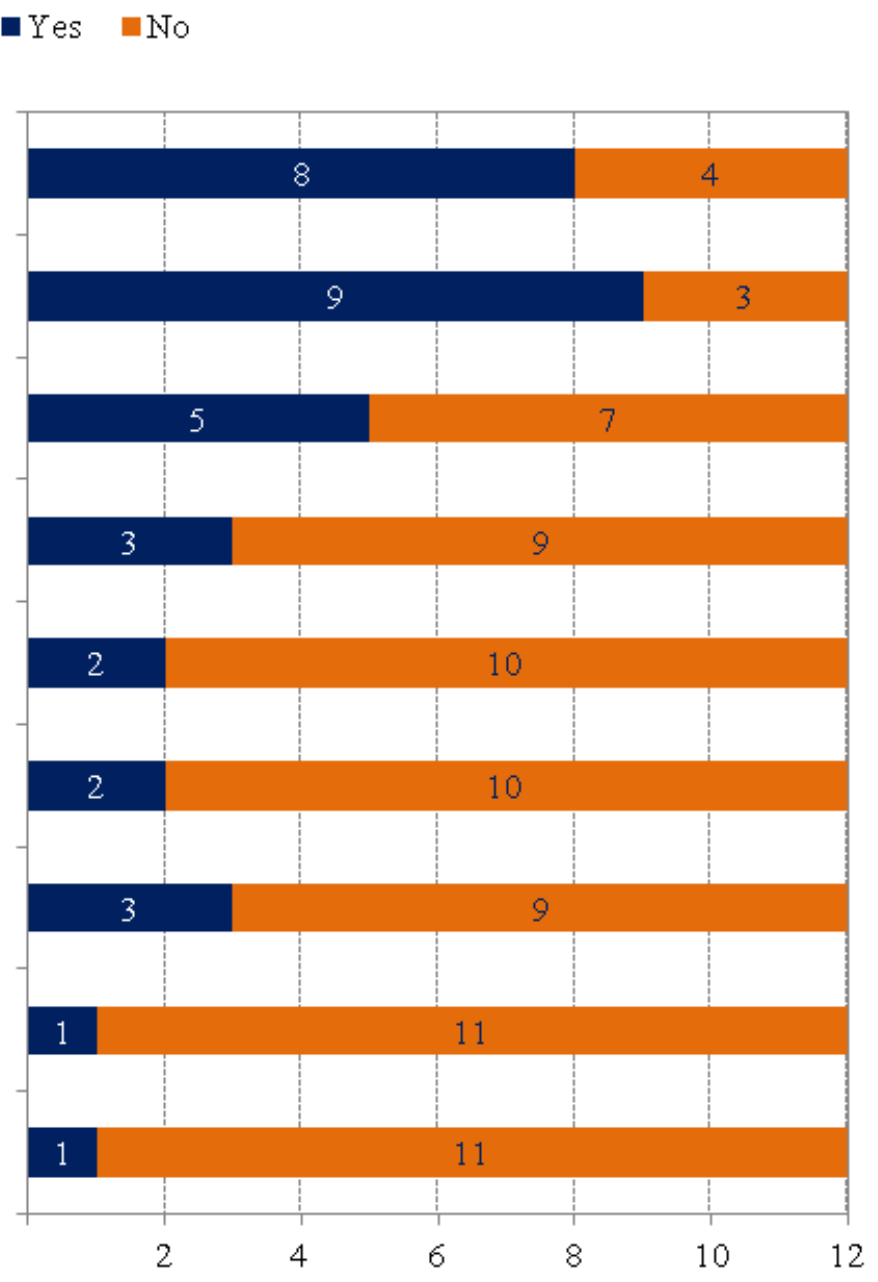

\section{Max-Planck-Institute}

For the purposes of research and knowledge acquisition, 7 percent of the surveyed firms that cooperate with the research sector use the services of the Max-Planck-Institute in Magdeburg. Informal cooperation with individual scientists and contract research funded by grant programs were stated as the only forms of knowledge exchange.

\section{Research institutions in Saxony-Anhalt}

19 percent of companies that cooperate with the research sector engage in interaction with other research institutes in Saxony-Anhalt (outside of Magdeburg). Of these companies, all use informal cooperation as a medium to transfer R\&D knowledge. In addition, contract research, funded by grant programs, is of high priority for the cooperation between enterprises and research institutes in SaxonyAnhalt, as Figure 58 reveals. 
Figure 58. Forms of knowledge exchange with other research institutes in Saxony-Anhalt



\section{Research institutes in Germany}

11 percent of the firms (in total three firms) engage in relations with other research institutes in Germany, outside of Saxony-Anhalt. The forms of cooperation are mainly confined to informal cooperation with individual scientists and the use of laboratory and research facilities of the Institutes.

\section{Research institutes abroad}

Cooperation with research institutes abroad is confined to contract research, funded by grant programs, and is only relevant for one firm.

\section{Difficulties in cooperation between science and industry}

Of the companies that cooperate with the research sector in order to generate R\&D knowledge, 70 percent see a problem in the unsuitability of the research focuses to match the R\&D needs of the firms, as is clear from Figure 59. 56 percent of firms see a barrier to cooperation both in the disagreement over the project period and the different commercialization interests between science 
and industry. 48 percent of firms consider working with the research sector as too bureaucratic. Communication problems during cooperation cannot be ignored, but are subordinate to other causes.

Figure 59. Difficulties in cooperation between science and industry

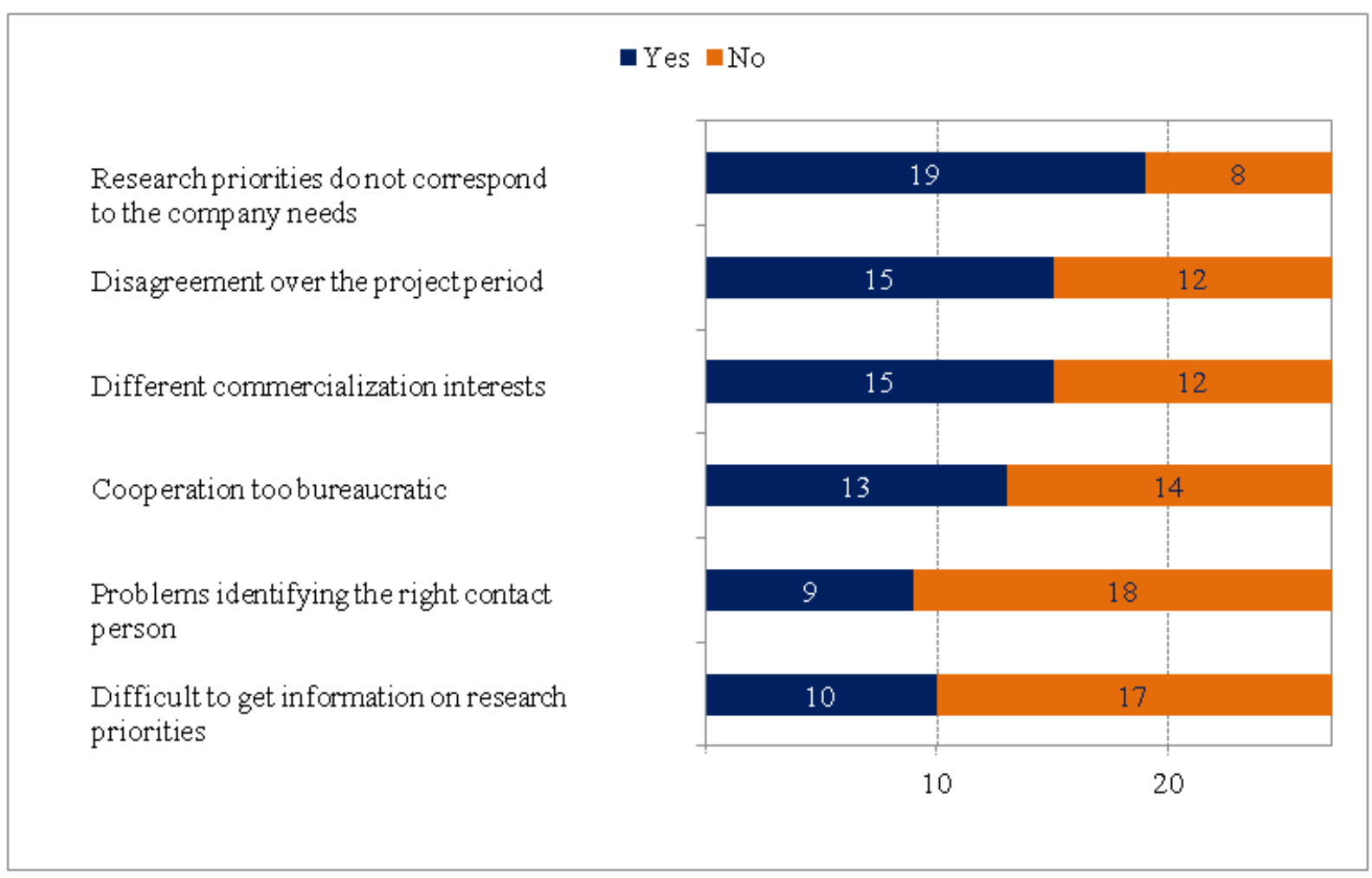

\section{Other facilities for the acquisition of R\&D knowledge}

Besides the interaction with the research sector and other companies, the firms in the Magdeburg region were also asked which other institutions are important to them in the pursuit of R\&D knowledge. For 62 percent of the firms, the CIC Magdeburg counts as a key contact partner for R\&D, as Figure 60 shows. Of the transfer facilities, the Association for Technology Transfer and Promotion of Innovation (tti GmbH) a key contact partner for R\&D for 49 percent of the firms. In contrast, the Technology Transfer Center at Otto-von-Guericke University, Magdeburg (TTZ), and the Competence Network for Applied and Transfer Oriented Research (KAT) have thus far not played a significant role for the surveyed firms for the transfer of knowledge. The structure of the special mechanical and systems engineering cluster at the state level, controlled by the tti $\mathrm{GmbH}$, is relevant for 49 percent of the firms. Here one can presume a direct correlation between the cluster and project funding authority. A confirmation for this assumption is found when looking at the automotive cluster at the state level and its funding authority SAA e.V. as an industry-specific association. Both are relevant for 22 percent of companies engaged in R\&D. The Association for Economic Services of Magdeburg (GWM), whose industry classification forms the basis for the selection of the investigated sectors in this study, is used by 20 percent of the firms as a direct point of contact for the acquisition of $R \& D$ knowledge. Of the infrastructure facilities, the Innovations and Founder Center Magdeburg (IGZ) is considered a suitable environment for 27 percent of the firms in order to generate new knowledge from R\&D. 
Figure 60. Additional facilities for the acquisition of R\&D

knowledge

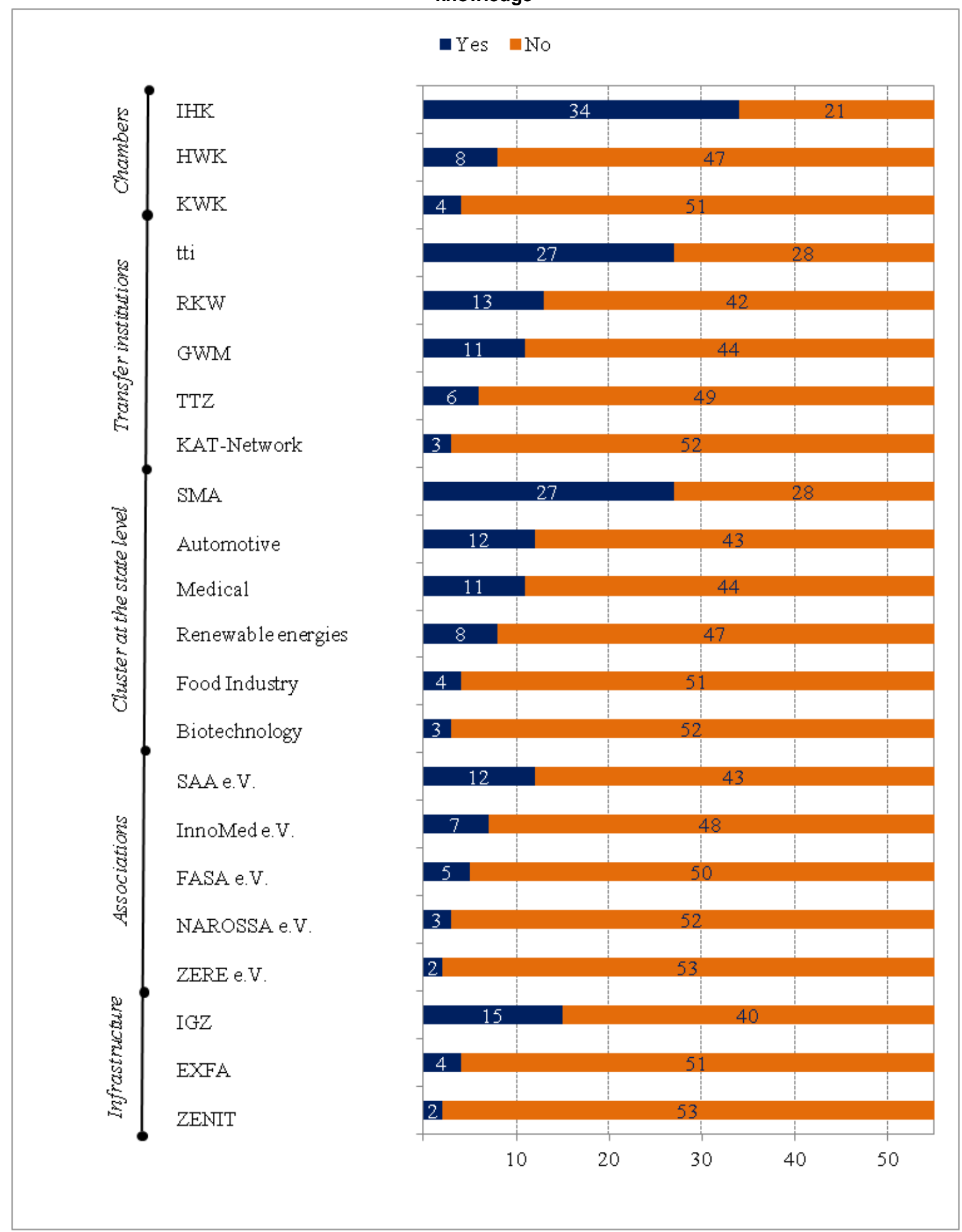

Additional alternatives for the acquisition of $R \& D$ knowledge

When asked what alternative sources are used for the acquisition of R\&D knowledge, 89 percent of the surveyed firms report that the trade press is a suitable medium. In addition, 80 per cent of the 
companies also use the interaction with their customers to new generate new knowledge in the field of research and development. The forms of staff training, trade shows, and exhibitions, as well as the recruitment of qualified personnel are also important tools for knowledge transfer, as Figure 61 shows.

Figure 61. Additional alternatives for the acquisition of R\&D knowledge

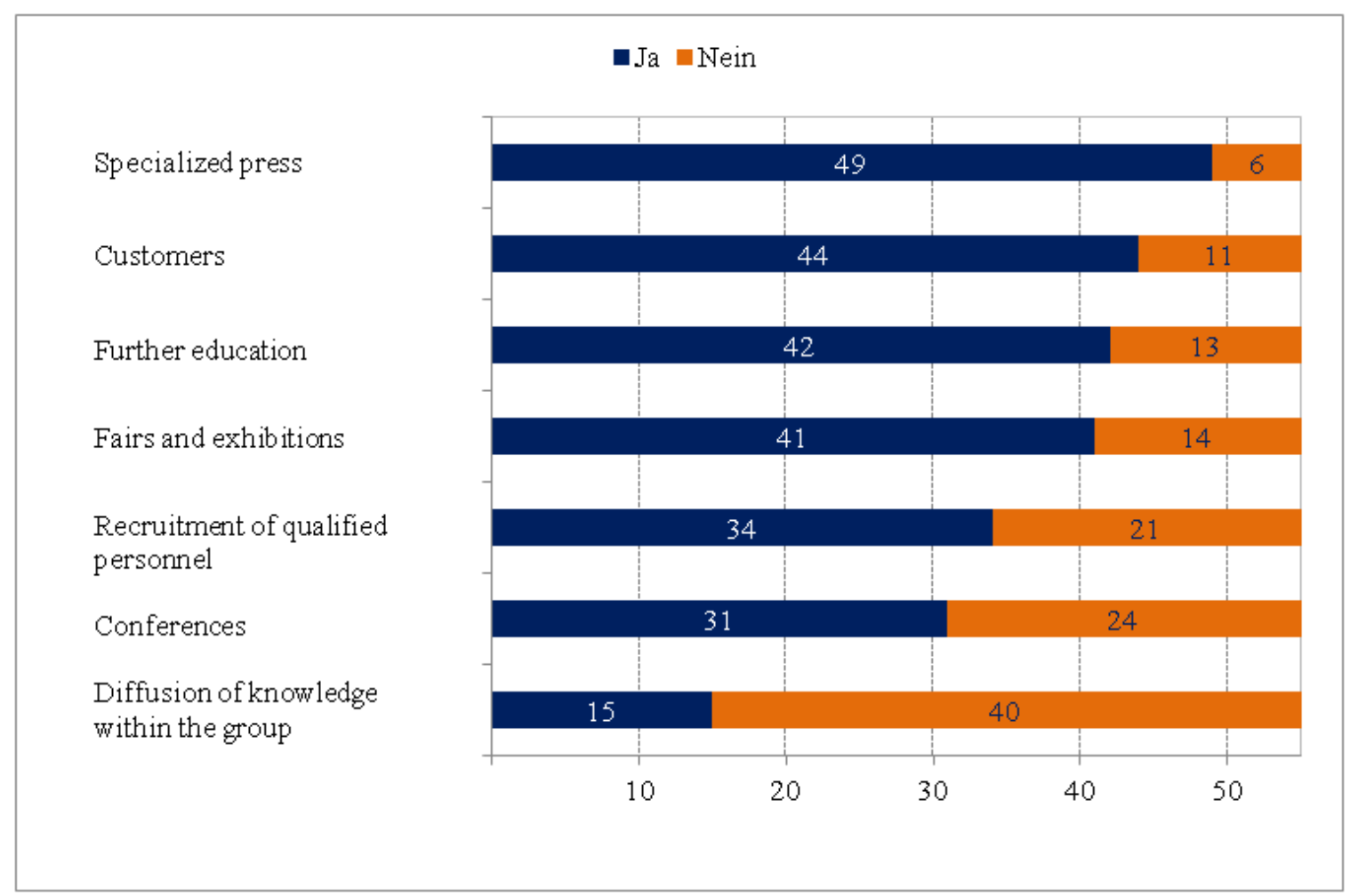

Influence of grant programs on R\&D in firms

Figure 62. Influence of grant programs on R\&D in firms

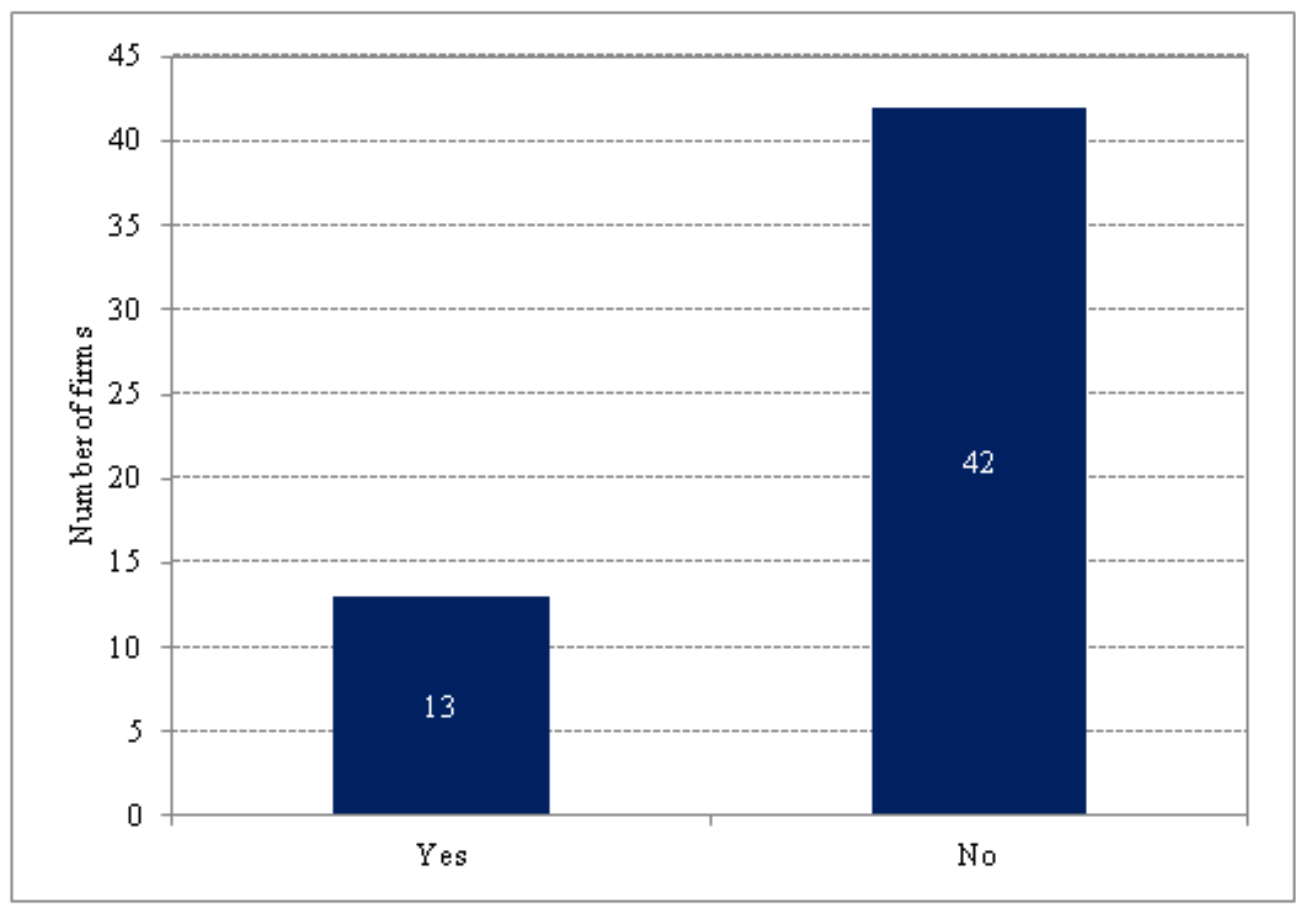


Figure 62 reveals that 76 percent of the surveyed enterprises would not have been able to implement innovative processes to the same extent, without fun-ding from the R\&D grant programs. This documents the centrality of $R \& D$ funding with a particular focus on the micro and small-size enterprises in the economic region of Magdeburg.

\section{R\&D framework conditions in the economic region of Magdeburg}

Figure 63 shows the evaluations of the framework conditions for $R \& D$ in the region of Magdeburg. The training of qualified personnel is considered by 20 percent of the surveyed firms as being deficient. 51 percent of the firms report that there is at least a sufficient level of training of qualified personnel in the Human Resources sector of the economic region of Magdeburg. 64 percent of the firms consider financing of $R \& D$ through grant programs to be at least adequate. The dissemination of information on these grant programs is estimated to be at least adequate by 67 percent of the firms, and 7 percent even consider it to be excellent. Moreover, the development of network structures is considered to be at least adequate by 58 percent of the firms. Remarkably, most of the firms state that they are unable to evaluate the support of competitiveness and internationalisation or the quality standards of the public administration that supports R\&D. In both categories, the proportion of companies that can attest at least sufficient conditions is below 50 percent.

\section{Figure 63. Framework conditions for R\&D in the region of Magdeburg}

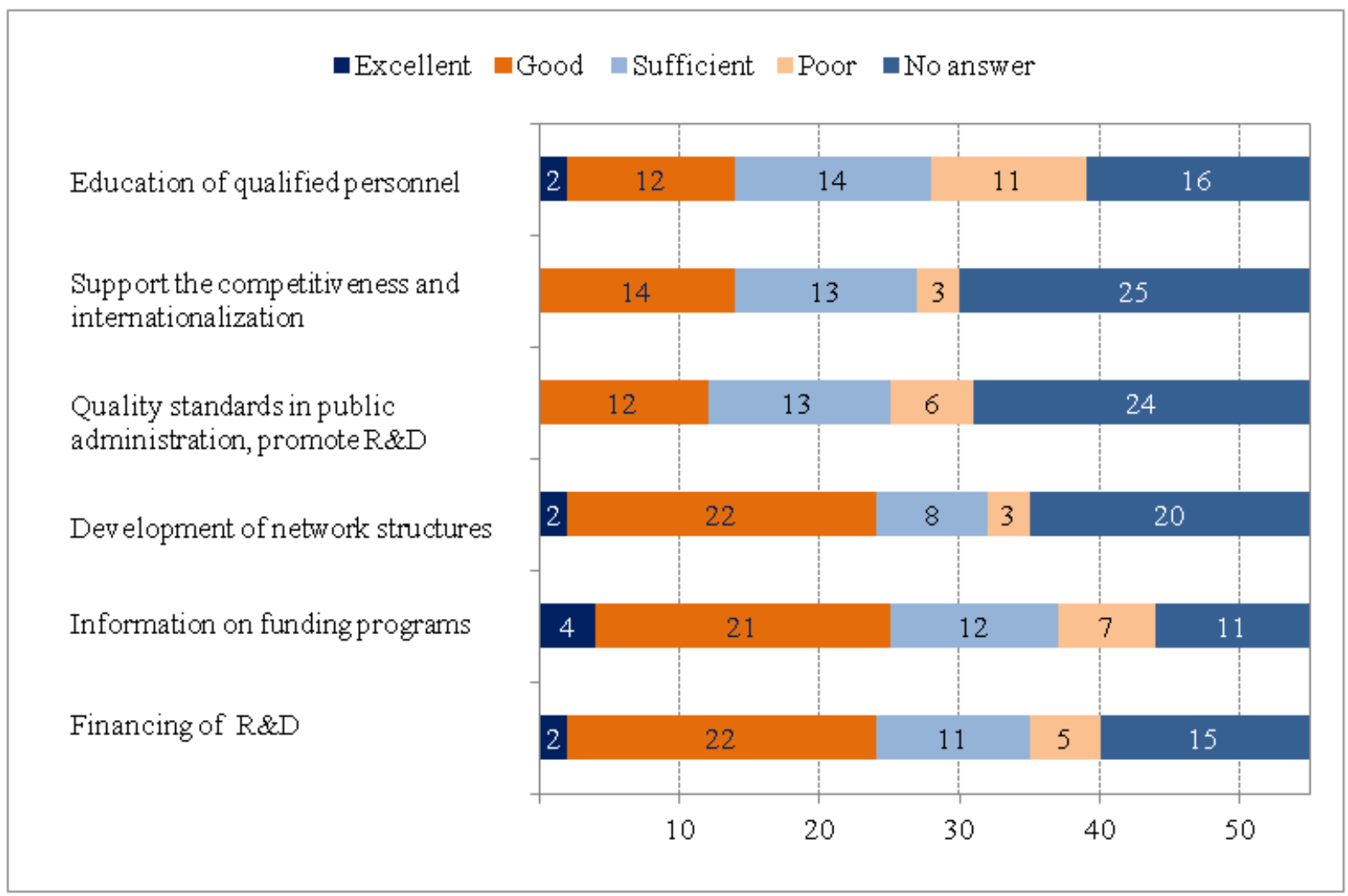




\section{Network structures}

\section{Integration in network structures}

According to Figure 64, 80 percent of the surveyed firms are currently integrated in a network structure. Only 29 percent of the firms are active in a cluster at the state level and in a sector-specific club or organization. Furthermore, 27 percent of the firms use only the structure of the clusters at the state level and 24 percent only that of sector-specific clubs or associations for their networking activities.

Figure 64. Integration in network structures

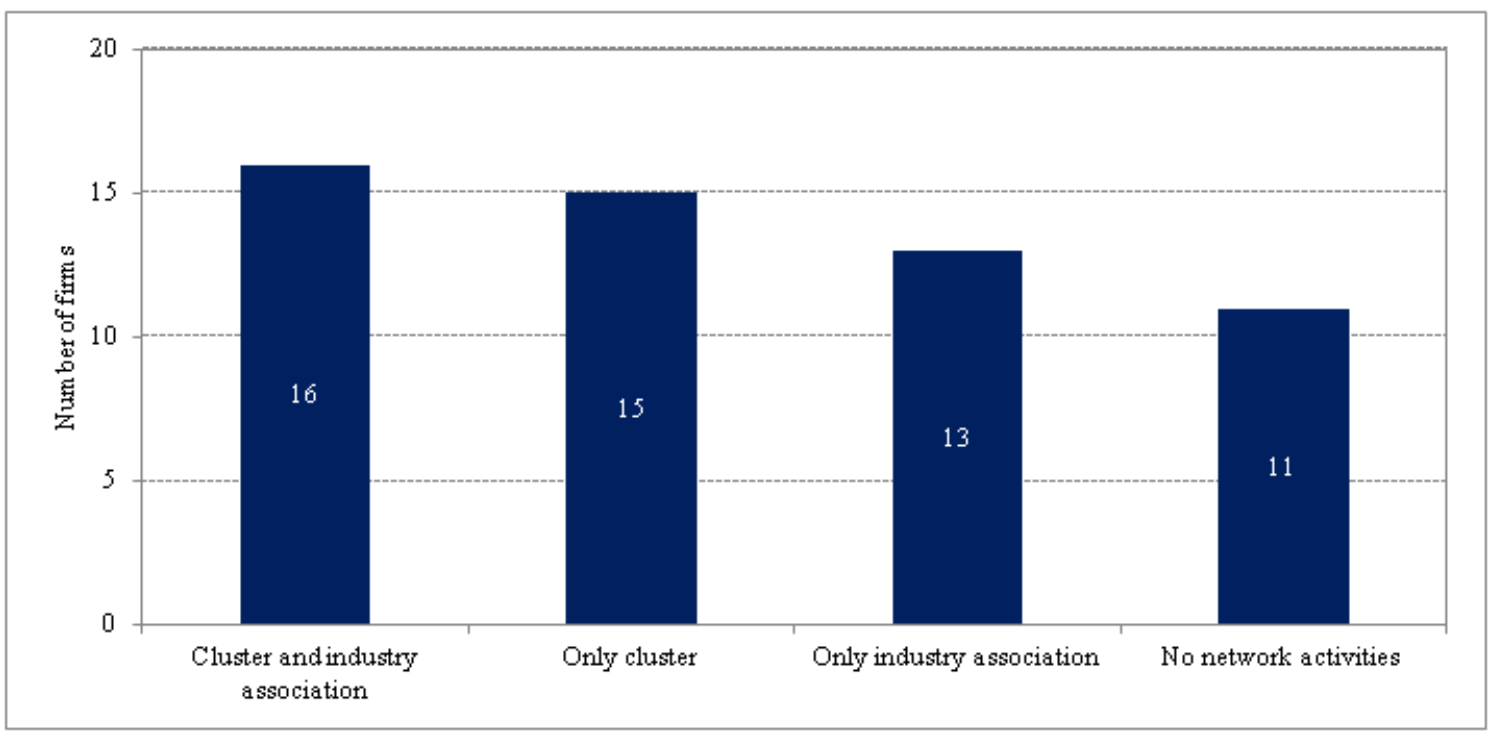

\section{Benefits of network structures}

Of the firms active in network structures, 82 percent were able to exploit or apply at least one of the benefits shown in Figure 65 for their firms. For example, 71 percent of the firms currently benefit from improved access to business partners. In addition, 64 percent report improved access to funding programs through the use of network structures. A greater understanding of the processes of innovation through $\mathrm{R} \& \mathrm{D}$, because of their networking activities, have been reported by 53 percent of the firms. 
Figure 65. Network benefits to the firms

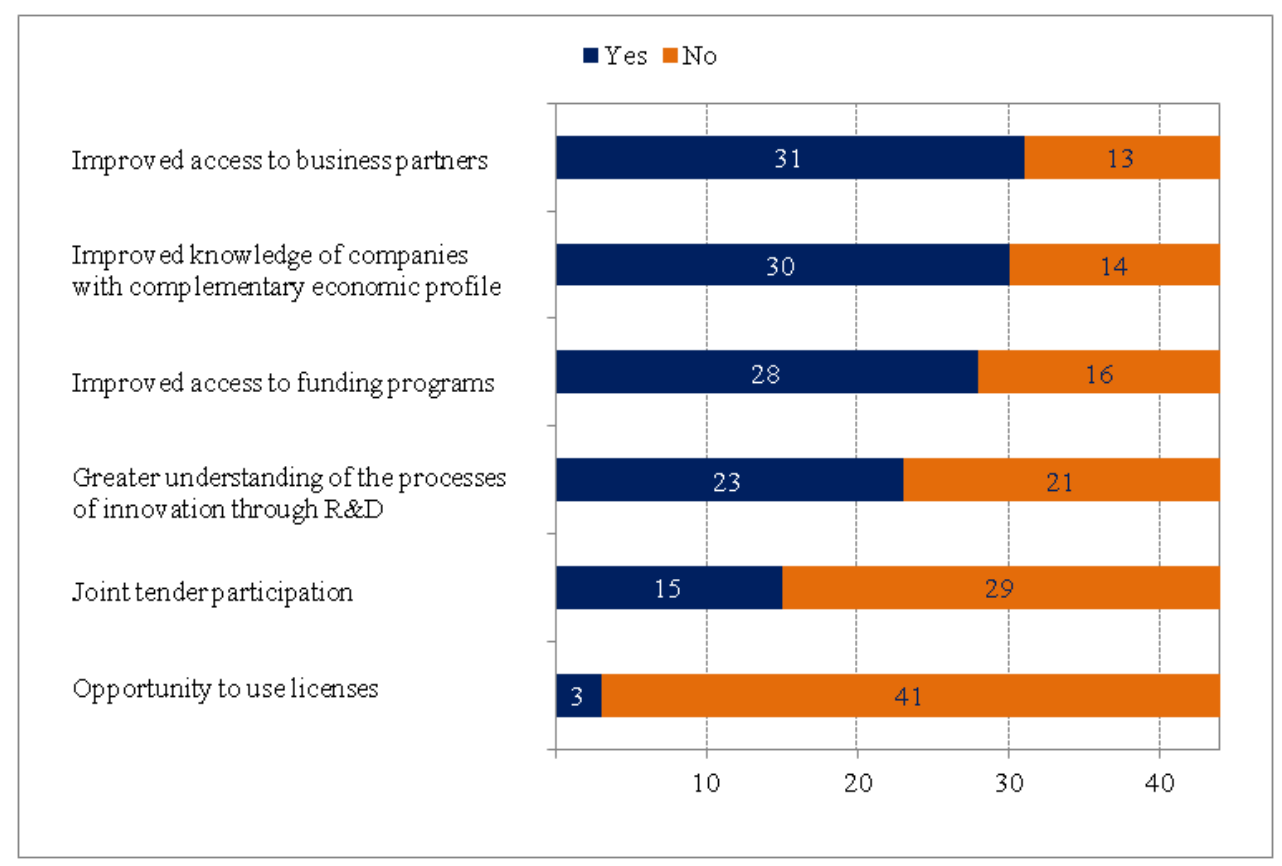

Network optimization options

Figure 66 shows how the firms evaluate the optimization options for R\&D knowledge transfer. 69 percent of the firms would benefit from improved coordination within public projects between academia and industry were. In addition, 64 percent of the firms consider there to be potential for improvement in the industry-related training of students in higher education. Around 50 percent of the companies would benefit from an improved shared use of the available infrastructure of science and industry. In addition, 47 percent favor a further development of the economic clusters of the City of Magdeburg.

Figure 66. Optimization possibilities of networks

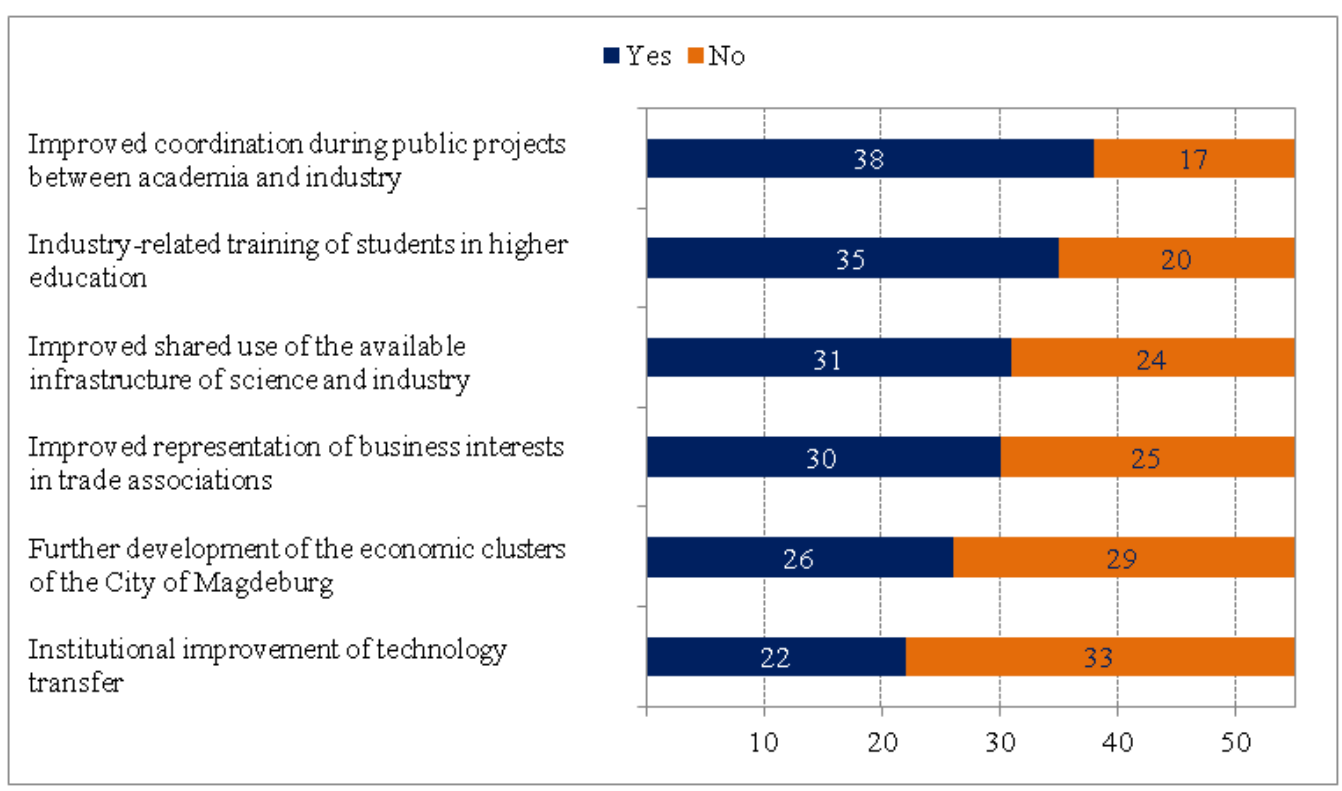




\section{FURTHER ANALYSIS}

In this chapter, the results of previous evaluations are condensed by means of crosstabs. The aim is to obtain qualitative information about each variable and to identify possible dependencies on other variables. Due to the partially low frequencies $(<5)$ of individual variables, there is no need for a significance test at this point, because a representative result cannot be guaranteed. Nevertheless, implications and trends can be shown.

\section{Industry code}

According to the definition of new firms in this study, the highest percentage share of new firms is in the environmental technology and recycling management industry, as shown in Table 28. In addition, it is apparent that the mechanical engineering sector firms, at over 90 percent, are the ones most prominently involved in networks. Furthermore, this sector has by far the highest patent activity. 
Table 28. Industry code 1

\begin{tabular}{|c|c|c|c|c|c|c|c|}
\hline & & & \multicolumn{4}{|c|}{ Industry code } & \multirow[b]{2}{*}{ Total } \\
\hline & & & $\begin{array}{l}\text { Mechanical } \\
\text { engineering }\end{array}$ & $\begin{array}{c}\text { Environm.tech. } \\
\text { and recycling } \\
\text { man. }\end{array}$ & $\begin{array}{c}\text { Healthcare } \\
\text { sector }\end{array}$ & Other & \\
\hline \multirow{9}{*}{$\begin{array}{l}\text { New and } \\
\text { old firms }\end{array}$} & Old & Number & 17 & 5 & 4 & 18 & 44 \\
\hline & & Expected number & 16.8 & 7.2 & 4.8 & 15.2 & 44.0 \\
\hline & & $\%$ within industry & $81.0 \%$ & $55.6 \%$ & $66.7 \%$ & $94.7 \%$ & $80.0 \%$ \\
\hline & & code & & & & & \\
\hline & & Residuals & .2 & -2.2 & -.8 & 2.8 & \\
\hline & New & Number & 4 & 4 & 2 & 1 & 11 \\
\hline & & Expected number & 4.2 & 1.8 & 1.2 & 3.8 & 11.0 \\
\hline & & $\begin{array}{l}\% \text { within industry } \\
\text { code }\end{array}$ & $19.0 \%$ & $44.4 \%$ & $33.3 \%$ & $5.3 \%$ & $20.0 \%$ \\
\hline & & Residuals & -.2 & 2.2 & .8 & -2.8 & \\
\hline \multirow{9}{*}{$\begin{array}{l}\text { Network } \\
\text { affiliation }\end{array}$} & Yes & Number & 19 & 7 & 4 & 14 & 44 \\
\hline & & Expected number & 16.8 & 7.2 & 4.8 & 15.2 & 44.0 \\
\hline & & $\%$ within industry & $90.5 \%$ & $77.8 \%$ & $66.7 \%$ & $73.7 \%$ & $80.0 \%$ \\
\hline & & code & & & & & \\
\hline & & Residuals & 2.2 & -.2 & -.8 & -1.2 & \\
\hline & No & Number & 2 & 2 & 2 & 5 & 11 \\
\hline & & Expected number & 4.2 & 1.8 & 1.2 & 3.8 & 11.0 \\
\hline & & $\begin{array}{l}\% \text { within industry } \\
\text { code }\end{array}$ & $9.5 \%$ & $22.2 \%$ & $33.3 \%$ & $26.3 \%$ & $20.0 \%$ \\
\hline & & Residuals & -2.2 & .2 & .8 & 1.2 & \\
\hline \multirow{9}{*}{$\begin{array}{l}\text { Patent } \\
\text { activity }\end{array}$} & Yes & Number & 9 & 2 & 1 & 4 & 16 \\
\hline & & Expected number & 6.1 & 2.6 & 1.7 & 5.5 & 16.0 \\
\hline & & $\%$ within industry & $42.9 \%$ & $22.2 \%$ & $16.7 \%$ & $21.1 \%$ & $29.1 \%$ \\
\hline & & code & & & & & \\
\hline & & Residuals & 2.9 & -.6 & -.7 & -1.5 & \\
\hline & No & Number & 12 & 7 & 5 & 15 & 39 \\
\hline & & Expected number & 14.9 & 6.4 & 4.3 & 13.5 & 39.0 \\
\hline & & $\begin{array}{l}\% \text { within industry } \\
\text { code }\end{array}$ & $57.1 \%$ & $77.8 \%$ & $83.3 \%$ & $78.9 \%$ & $70.9 \%$ \\
\hline & & Residuals & -2.9 & .6 & .7 & 1.5 & \\
\hline
\end{tabular}

Only 33 percent of companies in the healthcare sector have accessed funding during the 2005 - 
2010 period. In the mechanical engineering industry, however, this share is over 80 percent, as illustrated in Table 29. In addition, more than 90 percent of the companies in this industry employ $\mathrm{R} \& \mathrm{D}$ personnel and can, therefore, per definition according to this study, be defined as $\mathrm{R} \& \mathrm{D}$ companies. Remarkably, only the mechanical engineering industry, with a value of less than $20 \%$, would have been able to implement $R \& D$ processes without $R \& D$ funding during the $2005-2010$ period. These findings reveal that the R\&D activity of firms in one industry in the economic region of Magdeburg is positively correlated with the existence of specially modified funding programs. The $\mathrm{R} \& \mathrm{D}$ activities of companies within the healthcare industry sectors as well as the environmental technology and recycling management sectors are significantly influenced by the presence of R\&D support programs. However, the percentage of companies that rely on this support is not nearly as high as in the mechanical engineering industry. 
Table 29. Industry code 2

\begin{tabular}{|c|c|c|c|c|c|c|c|}
\hline & & & \multicolumn{4}{|c|}{ Industry code } & \multirow[b]{2}{*}{ Total } \\
\hline & & & $\begin{array}{l}\text { Mechanical } \\
\text { engineering }\end{array}$ & $\begin{array}{c}\text { Environm.tech. } \\
\text { and recycling } \\
\text { man. }\end{array}$ & $\begin{array}{c}\text { Healthcare } \\
\text { sector }\end{array}$ & Other & \\
\hline \multirow{8}{*}{$\begin{array}{l}\text { Use of } \\
\text { funding }\end{array}$} & \multirow[t]{4}{*}{ Yes } & Number & 17 & 4 & 2 & 8 & 31 \\
\hline & & Expected number & 11.8 & 5.1 & 3.4 & 10.7 & 31.0 \\
\hline & & $\begin{array}{l}\% \text { within industry } \\
\text { code }\end{array}$ & $81.0 \%$ & $44.4 \%$ & $33.3 \%$ & $42.1 \%$ & $56.4 \%$ \\
\hline & & Residuals & 5.2 & -1.1 & -1.4 & -2.7 & \\
\hline & \multirow[t]{4}{*}{ No } & Number & 4 & 5 & 4 & 11 & 24 \\
\hline & & Expected number & 9.2 & 3.9 & 2.6 & 8.3 & 24.0 \\
\hline & & $\begin{array}{l}\% \text { within industry } \\
\text { code }\end{array}$ & $19.0 \%$ & $55.6 \%$ & $66.7 \%$ & $57.9 \%$ & $43.6 \%$ \\
\hline & & Residuals & -5.2 & 1.1 & 1.4 & 2.7 & \\
\hline \multirow{9}{*}{$\begin{array}{l}\text { R\&D } \\
\text { personnel } \\
\text { in the } \\
\text { company }\end{array}$} & \multirow[t]{5}{*}{ Yes } & Number & 19 & 5 & 2 & 13 & 39 \\
\hline & & Expected number & 14.9 & 6.4 & 4.3 & 13.5 & 39.0 \\
\hline & & $\%$ within industry & $90.5 \%$ & $55.6 \%$ & $33.3 \%$ & $68.4 \%$ & $70.9 \%$ \\
\hline & & code & & & & & \\
\hline & & Residuals & 4.1 & -1.4 & -2.3 & -.5 & \\
\hline & \multirow[t]{4}{*}{ No } & Number & 2 & 4 & 4 & 6 & 16 \\
\hline & & Expected number & 6.1 & 2.6 & 1.7 & 5.5 & 16.0 \\
\hline & & $\begin{array}{l}\% \text { within industry } \\
\text { code }\end{array}$ & $9.5 \%$ & $44.4 \%$ & $66.7 \%$ & $31.6 \%$ & $29.1 \%$ \\
\hline & & Residuals & -4.1 & 1.4 & 2.3 & .5 & \\
\hline \multirow{8}{*}{$\begin{array}{l}\text { R\&D on } \\
\text { the same } \\
\text { scale } \\
\text { without } \\
\text { subsidies }\end{array}$} & \multirow[t]{4}{*}{ Yes } & Number & 4 & 4 & 3 & 2 & 13 \\
\hline & & Expected number & 5.0 & 2.1 & 1.4 & 4.5 & 13.0 \\
\hline & & $\begin{array}{l}\% \text { within industry } \\
\text { code }\end{array}$ & $19.0 \%$ & $44.4 \%$ & $50.0 \%$ & $10.5 \%$ & $23.6 \%$ \\
\hline & & Residuals & -1.0 & 1.9 & 1.6 & -2.5 & \\
\hline & \multirow[t]{4}{*}{ No } & Number & 17 & 5 & 3 & 17 & 42 \\
\hline & & Expected number & 16.0 & 6.9 & 4.6 & 14.5 & 42.0 \\
\hline & & $\begin{array}{l}\% \text { within industry } \\
\text { code }\end{array}$ & $81.0 \%$ & $55.6 \%$ & $50.0 \%$ & $89.5 \%$ & $76.4 \%$ \\
\hline & & Residuals & 1.0 & -1.9 & -1.6 & 2.5 & \\
\hline
\end{tabular}

The companies surveyed see potential across the industries for improvement in the coordination 
of projects with partners from academia and industry. In light of the existing clusters at the state level and the already defined priority sectors in Magdeburg, this is an important finding. Also, more than 50 percent of the companies would benefit from improving the joint use of the existing infrastructure. More than 50 percent of the firms, both from the mechanical engineering and environmental technology and recycling management industries, would like an institutional improvement of technology transfer. In the healthcare sector, $67 \%$ of companies do not see potential for improvement in knowledge exchange. 
Table 30 . Industry code 3

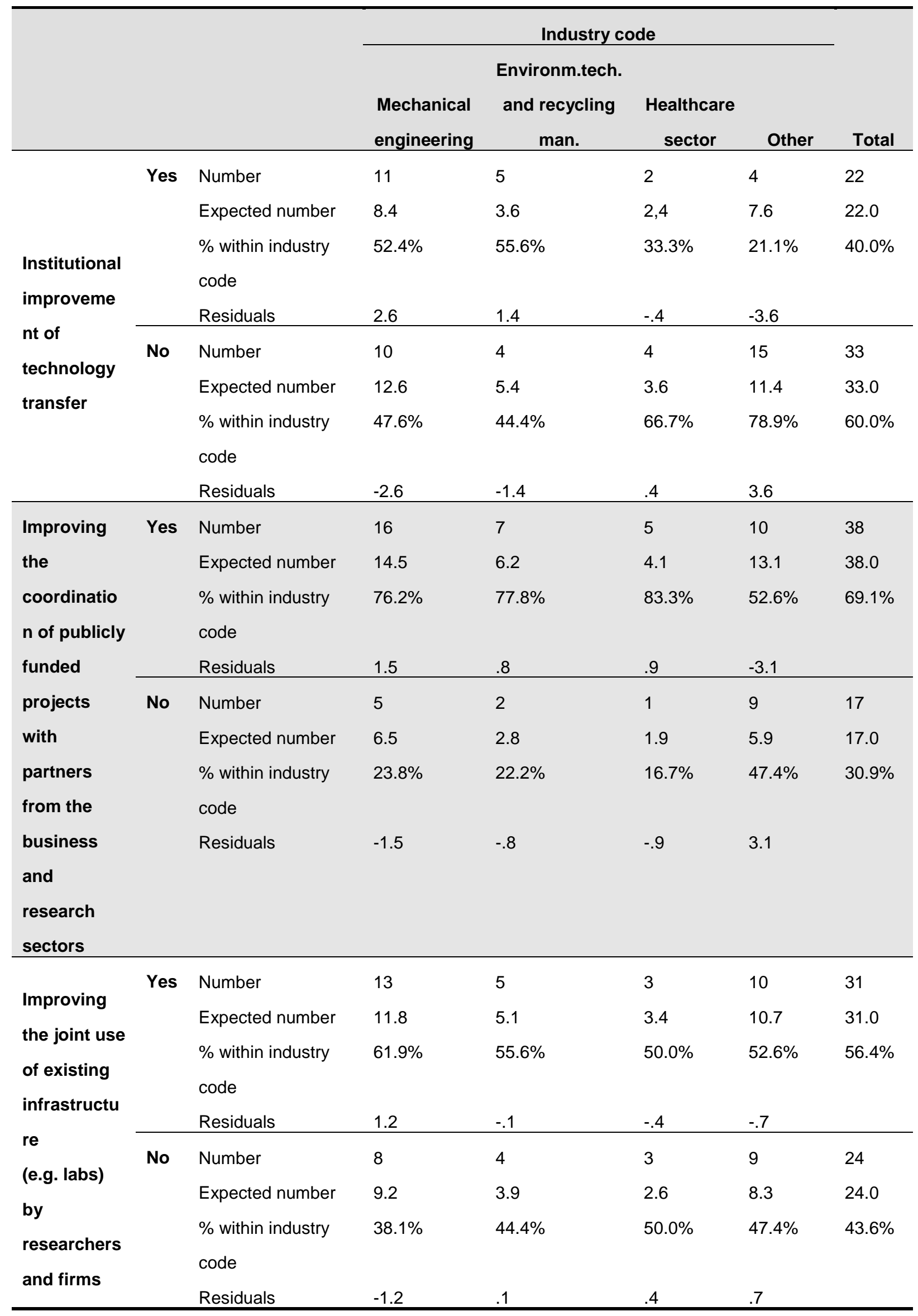


More than 60 percent of the firms consider there to be potential for improvement across the industries in the industry-related education of students at universities, as Table 31 shows. The proportion of companies that consider there to be a backlog in this area is particularly high in the mechanical engineering sector. This reveals firms' desire for improved coordination of the research priorities of universities to match the needs of the firms. Over 77 percent of the firms in the environmental technology and recycling management sector would benefit from an improved representation of business interests in trade associations. For the other sectors, as well, this is an important consideration; however, the percentage of companies that see potential for improvement is much lower there. In addition, especially the firms in the mechanical engineering sector see the further development of economic clusters in the city of Magdeburg as an opportunity to improve knowledge transfer. In the healthcare sector, with only 33 percent of the firms, the value is substantially less. 
Table 31. Industry code 4

\begin{tabular}{|c|c|c|c|c|c|c|c|}
\hline & & & \multicolumn{4}{|c|}{ Industry code } & \multirow[b]{2}{*}{ Total } \\
\hline & & & $\begin{array}{l}\text { Mechanical } \\
\text { engineering }\end{array}$ & $\begin{array}{c}\text { Environm.tech. } \\
\text { and recycling } \\
\text { man. }\end{array}$ & $\begin{array}{c}\text { Healthcare } \\
\text { sector } \\
\end{array}$ & Other & \\
\hline \multirow{9}{*}{$\begin{array}{l}\text { Industry- } \\
\text { related } \\
\text { education } \\
\text { of students } \\
\text { at } \\
\text { universities }\end{array}$} & \multirow[t]{5}{*}{ Yes } & Number & 16 & 5 & 3 & 11 & 35 \\
\hline & & Expected number & 13.4 & 5.7 & 3.8 & 12.1 & 35.0 \\
\hline & & $\%$ within industry & $76.2 \%$ & $55.6 \%$ & $50.0 \%$ & $57.9 \%$ & $63.6 \%$ \\
\hline & & code & & & & & \\
\hline & & Residuals & 2.6 & -.7 & -.8 & -1.1 & \\
\hline & \multirow[t]{4}{*}{ No } & Number & 5 & 4 & 3 & 8 & 20 \\
\hline & & Expected number & 7.6 & 3.3 & 2.2 & 6.9 & 20.0 \\
\hline & & $\begin{array}{l}\% \text { within industry } \\
\text { code }\end{array}$ & $23.8 \%$ & $44.4 \%$ & $50.0 \%$ & $42.1 \%$ & $36.4 \%$ \\
\hline & & Residuals & -2.6 & .7 & .8 & 1.1 & \\
\hline \multirow{8}{*}{$\begin{array}{l}\text { Improveme } \\
\text { nt in the } \\
\text { representati } \\
\text { on of } \\
\text { business } \\
\text { interests in } \\
\text { trade } \\
\text { association } \\
\text { s }\end{array}$} & \multirow[t]{4}{*}{ Yes } & Number & 12 & 7 & 3 & 8 & 30 \\
\hline & & Expected number & 11.5 & 4,9 & 3.3 & 10.4 & 30.0 \\
\hline & & $\begin{array}{l}\% \text { within industry } \\
\text { code }\end{array}$ & $57.1 \%$ & $77.8 \%$ & $50.0 \%$ & $42.1 \%$ & $54.5 \%$ \\
\hline & & Residuals & .5 & 2.1 & -.3 & -2.4 & \\
\hline & \multirow[t]{4}{*}{ No } & Number & 9 & 2 & 3 & 11 & 25 \\
\hline & & Expected number & 9.5 & 4,1 & 2,7 & 8.6 & 25.0 \\
\hline & & $\begin{array}{l}\% \text { within industry } \\
\text { code }\end{array}$ & $42.9 \%$ & $22.2 \%$ & $50.0 \%$ & $57.9 \%$ & $45.5 \%$ \\
\hline & & Residuals & -.5 & -2.1 & .3 & 2.4 & \\
\hline \multirow{8}{*}{$\begin{array}{l}\text { Further } \\
\text { developmen } \\
\text { t of }\end{array}$} & \multirow[t]{4}{*}{ Yes } & Number & 13 & 4 & 2 & 7 & 26 \\
\hline & & Expected number & 9.9 & 4.3 & 2.8 & 9.0 & 26.0 \\
\hline & & $\begin{array}{l}\% \text { within industry } \\
\text { code }\end{array}$ & $61.9 \%$ & $44.4 \%$ & $33.3 \%$ & $36.8 \%$ & $47.3 \%$ \\
\hline & & Residuals & 3.1 & -.3 & -.8 & -2.0 & \\
\hline & \multirow[t]{4}{*}{ No } & Number & 8 & 5 & 4 & 12 & 29 \\
\hline & & Expected number & 11.1 & 4.7 & 3.2 & 10.0 & 29.0 \\
\hline & & $\begin{array}{l}\% \text { within industry } \\
\text { code }\end{array}$ & $38.1 \%$ & $55.6 \%$ & $66.7 \%$ & $63.2 \%$ & $52.7 \%$ \\
\hline & & Residuals & -3.1 & .3 & .8 & 2.0 & \\
\hline
\end{tabular}




\section{Business categories}

With regard to patent activities, the business category of small-sized enterprises shows the greatest activity (cf. Tab. 32). Within this category, 35 percent of the firms reported patent activities. The lowest activity in this segment was shown by the medium-sized enterprises. In the sector of environmental technology and recycling management, micro-sized enterprises operate almost exclusively. In contrast, in the mechanical engineering sector, the business category of small firms is the one that is most often represented. For the sector of environmental technology and recycling management, micro-firms dominate once more. 
Table 32. Business categories 1

\begin{tabular}{|c|c|c|c|c|c|c|}
\hline & & & \multicolumn{3}{|c|}{ Business categories } & \multirow[b]{2}{*}{ Total } \\
\hline & & & $\begin{array}{l}\text { Micro-sized } \\
\text { enterprises }\end{array}$ & $\begin{array}{l}\text { Small-sized } \\
\text { enterprises }\end{array}$ & $\begin{array}{c}\text { Medium-sized } \\
\text { enterprises } \\
\end{array}$ & \\
\hline \multirow{10}{*}{$\begin{array}{l}\text { Patent } \\
\text { activity }\end{array}$} & Yes & Number & 8 & 7 & 1 & 16 \\
\hline & & Expected number & 8.1 & 5.8 & 2.0 & 16.0 \\
\hline & & $\%$ within business & $28.6 \%$ & $35.0 \%$ & $14.3 \%$ & $29.1 \%$ \\
\hline & & categories & & & & \\
\hline & & Residuals & -.1 & 1.2 & -1.0 & \\
\hline & No & Number & 20 & 13 & 6 & 39 \\
\hline & & Expected number & 19.9 & 14.2 & 5.0 & 39.0 \\
\hline & & $\%$ within business & $71.4 \%$ & $65.0 \%$ & $85.7 \%$ & $70.9 \%$ \\
\hline & & categories & & & & \\
\hline & & Residuals & .1 & -1.2 & 1.0 & \\
\hline \multirow{20}{*}{$\begin{array}{l}\text { Industr } \\
\text { y code }\end{array}$} & Mechanical & Number & 8 & 10 & 3 & 21 \\
\hline & engineering & Expected number & 10.7 & 7.6 & 2.7 & 21.0 \\
\hline & & $\%$ within business & $28.6 \%$ & $50.0 \%$ & $42.9 \%$ & $38.2 \%$ \\
\hline & & categories & & & & \\
\hline & & Residuals & -2.7 & 2.4 & .3 & \\
\hline & Environment & Number & 8 & 1 & 0 & 9 \\
\hline & al & Expected number & 4.6 & 3.3 & 1.1 & 9.0 \\
\hline & technology & $\%$ within business & $28.6 \%$ & $5.0 \%$ & $.0 \%$ & $16.4 \%$ \\
\hline & and & categories & & & & \\
\hline & recycling & Residuals & 3.4 & -2.3 & -1.1 & \\
\hline & management & & & & & \\
\hline & \multirow{5}{*}{$\begin{array}{l}\text { Healthcare } \\
\text { sector }\end{array}$} & Number & 3 & 2 & 1 & 6 \\
\hline & & Expected number & 3.1 & 2.2 & .8 & 6.0 \\
\hline & & $\%$ within business & $10.7 \%$ & $10.0 \%$ & $14.3 \%$ & $10.9 \%$ \\
\hline & & categories & & & & \\
\hline & & Residuals & -.1 & -.2 & .2 & \\
\hline & \multirow[t]{4}{*}{ Other } & Number & 9 & 7 & 3 & 19 \\
\hline & & Expected number & 9.7 & 6.9 & 2.4 & 19.0 \\
\hline & & $\begin{array}{l}\% \text { within business } \\
\text { categories }\end{array}$ & $32.1 \%$ & $35.0 \%$ & $42.9 \%$ & $34.5 \%$ \\
\hline & & Residuals & -.7 & .1 & .6 & \\
\hline
\end{tabular}

In the category of micro-firms, 68 percent of the surveyed companies have full- or part-time 
R\&D employees, as Table 33 shows. The observed number is lower than the expected number. The highest proportion of companies that employ R\&D staff can be found in the category of small-size enterprises, the lowest proportion in the category of medium-sized enterprises. In contrast, all (100 percent) medium-sized enterprises are integrated in network structures, for small-size enterprises it is 85 percent, and 71 percent for the micro-firms. Here, one can presume the tendency that, with a growing business category, in terms of number of employees, the percentage of companies that have network activity also rises within the business category. Regardless of the business category, at least 75 percent of the companies would not have been able to implement $R \& D$ to the same extent without funding. 
Table 33. Business categories 2

\begin{tabular}{|c|c|c|c|c|c|c|}
\hline & & & \multicolumn{3}{|c|}{ Business categories } & \multirow[b]{2}{*}{ Total } \\
\hline & & & $\begin{array}{l}\text { Micro-sized } \\
\text { enterprises }\end{array}$ & $\begin{array}{l}\text { Small-sized } \\
\text { enterprises }\end{array}$ & $\begin{array}{c}\text { Medium-sized } \\
\text { enterprises }\end{array}$ & \\
\hline \multirow{9}{*}{$\begin{array}{l}\text { R\&D staff in } \\
\text { the firms }\end{array}$} & Yes & Number & 19 & 16 & 4 & 39 \\
\hline & & Expected number & 19.9 & 14.2 & 5.0 & 39.0 \\
\hline & & $\%$ within business & $67.9 \%$ & $80.0 \%$ & $57.1 \%$ & $70.9 \%$ \\
\hline & & categories & & & & \\
\hline & & Residuals & -.9 & 1.8 & -1.0 & \\
\hline & No & Number & 9 & 4 & 3 & 16 \\
\hline & & Expected number & 8.1 & 5.8 & 2.0 & 16.0 \\
\hline & & $\begin{array}{l}\% \text { within business } \\
\text { categories }\end{array}$ & $32.1 \%$ & $20.0 \%$ & $42.9 \%$ & $29.1 \%$ \\
\hline & & Residuals & .9 & -1.8 & 1.0 & \\
\hline \multirow{9}{*}{$\begin{array}{l}\text { Network } \\
\text { affiliation }\end{array}$} & Yes & Number & 20 & 17 & 7 & 44 \\
\hline & & Expected number & 22.4 & 16.0 & 5.6 & 44.0 \\
\hline & & $\%$ within business & $71.4 \%$ & $85.0 \%$ & $100.0 \%$ & $80.0 \%$ \\
\hline & & categories & & & & \\
\hline & & Residuals & -2.4 & 1.0 & 1.4 & \\
\hline & No & Number & 8 & 3 & 0 & 11 \\
\hline & & Expected number & 5.6 & 4.0 & 1.4 & 11.0 \\
\hline & & $\begin{array}{l}\% \text { within business } \\
\text { categories }\end{array}$ & $28.6 \%$ & $15.0 \%$ & $.0 \%$ & $20.0 \%$ \\
\hline & & Residuals & 2.4 & -1.0 & -1.4 & \\
\hline \multirow{9}{*}{$\begin{array}{l}\text { R\&D of the } \\
\text { same extent } \\
\text { without } \\
\text { funding }\end{array}$} & Yes & Number & 7 & 5 & 1 & 13 \\
\hline & & Expected number & 6.6 & 4.7 & 1.7 & 13.0 \\
\hline & & $\%$ within business & $25.0 \%$ & $25.0 \%$ & $14.3 \%$ & $23.6 \%$ \\
\hline & & categories & & & & \\
\hline & & Residuals & .4 & .3 & -.7 & \\
\hline & No & Number & 21 & 15 & 6 & 42 \\
\hline & & Expected number & 21.4 & 15.3 & 5.3 & 42.0 \\
\hline & & $\begin{array}{l}\% \text { within business } \\
\text { categories }\end{array}$ & $75.0 \%$ & $75.0 \%$ & $85.7 \%$ & $76.4 \%$ \\
\hline & & Residuals & -.4 & -.3 & .7 & \\
\hline
\end{tabular}

29 percent of the medium-sized enterprises cooperate with the research sector. For small-size firms, this value is 55 percent, and micro-enterprises are at 50 percent. 70 percent of small-size 
firms have used available funding options for the implementation of R\&D processes, as Table 34 illustrates. For the category of medium-sized enterprises, this figure was 57 percent, and for microenterprises it was 50 percent. Within the category of micro-enterprises, 32 percent are startups. As was to be expected, this presents the highest value among the business categories. The highest value of the established firms, at 95 percent, can be found in the category of small-size enterprises. Therefore, it is not possible to establish a positive correlation between business category and company age for the sample firms under investigation here. 
Table 34. Business categories 3

\begin{tabular}{|c|c|c|c|c|c|c|}
\hline & & & \multicolumn{3}{|c|}{ Business categories } & \multirow[b]{2}{*}{ Total } \\
\hline & & & $\begin{array}{l}\text { Micro-sized } \\
\text { enterprises } \\
\end{array}$ & $\begin{array}{l}\text { Small-sized } \\
\text { enterprises } \\
\end{array}$ & $\begin{array}{c}\text { Medium-sized } \\
\text { enterprises } \\
\end{array}$ & \\
\hline \multirow{10}{*}{$\begin{array}{l}\text { Cooperation } \\
\text { with the } \\
\text { research }\end{array}$} & Yes & Number & 14 & 11 & 2 & 27 \\
\hline & & Expected number & 13.7 & 9.8 & 3.4 & 27.0 \\
\hline & & $\%$ within business & $50.0 \%$ & $55.0 \%$ & $28.6 \%$ & $49.1 \%$ \\
\hline & & categories & & & & \\
\hline & & Residuals & .3 & 1.2 & -1.4 & \\
\hline & No & Number & 14 & 9 & 5 & 28 \\
\hline & & Expected number & 14.3 & 10.2 & 3.6 & 28.0 \\
\hline & & $\%$ within business & $50.0 \%$ & $45.0 \%$ & $71.4 \%$ & $50.9 \%$ \\
\hline & & categories & & & & \\
\hline & & Residuals & -.3 & -1.2 & 1.4 & \\
\hline \multirow{9}{*}{$\begin{array}{l}\text { Use of } \\
\text { funding }\end{array}$} & Yes & Number & 14 & 14 & 3 & 31 \\
\hline & & Expected number & 15.8 & 11.3 & 3.9 & 31.0 \\
\hline & & $\%$ within business & $50.0 \%$ & $70.0 \%$ & $42.9 \%$ & $56.4 \%$ \\
\hline & & categories & & & & \\
\hline & & Residuals & -1.8 & 2.7 & -.9 & \\
\hline & No & Number & 14 & 6 & 4 & 24 \\
\hline & & Expected number & 12.2 & 8.7 & 3.1 & 24.0 \\
\hline & & $\begin{array}{l}\% \text { within business } \\
\text { categories }\end{array}$ & $50.0 \%$ & $30.0 \%$ & $57.1 \%$ & $43.6 \%$ \\
\hline & & Residuals & 1.8 & -2.7 & .9 & \\
\hline \multirow{8}{*}{$\begin{array}{l}\text { New and old } \\
\text { firms }\end{array}$} & Old & Number & 19 & 19 & 6 & 44 \\
\hline & & Expected number & 22.4 & 16.0 & 5.6 & 44.0 \\
\hline & & $\begin{array}{l}\% \text { within business } \\
\text { categories }\end{array}$ & $67.9 \%$ & $95.0 \%$ & $85.7 \%$ & $80.0 \%$ \\
\hline & & Residuals & -3.4 & 3.0 & .4 & \\
\hline & New & Number & 9 & 1 & 1 & 11 \\
\hline & & Expected number & 5.6 & 4.0 & 1.4 & 11.0 \\
\hline & & $\begin{array}{l}\% \text { within business } \\
\text { categories }\end{array}$ & $32.1 \%$ & $5.0 \%$ & $14.3 \%$ & $20.0 \%$ \\
\hline & & Residuals & 3.4 & -3.0 & -.4 & \\
\hline
\end{tabular}

50 per cent of micro-firms would benefit from an institutional improvement of technology transfer. In the category of small-size enterprises, the number is 30 percent and in the category of 
medium-sized enterprises it is 29 percent. This leads to the conclusion that there is a negative correlation between business category and the improvement of institutional technology transfer for firms of the same category. The same assumption also applies for the improved coordination of publicly funded projects between academia and industry. However, here the percentage rates of the benefitting companies are much higher across all business categories than in the previous case. As Table 35 shows, the percentage of companies that benefit from an improved joint use of existing infrastructure is at over 50 percent, across all business categories. 
Table 35. Business categories 4

\begin{tabular}{|c|c|c|c|c|c|c|}
\hline & & & \multicolumn{3}{|c|}{ Business categories } & \multirow[b]{2}{*}{ Total } \\
\hline & & & $\begin{array}{l}\text { Micro-sized } \\
\text { enterprises }\end{array}$ & $\begin{array}{l}\text { Small-sized } \\
\text { enterprises }\end{array}$ & $\begin{array}{c}\text { Medium-sized } \\
\text { enterprises }\end{array}$ & \\
\hline \multirow{10}{*}{$\begin{array}{l}\text { Institutional } \\
\text { improvement } \\
\text { of technology } \\
\text { transfer }\end{array}$} & \multirow[t]{5}{*}{ Yes } & Number & 14 & 6 & 2 & 22 \\
\hline & & Expected number & 11.2 & 8.0 & 2.8 & 22.0 \\
\hline & & $\%$ within business & $50.0 \%$ & $30.0 \%$ & $28.6 \%$ & $40.0 \%$ \\
\hline & & categories & & & & \\
\hline & & Residuals & 2.8 & -2.0 & -.8 & \\
\hline & \multirow[t]{5}{*}{ No } & Number & 14 & 14 & 5 & 33 \\
\hline & & Expected number & 16.8 & 12.0 & 4.2 & 33.0 \\
\hline & & $\%$ within business & $50.0 \%$ & $70.0 \%$ & $71.4 \%$ & $60.0 \%$ \\
\hline & & categories & & & & \\
\hline & & Residuals & -2.8 & 2.0 & .8 & \\
\hline \multirow{10}{*}{$\begin{array}{l}\text { Improving the } \\
\text { coordination } \\
\text { of publicly } \\
\text { funded } \\
\text { projects with } \\
\text { partners from } \\
\text { the industry } \\
\text { and research } \\
\text { sectors }\end{array}$} & \multirow[t]{5}{*}{ Yes } & Number & 21 & 13 & 4 & 38 \\
\hline & & Expected number & 19.3 & 13.8 & 4.8 & 38.0 \\
\hline & & $\%$ within business & $75.0 \%$ & $65.0 \%$ & $57.1 \%$ & $69.1 \%$ \\
\hline & & categories & & & & \\
\hline & & Residuals & 1.7 & -.8 & -.8 & \\
\hline & \multirow[t]{5}{*}{ No } & Number & 7 & 7 & 3 & 17 \\
\hline & & Expected number & 8.7 & 6.2 & 2.2 & 17.0 \\
\hline & & $\%$ within business & $25.0 \%$ & $35.0 \%$ & $42.9 \%$ & $30.9 \%$ \\
\hline & & categories & & & & \\
\hline & & Residuals & -1.7 & .8 & .8 & \\
\hline \multirow{10}{*}{$\begin{array}{l}\text { Improving the } \\
\text { joint use of } \\
\text { existing } \\
\text { infrastructure } \\
\text { (e.g. labs) by }\end{array}$} & \multirow[t]{5}{*}{ Yes } & Number & 15 & 12 & 4 & 31 \\
\hline & & Expected number & 15.8 & 11.3 & 3.9 & 31.0 \\
\hline & & $\%$ within business & $53.6 \%$ & $60.0 \%$ & $57.1 \%$ & $56.4 \%$ \\
\hline & & categories & & & & \\
\hline & & Residuals & -.8 & .7 & .1 & \\
\hline & \multirow[t]{5}{*}{ No } & Number & 13 & 8 & 3 & 24 \\
\hline & & Expected number & 12.2 & 8.7 & 3.1 & 24.0 \\
\hline & & $\%$ within business & $46.4 \%$ & $40.0 \%$ & $42.9 \%$ & $43.6 \%$ \\
\hline & & categories & & & & \\
\hline & & Residuals & .8 & -.7 & -.1 & \\
\hline
\end{tabular}

Regardless of the business category, more than 60 percent of those asked see potential for optimization in an improved industry-related education of students at universities, as Table 36 shows. 
Moreover, there is an almost identical picture concerning the improvement of the representation of business interests in trade associations. A further development of the economic clusters of the City of Magdeburg would benefit 54 percent of micro-enterprises. For the medium-sized enterprises, the rate is 43 percent, and for small-size firms it is 40 percent. 
Table 36. Business categories 5

\begin{tabular}{|c|c|c|c|c|c|c|}
\hline & & & \multicolumn{3}{|c|}{ Business categories } & \multirow[b]{2}{*}{ Total } \\
\hline & & & $\begin{array}{l}\text { Micro-sized } \\
\text { enterprises }\end{array}$ & $\begin{array}{l}\text { Small-sized } \\
\text { enterprises }\end{array}$ & $\begin{array}{c}\text { Medium-sized } \\
\text { enterprises }\end{array}$ & \\
\hline \multirow{9}{*}{$\begin{array}{l}\text { Industry- } \\
\text { related } \\
\text { education of } \\
\text { students at } \\
\text { universities }\end{array}$} & Yes & Number & 18 & 13 & 4 & 35 \\
\hline & & Expected number & 17.8 & 12.7 & 4.5 & 35.0 \\
\hline & & $\begin{array}{l}\% \text { within business } \\
\text { categories }\end{array}$ & $64.3 \%$ & $65.0 \%$ & $57.1 \%$ & $63.6 \%$ \\
\hline & & Residuals & .2 & .3 & -.5 & \\
\hline & No & Number & 10 & 7 & 3 & 20 \\
\hline & & Expected number & 10.2 & 7.3 & 2.5 & 20.0 \\
\hline & & $\%$ within business & $35.7 \%$ & $35.0 \%$ & $42.9 \%$ & $36.4 \%$ \\
\hline & & categories & & & & \\
\hline & & Residuals & -.2 & -.3 & .5 & \\
\hline \multirow{9}{*}{$\begin{array}{l}\text { Improvement } \\
\text { of the } \\
\text { representation } \\
\text { of business } \\
\text { interests in } \\
\text { trade } \\
\text { associations }\end{array}$} & Yes & Number & 15 & 11 & 4 & 30 \\
\hline & & Expected number & 15.3 & 10.9 & 3.8 & 30.0 \\
\hline & & $\%$ within business & $53.6 \%$ & $55.0 \%$ & $57.1 \%$ & $54.5 \%$ \\
\hline & & categories & & & & \\
\hline & & Residuals & -.3 & .1 & .2 & \\
\hline & No & Number & 13 & 9 & 3 & 25 \\
\hline & & Expected number & 12.7 & 9.1 & 3.2 & 25.0 \\
\hline & & $\begin{array}{l}\% \text { within business } \\
\text { categories }\end{array}$ & $46.4 \%$ & $45.0 \%$ & $42.9 \%$ & $45.5 \%$ \\
\hline & & Residuals & .3 & -.1 & -.2 & \\
\hline \multirow{6}{*}{$\begin{array}{l}\text { Further } \\
\text { development of } \\
\text { the economic } \\
\text { clusters of the }\end{array}$} & Yes & Number & 15 & 8 & 3 & 26 \\
\hline & & Expected number & 13.2 & 9.5 & 3.3 & 26.0 \\
\hline & & $\%$ within business & $53.6 \%$ & $40.0 \%$ & $42.9 \%$ & $47.3 \%$ \\
\hline & & categories & & & & \\
\hline & & Residuals & 1.8 & -1.5 & -.3 & \\
\hline & No & Number & 13 & 12 & 4 & 29 \\
\hline City of & & Expected number & 14.8 & 10.5 & 3.7 & 29.0 \\
\hline \multirow[t]{2}{*}{ Magdeburg } & & $\begin{array}{l}\% \text { within business } \\
\text { categories }\end{array}$ & $46.4 \%$ & $60.0 \%$ & $57.1 \%$ & $52.7 \%$ \\
\hline & & Residuals & -1.8 & 1.5 & .3 & \\
\hline
\end{tabular}




\section{Network affiliation}

59 percent of the companies that are organized in networks regardless of the industry have used outside funding for R\&D. This figure is 14 percent higher than for the firms that have no network affiliation. This result shows that networks present a convenient way for companies to increase their access to and their actual use of R\&D funding through successful application. Regarding patent activity and $R \& D$ personnel within firms, there are virtually no differences between firms that are organized in networks and firms that report no network activity. In this respect, the hypothesis that industry-based business networks are instrumental in increasing R\&D-affinity of the participating firms in the form of a higher proportion of $\mathrm{R} \& \mathrm{D}$ personnel, in contrast to non-involved firms, cannot be confirmed, as Table 37 illustrates. 
Table 37. Network affiliation 1

\begin{tabular}{|c|c|c|c|c|c|}
\hline & & & \multicolumn{2}{|c|}{ Network Affiliation } & \multirow[b]{2}{*}{ Total } \\
\hline & & & Yes & No & \\
\hline \multirow{8}{*}{$\begin{array}{l}\text { Use of available } \\
\text { funding }\end{array}$} & Yes & Number & 26 & 5 & 31 \\
\hline & & Expected number & 24.8 & 6.2 & 31.0 \\
\hline & & $\%$ with network affiliation & $59.1 \%$ & $45.5 \%$ & $56.4 \%$ \\
\hline & & Residuals & 1.2 & -1.2 & \\
\hline & No & Number & 26 & 5 & 31 \\
\hline & & Expected number & 24.8 & 6.2 & 31.0 \\
\hline & & $\%$ with network affiliation & $59.1 \%$ & $45.5 \%$ & $56.4 \%$ \\
\hline & & Residuals & 1.2 & -1.2 & \\
\hline \multirow{8}{*}{ Patent activity } & Yes & Number & 13 & 3 & 16 \\
\hline & & Expected number & 12.8 & 3.2 & 16.0 \\
\hline & & $\%$ with network affiliation & $29.5 \%$ & $27.3 \%$ & $29.1 \%$ \\
\hline & & Residuals & .2 & -.2 & \\
\hline & No & Number & 31 & 8 & 39 \\
\hline & & Expected number & 31.2 & 7.8 & 39.0 \\
\hline & & $\%$ with network affiliation & $70.5 \%$ & $72.7 \%$ & $70.9 \%$ \\
\hline & & Residuals & -.2 & .2 & \\
\hline \multirow{8}{*}{$\begin{array}{l}\text { R\&D staff in the } \\
\text { firms }\end{array}$} & Yes & Number & 31 & 8 & 39 \\
\hline & & Expected number & 31.2 & 7.8 & 39.0 \\
\hline & & $\%$ with network affiliation & $70.5 \%$ & $72.7 \%$ & $70.9 \%$ \\
\hline & & Residuals & -.2 & .2 & \\
\hline & No & Number & 13 & 3 & 16 \\
\hline & & Expected number & 12.8 & 3.2 & 16.0 \\
\hline & & $\%$ with network affiliation & $29.5 \%$ & $27.3 \%$ & $29.1 \%$ \\
\hline & & Residuals & .2 & -.2 & \\
\hline \multirow{8}{*}{$\begin{array}{l}R \& D \text { of the same } \\
\text { extent without } \\
\text { funding }\end{array}$} & Yes & Number & 8 & 5 & 13 \\
\hline & & Expected number & 10.4 & 2.6 & 13.0 \\
\hline & & $\%$ with network affiliation & $18.2 \%$ & $45.5 \%$ & $23.6 \%$ \\
\hline & & Residuals & -2.4 & 2.4 & \\
\hline & No & Number & 36 & 6 & 42 \\
\hline & & Expected number & 33.6 & 8.4 & 42.0 \\
\hline & & $\%$ with network affiliation & $81.8 \%$ & $54.5 \%$ & $76.4 \%$ \\
\hline & & Residuals & 2.4 & -2.4 & \\
\hline
\end{tabular}

Also, it can be seen that companies without a network affiliation implement R\&D activities in a much more self-sufficient manner than firms organized in networks. For instance, there is a difference 
of 27 percent compared to those companies that would have implemented R\&D to the same extent even without $R \& D$ funding. Also, 43 percent of the network companies would benefit from institutional improvement of technology transfer. In contrast, this benefit would only be identified for 27 percent of the firms that are not organized in networks. Optimization potential in improving the coordination of publicly funded projects with partners from the industry and the research sector are identified by 69 percent of all enterprises. Within the networking companies, this proportion is even 71 percent. In this respect, the networks cannot currently provide a satisfactory coordination of science and industry for the firms when it comes to public projects of both partners. Furthermore, 61 percent of the networking firms identify a backlog in joint use of the existing infrastructure of science and industry, as Table 38 shows.

Table 38. Network affiliation 2

\begin{tabular}{|c|c|c|c|c|c|}
\hline & & & \multicolumn{2}{|c|}{ Network Affiliation } & \multirow[b]{2}{*}{ Total } \\
\hline & & & Yes & No & \\
\hline \multirow{8}{*}{$\begin{array}{l}\text { Institutional } \\
\text { improvement of } \\
\text { technology } \\
\text { transfer }\end{array}$} & \multirow[t]{4}{*}{ Yes } & Number & 19 & 3 & 22 \\
\hline & & Expected number & 17.6 & 4.4 & 22.0 \\
\hline & & $\%$ with network affiliation & $43.2 \%$ & $27.3 \%$ & $40.0 \%$ \\
\hline & & Residuals & 1.4 & -1.4 & \\
\hline & \multirow[t]{4}{*}{ No } & Number & 25 & 8 & 33 \\
\hline & & Expected number & 26.4 & 6.6 & 33.0 \\
\hline & & $\%$ with network affiliation & $56.8 \%$ & $72.7 \%$ & $60.0 \%$ \\
\hline & & Residuals & -1.4 & 1.4 & \\
\hline \multirow{8}{*}{$\begin{array}{l}\text { Improving the } \\
\text { coordination of } \\
\text { publicly funded } \\
\text { projects with } \\
\text { partners from the } \\
\text { industry and } \\
\text { research sector }\end{array}$} & \multirow[t]{4}{*}{ Yes } & Number & 31 & 7 & 38 \\
\hline & & Expected number & 30.4 & 7.6 & 38.0 \\
\hline & & $\%$ with network affiliation & $70.5 \%$ & $63.6 \%$ & $69.1 \%$ \\
\hline & & Residuals & .6 & -.6 & \\
\hline & \multirow[t]{4}{*}{ No } & Number & 13 & 4 & 17 \\
\hline & & Expected number & 13.6 & 3.4 & 17.0 \\
\hline & & $\%$ with network affiliation & $29.5 \%$ & $36.4 \%$ & $30.9 \%$ \\
\hline & & Residuals & -.6 & .6 & \\
\hline \multirow{4}{*}{$\begin{array}{l}\text { Improving joint } \\
\text { use of the } \\
\text { existing } \\
\text { infrastructure }\end{array}$} & \multirow[t]{4}{*}{ Yes } & Number & 27 & 4 & 31 \\
\hline & & Expected number & 24.8 & 6.2 & 31.0 \\
\hline & & $\%$ with network affiliation & $61.4 \%$ & $36.4 \%$ & $56.4 \%$ \\
\hline & & Residuals & 2.2 & -2.2 & \\
\hline (o a lahel hy & \multirow[t]{4}{*}{ No } & Number & 17 & 7 & 24 \\
\hline 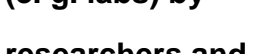 & & Expected number & 19.2 & 4.8 & 24.0 \\
\hline \multirow{2}{*}{ firms } & & $\%$ with network affiliation & $38.6 \%$ & $63.6 \%$ & $43.6 \%$ \\
\hline & & Residuals & -2.2 & 2.2 & \\
\hline
\end{tabular}


Completely identical results, regardless of the network affiliation of the companies, were to be found in answers to the question concerning an improved industry-related education of students in higher education. 64 percent of the firms would benefit from an optimization. The same picture emerges for the representation of business interests in trade associations. 55 percent of firms identify a backlog here. For both issues, the observed frequencies correspond to the expected ones. Concerning the question of further development of the economic clusters in the City of Magdeburg, 50 percent of the network companies are in favor. In contrast, only 36 percent of the companies without network activities can see an optimization potential in this area, as Table 39 shows.

Table 39. Network affiliation 3

\begin{tabular}{|c|c|c|c|c|c|}
\hline & & & \multicolumn{2}{|c|}{ Network Affiliation } & \multirow[b]{2}{*}{ Total } \\
\hline & & & Yes & No & \\
\hline \multirow{8}{*}{$\begin{array}{l}\text { Industry-related } \\
\text { education of } \\
\text { students at } \\
\text { universities }\end{array}$} & \multirow[t]{4}{*}{ Yes } & Number & 28 & 7 & 35 \\
\hline & & Expected number & 28.0 & 7.0 & 35.0 \\
\hline & & $\%$ with network affiliation & $63.6 \%$ & $63.6 \%$ & $63.6 \%$ \\
\hline & & Residuals & .0 & .0 & \\
\hline & \multirow[t]{4}{*}{ No } & Number & 16 & 4 & 20 \\
\hline & & Expected number & 16.0 & 4.0 & 20.0 \\
\hline & & $\%$ with network affiliation & $36.4 \%$ & $36.4 \%$ & $36.4 \%$ \\
\hline & & Residuals & .0 & .0 & \\
\hline \multirow{8}{*}{$\begin{array}{l}\text { Improvement of } \\
\text { the } \\
\text { representation of } \\
\text { business } \\
\text { interests in trade } \\
\text { associations }\end{array}$} & \multirow[t]{4}{*}{ Yes } & Number & 24 & 6 & 30 \\
\hline & & Expected number & 24.0 & 6.0 & 30.0 \\
\hline & & $\%$ with network affiliation & $54.5 \%$ & $54.5 \%$ & $54.5 \%$ \\
\hline & & Residuals & .0 & .0 & \\
\hline & \multirow[t]{4}{*}{ No } & Number & 20 & 5 & 25 \\
\hline & & Expected number & 20.0 & 5.0 & 25.0 \\
\hline & & $\%$ with network affiliation & $45.5 \%$ & $45.5 \%$ & $45.5 \%$ \\
\hline & & Residuals & .0 & .0 & \\
\hline \multirow{5}{*}{$\begin{array}{l}\text { Further } \\
\text { development of } \\
\text { the economic } \\
\text { clusters of the }\end{array}$} & \multirow[t]{4}{*}{ Yes } & Number & 22 & 4 & 26 \\
\hline & & Expected number & 20.8 & 5.2 & 26.0 \\
\hline & & $\%$ with network affiliation & $50.0 \%$ & $36.4 \%$ & $47.3 \%$ \\
\hline & & Residuals & 1.2 & -1.2 & \\
\hline & \multirow[t]{4}{*}{ No } & Number & 22 & 7 & 29 \\
\hline City of & & Expected number & 23.2 & 5.8 & 29.0 \\
\hline \multirow[t]{2}{*}{ Magdeburg } & & $\%$ with network affiliation & $50.0 \%$ & $63.6 \%$ & $52.7 \%$ \\
\hline & & Residuals & -1.2 & 1.2 & \\
\hline
\end{tabular}




\section{Older and new firms}

Looking at the differentiation between companies regarding the company age, according to the definition of this study, it can be seen from Tab. 40 that the older companies are active in networks to a greater degree than newly established firms. Regardless of company age, 80 percent of the firms are active in networks. It is remarkable that 82 percent of the new firms have their own R\&D personnel and, hence, at 14 percent, have more than the existing firms with R\&D staff. Thus, no correlation can be found between company age and R\&D activities of firms in the form of private R\&D personnel. Of the older companies, 32 percent were active in the patent field in the 2005 - 2010 period. Among the new companies, this concerns 18 percent of the firms. 
Table 40. Old and new enterprises 1

\begin{tabular}{|c|c|c|c|c|c|}
\hline & & & \multicolumn{2}{|c|}{ Firm } & \multirow[b]{2}{*}{ Total } \\
\hline & & & Old & New & \\
\hline \multirow{10}{*}{$\begin{array}{l}\text { Network } \\
\text { affiliation }\end{array}$} & Yes & Number & 36 & 8 & 44 \\
\hline & & Expected number & 35.2 & 8.8 & 44.0 \\
\hline & & $\%$ within old and new & $81.8 \%$ & $72.7 \%$ & $80.0 \%$ \\
\hline & & enterprises & & & \\
\hline & & Residuals & .8 & -.8 & \\
\hline & No & Number & 8 & 3 & 11 \\
\hline & & Expected number & 8.8 & 2.2 & 11.0 \\
\hline & & $\%$ within business & $18.2 \%$ & $27.3 \%$ & $20.0 \%$ \\
\hline & & categories & & & \\
\hline & & Residuals & -.8 & .8 & \\
\hline \multirow{10}{*}{$\begin{array}{l}\text { R\&D staff in the } \\
\text { firm }\end{array}$} & Yes & Number & 30 & 9 & 39 \\
\hline & & Expected number & 31.2 & 7.8 & 39.0 \\
\hline & & $\%$ within old and new & $68.2 \%$ & $81.8 \%$ & $70.9 \%$ \\
\hline & & enterprises & & & \\
\hline & & Residuals & -1.2 & 1.2 & \\
\hline & No & Number & 14 & 2 & 16 \\
\hline & & Expected number & 12.8 & 3.2 & 16.0 \\
\hline & & $\%$ within business & $31.8 \%$ & $18.2 \%$ & $29.1 \%$ \\
\hline & & categories & & & \\
\hline & & Residuals & 1.2 & -1.2 & \\
\hline \multirow{9}{*}{ Patent activity } & Yes & Number & 14 & 2 & 16 \\
\hline & & Expected number & 12.8 & 3.2 & 16.0 \\
\hline & & $\%$ within old and new & $31.8 \%$ & $18.2 \%$ & $29.1 \%$ \\
\hline & & enterprises & & & \\
\hline & & Residuals & 1.2 & -1.2 & \\
\hline & No & Number & 30 & 9 & 39 \\
\hline & & Expected number & 31.2 & 7.8 & 39.0 \\
\hline & & $\begin{array}{l}\% \text { within old and new } \\
\text { enterprises }\end{array}$ & $68.2 \%$ & $81.8 \%$ & $70.9 \%$ \\
\hline & & Residuals & -1.2 & 1.2 & \\
\hline
\end{tabular}

Of all the firms that have participated in the company survey, 56 percent have used outside funding for R\&D activities during the 2005 - 2010 period. Of the startups, this concerned 64 percent, compared with 55 percent of the established companies. In relation to this question, a distorted image 
emerges when looking at whether the firms would have carried out $R \& D$ activities to the same extent even without any subsidies. Here, 75 percent of the older companies reported that they would not have been able to do so. It should be noted that only 55 percent of the older companies have accessed funding. Independently of this, it can be seen that the R\&D activities of firms in the $2005-2010$ period were critically dependent on the existence of relevant R\&D funding. This affects 76 percent of the firms, as Table 41 illustrates.

Table 41. Old and new enterprises 2

\begin{tabular}{|c|c|c|c|c|c|}
\hline & & & \multicolumn{2}{|c|}{ Firm } & \multirow[b]{2}{*}{ Total } \\
\hline & & & Old & New & \\
\hline \multirow{10}{*}{$\begin{array}{l}\text { Use of available } \\
\text { funding }\end{array}$} & \multirow[t]{5}{*}{ Yes } & Number & 24 & 7 & 31 \\
\hline & & Expected number & 24.8 & 6.2 & 31.0 \\
\hline & & $\%$ within old and new & $54.5 \%$ & $63.6 \%$ & $56.4 \%$ \\
\hline & & enterprises & & & \\
\hline & & Residuals & -.8 & .8 & \\
\hline & \multirow[t]{5}{*}{ No } & Number & 20 & 4 & 24 \\
\hline & & Expected number & 19.2 & 4.8 & 24.0 \\
\hline & & $\%$ within business & $45.5 \%$ & $36.4 \%$ & $43.6 \%$ \\
\hline & & categories & & & \\
\hline & & Residuals & .8 & -.8 & \\
\hline \multirow{9}{*}{$\begin{array}{l}\text { R\&D of the same } \\
\text { extent without } \\
\text { funding }\end{array}$} & \multirow[t]{5}{*}{ Yes } & Number & 11 & 2 & 13 \\
\hline & & Expected number & 10.4 & 2.6 & 13.0 \\
\hline & & $\%$ within old and new & $25.0 \%$ & $18.2 \%$ & $23.6 \%$ \\
\hline & & enterprises & & & \\
\hline & & Residuals & .6 & -.6 & \\
\hline & \multirow[t]{4}{*}{ No } & Number & 33 & 9 & 42 \\
\hline & & Expected number & 33.6 & 8.4 & 42.0 \\
\hline & & $\begin{array}{l}\% \text { within business } \\
\text { categories }\end{array}$ & $75.0 \%$ & $81.8 \%$ & $76.4 \%$ \\
\hline & & Residuals & -.6 & .6 & \\
\hline
\end{tabular}

At a rate of 73 percent, the startups, primarily, would benefit from an institutional improvement of technology transfer. Here, the observed frequency is far above the expected frequency. In contrast, only 32 percent of the older companies see a need to act within this thematic field. For 91 percent of the new companies, there was also an interest expressed in the improved coordination of publicly funded projects, with partners from academia and industry. For the older companies, the proportion is at least 64 percent. Less critical differences between new and older companies can be found when it comes to the joint use of existing infrastructure by science and industry. Overall, 56 percent of all 
companies see a need for optimization, as shown in Table 42.

Table 42. Old and new enterprises 3

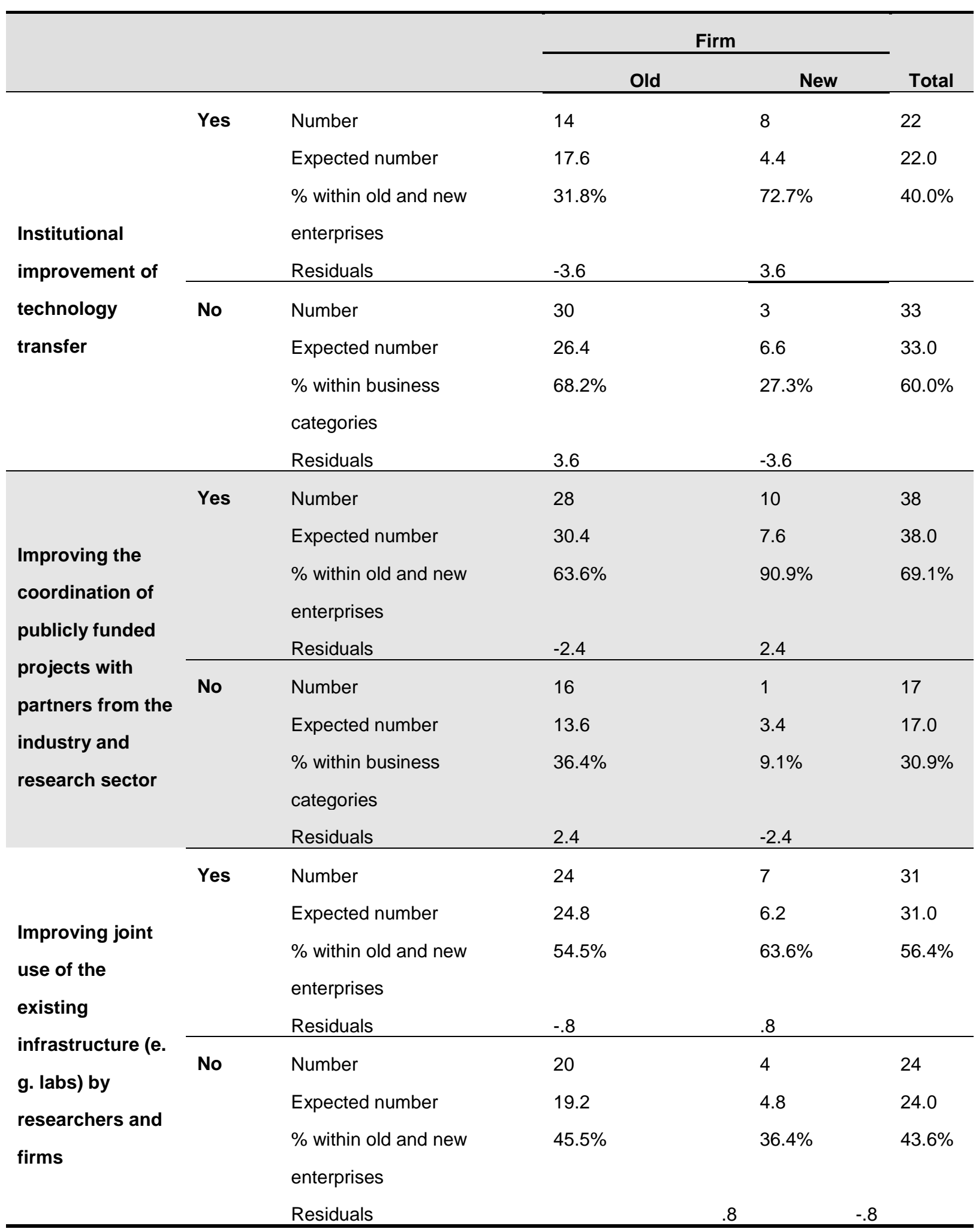

73 percent of new businesses would benefit from an improved industry-related education of students at universities, as Table 43 shows. Among the older companies, 61 percent identify a need for 
action and optimization in this field. 55 percent of new and older companies, respectively, desire a better representation of business interests within trade organizations. Further development of the economic clusters of the City of Magdeburg is important for 50 percent of the older companies and 36 percent of the new ones.

Table 43. Old and new enterprises 4

\begin{tabular}{|c|c|c|c|c|c|}
\hline & & & \multicolumn{2}{|c|}{ Firm } & \multirow[b]{2}{*}{ Total } \\
\hline & & & Old & New & \\
\hline \multirow{9}{*}{$\begin{array}{l}\text { Industry-related } \\
\text { education of } \\
\text { students at } \\
\text { universities }\end{array}$} & Yes & Number & 27 & 8 & 35 \\
\hline & & Expected number & 28.0 & 7.0 & 35.0 \\
\hline & & $\%$ within old and new & $61.4 \%$ & $72.7 \%$ & $63.6 \%$ \\
\hline & & enterprises & & & \\
\hline & & Residuals & -1.0 & 1.0 & \\
\hline & No & Number & 17 & 3 & 20 \\
\hline & & Expected number & 16.0 & 4.0 & 20.0 \\
\hline & & $\begin{array}{l}\% \text { within business } \\
\text { categories }\end{array}$ & $38.6 \%$ & $27.3 \%$ & $36.4 \%$ \\
\hline & & Residuals & 1.0 & -1.0 & \\
\hline \multirow{9}{*}{$\begin{array}{l}\text { Improvement of } \\
\text { the } \\
\text { representation of } \\
\text { business } \\
\text { interests in trade } \\
\text { associations }\end{array}$} & Yes & Number & 24 & 6 & 30 \\
\hline & & Expected number & 24.0 & 6.0 & 30.0 \\
\hline & & $\%$ within old and new & $54.5 \%$ & $54.5 \%$ & $54.5 \%$ \\
\hline & & enterprises & & & \\
\hline & & Residuals & .0 & .0 & \\
\hline & No & Number & 20 & 5 & 25 \\
\hline & & Expected number & 20.0 & 5.0 & 25.0 \\
\hline & & $\begin{array}{l}\% \text { within business } \\
\text { categories }\end{array}$ & $45.5 \%$ & $45.5 \%$ & $45.5 \%$ \\
\hline & & Residuals & .0 & .0 & \\
\hline \multirow{6}{*}{$\begin{array}{l}\text { Further } \\
\text { development of } \\
\text { the economic } \\
\text { clusters of the }\end{array}$} & Yes & Number & 22 & 4 & 26 \\
\hline & & Expected number & 20.8 & 5.2 & 26.0 \\
\hline & & $\%$ within old and new & $50.0 \%$ & $36.4 \%$ & $47.3 \%$ \\
\hline & & enterprises & & & \\
\hline & & Residuals & 1.2 & -1.2 & \\
\hline & No & Number & 22 & 7 & 29 \\
\hline City of & & Expected number & 23.2 & 5.8 & 29.0 \\
\hline \multirow[t]{2}{*}{ Magdeburg } & & $\begin{array}{l}\% \text { within old and new } \\
\text { enterprises }\end{array}$ & $50.0 \%$ & $63.6 \%$ & $52.7 \%$ \\
\hline & & Residuals & -1.2 & 1.2 & \\
\hline
\end{tabular}




\section{IMPLICATIONS}

The expert interviews, analysed in chapter 6, provided an insight into the relevant questions for the firm survey, analysed in chapter 7 and 8 . Over all, the data of the firm survey support the experts' views. The implications drawn in this chapter refer to policy recommendations for standardized terminology, communication processes, organization of value chains, network management, knowledge transfer networks, and R\&D funding. All implications include questions for further research.

\section{Technical Terms}

In this study and, in particular, in the industry description and the analysis of expert interviews, the terms sector/industry, priority sector, cluster and network were frequently used in different contexts and were partly used interchangeably. The motivation for this approach was the neutral rendition of the results and information from the expert interviews and the literature used. However, the use of these terms in different contexts makes it more difficult for interested parties to identify the existing network structures. For a clearer understanding of the network structures in the future use of these terms, they must first be defined individually.

Industry/Sector: Within the economy, this denotes a group of companies that produces closely related substitutes. ${ }^{179}$ The basis for the classification of industries is the WZ 2008, which is based on the classification of economic sectors in the European Union (NACE), but beyond that, also uses a finer hierarchy level. ${ }^{180}$

Network: At least two distinguishable units and a number of specific relationships between units. ${ }^{181}$ In addition, the definition of knowledge transfer network is used according to this study

Cluster: A specialized network with a geographical concentration of interconnected companies in related industries and supporting organizations (research institutions, chambers and associations) along a value chain that are competing and cooperating simultaneously. In addition, several value

\footnotetext{
${ }^{179}$ Porter (1980, p. 3 pp.).

${ }^{180}$ Federal Statistical Office. http://www.destatis.de/jetspeed/portal/cms/Sites/destatis/Internet/DE/Content/Klassifikationen/GueterWirts chaftklassifikationen/klassifikationwz2008 erl,property=file.pdf).

${ }^{181}$ Broch, Rassiller and Schroll (2007, p. 13).
} 
chains may complement each other in a cluster, or be related to each other. ${ }^{182}$

Priority sector: The definition of priority sectors in the economic region of Magdeburg was based on the necessary criteria for definition of clusters. Accordingly, the notion of a priority sector, as used in the economic region of Magdeburg, relates to the cluster concept.

For the priority sectors in the investigated economic region of Magdeburg, there is no detailed classification of economic sectors according to the WZ 2008 yet. It would be advisable to create transparency through a unified terminology, at the state as well as the municipal level. By definition, any priority sector can be described as and, hence, named a network. In order to replace the term priority sector by the term cluster, as it has been introduced and established in research, economics and politics, a micro study to determine the necessary criteria for clustering is recommended, because local and regional cluster formations particularity have different profiles. In addition, there should be a breakdown of the combined industries per cluster in accordance with the WZ 2008. The thematic relevance of this issue is supported by the findings of this study, according to which the experts frequently identify the microstructure of the networks as not being transparent (cf. section 6.2). This limitation is reflected in the results of the questionnaire, where 47 percent of the firms are in favor of a further development of the key industries in the economic region of Magdeburg. This desideratum relates to the desire for increased transparency of the investigated networks in the economic region of Magdeburg.

\section{Awareness and communication}

In Chapter 3, it was shown that only 300 companies in Saxony-Anhalt are continuously or temporarily involved in R\&D. This immediately suggests a further increasing awareness among companies of the need for the initialization of $R \& D$ processes as a central task. An identical result was also obtained from the expert interviews. The initialization of $R \& D$ processes in firms can have a lasting positive impact on the achievement of economic policy objectives, such as the sustainability and the growth of the company.

The Chamber of Industry and Commerce Magdeburg (CIC) was identified by 62 percent of the firms as a contact point for the acquisition of $R \& D$ knowledge. For a differentiation according to the priority sectors in the economic region of Magdeburg, the respective clusters at the state level also play a crucial role for the firms when it comes to the acquisition of new R\&D knowledge. 20 percent of the companies consider the GWM as the appropriate contact point in the R\&D area. Among the infrastructure funding agencies, the IGZ Magdeburg-Barleben should be emphasized, which is relevant for 27 percent of the firms. Due to this perception by the companies surveyed, the abovementioned institutions increasingly assume the role of the driving motor behind accumulated R\&D awareness of the firms. A suitable measure might be the initialization of a dialogic process involving

\footnotetext{
${ }^{182}$ Schiele (2003, p. 27 pp.).
} 
all R\&D-relevant players, in order to develop a communication strategy. Initial content design and optimization approaches arise from the company survey. For example, 54 percent of the firms that have not yet cooperated with the research sector, report that they do not know of possibilities for cooperation, and for 50 percent of the firms, it is difficult to identify the right contact person. An important finding of the company survey is that the most common form of knowledge transfer between research and industry is the informal cooperation with individual researchers, i.e., there are "invisible networks" that make up the main transfer channel and probably have a cross-industry structure.

\section{The process chain of knowledge transfer networks}

Based on the analysis of the expert interviews, the process chain, across industries, of the knowledge transfer networks has the form shown in Figure 67.

Figure 67. Process chain of knowledge transfer networks

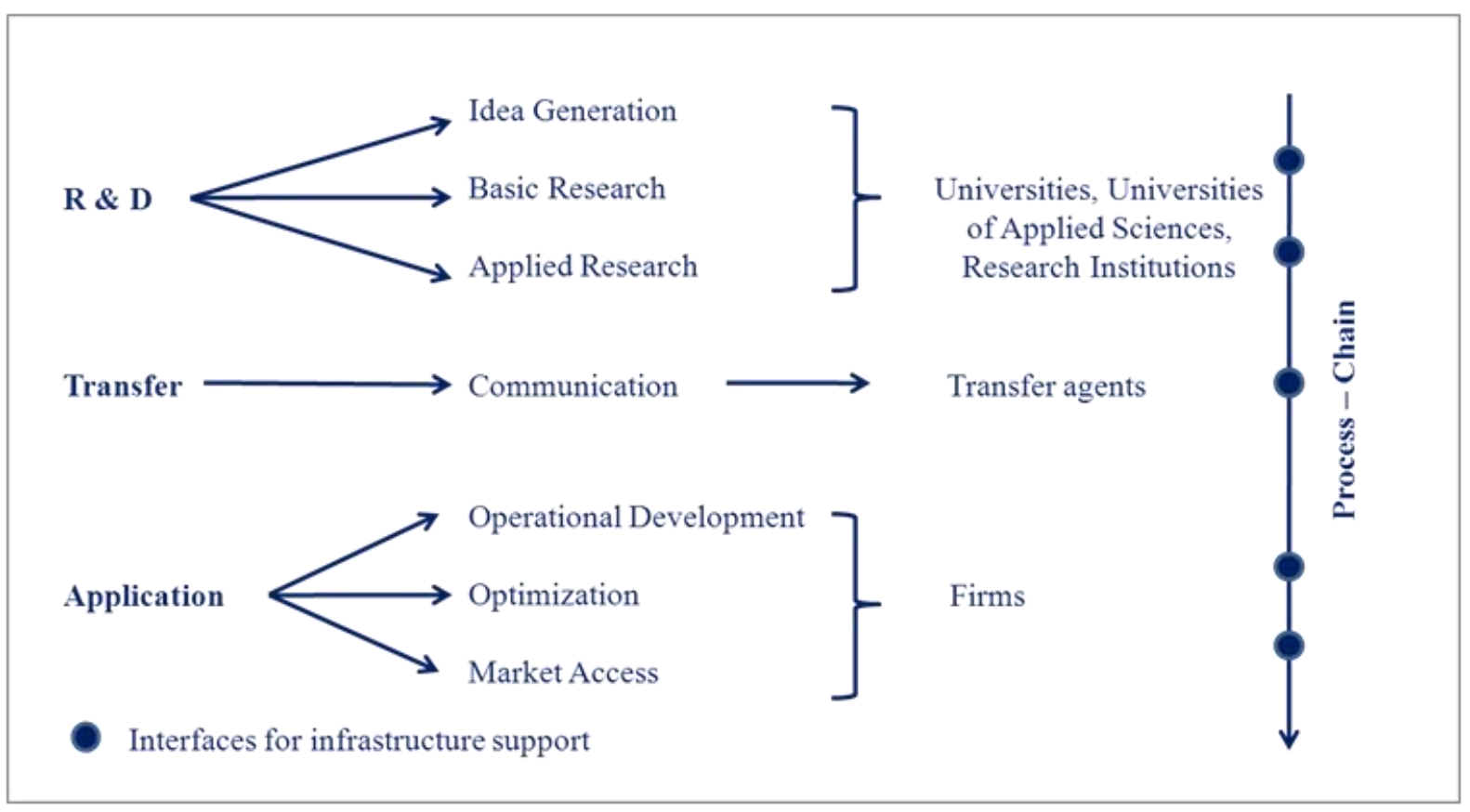

Source: Own depiction

According to the experts, the lacking ability of the regional firms to initialize and implement inhouse $R \& D$ processes, implies that $R \& D$ within knowledge transfer networks is mainly conducted by universities and research institutions. In addition, the interviewed experts attest local firms an insufficient commitment to innovation. Moreover, the experts confirm a great need for additional innovative firms. Furthermore, there is criticism that the firms are currently far from exploiting all available growth options resulting from the R\&D processes. In contrast, 64 percent of firms state that the research priorities of the research community do not correspond to their own R\&D requirements. To address this problem in a more detailed analysis, it is advisable to identify both the R\&D needs of 
the local firms in the various priority sectors in the economic region of Magdeburg, on the one hand, and to reveal the R\&D potential of the research sector by specific topics, on the other hand. This is the only way a valid conclusion can be reached on whether or not the research priorities meet the R\&D requirements of the firms and whether or not the firms lack a sufficient desire for innovation. Of relevance to $R \& D$ development and transfer is also the issue concerning the generation of incentives for researchers that induce them to devote more time to knowledge transfer and place greater emphasis on transfer-related issues. To support transfer within a given process chain, transfer offices have been established at the universities. The transfer of knowledge is a further mission that universities are obliged to carry out by the Higher Education Act, where the transfer of knowledge is manifested as the third key task of the universities, next to research and teaching. The transfer offices are designed to stimulate the $R \& D$ transfer by means of information exchange with existing firms and to provide support by assuming the role of a mediator between research and industry. According to the analysis of the company survey, it is not entirely clear for the economic players how this role is filled by the transfer offices. Only 11 percent of the companies interviewed consider the transfer office (TTZ) of the OvGU, and only 6 percent the CAT network, as an appropriate facility or point of contact for the acquisition of R\&D knowledge. Here a more nuanced view of the causes is required. Aside from their responsibility to collect university research findings and handle industrial inquiries, the university transfer offices in Magdeburg also perform a variety of other tasks: Supporting spin-offs, generating revenue, providing support for the acquisition of external funding, protecting industrial property rights, and staff transfer. ${ }^{183}$ With their given resources, the transfer offices need to focus on specific tasks that are interrelated. There is for example a positive correlation between the exchange of industry contacts and the key figures cost coverage or profit and a negative correlation between the acquisition of external funding and the number of spin-offs from the university. ${ }^{184}$ The limited resources and the numerous tasks of the transfer offices were identified in the expert interviews as decisive causes for existing deficits in handling the transfer of research knowledge to the desired extent. In order to address these problems, the development of a knowledge transfer concept for universities is recommended. The concept should consider the following aspects:

- Commercialization options for R\&D knowledge (e.g., transfer to existing companies and establishment of new firms)

- Incentive options for scientists and enterprises for an enhanced knowledge transfer

- Absorption capacity of regional firms for R\&D injections from the research sector, e.g. through focused cooperation between universities and chambers of industry and commerce

- Structural and organizational development and the implementation of appropriate transfer units at universities

\footnotetext{
${ }^{183}$ Kratzer, Haase and Lautenschläger (2010, p. 32 pp.).

${ }^{184}$ Kratzer, Haase and Lautenschläger (2010, p. 33).
} 
- Financing instruments to provide adequate capital for transfer units in universities

- Investment opportunities for universities with the objective of refinancing themselves from the commercialization of research knowledge

As part of the development of such a transfer concept for the universities, there is an apparent need for a detailed analysis of the $R \& D$ potential of the research sector and the disclosure of the R\&D needs of regional firms. This forms the basis for jointly working out and successfully implementing a development concept between science and industry. The presence and continued improvement of existing regional economic clusters can initiate a mutual catalytic effect in this context. As the expert interviews reveal, the necessity arises from the still unsatisfactory R\&D knowledge transfer between science and industry, which results primarily from the sometimes divergent interests and concepts of science and industry concerning the transfer of knowledge as well as its necessity and design. Thus, for example, 56 percent of the companies that cooperate with the research sector have developed different ideas about the project period over the course of their collaboration and, also 56 percent have complained about opposing commercialization interests between science and industry.

\section{Network structure}

As a result of the expert interviews and further related research, it was possible to reveal the structural surface of the transfer of knowledge networks within the examined priority sectors. Accordingly, the following components play a central role in implementing knowledge transfer: The main clusters of Saxony-Anhalt, industry-specific associations, and R\&D project networks. As Figure 68 shows, these components operate interdependently. At their intersection, knowledge transfer in the network takes place in the most dynamic manner along the previously described process chain, provided that appropriate external infrastructure, consulting, and finances are available. In contrast to the experts' views, the firm and industry analyses revealed that it is irrelevant from which component the impulse for the transfer of knowledge is triggered. Moreover, players within the network do not necessarily need to be assigned to one single component, but could belong to two or three different components. 
Figure 68. Structure of knowledge transfer networks

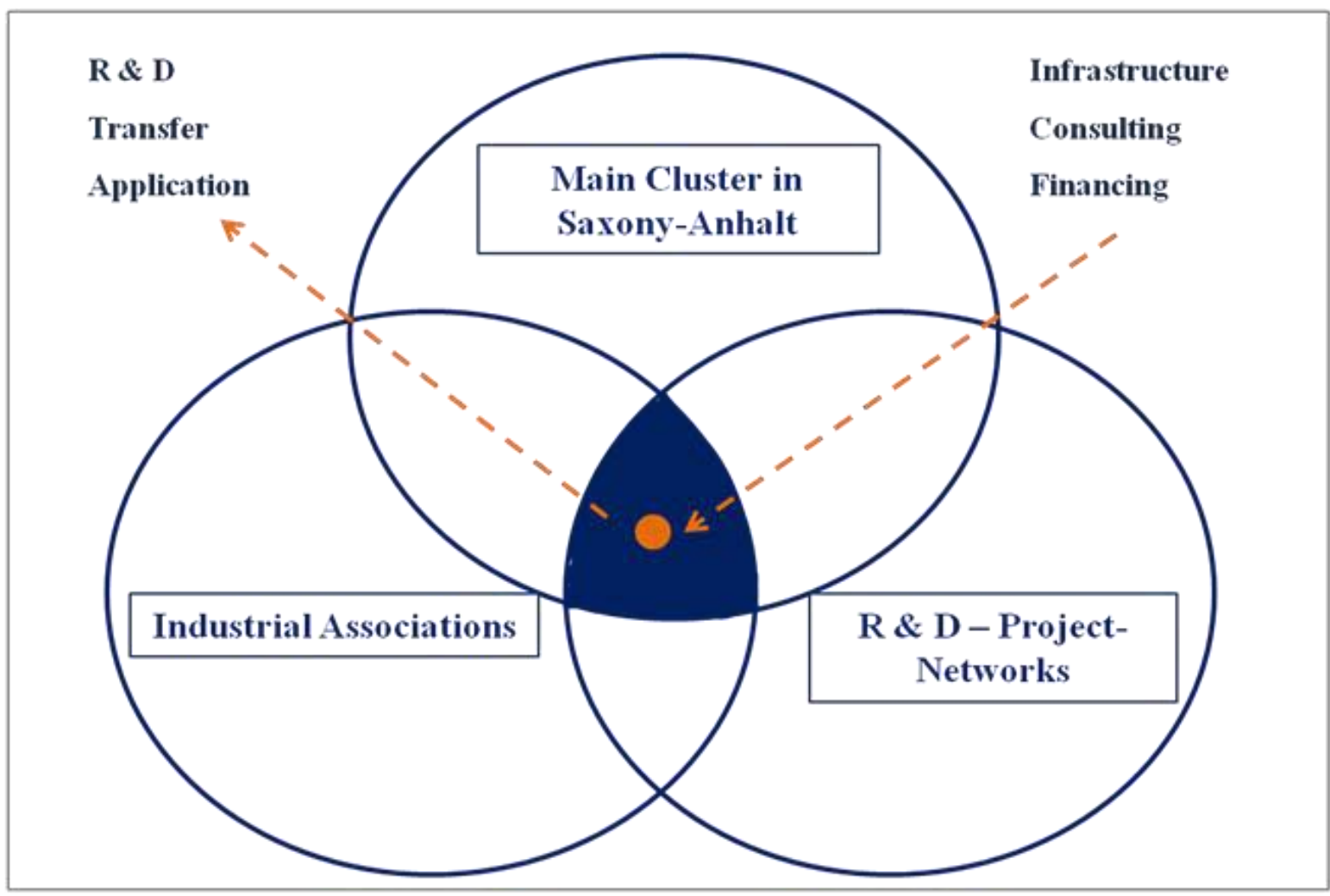

Source: Own depictionThis visual depiction of the network structure for the priority sectors in the economic region of Magdeburg is also an opportunity for potentially interested parties, in terms of increased transparency, to obtain a detailed overview of the relevant players within the three components, including the available framework conditions. For the future, a detailed breakdown of the priority sectors is recommended. Figure 69 shows the structure of the priority sector of mechanical and systems engineering. This is only an example, however, and should not be considered to be exhaustive and complete. Rather, there is a need for a periodic updating, because networks represent a dynamic rather than a fixed system. 
Figure 69. Network structure for the priority sector of mechanical and systems engineering



Source: Own depictionWhile the visual depiction of the network structure may be a probate means for communication and interaction, it is still unsuitable for a detailed network overview with the potential of indicating suitable steering approaches. Therefore, a micro-study is recommended, which assigns all players regardless of their component affiliation, to the individual components of the process chain of knowledge transfer, and sets out to identify and present all the available communication structures, using methods of network analysis. On this basis, optimization and further development approaches, with a focus on knowledge transfer within the networks, can be analyzed and discussed.

\section{Importance of knowledge transfer networks}

Of the companies under investigation as part of this study, 80 percent are active in networks. 71 percent of these companies benefit from the networks by improved access to business partners. Also, 64 percent of companies reported improved access to $R \& D$ funding programs. An improved understanding of innovation processes based on R\&D activities was reported by 52 percent of the firms. In considering these findings, it must be noted that the identified knowledge transfer networks constitute a suitable environment for raising awareness of local businesses in the economic region of Magdeburg as well as giving rise to the possibility of implementing the revealed R\&D process chain with the network partners by means of coordination. As 69 percent of the firms point out, there is a need for improving the central coordination of R\&D projects between academia and industry. In addition, 64 percent of the firms state that the joint use of the existing infrastructure of science and industry should be improved within the networks. Based on these results, a further development of networks is recommended by including a detailed analysis of the process chain, the visual depiction of the structure, and the development of a communications strategy. The food industry, as the largest 
economic sector in Saxony-Anhalt, is not currently defined as a priority sector in the economic region of Magdeburg. For this sector the consideration for the economic region of Magdeburg should be to what extent suitable partners from academia and industry are able to represent the entire $R \& D$ process chain, in order to discuss the implementation of another priority sector. It is conceivable that sciencebased $R \& D$ potential may need to be established or be imported into the economic region of Magdeburg.

\section{Importance of R\&D funding for firms and facilitation structures}

The analyses carried out as part of this case study led to the conclusion that R\&D funding, regardless of the source of funds, is of prime importance for the implementation of R\&D processes. For instance, 76 percent of the companies would not have been able to carry out R\&D innovation processes to the same extent during the $2005-2010$ period if there had not been outside funding through the R\&D grant programs. In addition, it is apparent that companies that belong to networks have obtained more funding in percentage terms than the rest of the firms. An important future task for economic promotion is, therefore, the design of framework conditions to focus $R \& D$ funding on the sustainability of (at least partial) in-house R\&D processes - this is one of the core findings of the expert interviews. Furthermore, it is essential to ensure secure long-term financing of the network coordination, because the dynamics in the implementation of $R \& D$ in networks is critically dependent on the activity and stability of the actors concerned. At present, the managers of the cluster at the state level as well as the coordinators of the priority sectors in the economic region of Magdeburg, are financed by transfer services. Self-financing through the network members is not currently provided across all sectors. If the sustainability of the network structure and the independence of transfers is the final objective, the refinancing options of the networks will have to be investigated. An analysis of the additional added value, from the network and for individual players, is conceivable, thereby ensuring, as a rational strategy, sustainable financing of the network management in the form of a contribution by the players themselves. 


\section{BIBLIOGRAPHY}

Bode, Jörg, und Günter Ihlow. „Sachbereicht des Clusters Sondermaschinen- und Anlagenbau 2009.“ 2009.

Broch, Jahn, Markus Rassiller, und Daniel Schroll. Netzwerke der Moderne - Erkundungen und Strategien. Würzburg: Verlag Königshausen \& Neumann GmbH, 2007.

Bühl, Achim. PASW 18 Einführung in die moderne Datenanalyse. München: Pearson Education Deutschland GmbH, 2010.

Clusterpotentialanalyse Sachsen-Anhalt, Technopolis GmbH, VDI Technologiezentrum GmbH, 2007.

Daten zur wirtschaftlichen Lage im Land Sachsen-Anhalt I - III Quartal 2009. Ministerium für Wirtschaft und Arbeit, 2009.

ExperConsult. „Strategische Neuorientierung der Wirtschaftförderungsaktivitäten der Landeshauptstadt Magdeburg.“ 2001.

Förderfibel für Sachsen-Anhalt. Magdeburg: Förderservice GmbH der Investitionsbank SachsenAnhalt, 2010.

GWM. Kreislaufwirtschaft und Umweltschutztechnologie. Magdeburg: Gesellschaft für Wirtschaftsservice Magdeburg mbH.

GWM. Maschinenbau. Magdeburg: Gesellschaft für Wirtschaftsservice Magdeburg mbH.

GWM. Medizintechnik, Biotechnologie, Pharmazie. Magdeburg: Gesellschaft für Wirtschaftsservice Magdeburg mbH.

Häder, Michael. Empirische Sozialforschung. Verlag für Sozialwissenschaften, 2010.

Hammann, Peter, und Bernd Erichson. Marktforschung. Stuttgart: Lucius \& Lucius Verlagsgesellschaft mbH, 2000.

Hausberg, Bernhard, Raimund Glitz, Silke Stahl-Rolf, Alexandra Rammer, und Jörg Leonhard. Clusterpotentialanalyse Sachsen-Anhalt. Düsseldorf, Wien: VDI Technologiezentrum, Technopolis GmbH, 2008.

„Innovationsstrategie 2013،“ Bundesland Sachsen-Anhalt. 
Kladroba, Andreas, Christoph Grenzmann, und Bernd Kreuels. FuE-Datenreport 2010. Essen: Wissenschaftsstatistik GmbH im Stiftungsverband für die Deutsche Wissenschaft, 2010.

Konzack, Tatjana, Claudia Hermann-Koitz, und Wolfgang Horlamus. Wachstumsdynamik und strukturelle Veränderungen der FuE-Potentiale im Wirtschaftssektor Ostdeutschlands und der neuen Bundesländer - FuE-Daten 2005 - 2008. Berlin: EURNorm Gesellschaft für Qualitätssicherung und Innovationsmanagement mbH, 2009.

Kratzer, Jan, Heiko Haase, und Arndt Lautenschläger. „Benchmaking Deutscher Transferstellen Transferpotential, Transferkapazitäten, Transferaktivitäten im deutschlandweitem Vergleich.“ 2010.

Magdeburger Statistische Blätter. Magdeburg: Amt für Statistik der Landeshauptstadt Magdeburg, 2008, 2009.

Operationelles Programm ESF Sachsen-Anhalt 2007 - 2013. Bundesland Sachsen-Anhalt, 2007.

Porter, Michael E. Clusters and Competition - New Agendas for Companies, Governments and Institutions. Boston: The Harvard Business School Publishing, 1998.

-. Competitive Strategy: Techniques for analyzing industries and competetions. New York: Fee Press, 1980.

Richtlinie für die Durchführung von Einzelprojekten zur präventiven Arbeitsmarktförderung mit besonderem Landesinteresse aus Mitteln des EURpäischen Sozialfonds und des Landes Sachsen-Anhalt. Ministerium für Wirtschaft und Arbeit des Landes Sachsen-Anhalt, 2007.

Richtlinie über die Gewährung von Zuwendungen für Maßnahmen und Einzelprojekten zur Sensibilisierung, Motivierung und Unterstützung von Existenzgründern. Ministerium für Wirtschaft und Arbeit des Landes Sachsen-Anhalt, 2010.

Richtlinie über die Gewährung von Zuwendungen für kleine und mittlere Unternehmen zur Beteiligung an Messen und Ausstellungen. Ministerium für Wirtschaft und Arbeit des Landes Sachsen-Anhalt, 2009.

Richtlinie über die Gewährung von Zuwendungen zur Beschäftigung von Innovationsassistenten und zur Förderung des Personalaustauschs. Ministerium für Wirtschaft und Arbeit des Landes Sachsen-Anhalt, 2005.

Richtlinie über die Gewährung von Zuwendungen zur Förderung des Schutzes und der Verwertung von Innovationen. Ministerium für Wirtschaft und Arbeit des Landes Sachsen-Anhalt, 2007.

Richtlinie über die Gewährung von Zuwendungen zur Förderung kleiner und mittlerer Unternehmen 
bei der erstmaligen Initiierung innovativer FuE-Projekte (Forschungsscheck) sowie zur Förderung von Unterstützungsmaßnahmen zur Teilnahme an EU-Wettbewerben. Ministerium für Wirtschaft und Arbeit des Landes Sachsen-Anhalt, 2007.

Richtlinie über die Gewährung von Zuwendungen zur Förderung von Einzel-, Gemeinschafts- und Verbundprojekten im Forschungs-, Entwicklungs- und Innovationsbereich. Ministerium für Wirtschaft und Arbeit des Landes Sachsen-Anhalt, 2009.

„Richtlinie über die Gewährung von Zuwendungen zur Förderung von Projekten des Wissens- und Technologietransfers.“

Schiele, Holger. Der Standortfaktor - Wie Unternehmen durch regionale Cluster ihre Produktivität und Innovationskraft steigern. Weinheim: Wiley-VCH Verlag GmbH \& Co. KGaA, 2003.

Zukunftsatlas Berlin: Prognos AG, 2004, 2007, 2010. 